
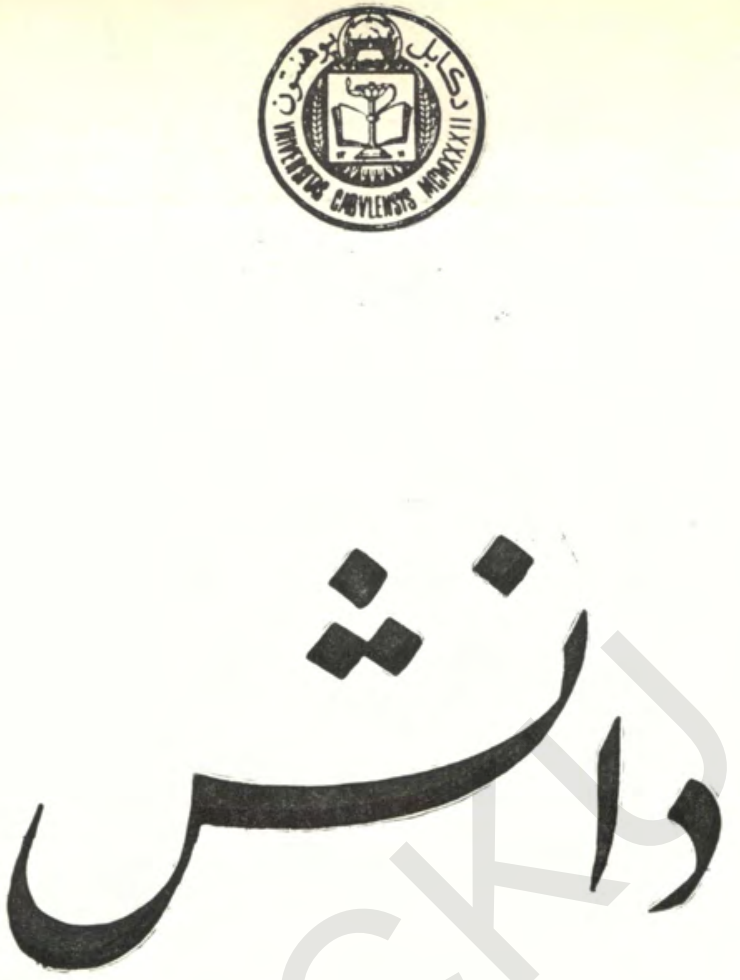

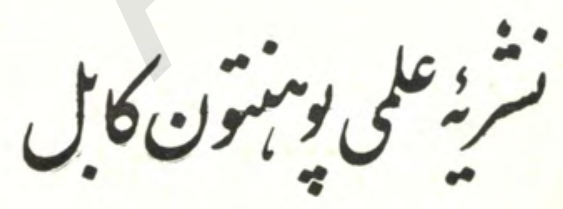

شمارؤ هنجم ـ سال اول

قوس - جدى דצr| 


\section{هيئت تحرير}

يو هئكى عنوم زبيعى

يو هنئى ز زبان و اديليات

يو هندى ز زئى اعت

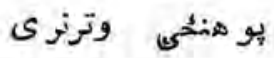

يو هنخى ز زبين شناسى

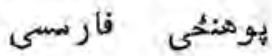

بوهنمى تاريستخ وفلسفه

يوه:ثى حتى حتوت

إيوهنى اقتى اقتصاد

يوهنى على علوم طبيعى
21د

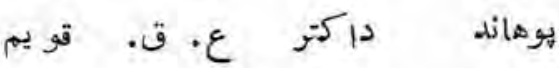

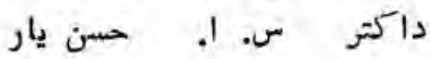

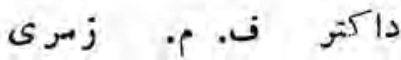

السين

$\tau$

مقالدر

•

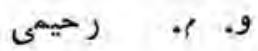

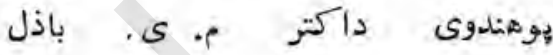

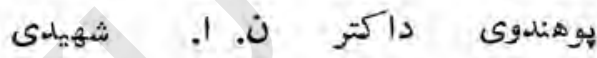

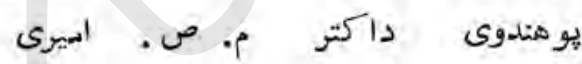

\section{صاحب أمتياز : يوهنتون كابل}

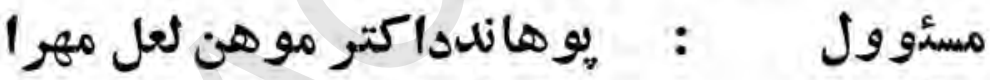

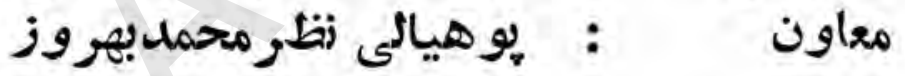

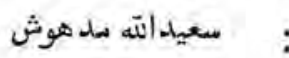

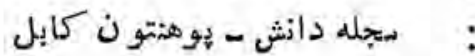
Tis mires: آدرس تيلفون

\section{: اشتراك سالانه}

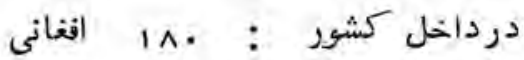

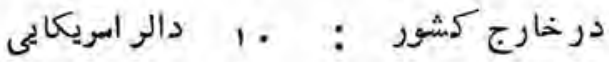
براى مجصلان : نصف قيمت

مطبعه وزارت تحصيلات عالى ومسيلى 


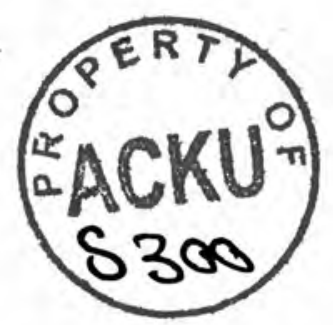

دانش

نشر يه علمى دوماهئ يوهنتون كابل

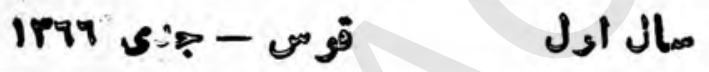

م:

\section{فهرست مندرجات}

صنiv

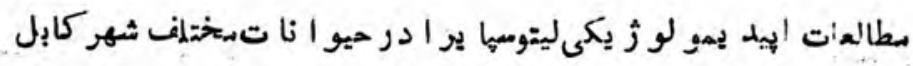

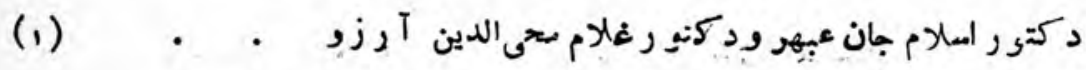

دشخءات زو تكميكى برقى از مئ اد خو را كه افغانستان (تركيب كيمياوى و ارز ش غذايى بر قى ازخو راكه ماى متر اكم لم ازر ثرى دار )

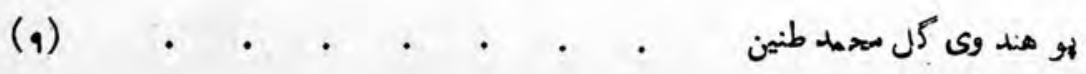


صaras

موضو

ثا ثير تراكم اترجى عذا بالالى نهو و تركيب فزهى

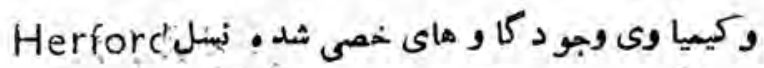
$(r v)$ بو هنمل د كتو رنو راحمد احمد

اسكانات هرو رش و كسترش بادام زمينى (Arachis hyp) gaeal) در افغانستان

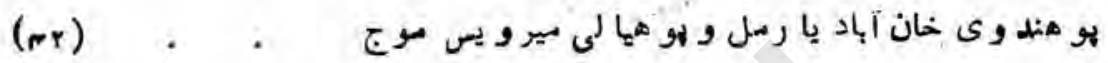

ميتابو ليزم كار بو ها يد ر ريت ها در بيوه انكور

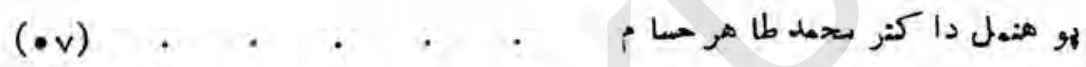
منشا تكا سل و اهميت اقتصادى إهب در افغا نستان

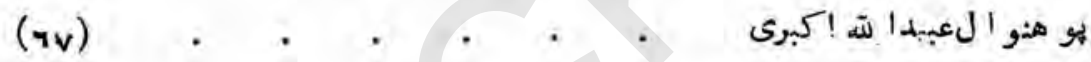
تحليل مبو لديت كار توليدى درزز ر اعت $(v r) \cdot \cdot \cdot$ بو هندوى عبدأ لغنى تاج

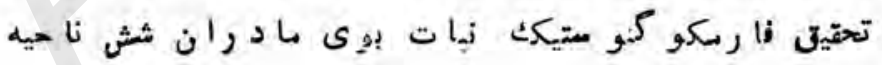
افغا نستان

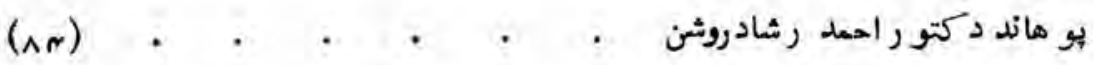
دن:كر هار ولايت دهر اختيا يى ير و زى ثير نه

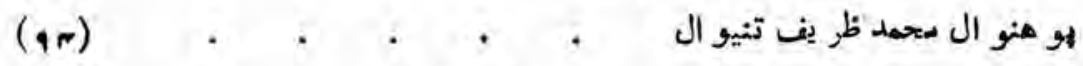
نو رم و نا بايدارى جر يانات مسالانه آب در در يا هائ افغانستان دكتو ر و. . و. ز يإيكين ،دكتو ر ايكو يشن ن. ن.

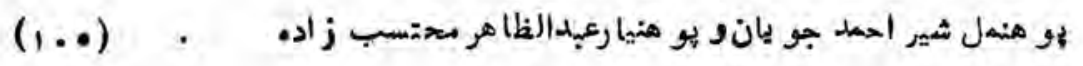

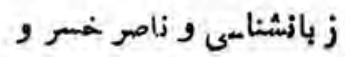

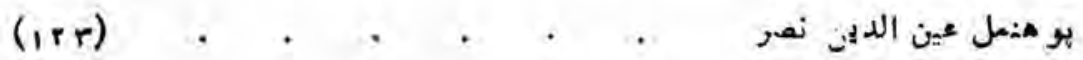


دازش، شمار • هنجم، مال רוז1

$$
\begin{aligned}
& \text { دكتو ر اسلام جان عبهر ودكتو رغلام متى الدين آرزو ، }
\end{aligned}
$$

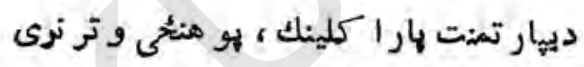

\section{مطالعات إيبليهولوزيكى ليتو سيايرا در حيوانات مختلف شهر كابل}

مقده مقه

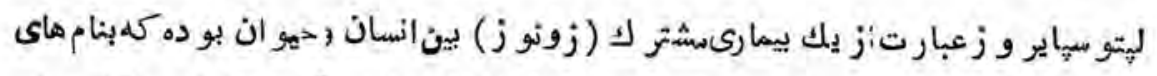
Stutgart

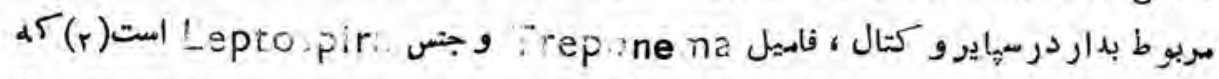

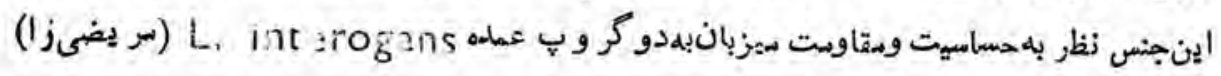

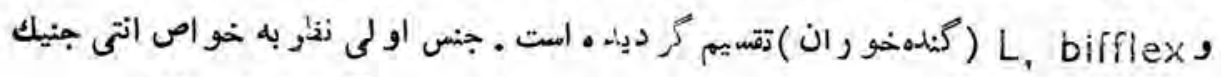

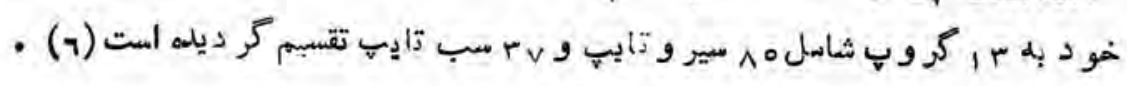


انو اع عمدة عاملين لجتوشيايرو زدر انسانها عبار ت از (لهتو مهاير ا اكتير و همو ار اجيا،

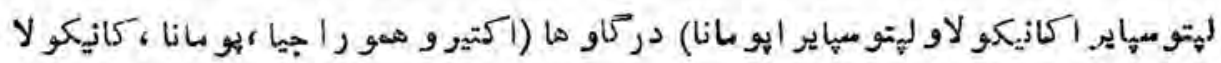

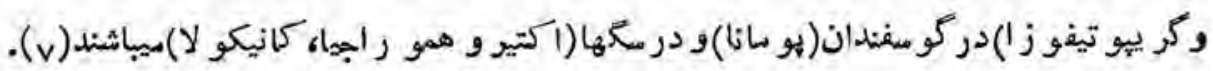
سنبع اصلى عفو نت مو شهاى صحر ابى وحيو انات دلموث بوده ؛ ازسانها ازطر يق تماس

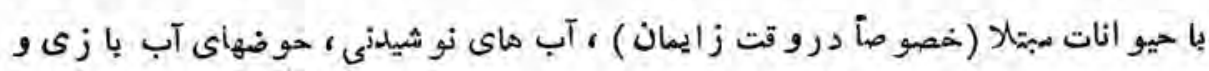

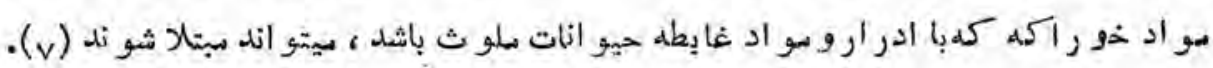

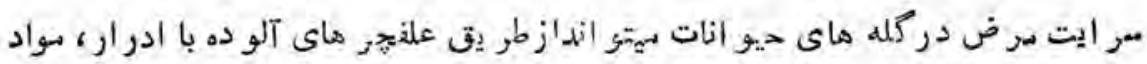

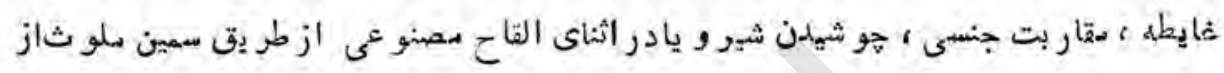

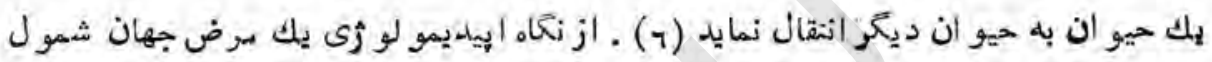

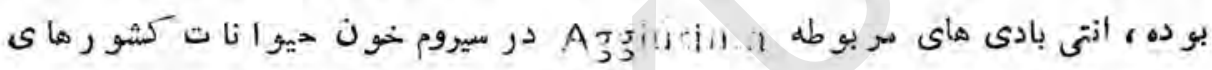

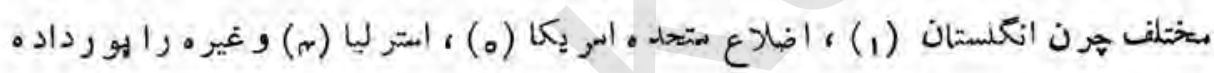
شيده امت .

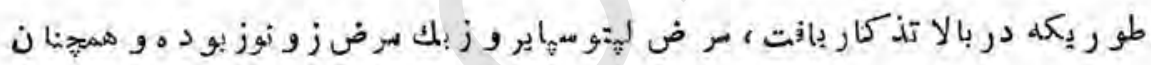

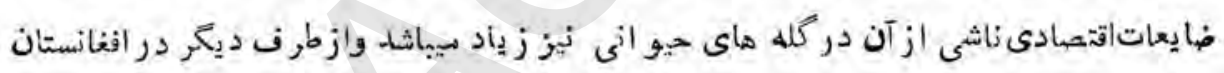

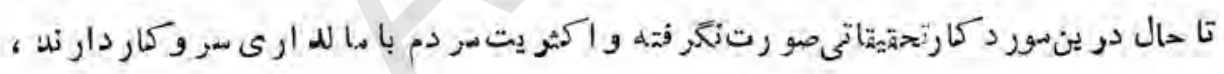

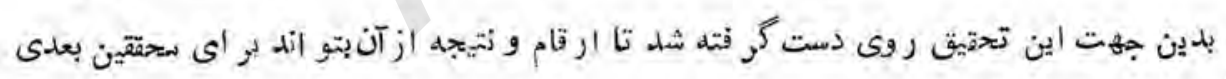
مو رد استفاده قر اركيرد.

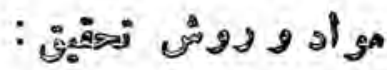

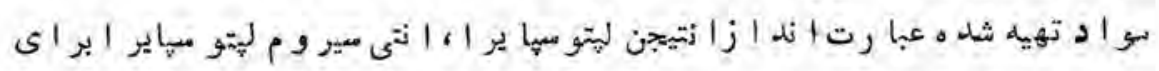

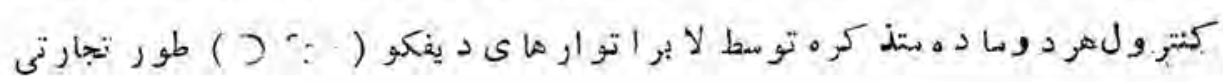

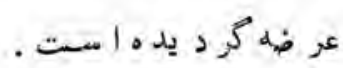




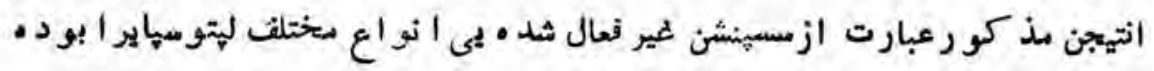

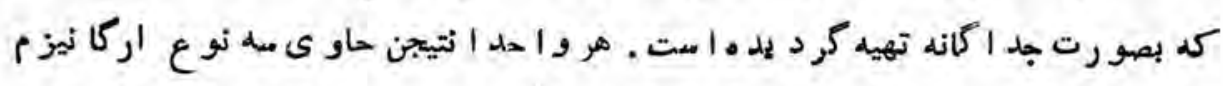

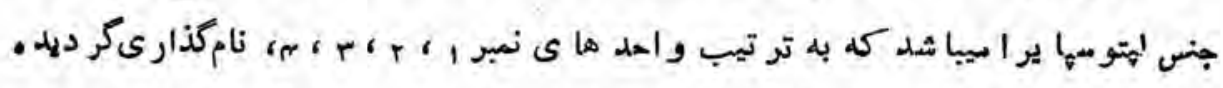

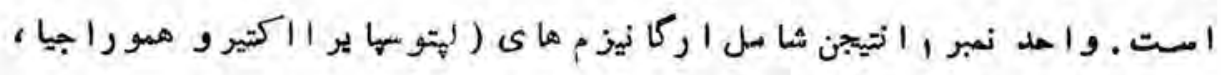

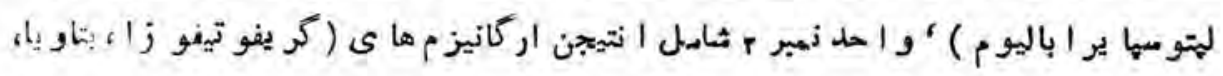

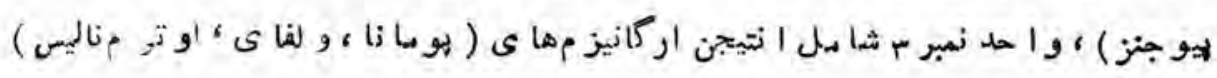

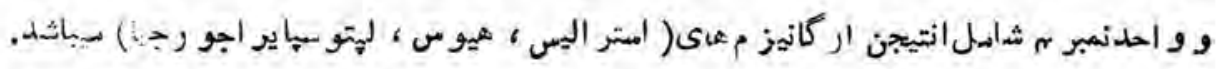

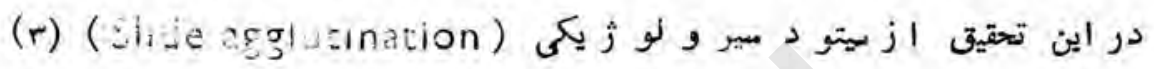

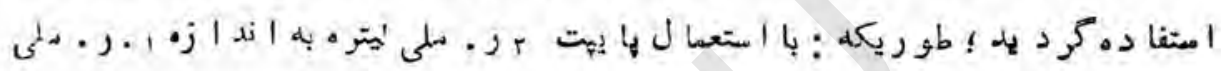

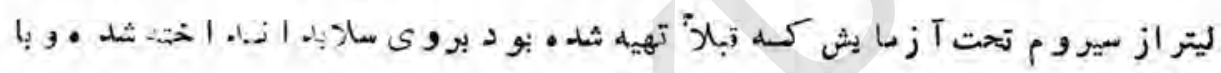

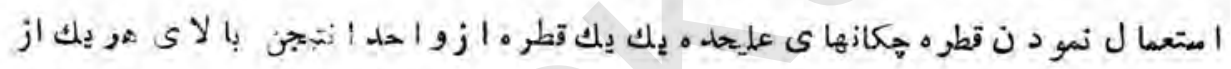

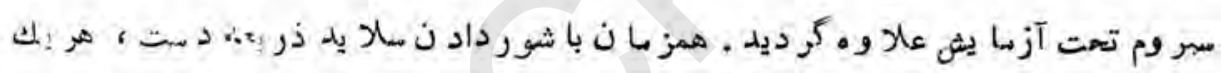

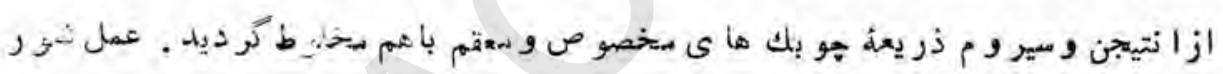

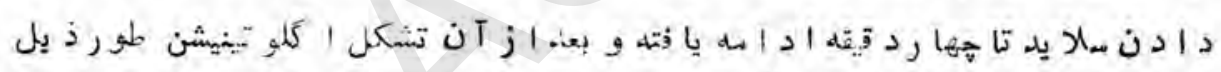

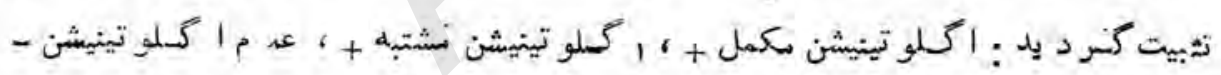

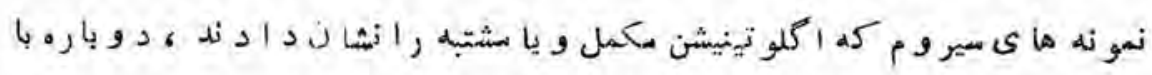

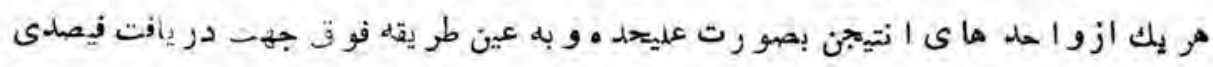

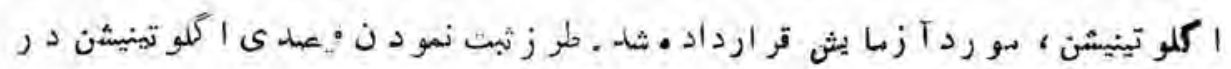

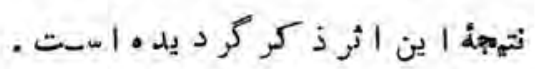

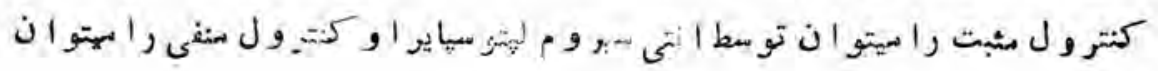

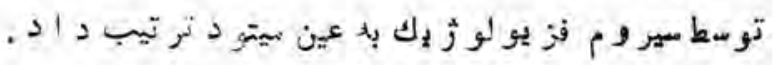




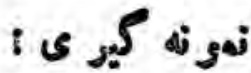

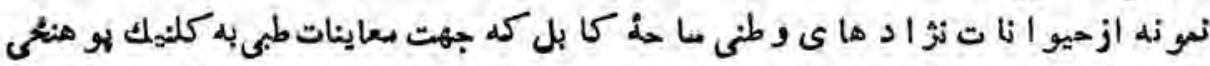

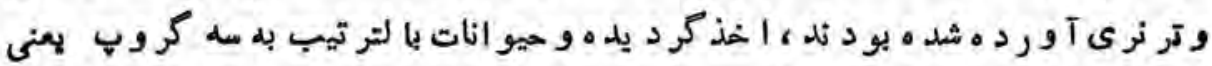

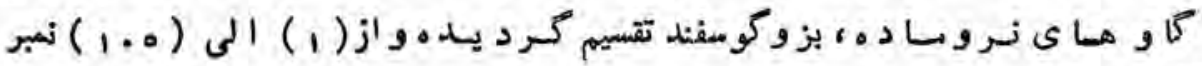

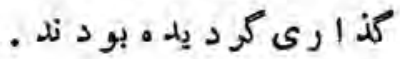

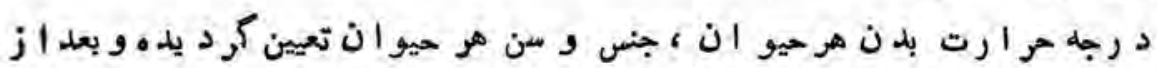

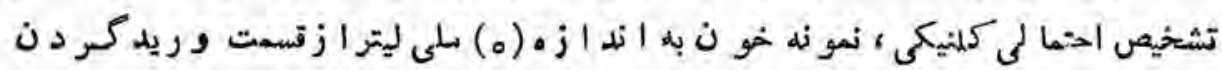

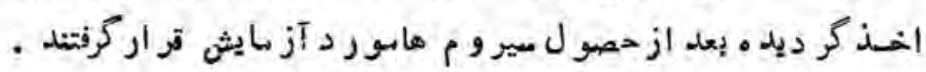

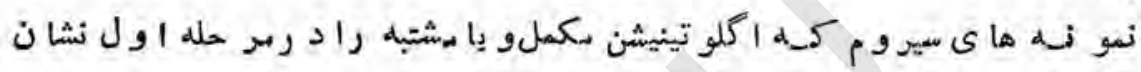

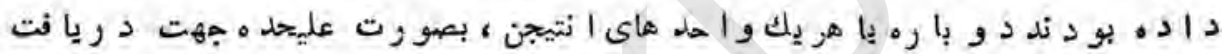

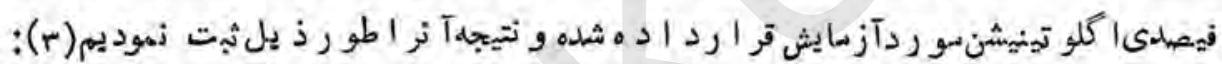

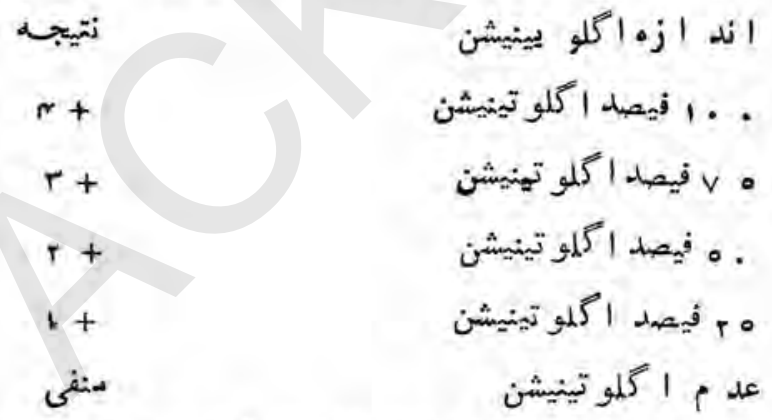

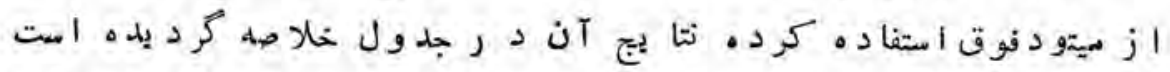

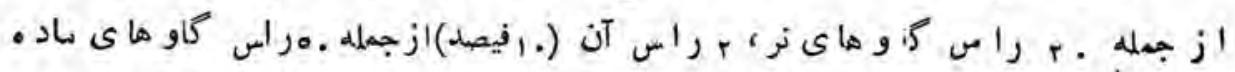

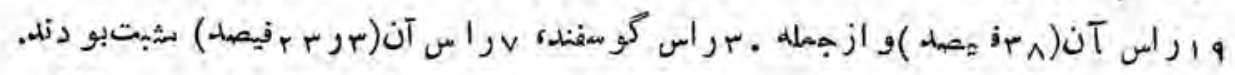

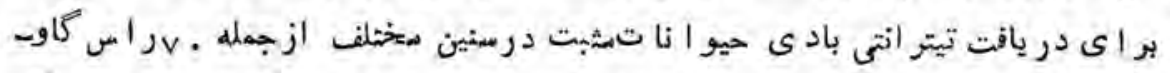

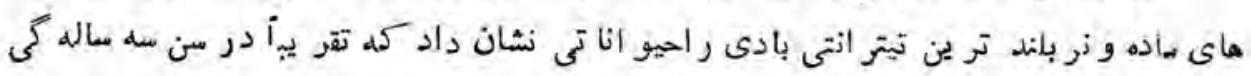

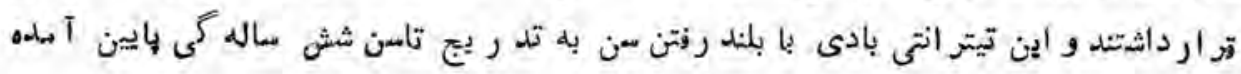




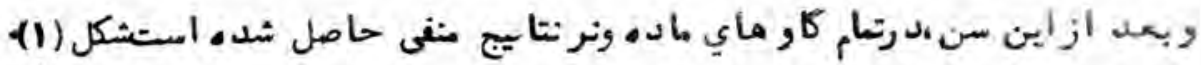

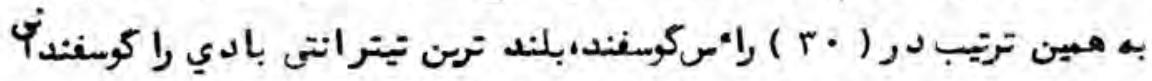

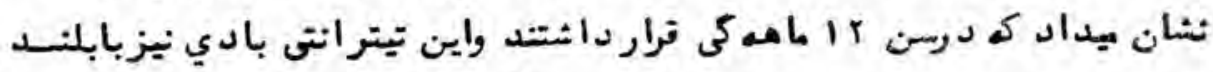

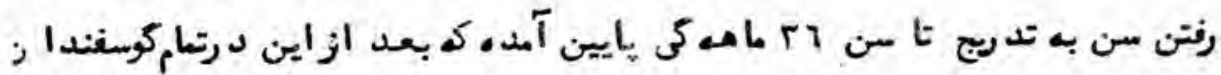
نتايبج منفى حاصل ثد (r)

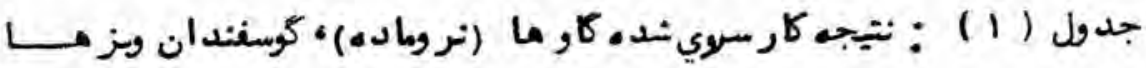

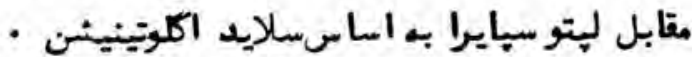

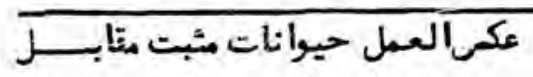
جمارواحد انتيجن ليتوسيايرا

|

\begin{tabular}{|c|c|c|c|c|c|c|c|}
\hline$\varepsilon$ & احد r r & $r-1$ r & حد-1-1 & & & شده & \\
\hline 1 & 1 & $r$ & $1^{\circ}$ & • افيصذ & T. & $r \cdot$ & זاونماي \\
\hline$r$ & 10 & 11 & Ir & ג זفيصد & 19 & 0. & كاوماي \\
\hline 0 & $\varepsilon$ & 7 & 1 & $\begin{array}{l}\text { فيصد }{ }^{r} \\
\end{array}$ & $\gamma$ & $r$. & كوستفندان السال \\
\hline- & - & - & - & • & - & - & ا_يزماسال \\
\hline
\end{tabular}




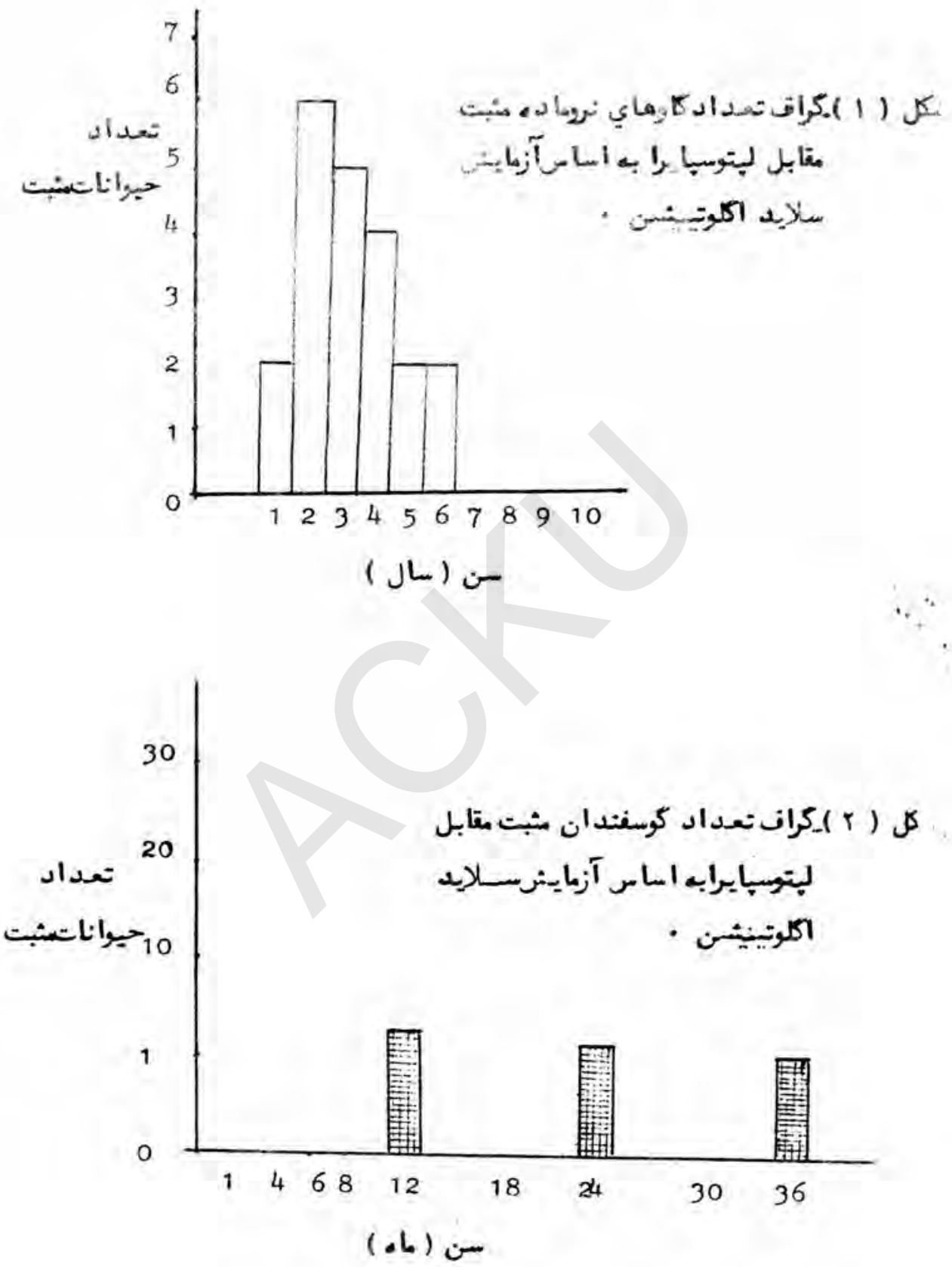




\section{: astic}

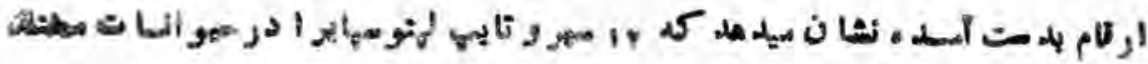

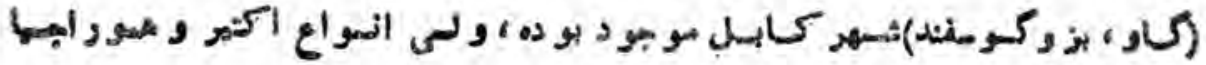

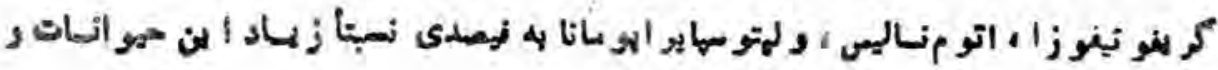

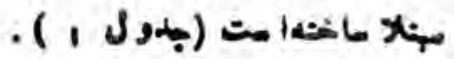

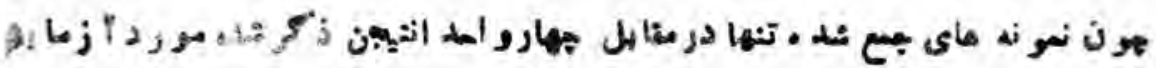

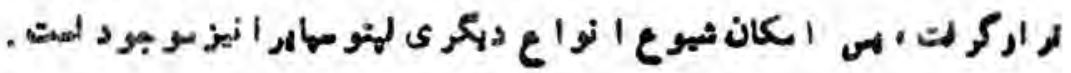

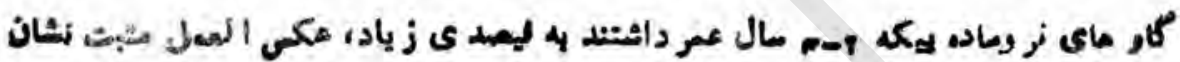

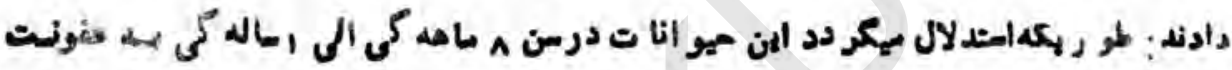

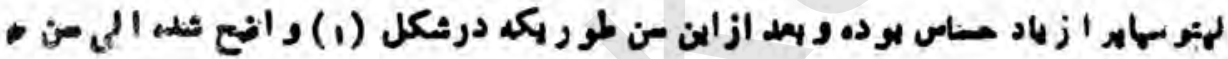

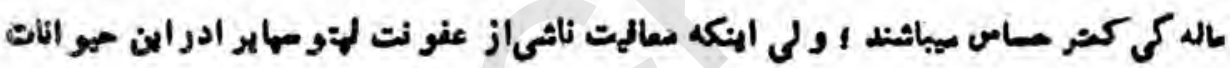

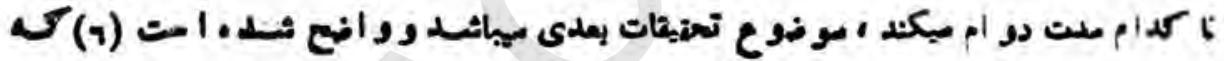

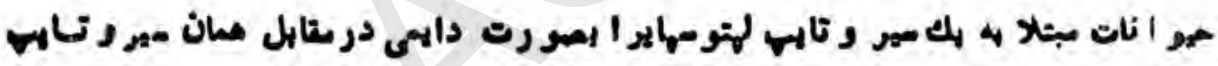

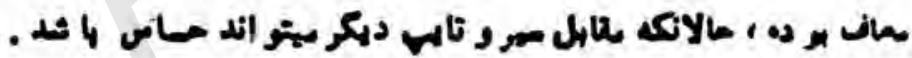

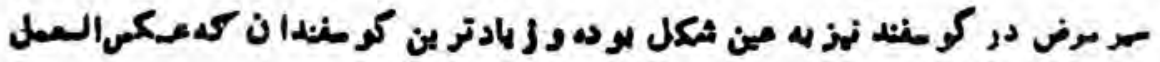

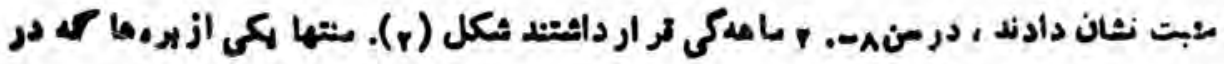

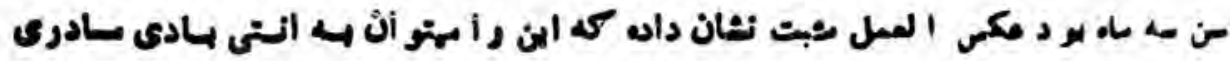

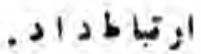

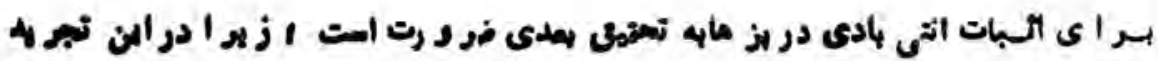

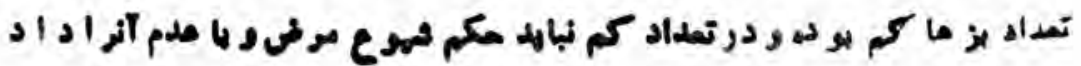




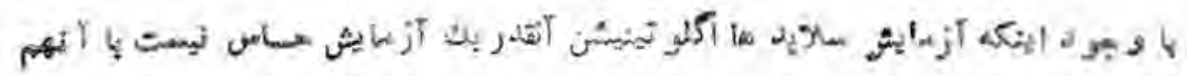

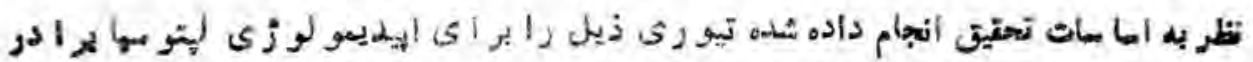

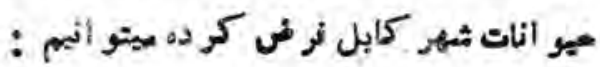

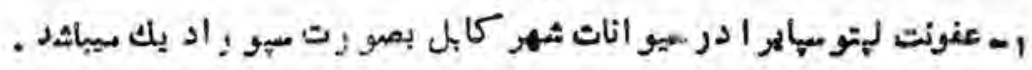

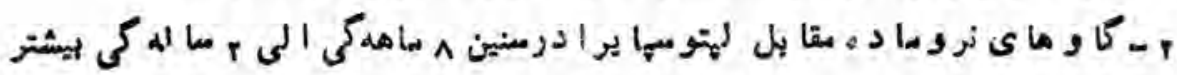

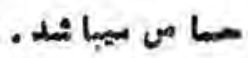

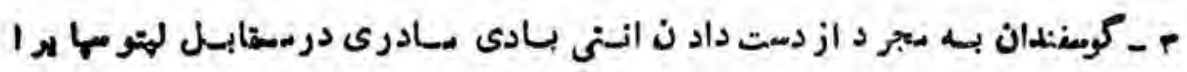

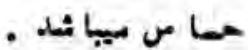

\section{REARRENCES:}

1. Broom, J. C. \& Macint're, A. B. (1948) A. survey of Lopt. ospirosia in England. Vet. Rec, 60: 487-488.

2. Bu.rows, W. (.965). Text book lof Microbiology, 19 th. Ed. (the spirochntes), 745-768.

3. Gglton, M.M., Fowers, D.S. Hal, A. D. \& Cornel, R. ( 958) Amer J. Vet . Res, 19: 505-512.

4. Cl on, G. E. B. (1958). The Presento of Leptospi os's off mild t pe in Queens Land. Aust. Med. Iour. I, 647.

5. Gochenour, W. S. JR, (1950). Antigenic similarity of Bovine strain of Leptospirosis (U.S) and L. Pomona. Proc. Soc.. Exp. Biol. Med. 74: 199-202.

6. Marchant, L. A, \& Packer, R. A. (1977). Yeterinary Bacieriology and Virology, 5th. Ed. (the spirochets), 486502.

7 Sastr, G. A. ( 75). Vetrinar/ pathology; 4th. Ed. (Leptd. spirosis), 558-562. 


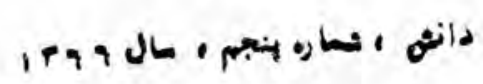

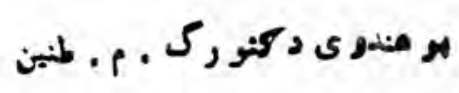

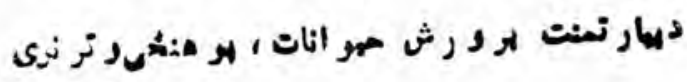

4S1, أن

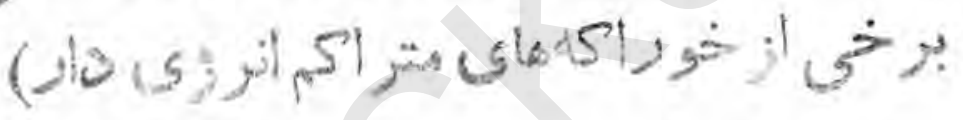

sentes

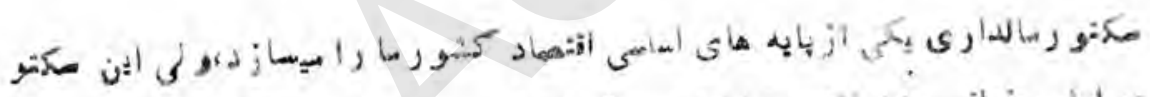

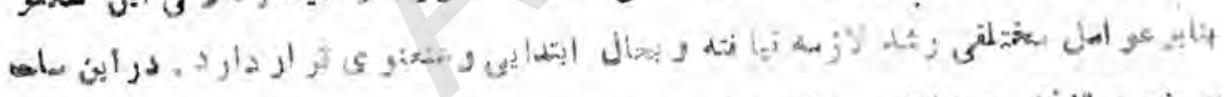

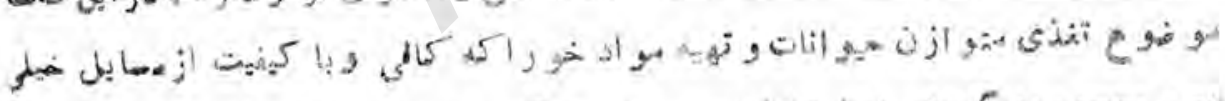

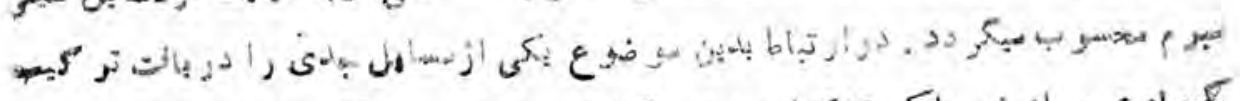

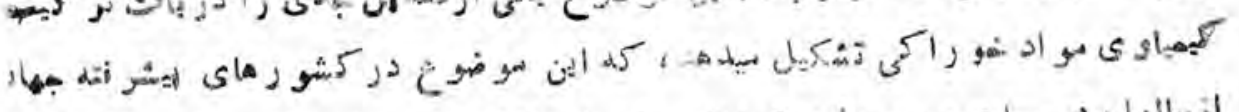

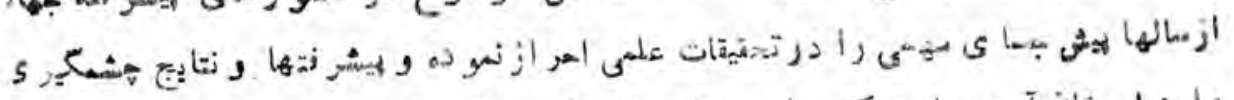

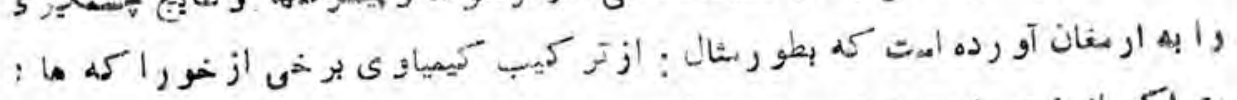

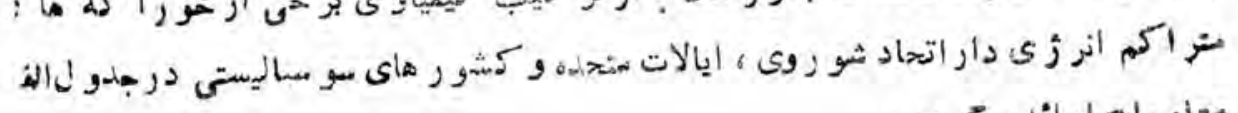
:

(1) 
جدول الف : تركيبكياوي برخى ازخوراك ماي مترام انرزي دار

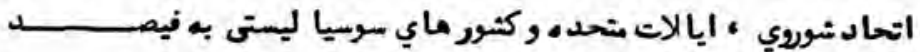
- $(\varepsilon, r \cdot 1)$

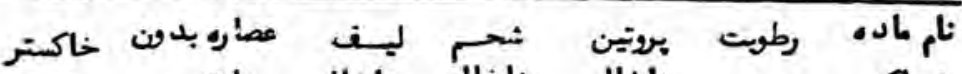

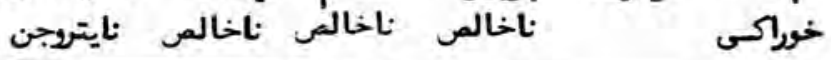

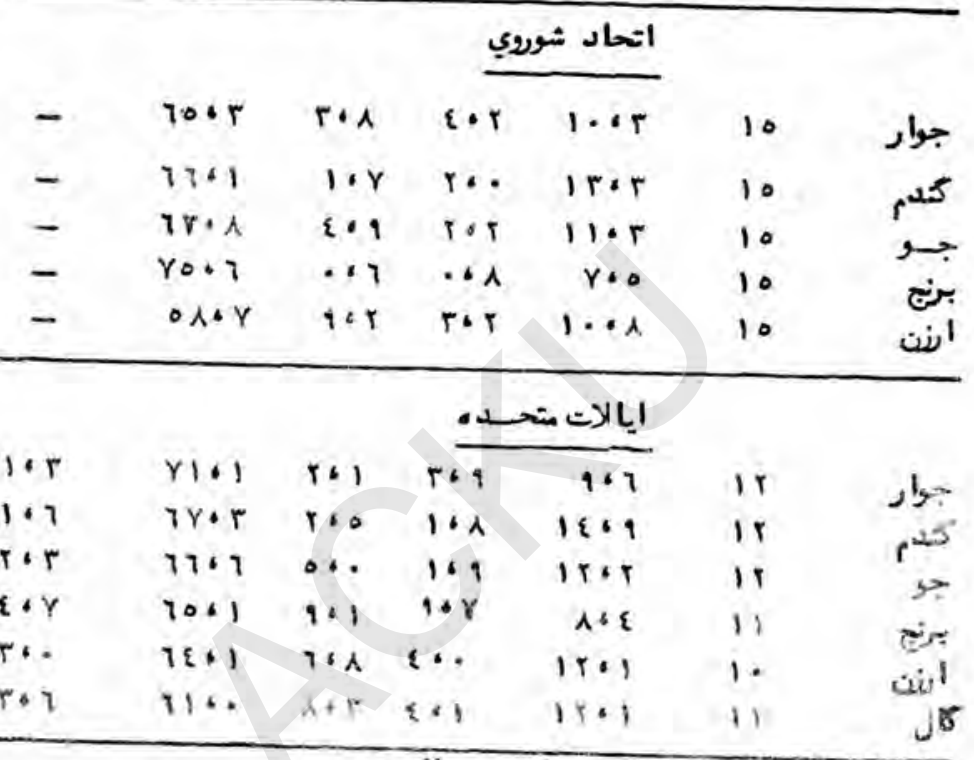




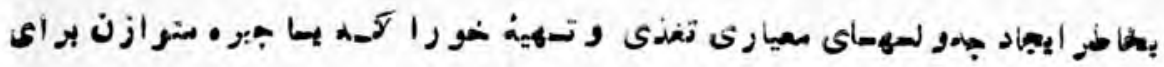

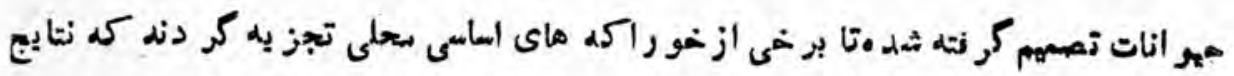

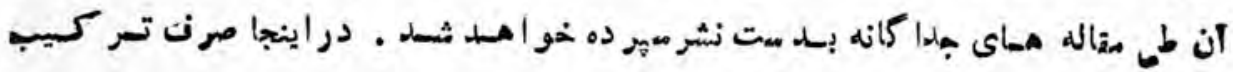

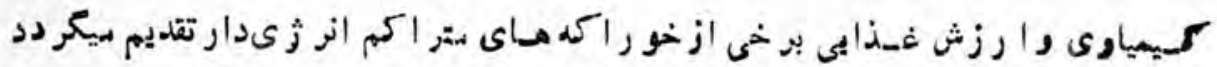

\section{مو أدورون مار :}

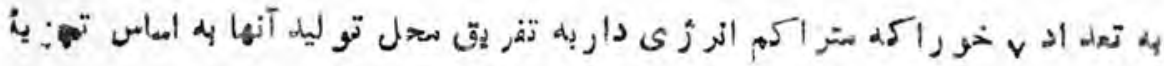

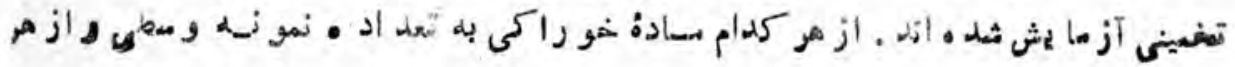

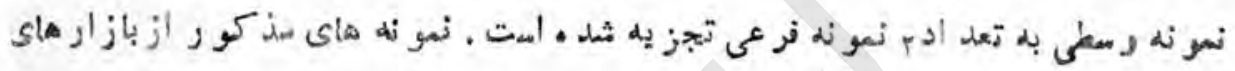

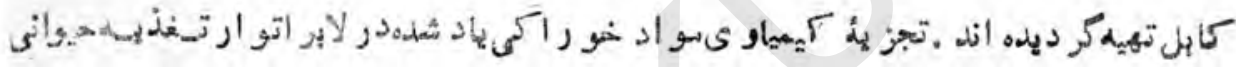

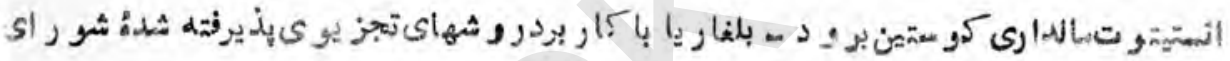

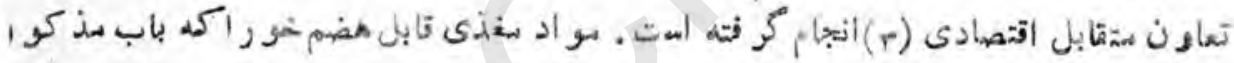

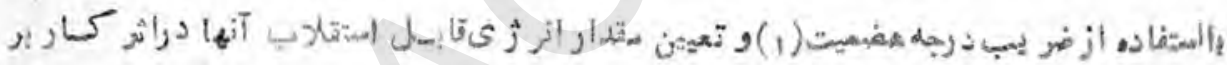

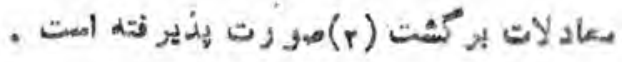

\section{conas a distio}

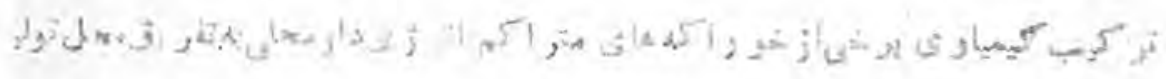

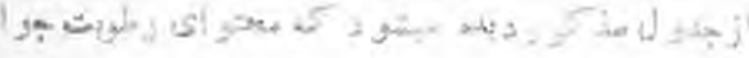

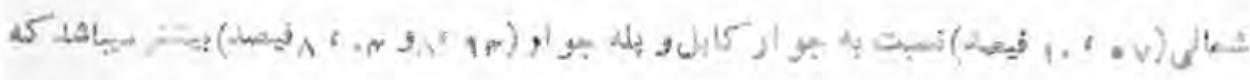

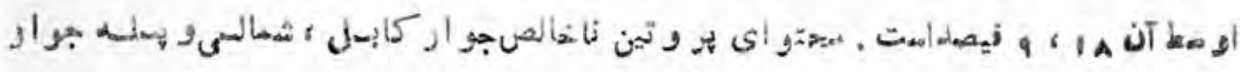

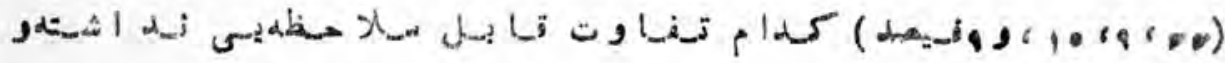

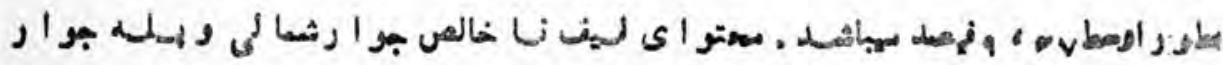


جدول I : تركبكيياوي برخى ازخوراك ماي مترام انرثي دارسله باساس ونن

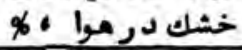

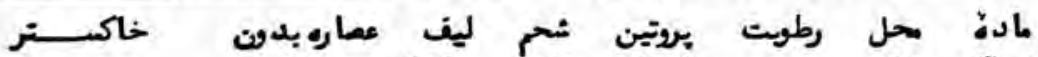
خوراك توليد

1.r. جوار

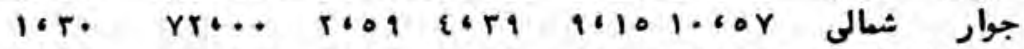
بله جوارنامعلم \& \&

\begin{tabular}{|c|c|c|c|c|c|c|}
\hline c $\varepsilon$ & ra.o & R.t. & $q 49$. & $q[\varepsilon V$ & 9.11 & اوسط \\
\hline$r$. & . r. & rot & I Iry & זד. 1 & 9685 & توتر \\
\hline 1678 & rialo & rof & 1.91 & $Y * 90$ & 9110 & كابل \\
\hline $1+y_{0}$ & YTOIE & rot. & 1.04 & 9.98 & $11 \ldots 7$ & \\
\hline 1.71 & roots. & T.OA & 1004 & 910. & $1.11 \mathrm{r}$ & أوسط \\
\hline T.TY & $\gamma / .9$. & 8018 & TCTq & 1.611 & T.RY & زئر زي \\
\hline i@Ot & r T & $\{\leftrightarrow 0$. & $T=I Y$ & 15619 & $9 \times 99$ & 1 \\
\hline ral1 & 1.11 & $\{011$ & ros & $1.6 \% 0$ & 1.3 & \\
\hline$T \cdot T r$ & 7961 & $\varepsilon+\varepsilon Y$ & $T \cdot 13$ & 11.41 & $9 \cdot \hat{A}$ & \\
\hline
\end{tabular}

\begin{tabular}{|c|c|c|c|c|c|}
\hline$\wedge$ & $1 \varepsilon+\gamma r$ & $T \cdot A$ & $76 \mathrm{Vo}$ & 9111 & كلج> \\
\hline ، $v 1$ & $r+9 q$ & 1.71 & 1678 & $1 \cdots 2$ & كلجو, با عيان \\
\hline $161 T$ & $Y \varepsilon+r \lambda$ & 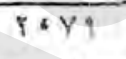 & $T \cdot+1$ & $9 \cdot 11$ & 9.11 \\
\hline $1+r 1$ & 61 & 1,10 & $\cdot 611$ & $\varepsilon \cdots 9$ & 11612 \\
\hline . ^r & $4 \mathrm{VT}$ & (ख⿰) & $.49 \varepsilon$ & $T \cdot 9<1$ & $\| \cdots \lambda_{0}$ \\
\hline . co. & Yq⿻or & $\cdots \cdot$ & .091 & TORT I & ITCK \\
\hline 611 & A.6. T & $.10 \mathrm{r}$ & .695 & 0.91 & 11.07 \\
\hline$r \cdot r q$ & ‘ . & 96. & 0,1 . & $1 \ldots 91$ & 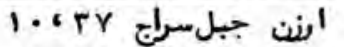 \\
\hline ^* & it & 1.1. & $\varepsilon+9$. & $\cdots 1$ & isra \\
\hline 711 & ६Y & $9 \cdot\{1$ & $\{\cdots\}$ & 1.00 & $11 \cdot r \lambda$ \\
\hline $0 . \varepsilon 7$ & $T 1 \cdot \mathrm{Yr}$ & 1008 & $\{01$ & A.ri & 1..Yr \\
\hline $0+9 \varepsilon$ & 716.8 & A.OT & $\{\circ 01$ & $96\{0$ & $1 . . \varepsilon Y$ \\
\hline $7+1 \varepsilon$ & $7 . \mathrm{YT}$ & 9.17 & 0.15 & A.OT & كال شعالى 1874 \\
\hline 2010 & $7 \varepsilon, 1 \varepsilon$ & $1 \cdot 1$. & $\varepsilon \circ r \gamma$ & $1 \ldots 0 r$ & 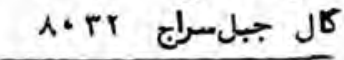 \\
\hline $0 a$ & $7 r=88$ & $\lambda \cdot \wedge \Lambda$ & $g, r$. & 9604 & $A \cdot 9 Y$ \\
\hline
\end{tabular}




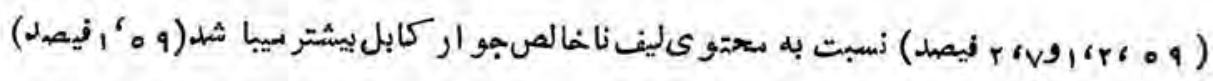

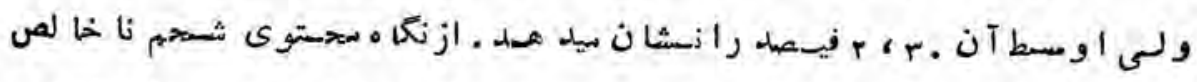

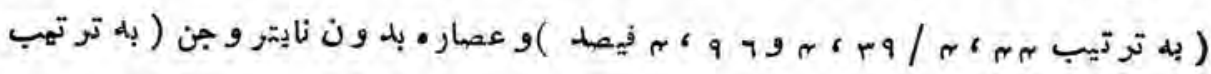

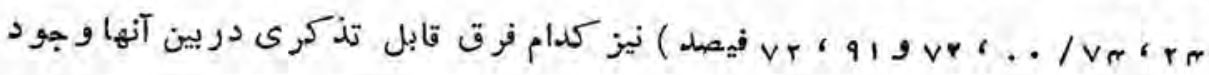

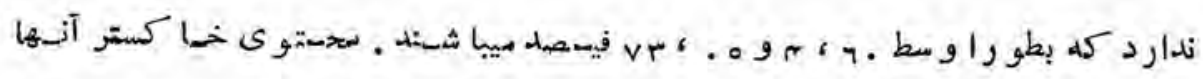

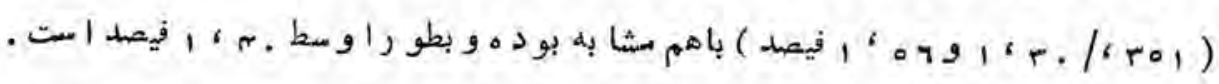

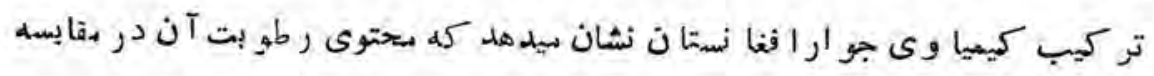

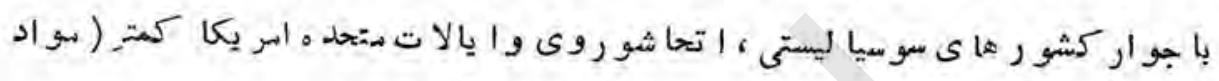

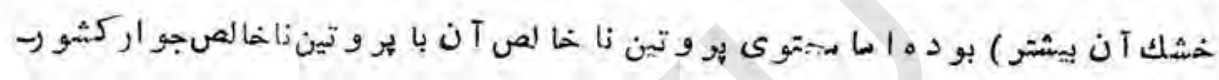

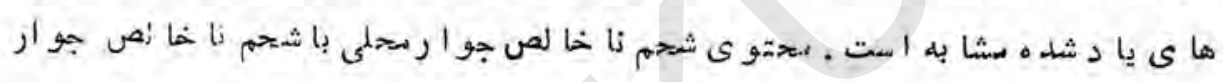

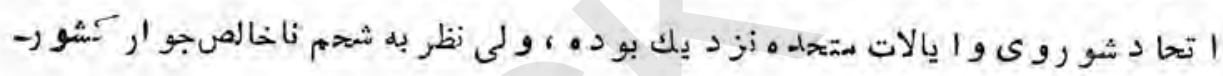

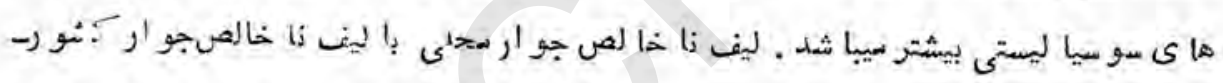

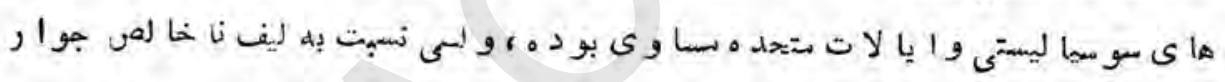

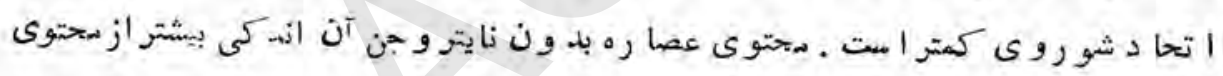

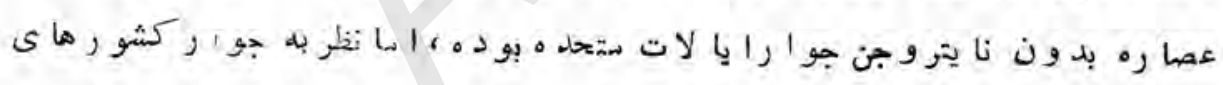

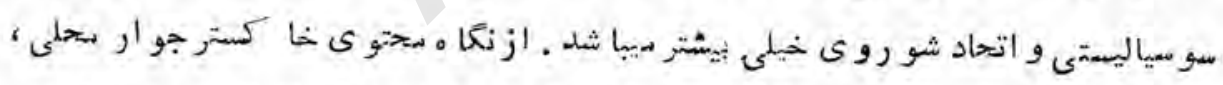

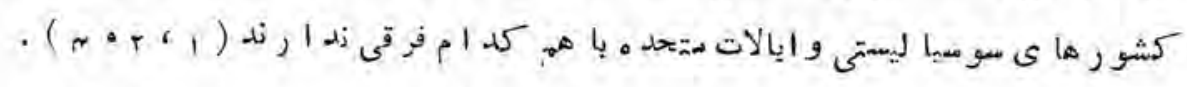

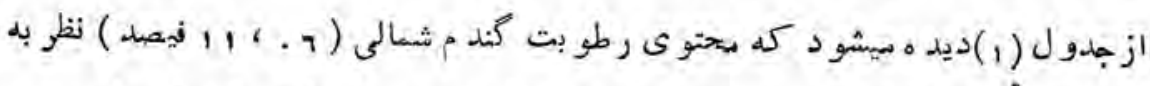

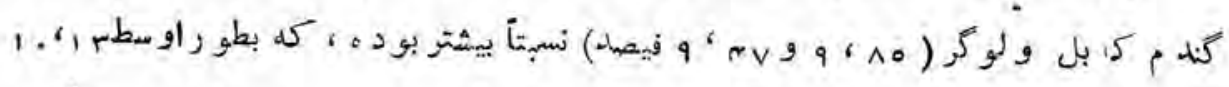

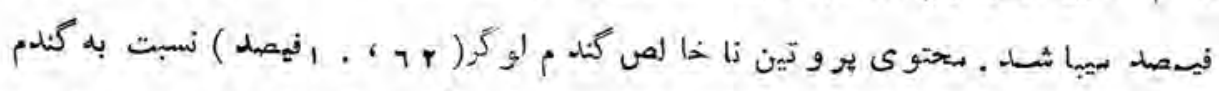

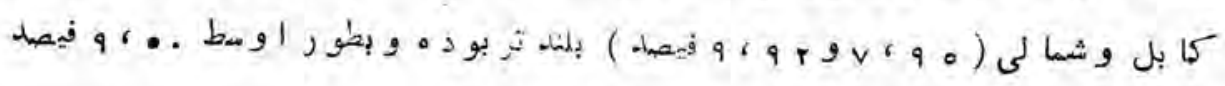




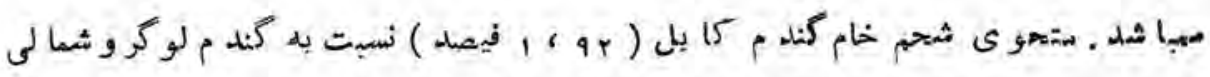

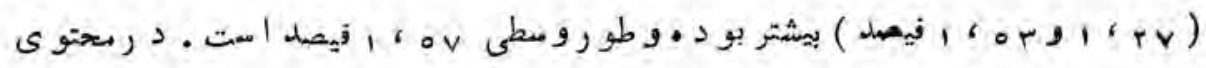

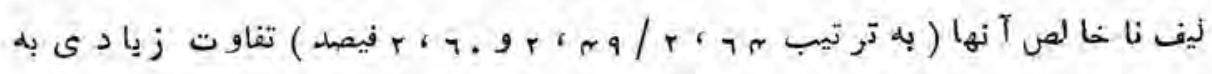

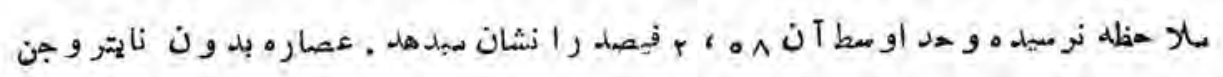

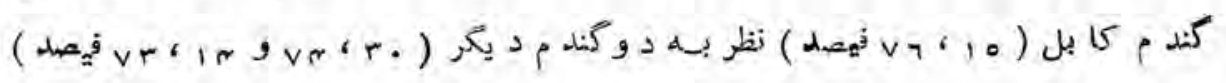

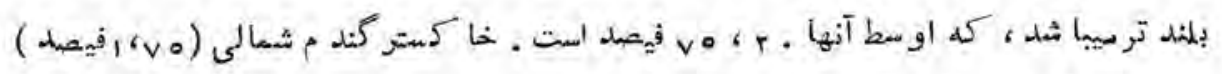

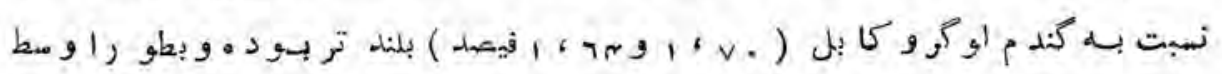
. TA

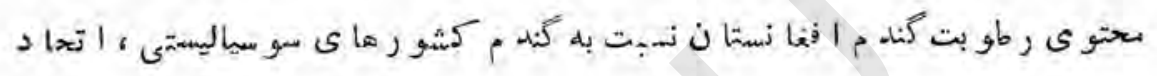

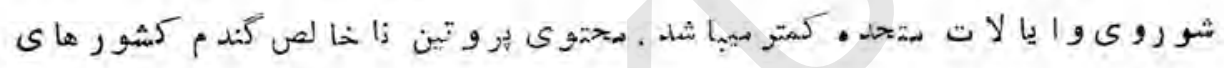

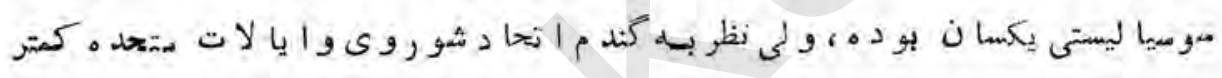

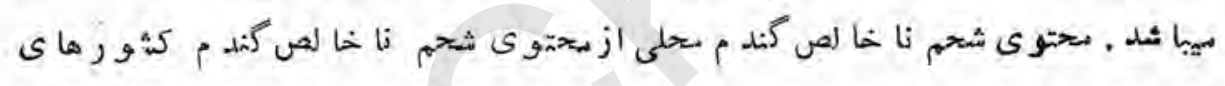

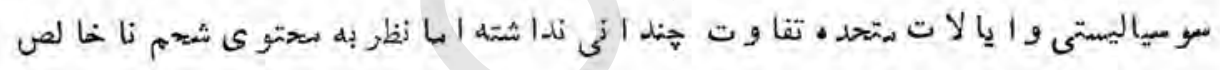

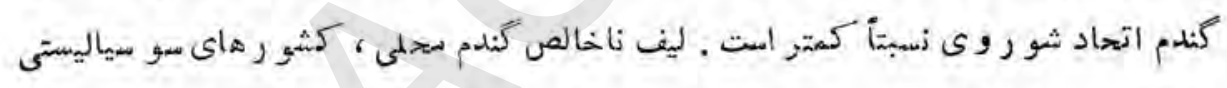

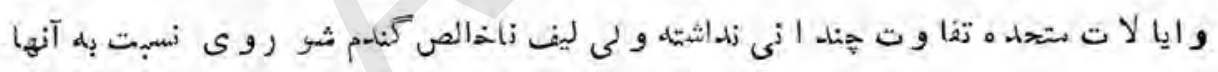

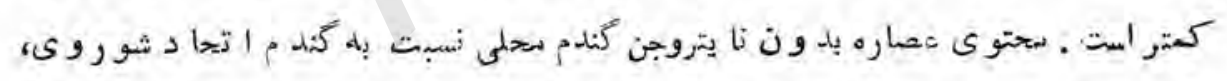

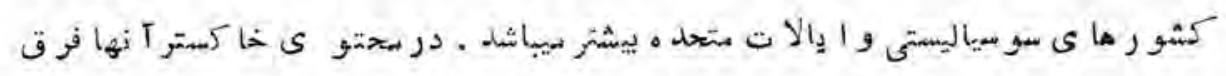

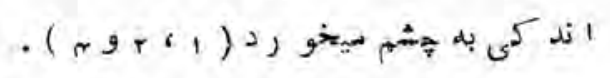

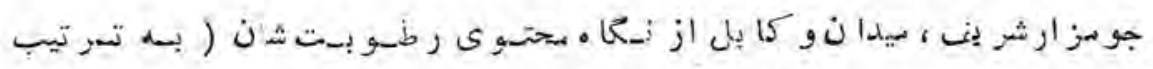

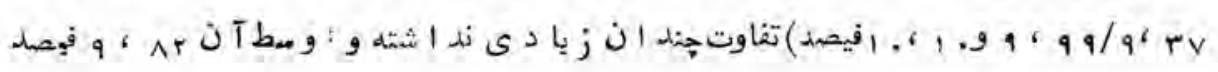

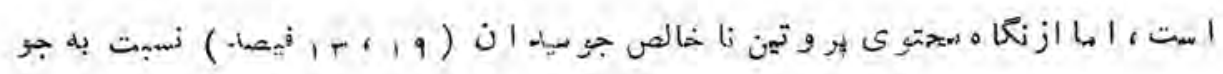




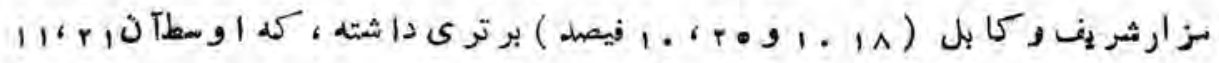

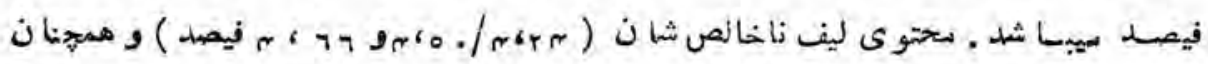

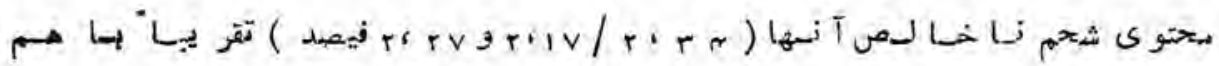

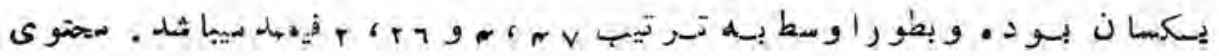

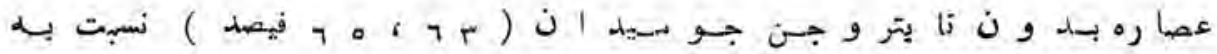

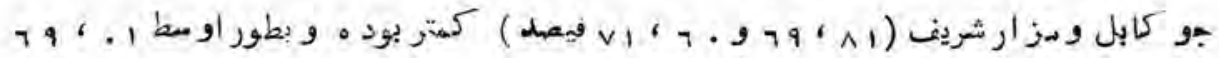

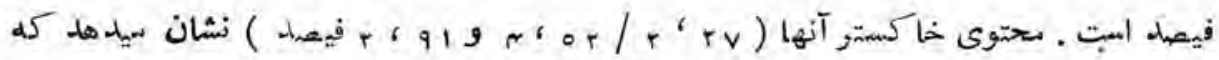

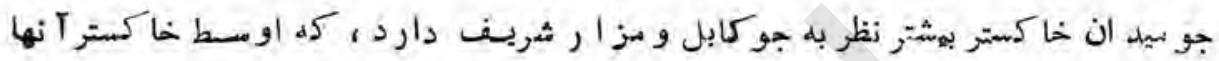

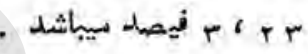

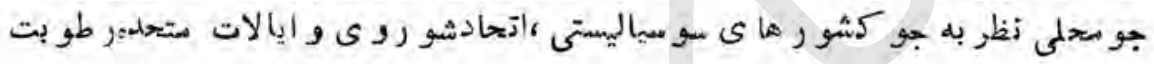

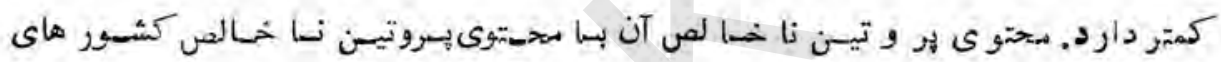

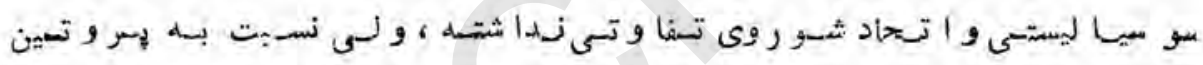

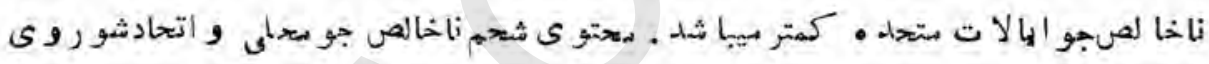

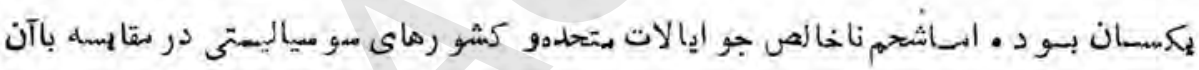

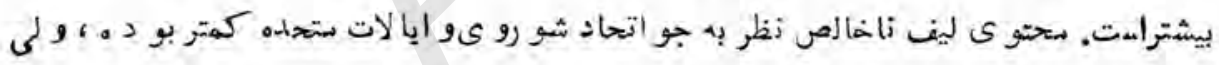

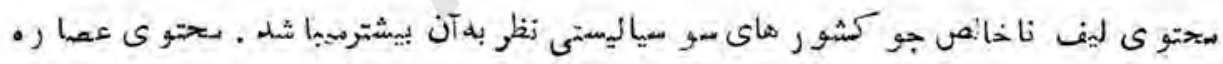

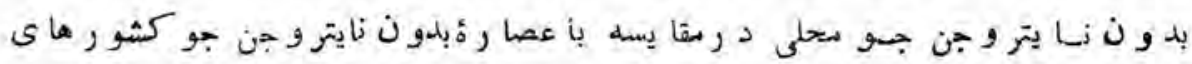

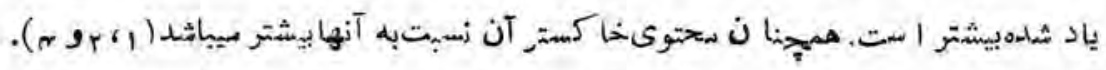

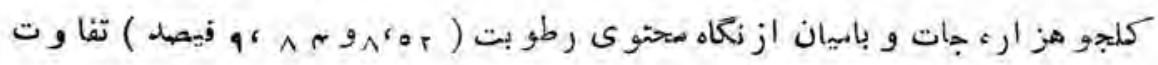

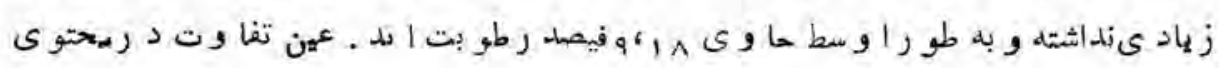

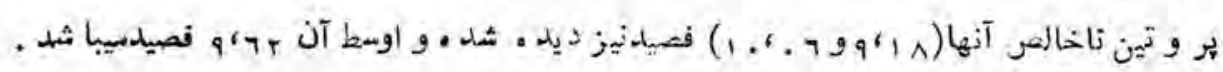




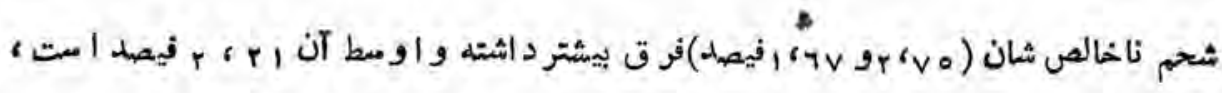

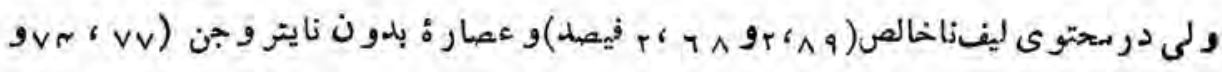

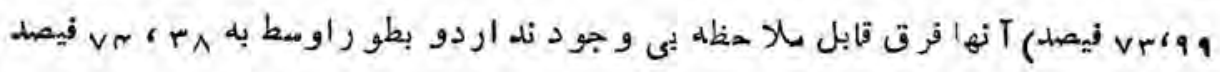

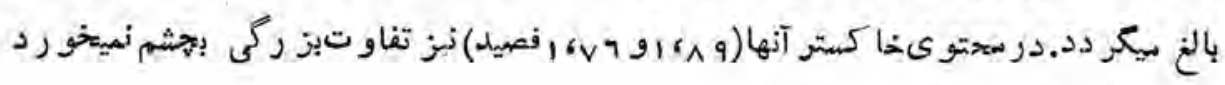

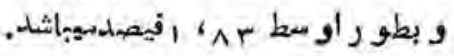

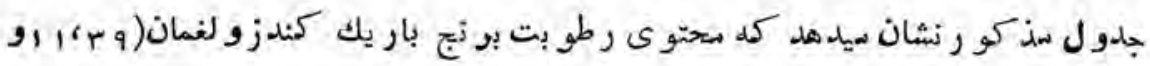

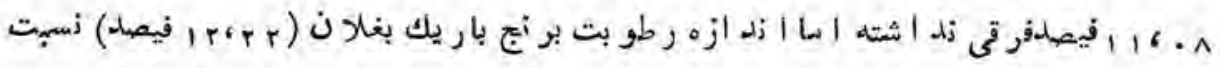

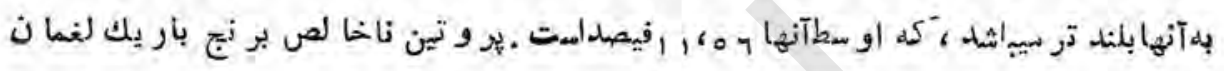

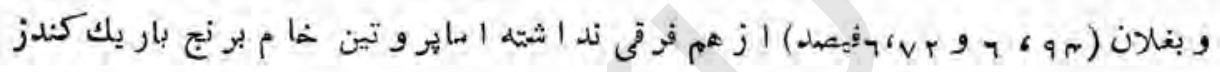

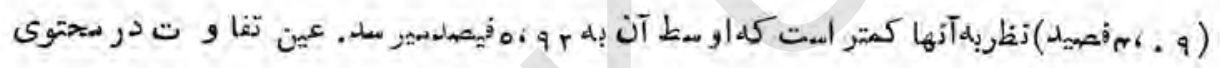

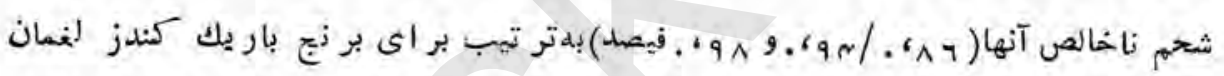

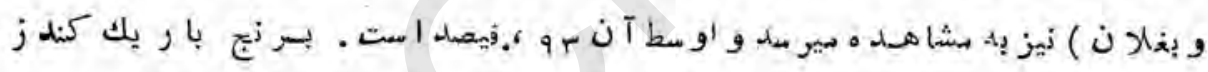

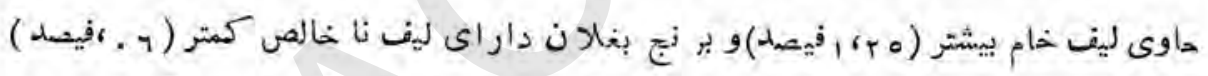

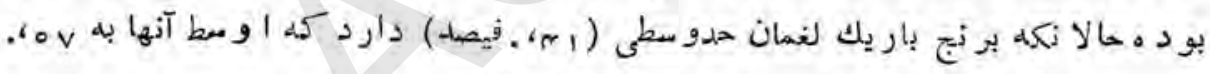

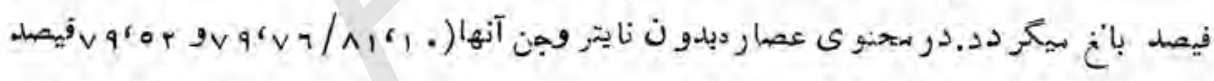

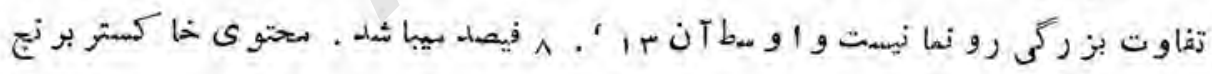

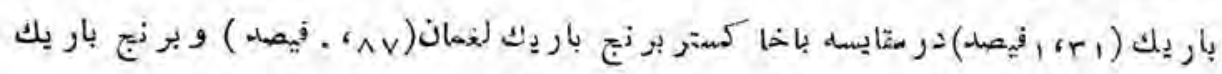

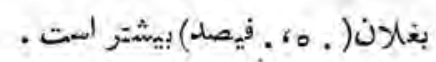

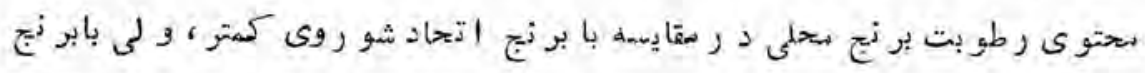

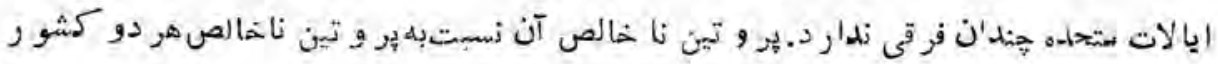

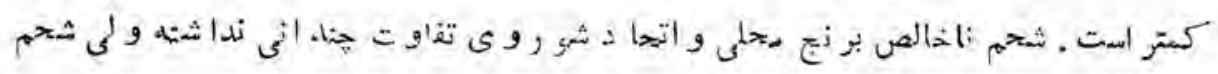




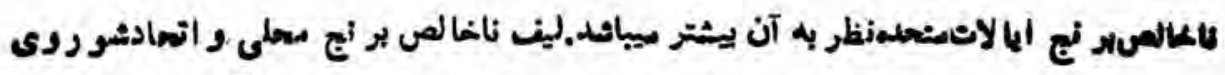

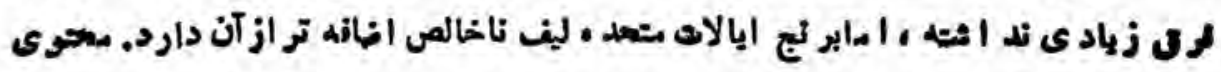

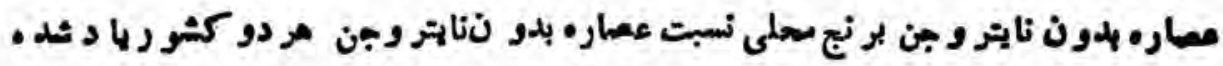

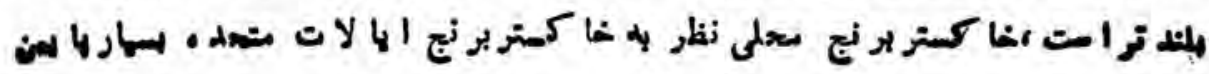

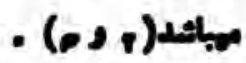

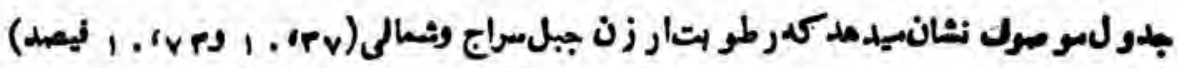

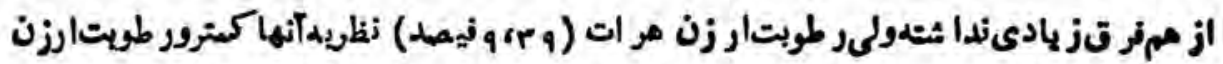

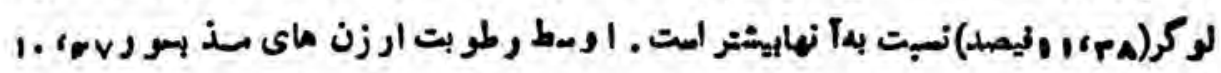

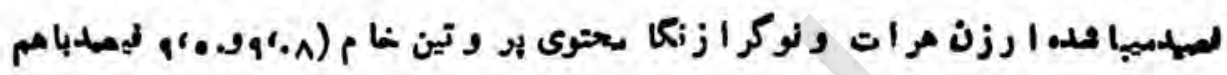

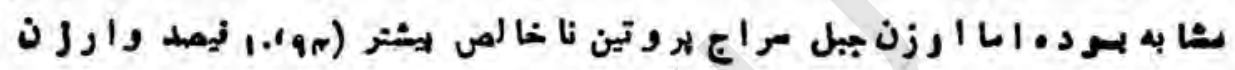

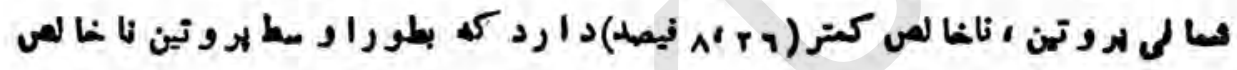

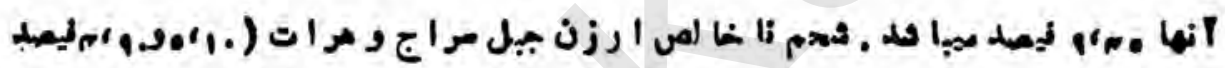

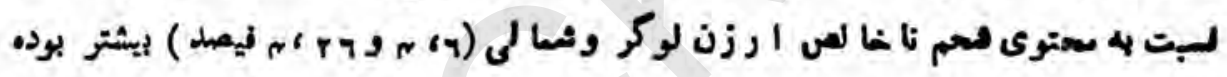

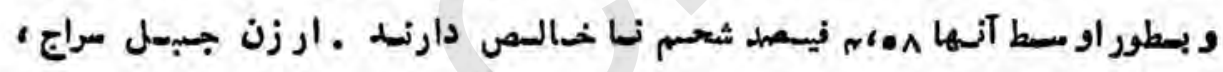

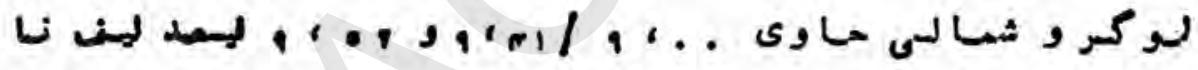

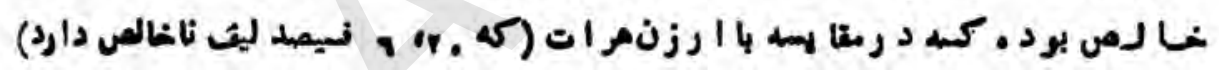

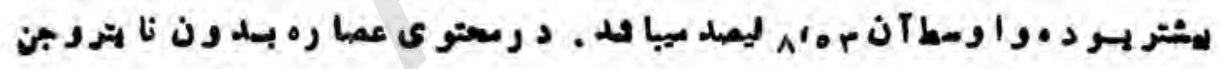

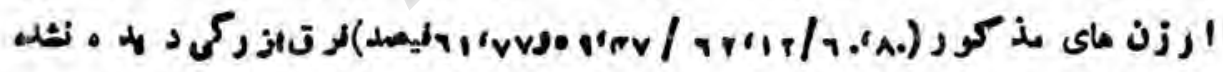

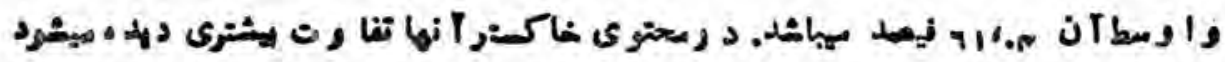

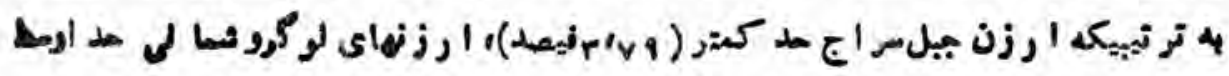

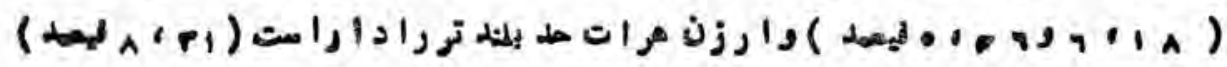

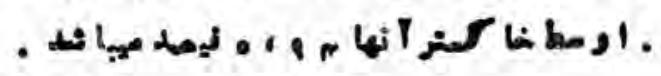

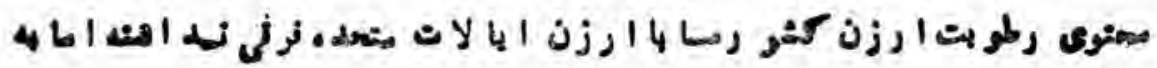

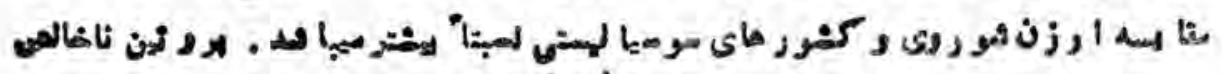
(iv) 


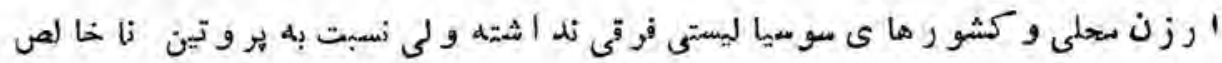

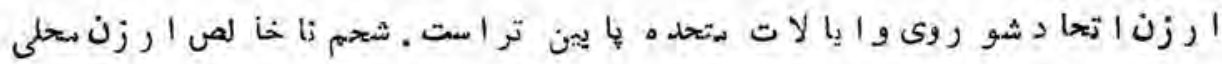

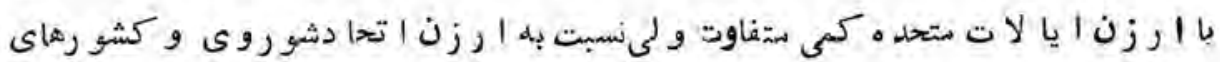

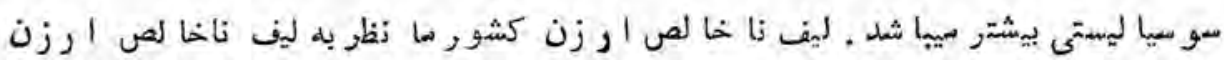

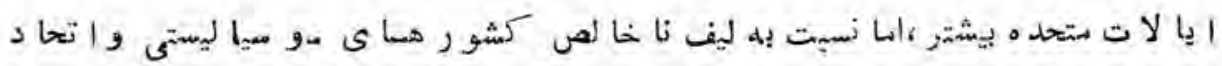

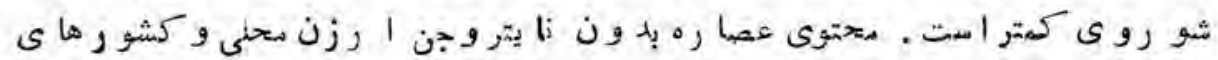

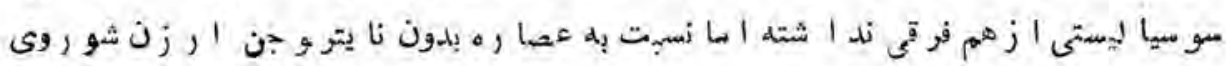

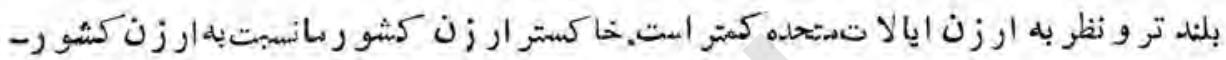

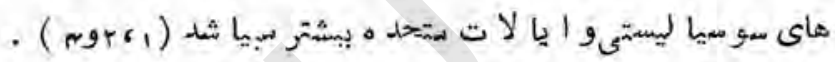

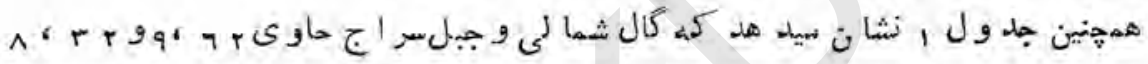

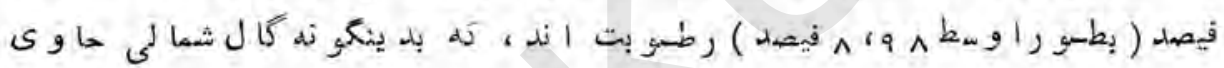

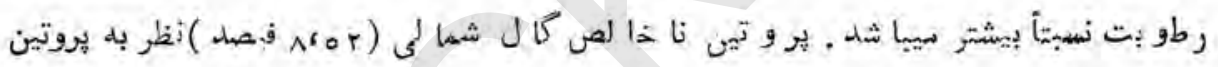

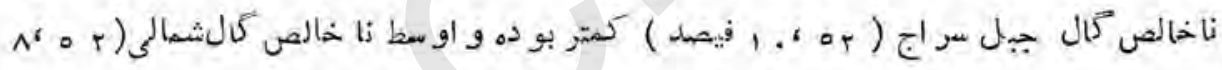

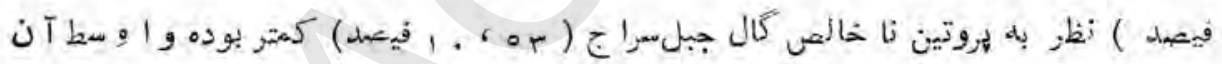

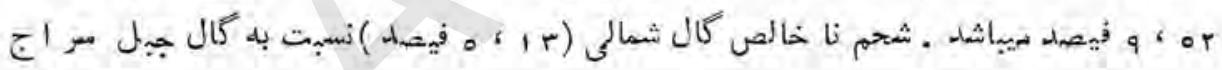

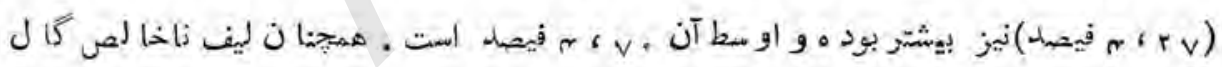

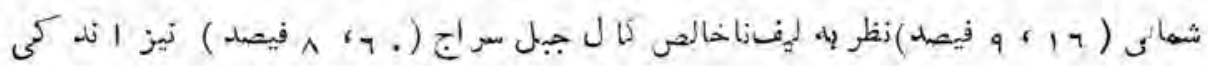

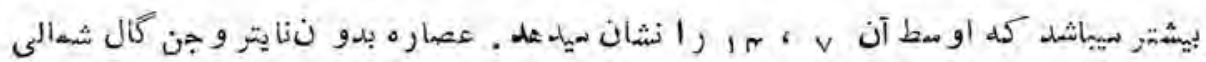

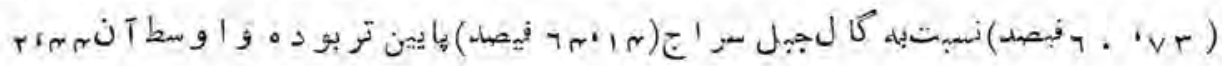

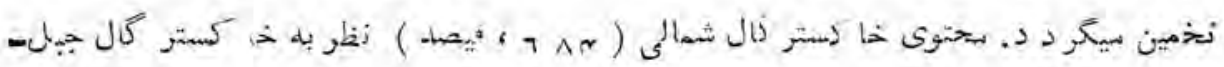

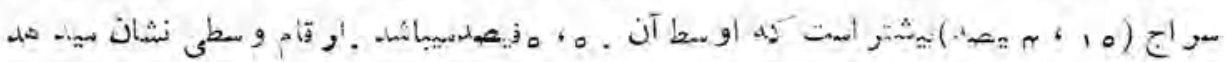

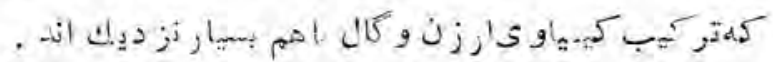


تحتوى رطو بت و بر و تين كاخحاله كال سحلى نسبت به كال ايالات متحلد مكتر بو دها. ولى مجتوى شحم ناخالضو ليف ناخالصآنهااز مممآتقدر فر قى ندار زند. عصاره بدو ننايتر وجن و خاكستركال هيخلى نسبت به كال أيالات تشتحه بيشتر است (م) . بايست خاطر نشان ساخت كم تر كيب كيهياوى، خو ر اكث، باب نظر بهخهو صياتارثى،

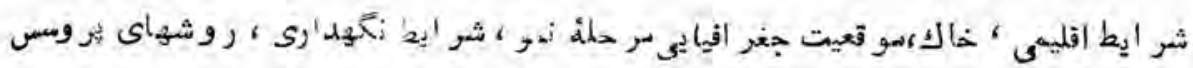
زهو د ن وحتى طر ز نمو نه كرفتن فر ق بيكند. بنابر ان لاز م است تا تر كبب كيهيا وى

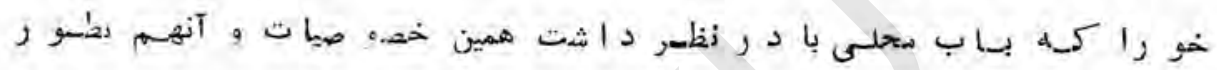

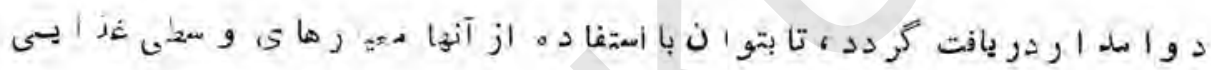

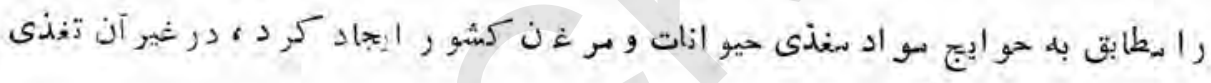

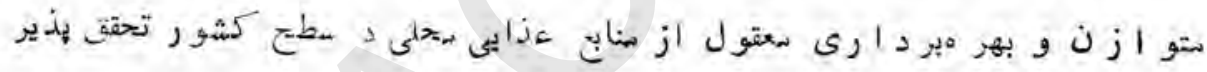
نخخو اهد بود .

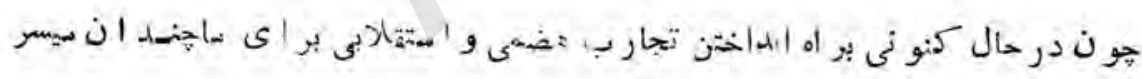

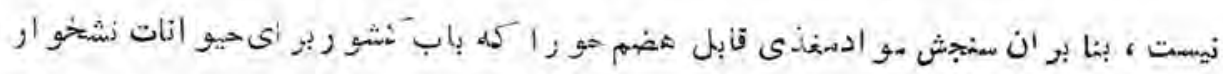

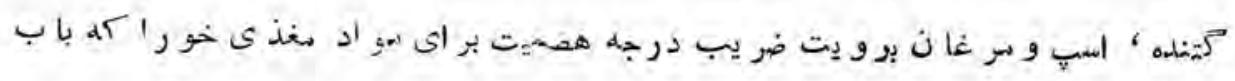

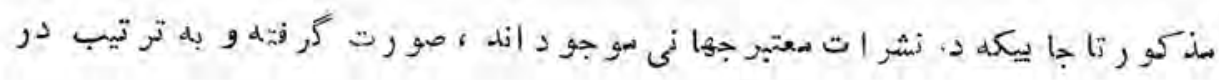

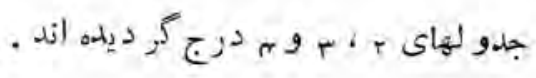




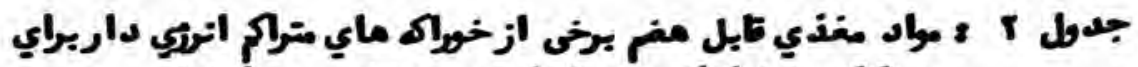

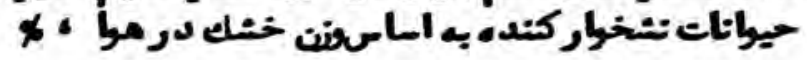

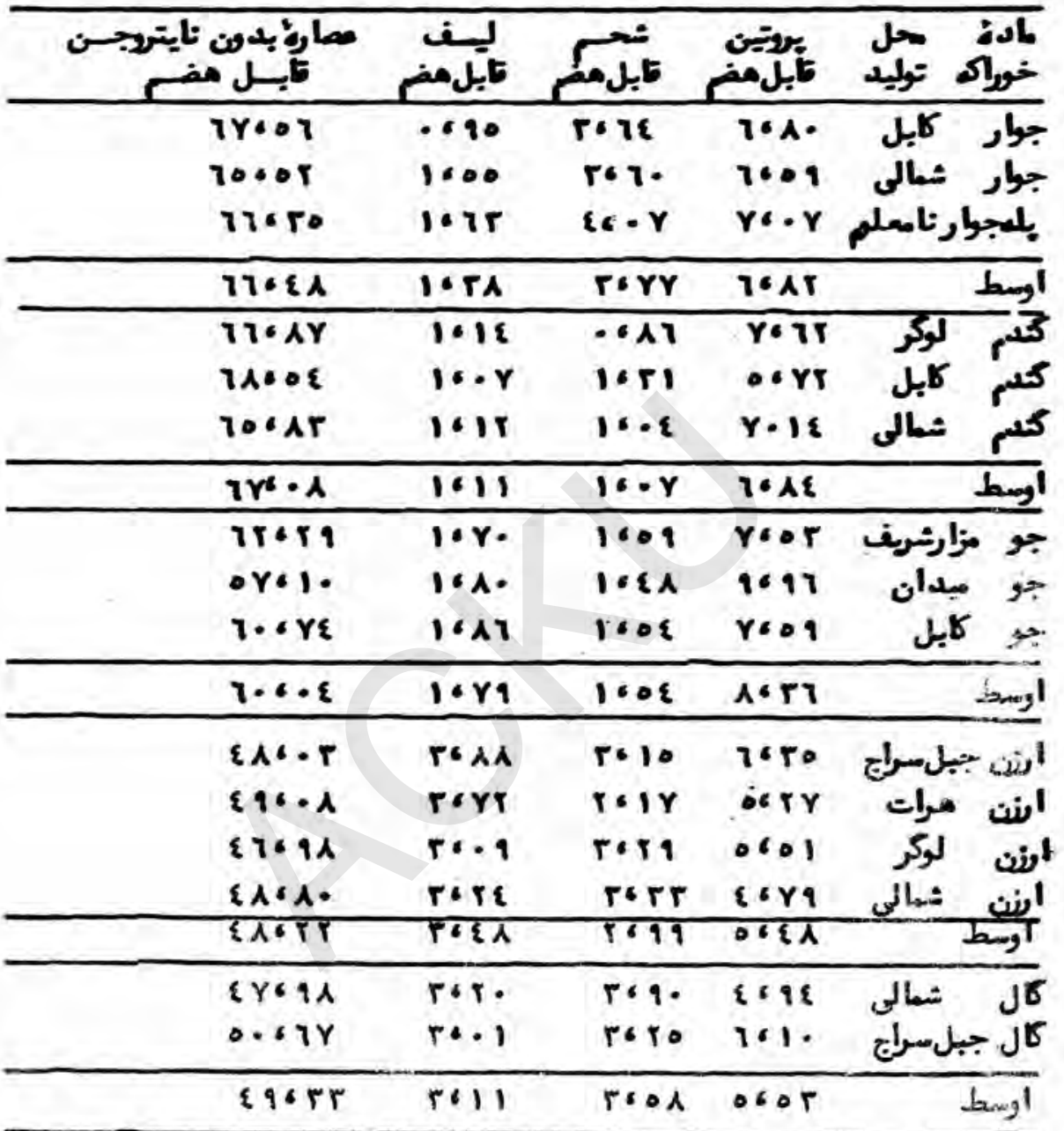

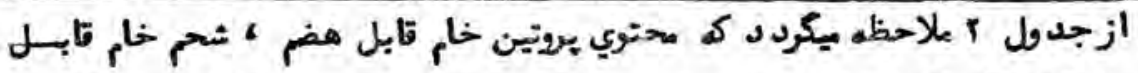

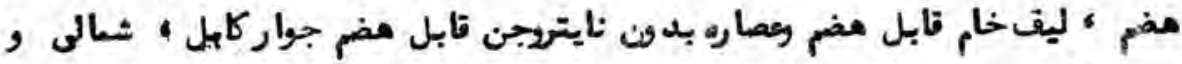

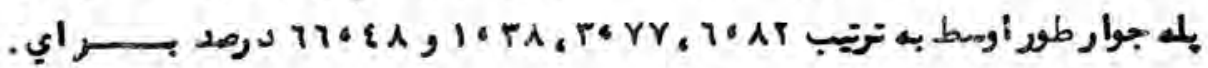




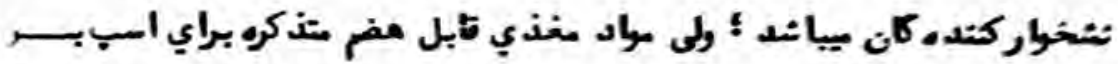

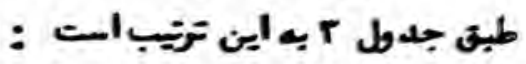

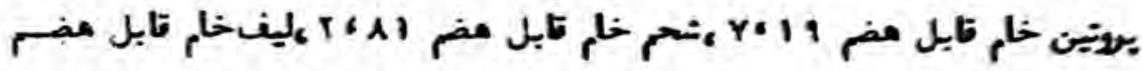

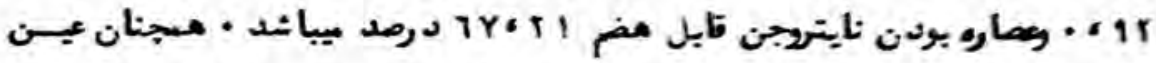

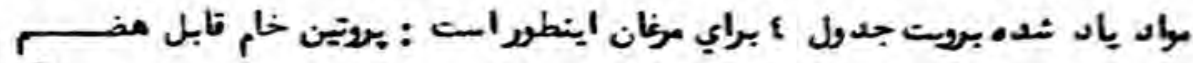

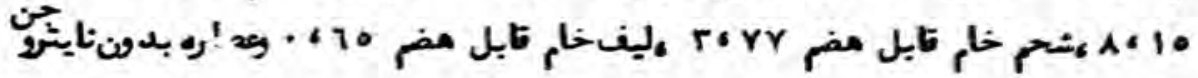

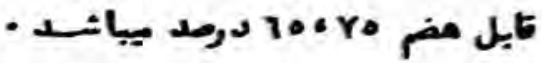

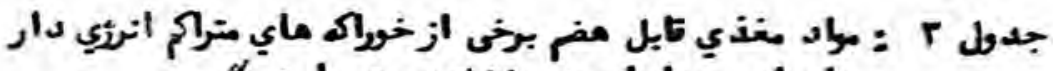

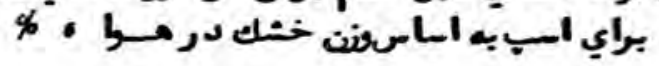

\begin{tabular}{|c|c|c|c|c|}
\hline نايترارجن أبلبل مغ & ليف قابل & شضم 5ابل & مضتينتابل & خوراك \\
\hline 11.5. & .018 & $r \cdot Y I$ & $r+1 Y$ & جوار \\
\hline Eם & 16.8 & $T \cdot T h$ & 7.10 & شمعالى \\
\hline Tra. A & $1 \cdots 1$ & $r \cdot r$ & $r \cdot\{1$ & يلجوار امعلر \\
\hline$T Y+T 1$ & .611 & $r \cdot 11$ & r.19 & $\overline{b y}$ \\
\hline $0 q \& \varepsilon T$ & $1 \cdot A r$ & $1.8 r$ & 1.11 & مزارثرف \\
\hline $0\{\cdot \varepsilon Y$ & $1 \cdot 91$ & I. rr & $\{C r \gamma$ & \\
\hline orois & 16.0 & 1. 1 & $0<90$ & جو كايل \\
\hline 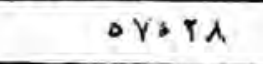 & 1698 & 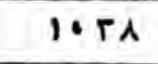 & 0.11 & أو \\
\hline
\end{tabular}

محتوي ماد مغذي قابل مضم كدم لوكر • كابل وثمالى بـ ترتيب طوراوسط براي

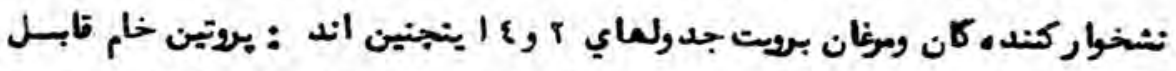

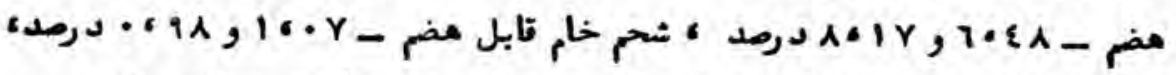

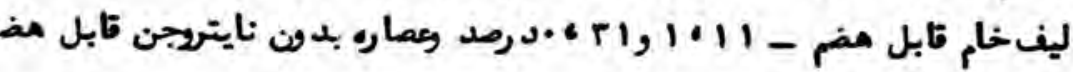
• 
جو مزارشري ، ميدان وكابل به ترتيبطوراوسط حاوي مواد مغذي آتى براي

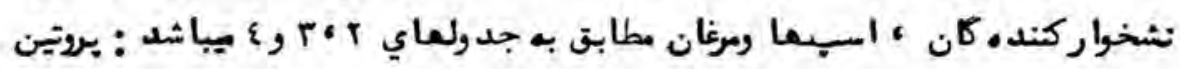

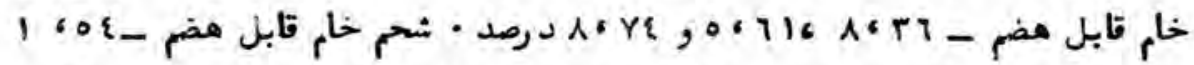

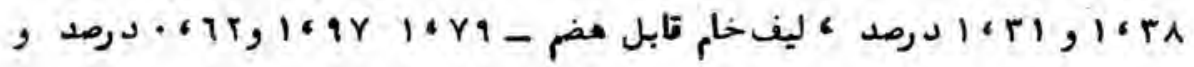

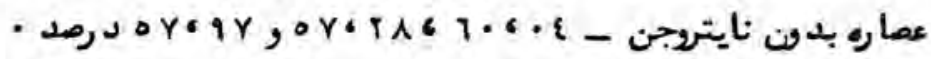

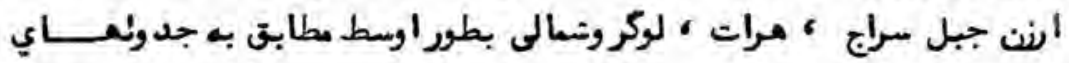

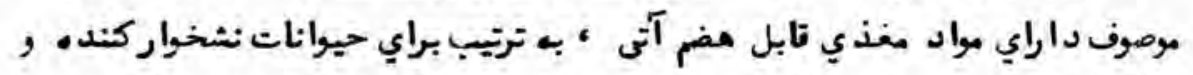

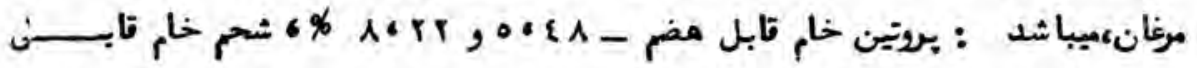

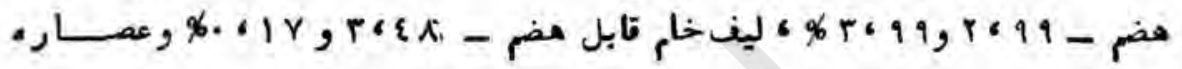

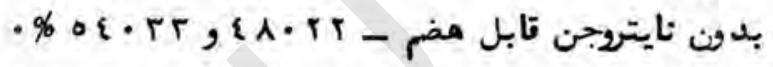

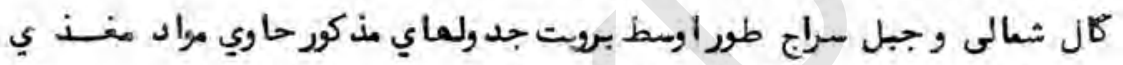

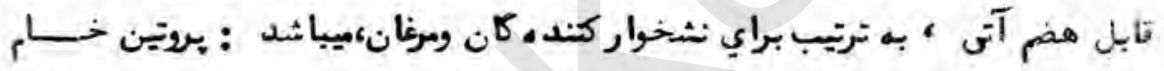

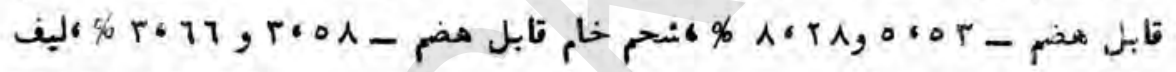

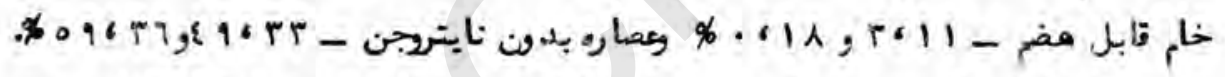

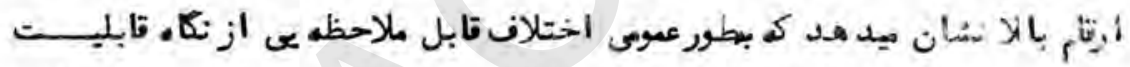

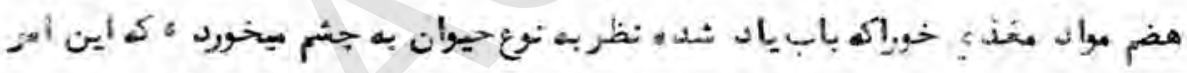

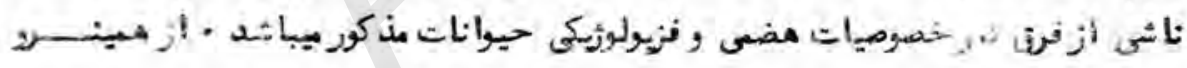

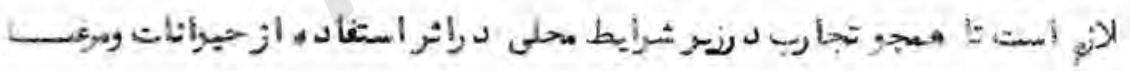

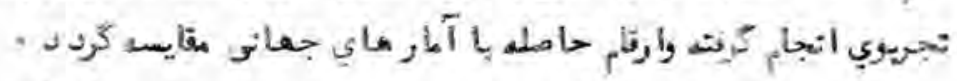

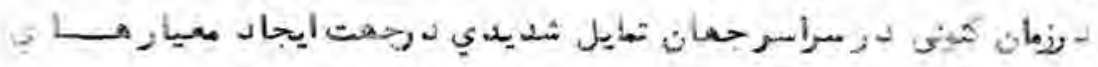

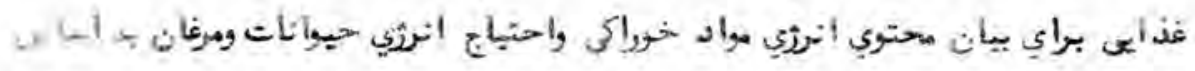

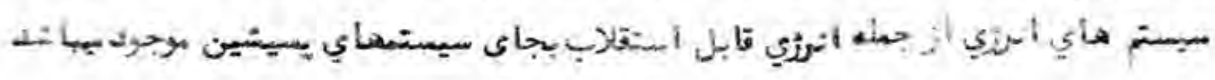

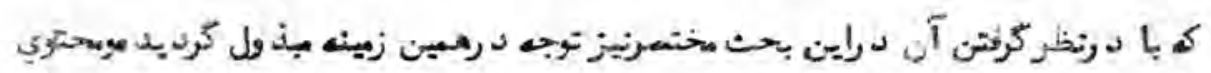

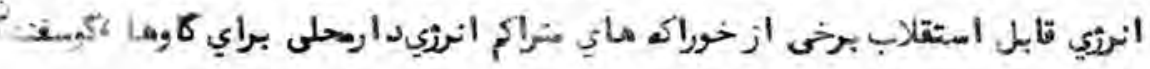

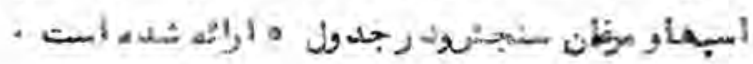




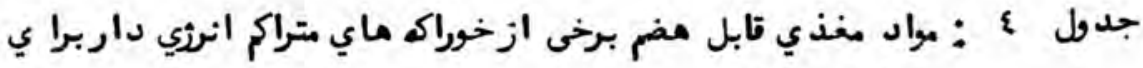

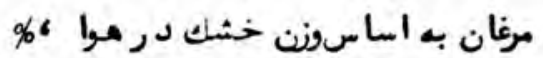

\begin{tabular}{|c|c|c|c|c|c|}
\hline قابل مضبد ونـنايتروجن & لمضــ قابل & شضخ قابل & مضضين تابل & توليدل & خوراك \\
\hline . & $\cdots\{0$ & $r \cdot T \varepsilon$ & $1.1 r$ & كابل & \\
\hline
\end{tabular}

\begin{tabular}{|c|c|c|c|c|}
\hline $\begin{array}{l}7 \varepsilon \cdot \lambda \\
7001 \%\end{array}$ & $\begin{array}{l}\cdots Y r \\
\text { * Gry }\end{array}$ & $\begin{array}{l}r \cdot r . \\
\varepsilon \cdot r\end{array}$ & $\begin{array}{l}Y \subset \wedge Y \\
\wedge \subset\{0\end{array}$ & لـه جوار بار شعالى \\
\hline 10.90 & $r \cdot 70$ & $r 6 V V$ & 1010 & اوسط \\
\hline$T T \cdot \lambda Y$ & . orr & $\cdots \mathrm{Yq}$ & $9 \cdot 15$ & لوكر \\
\hline $11.0 \varepsilon$ &.$\leftrightarrow r$ & 1.19 & $7 \cdot 1 \varepsilon$ & كابل \\
\hline Todᄉr & . r r & •१० & $1.0 r$ & شيالى \\
\hline $7 r \cdot 1$ & . (r) & .991 & $A \cdot 1 Y$ & اوسد \\
\hline 70418 & . .099 & 1.17 & $Y \circ 9 \varepsilon$ & مزارشريف \\
\hline $00, \varepsilon r$ & . tr & $1 \cdot 17$ & $1 \cdots 19$ & ميدان \\
\hline ONSY\& & .40 & 1.rT & $\wedge \cdots$ & كابل \\
\hline$O Y \circ A Y$ & .71 & $1 \cdot r 1$ & $\lambda \cdot Y \varepsilon$ & أومس \\
\hline $0 \leqslant 011$ & $\cdots 1 A$ & $\xi \leqslant\{\varepsilon$ & 4.0\% & ل سراج \\
\hline DO: Y 9 & $\therefore$ is & 80.7 & $y+9$. & $=1$ إن \\
\hline$=T=1 \mathrm{r}$ & $*+11$ & Ttor & Axty & اند فوكر \\
\hline$=5: 91$ & $=1+1$ & $r, Y s$ & $r+19$ & This \\
\hline 9.864 & $\cdots I Y$ & $7=99$ & K. 45 & اوسعة \\
\hline TIIT & $+\theta i \lambda$ & $T \cdot 09$ & $Y \leq \leq 1$ & شهائون \\
\hline$b y=1$ & $\therefore r$ & 5.45 & 1610 & جيل مرنج \\
\hline ר & $-21 \mathrm{~A}$ & $5 \cdot 7 \pi$ & $\operatorname{asch}$ & bagnt \\
\hline
\end{tabular}




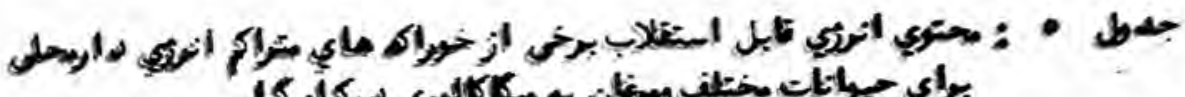

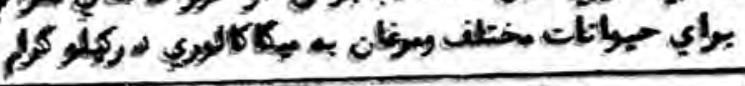

\begin{tabular}{|c|c|c|c|c|}
\hline ماي سرغ & براي السب & براي ك-كندا & برايكا, & خמص: \\
\hline 70.8 & 7611 & 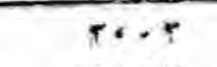 & r.9r & كايل \\
\hline$T+50$ & $7+11$ & $5.9 \mathrm{Y}$ & $r+11$ & \\
\hline r.so & $r+5$. & 5.7 & 5091 & نامعلم \\
\hline$\pi 601$ & $261 x$ & $5 . .5$ & $1+91$ & $\overline{q^{\prime}}$ \\
\hline$r 68$ & - & 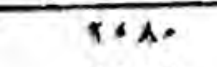 & $8+Y A$ & لوكم \\
\hline totr & - & $r \cdot A 1$ & $r+r q$ & \\
\hline$\pi+\pi 0$ & - & soro & TorE & הمانى \\
\hline ThT & - & T.89 & port & 1 \\
\hline $5 s .4$ & $r \times r \varepsilon$ & r.rT & $1 \cdot 39$ & مزأرشويف \\
\hline Toir & $x+\varepsilon A$ & toit & $r+1$. & جو م \\
\hline 1690 & $r \cdot 1 x$ & $\pi+17$ & 5025 & بح \\
\hline $869 Y$ & r.ir & r.Tr & 7.78 & \\
\hline 5615 & - & $r \cdot E r$ & 7650 & جيل سراd \\
\hline 56.9 & - & 8017 & $r+s \cdot$ & هـر \\
\hline 1097 & - & rरa & hat & يركـ \\
\hline 5699 & - & tot & tot & : \\
\hline$r e \cdot r$ & - & 1620 & $r+19$ & 1 \\
\hline hert & - & r.te & $R \cdot t \cdot$ & شعالى \\
\hline roir & - & $r \in q \varepsilon$ & T.TA & كال جبل سـراج \\
\hline rotr & - & $r \cdot \varepsilon \cdot$ & $r \cdot r \varepsilon$ & اوسط \\
\hline
\end{tabular}

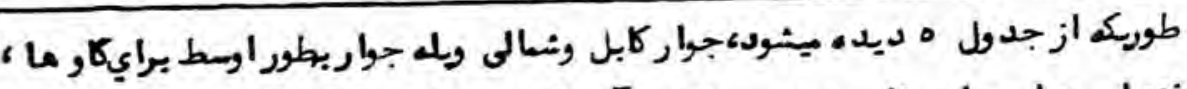

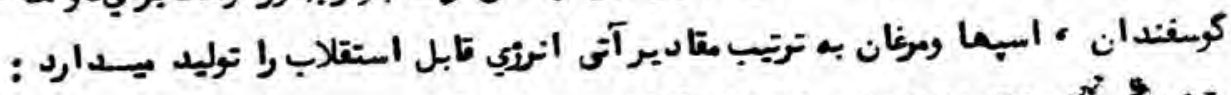

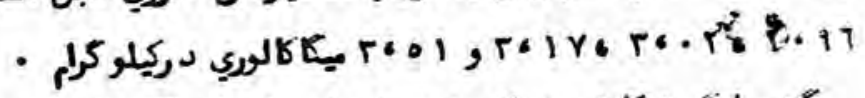

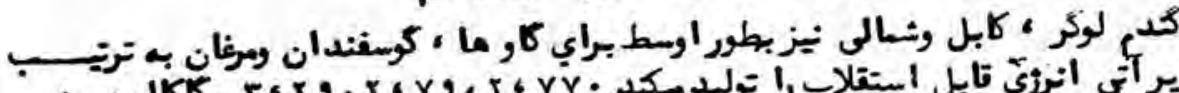

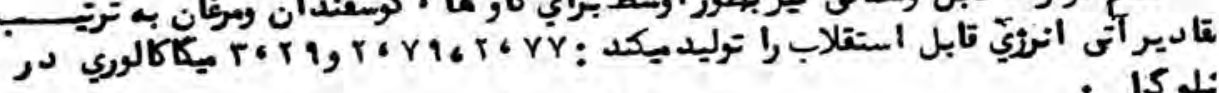




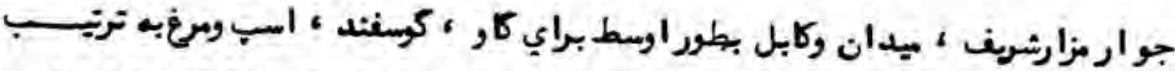

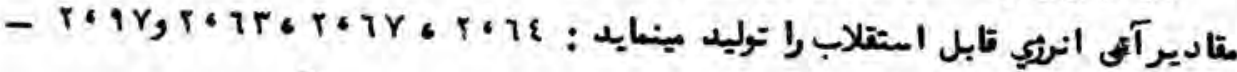

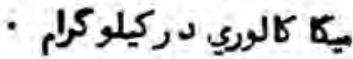

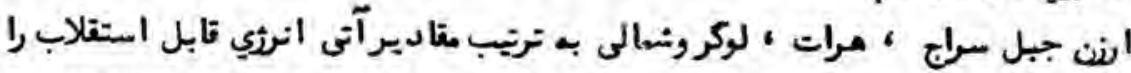

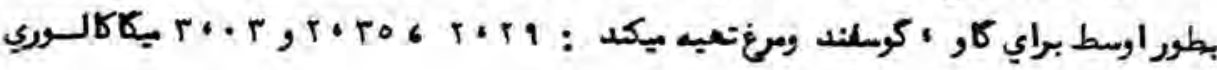
• دركيلو كراן

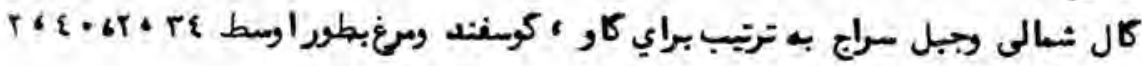

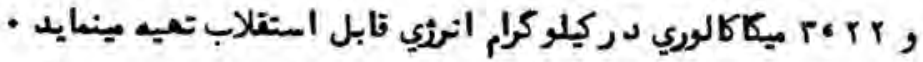

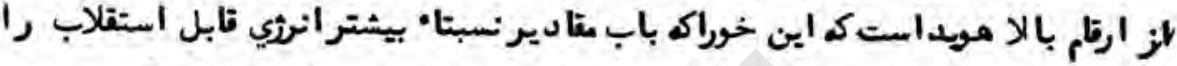

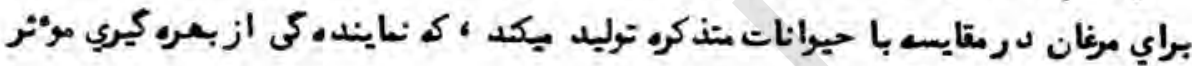
ترتوسط مرغان مينطايد

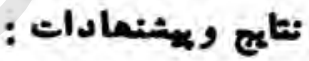

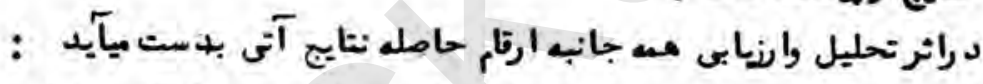

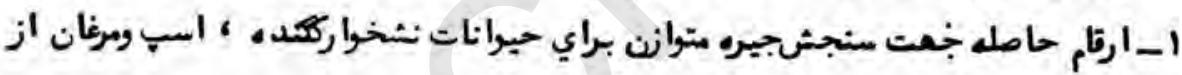

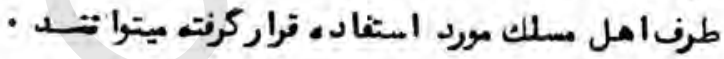

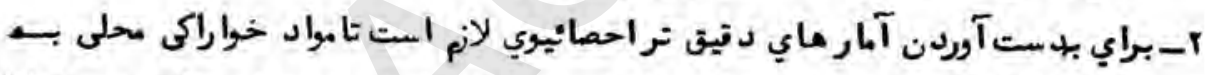

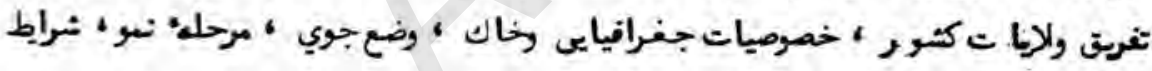

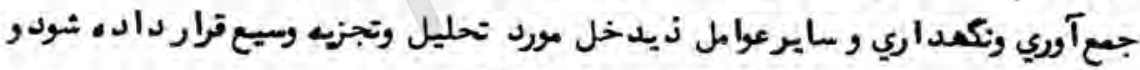

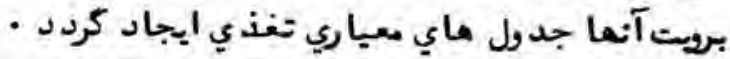

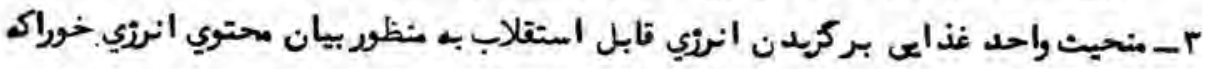

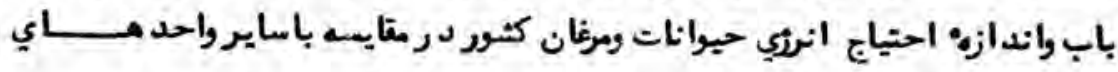

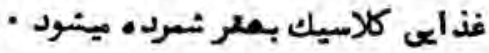

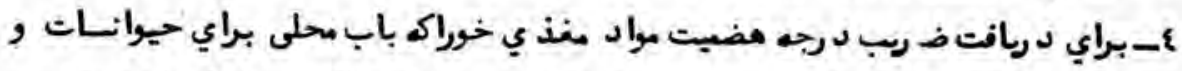

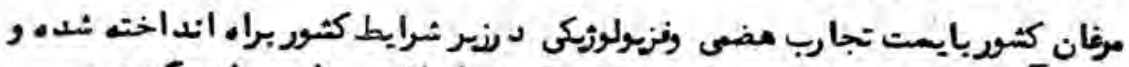

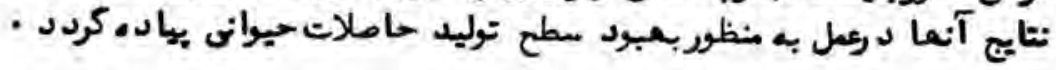




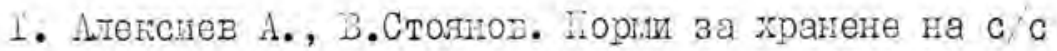
\#еотни п таблиц за хранителността на уурампте. Беншздат, Сорил, $1904,0.200-29 \%$.

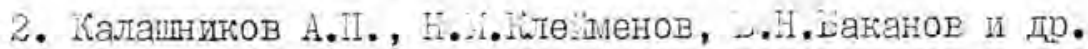
Нормы и рационы корімтенш $\mathrm{c} / \mathrm{x}$ мвотных. Справочное издание, носнва, Агропромшздат, 1985, с.7 и 339.

3. Сельское хозяйство за рубелол, јивотноводство, 1965, , $2,0.69$.

4. Ensminger,M.E., Olentine,G.C.: Feeds and Nutrition Complete. The The Ensminger Publishing Company, $197 \varepsilon$ pp $113 /-117 /$. 


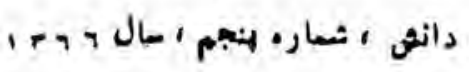

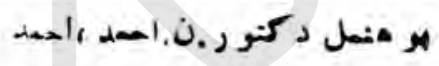

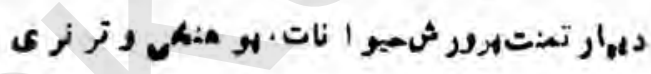

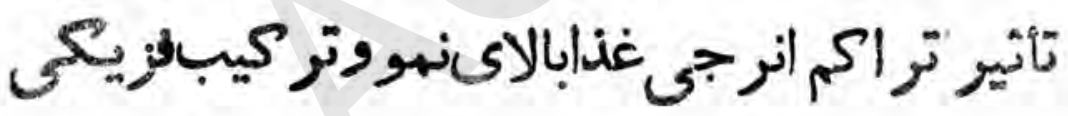

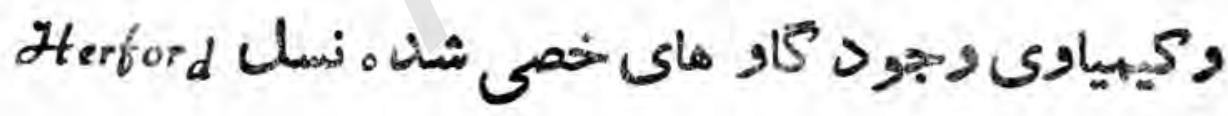

: ex sio

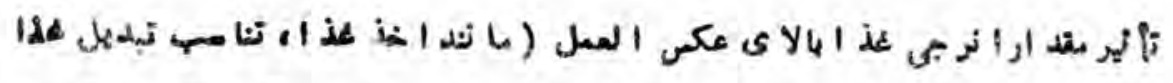

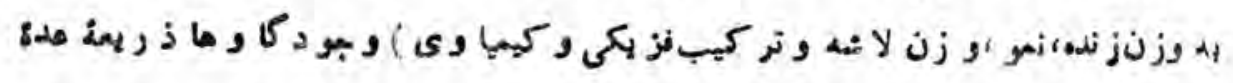

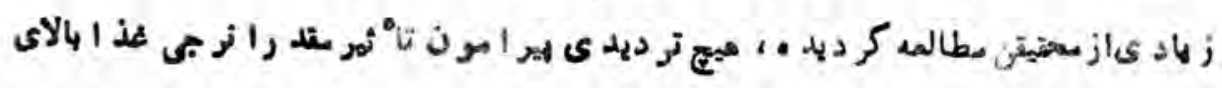

(vv) 


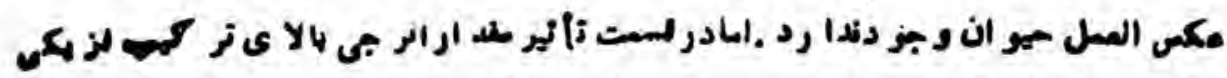

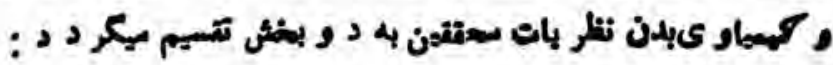

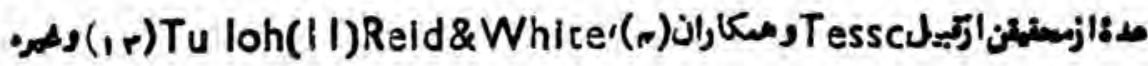

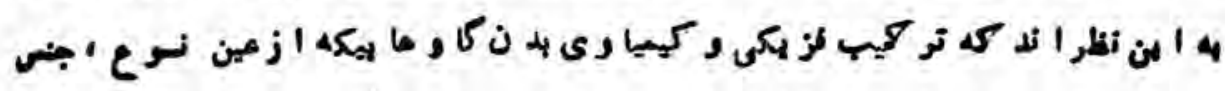

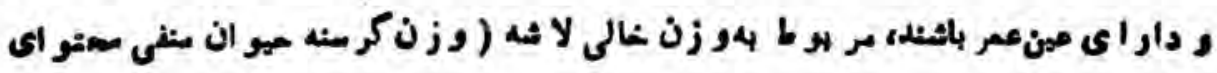

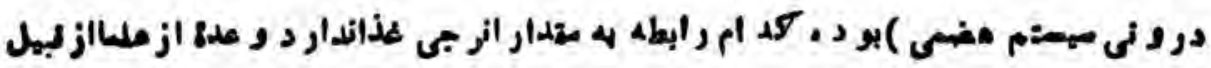

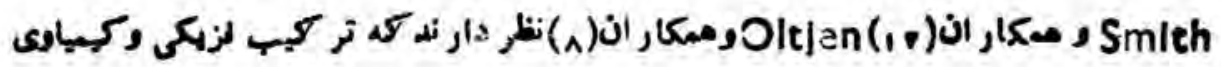

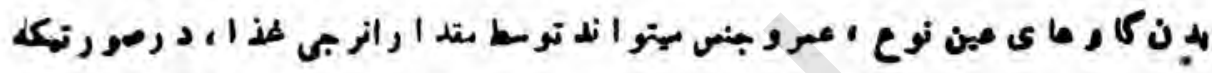

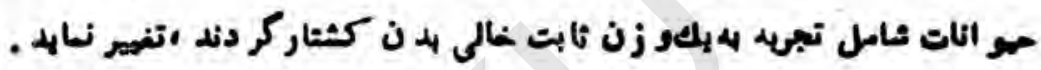

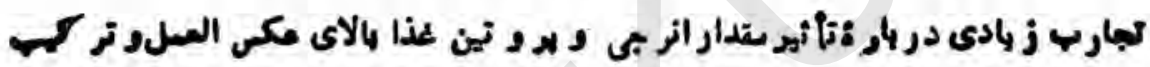

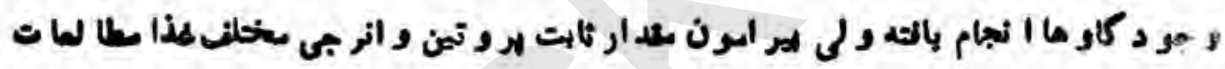

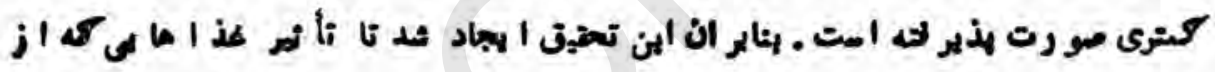

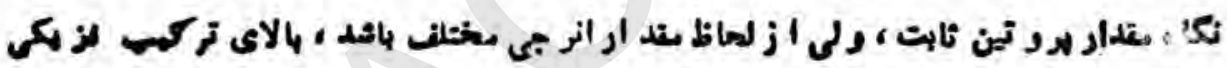

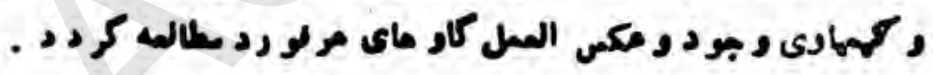

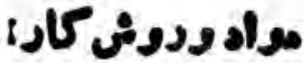

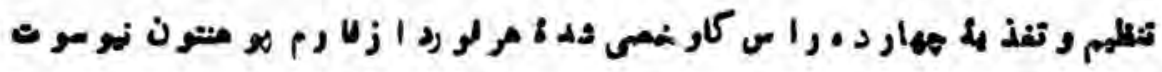

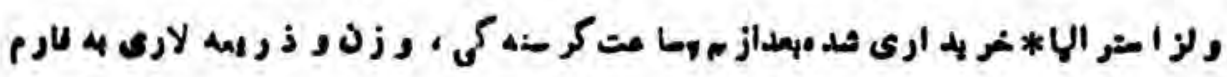

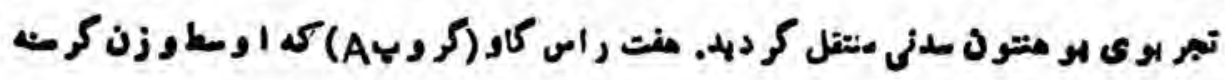

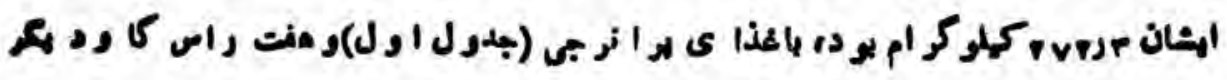

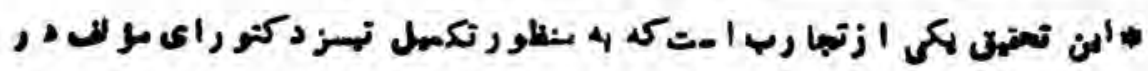

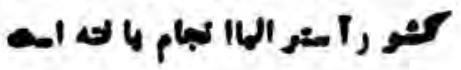




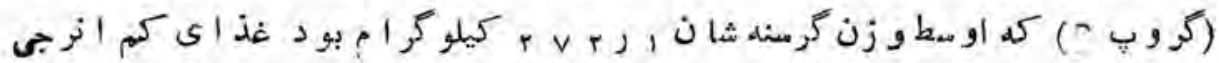

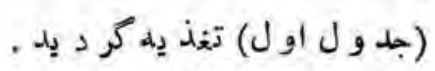

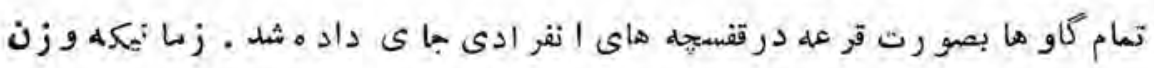

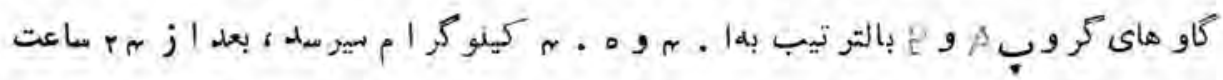
كر سته كى كثيار ميكر ديدند.

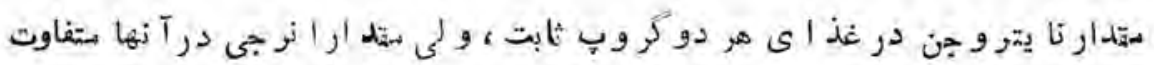

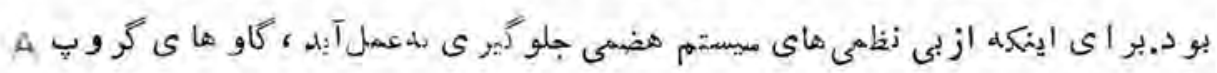

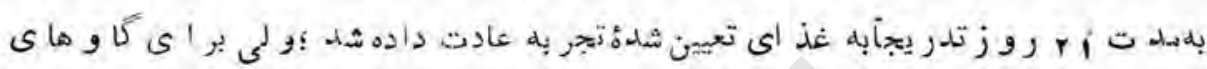

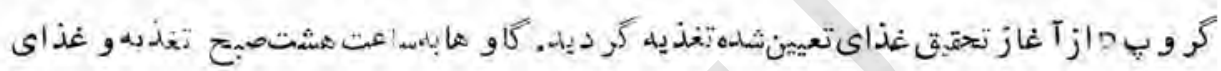

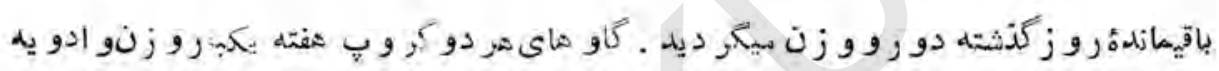

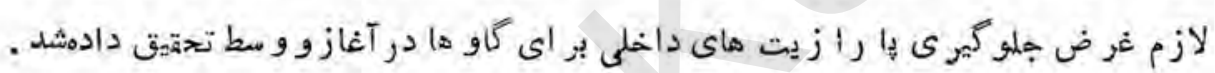

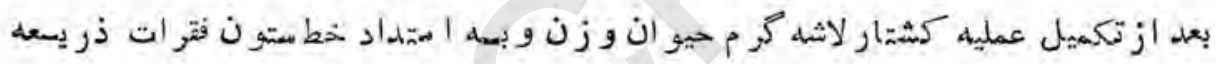

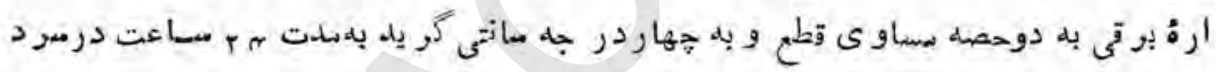

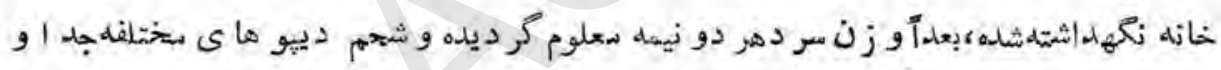
وزنمرديد

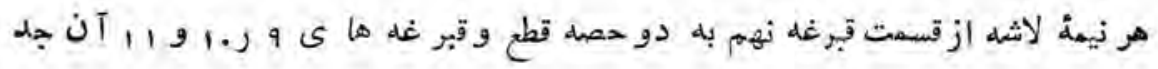

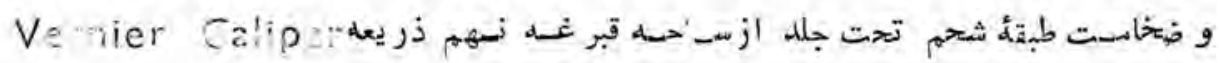

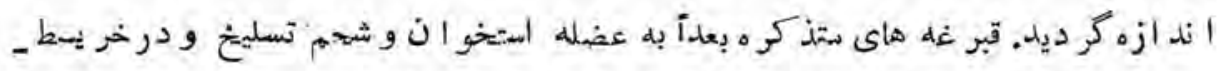

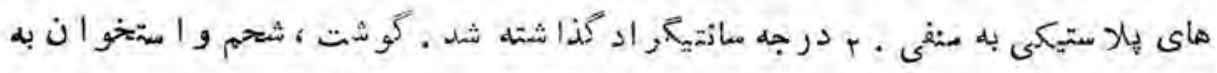

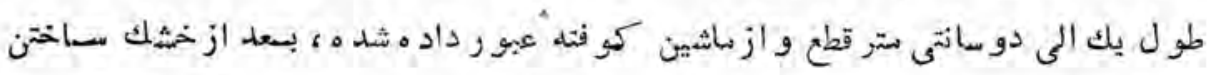

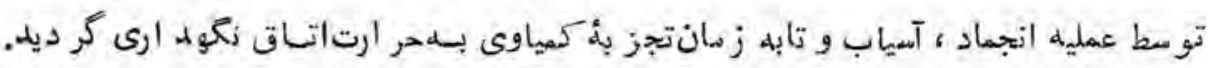




\section{بلدو ل اول - أجز ا وتر كيب كيمياوى ثـذا}

تركيب كيمياوى غذ' به كرام م:

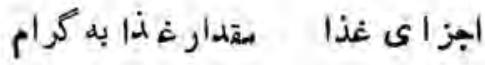

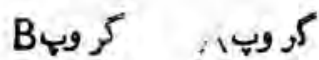

Bروب S

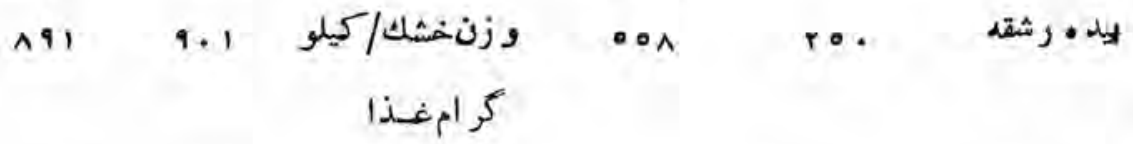

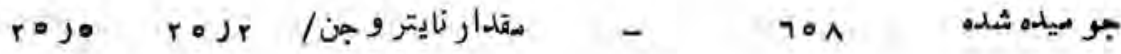

$$
\text { كيلوكر ام أم }
$$

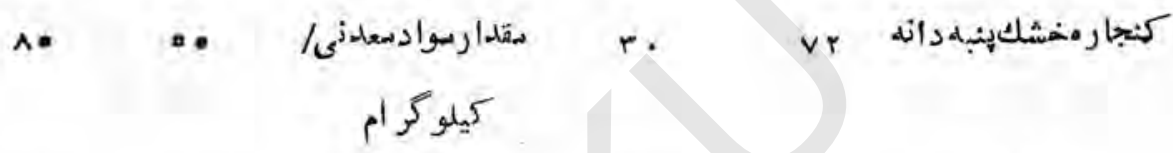

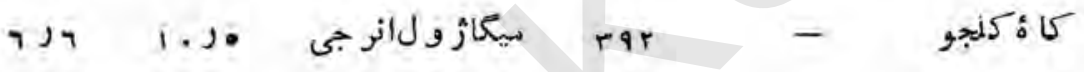
كابل استقلاب| كلموكرام (0)

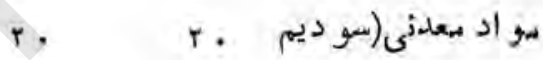
كلمو رايد)

\section{: نجزئه}

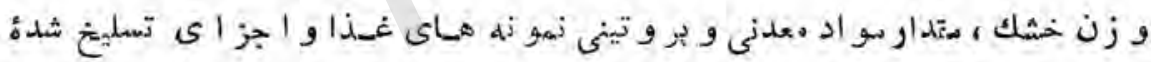

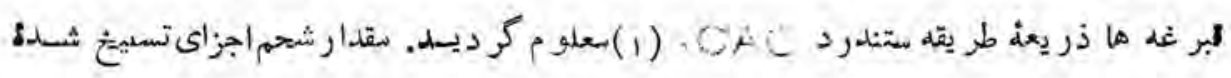

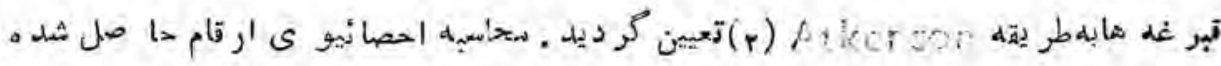

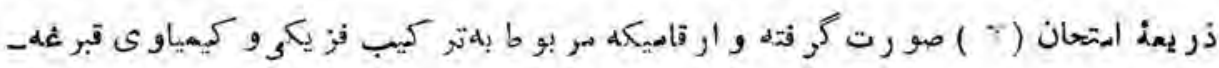

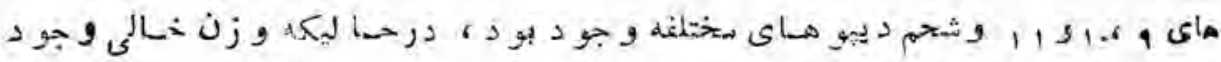

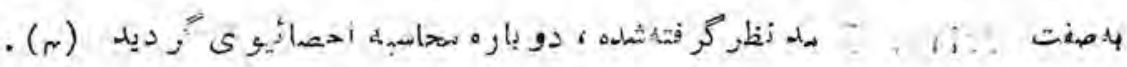




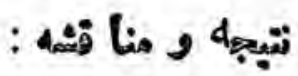

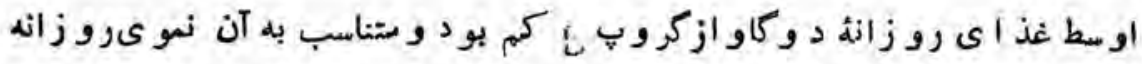

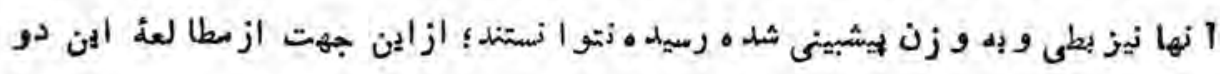
كا و صرف نظر بعمل آهد .

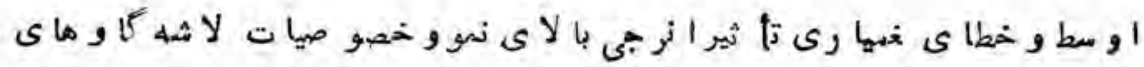

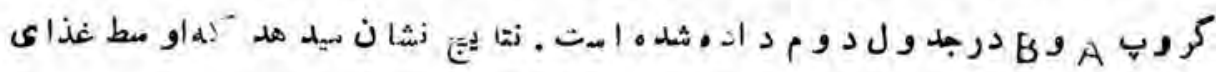

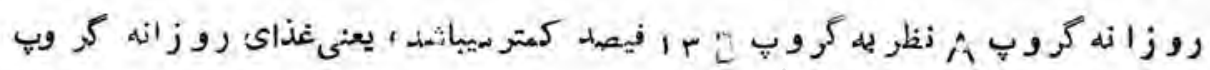

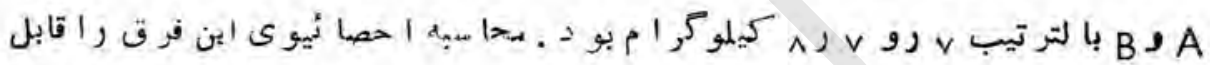

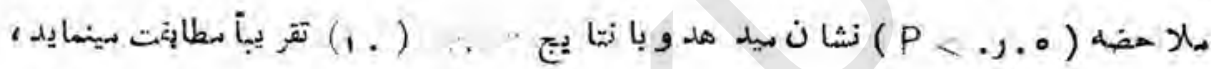

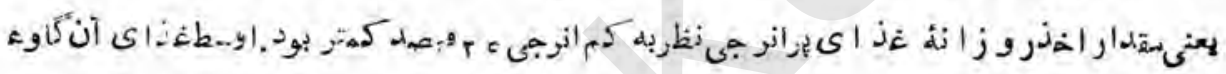

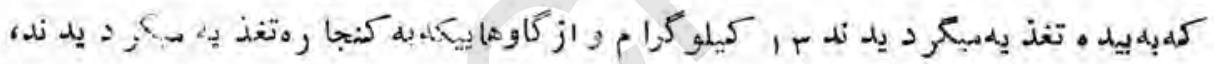

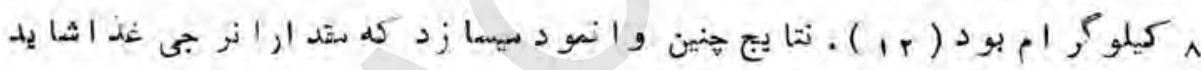

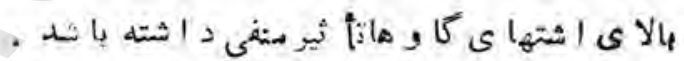

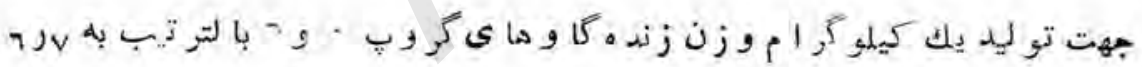

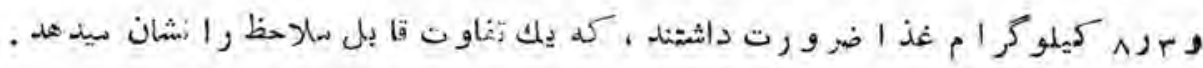

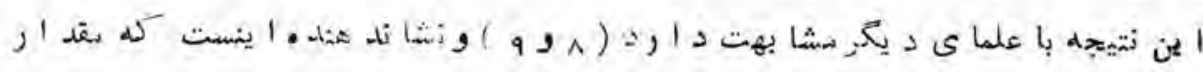

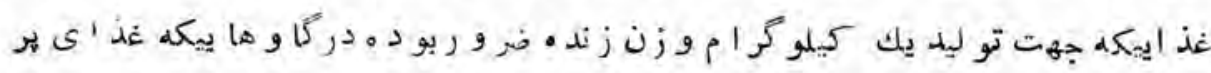

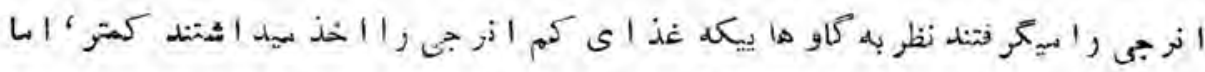

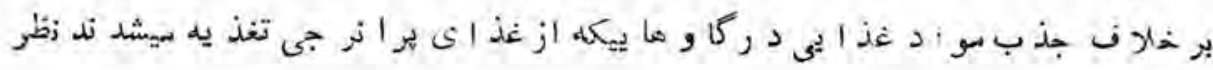

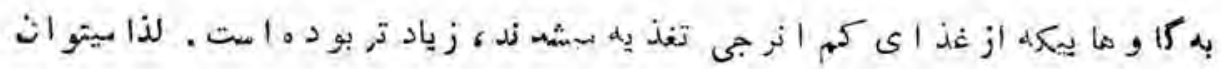

$(+1)$ 


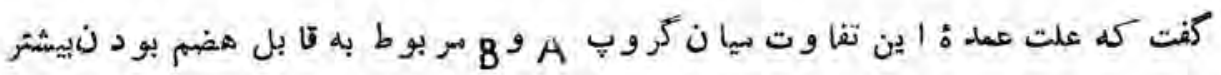

غذا أى بر ا نز جى نظر به كم انرجى است.

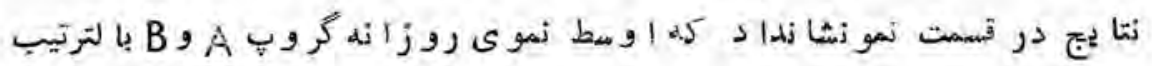

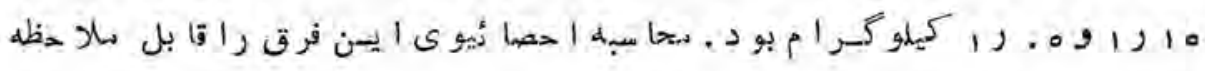

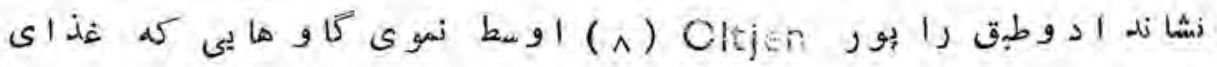

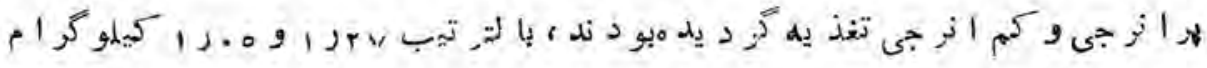

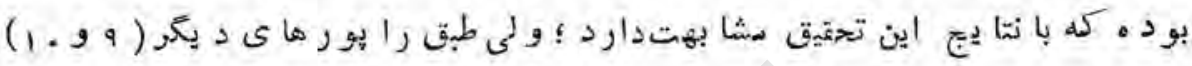

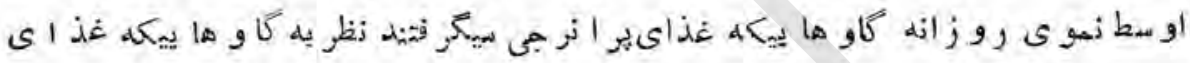

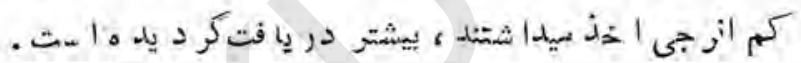

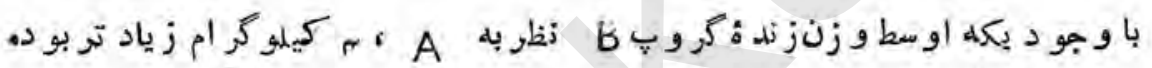

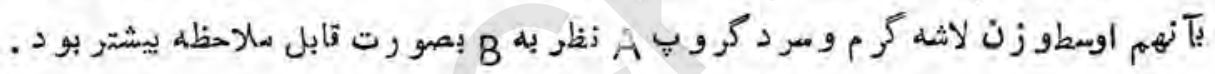

ائن فو ق بطو رعمده ممكن است كله سر بو ط به دو فكتو رباشد :

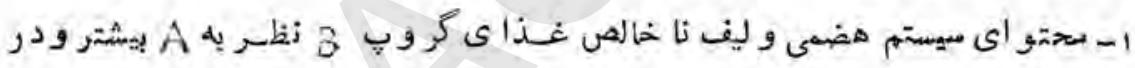

هقابل درجة هضميت و دقدار انو جي آن كمثر بو ده است .

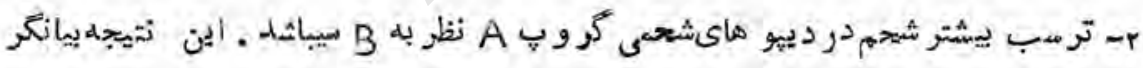

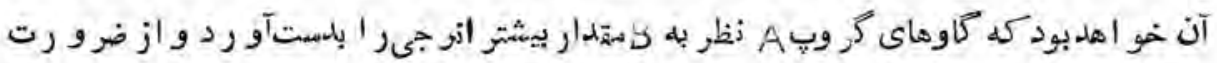

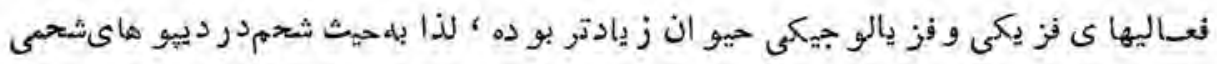

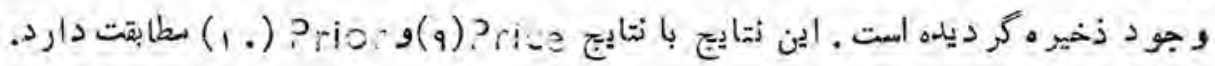

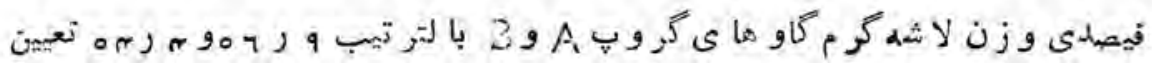

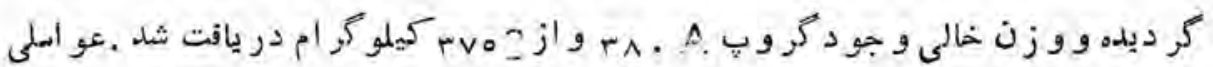

$(r r)$ 


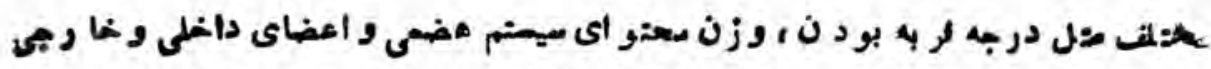

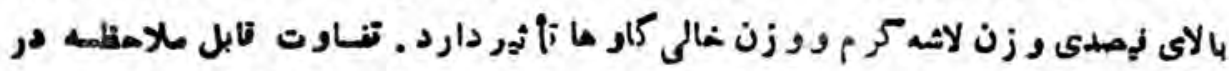

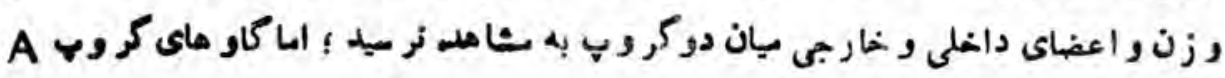

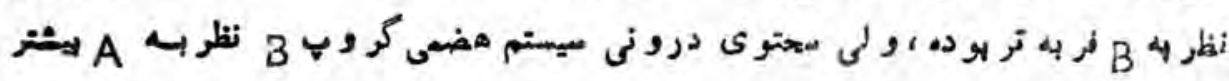

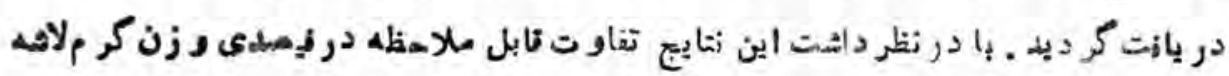

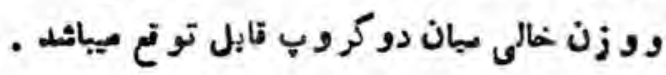

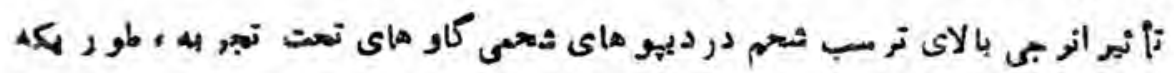

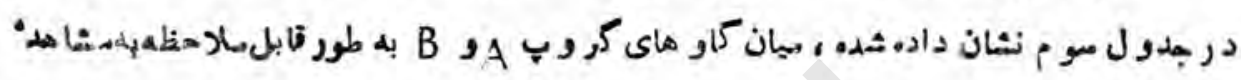

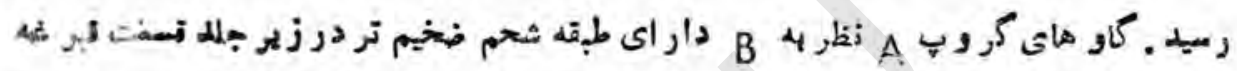

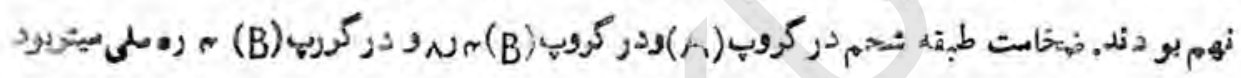

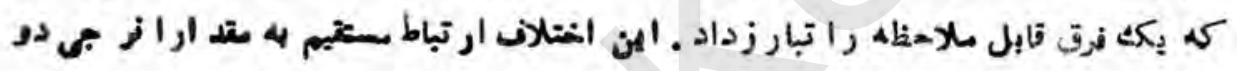

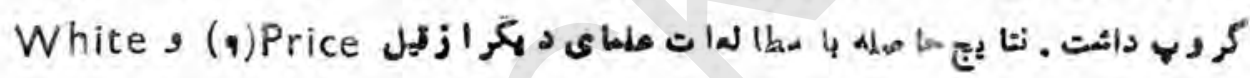

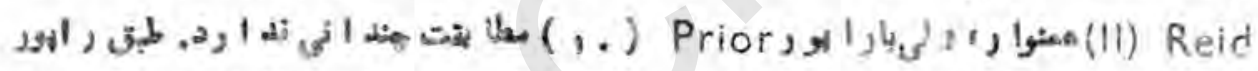

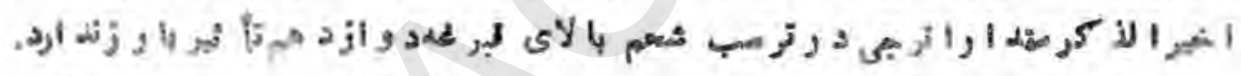

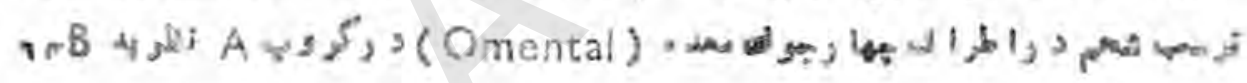

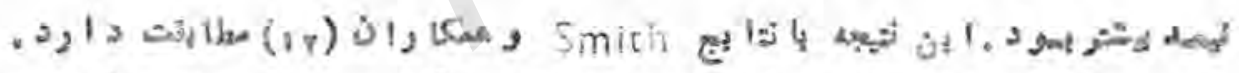

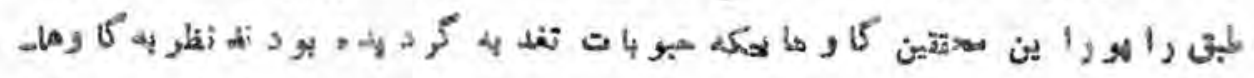

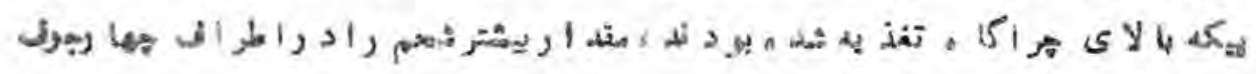

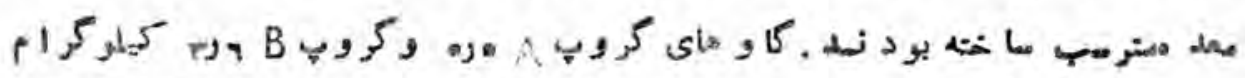

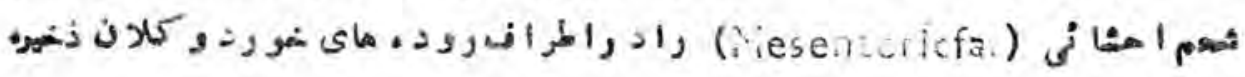

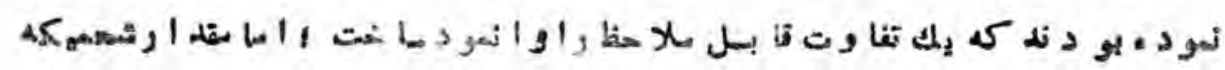

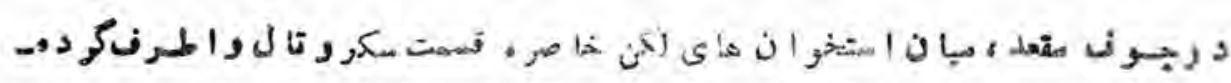

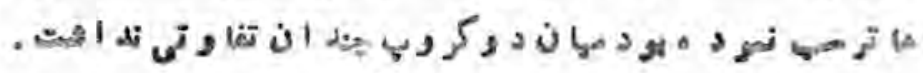
(Pr) 


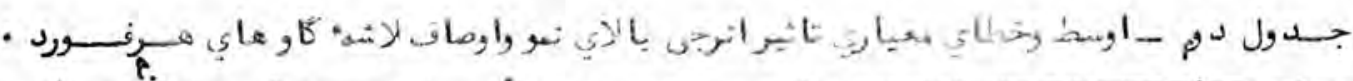

\begin{tabular}{|c|c|c|c|c|c|c|c|c|c|c|c|c|}
\hline 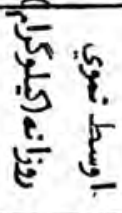 & दू & 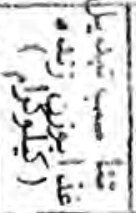 & {$\left[\begin{array}{l}1 \\
-5 \\
5 \\
5 \\
5\end{array}\right.$} & $\begin{aligned} & 6 \\
& \text { है } \\
&-14 \\
&-2 \\
&-5 \\
&-5.5\end{aligned}$ & 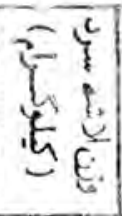 & $\begin{array}{c}-\varepsilon \\
\vec{G} \\
\vec{E}\end{array}$ & 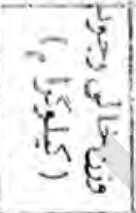 & $\begin{array}{l}50 \\
58 \\
5 \\
5 \\
5 \\
5 \\
5\end{array}$ & 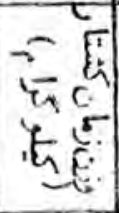 & 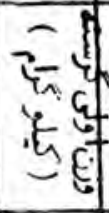 & $\begin{array}{ll}0 & 5 \\
5 & 5 \\
5 & 5 \\
5 & 5 \\
0 & 5\end{array}$ & \\
\hline 1,10 & $V, T$ & $7, \mathrm{TV}$ & 110 & * & * 10 & & res & $\begin{array}{ll}* \\
7 & 1\end{array}$ & $\varepsilon \cdot 1$ & $r, 5$ & \multirow[t]{2}{*}{ Y } & \multirow{2}{*}{$\begin{array}{c}\text { S } \\
\pm S E\end{array}$} \\
\hline$\cdot, \cdot \lambda$ & مזر & $0, r+$ & $1 \cdot 10$ & PT & $r, q$. & $r, \lambda$ & $r(1)$ & 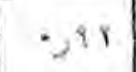 & 0,79 & & & \\
\hline 1,0 & $\begin{array}{l}* \\
\wedge, \gamma r\end{array}$ & ${ }^{*} \quad 1, r 1$ & irr & $a \varepsilon, \varepsilon$ & $x \cdot\left\{\jmath^{\varepsilon}\right.$ & $r \cdot \lambda, r$ & $r+\varepsilon, r$ & $r \vee \varepsilon, \lambda$ & $2 \cdot 0$ & $r \vee \zeta 1$ & 0 & $\begin{aligned} & B \\
& =5 e\end{aligned}$ \\
\hline ריקט & - &.,$r$. & $0, r \varepsilon$ & , & 1,07 & $1, \gamma 7$ & $1, \pi \leq$ & 1,17 & $09 \mathrm{r}$ & $\varepsilon, 1$. & & \\
\hline
\end{tabular}

$*(1<\ldots o)$

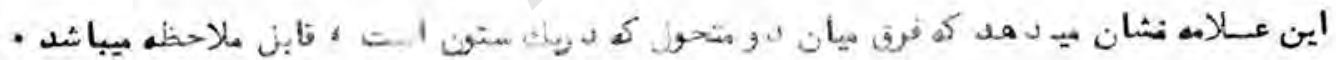


جدول سم : اوسط وخطاي مسياري تائرانرجى بالاي ترسب شحم در

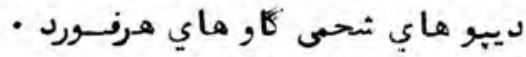

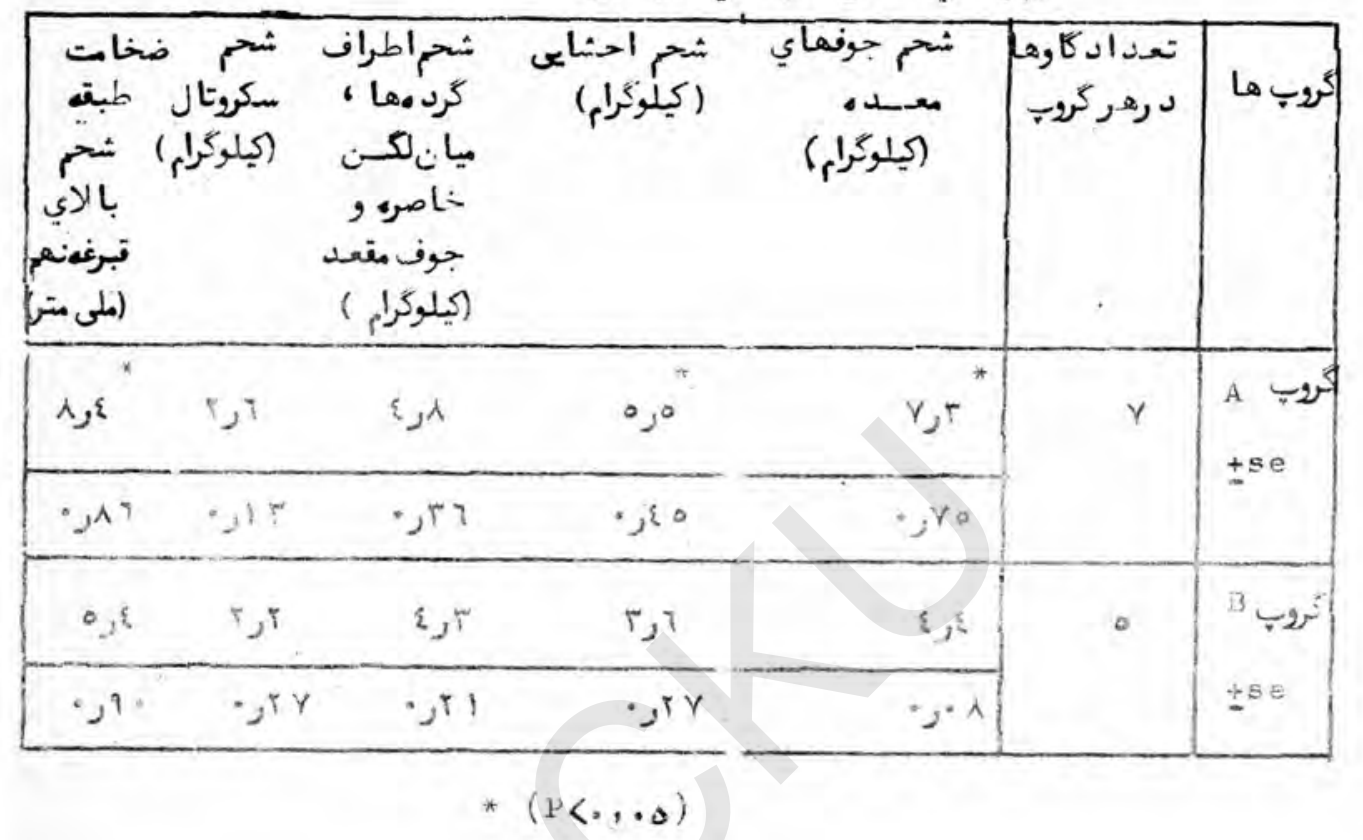

(To) 


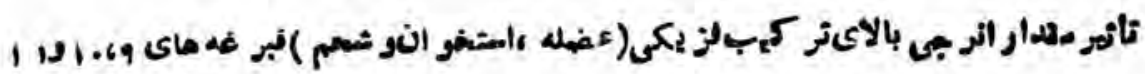

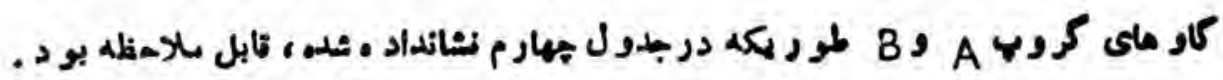

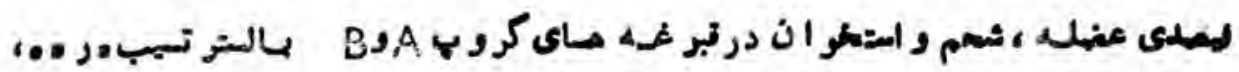

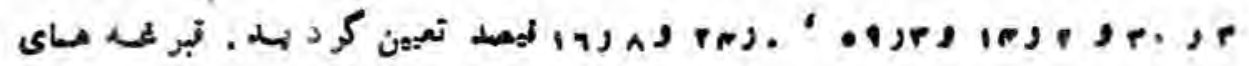

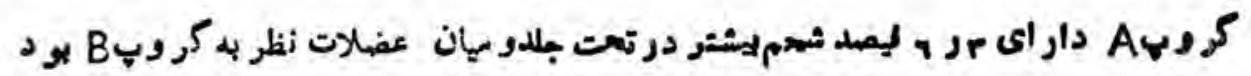

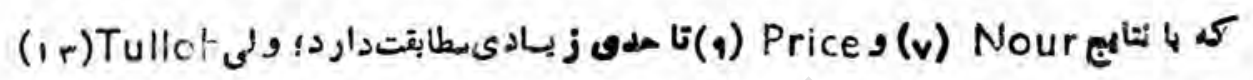

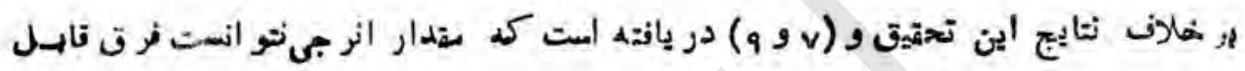

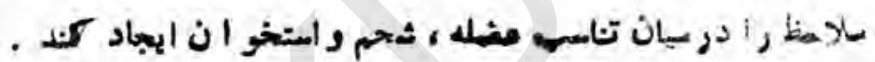

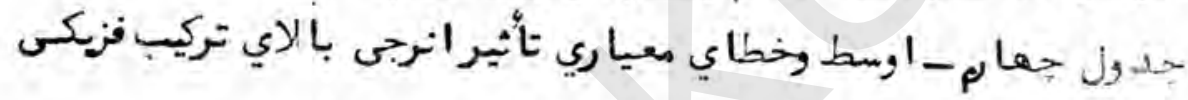

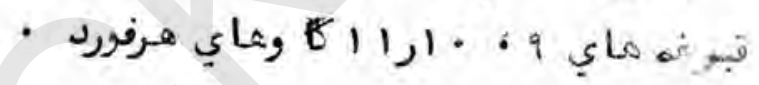

\begin{tabular}{|c|c|c|c|c|}
\hline 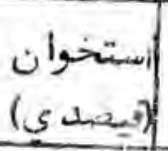 & (فيحد يمي & (فيدمله sa & 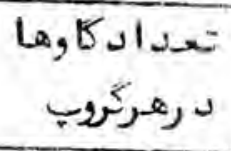 & $L_{2} \cdot-2,5$ \\
\hline $1 \leqslant$ & $r, r^{* *}$ & 00,0 & \multirow[t]{2}{*}{$Y$} & \multirow{2}{*}{$\begin{array}{l}A=25 \\
\pm \text { so }\end{array}$} \\
\hline 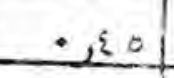 & $1, \leqslant r$ & $1,5$. & & \\
\hline $1 \overbrace{}^{* * *}$ & $r \leqslant$, & 09,5 & \multirow[t]{2}{*}{0} & \multirow{2}{*}{$\begin{array}{l}\text { B }-2,5 \\
\pm \text { se }\end{array}$} \\
\hline $0,1 \varepsilon$ & $1, i$. & 1,10 & & \\
\hline
\end{tabular}

** $(\mathrm{P}<\cdot, 1)$

${ }^{* * *}\left(\mathrm{~J}^{\prime}<\cdot, \cdot 1\right)$ 


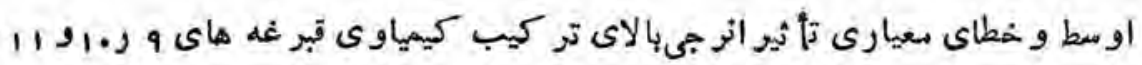

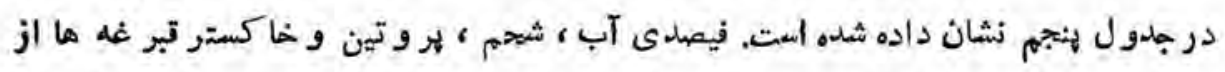

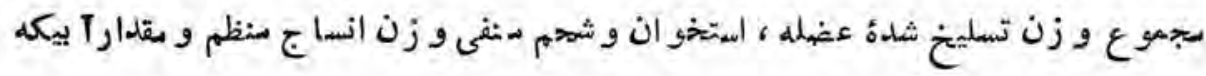

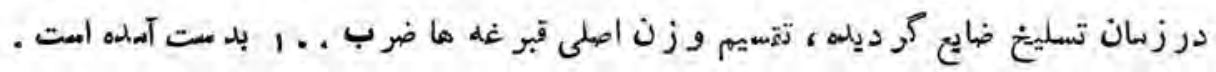

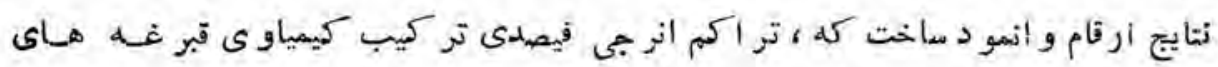

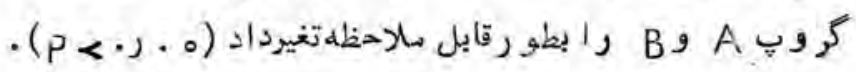

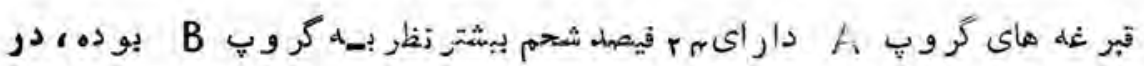

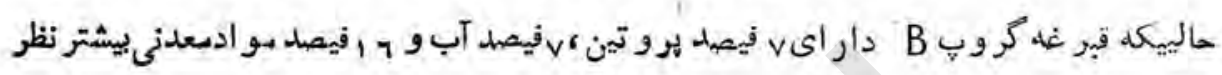

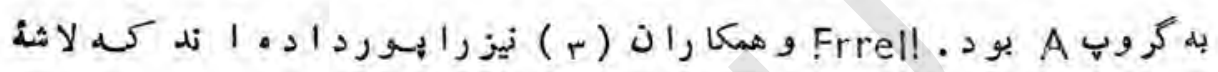

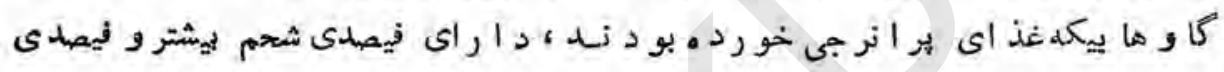

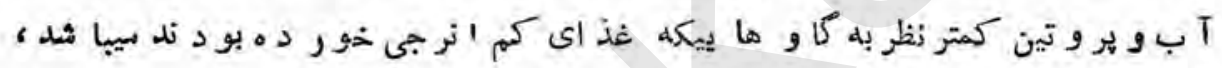

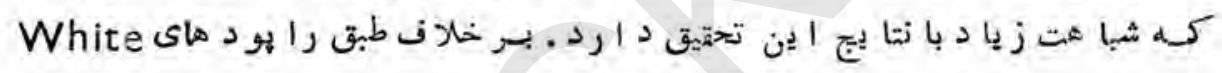

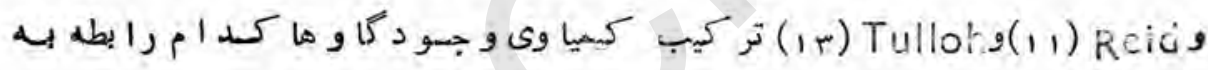

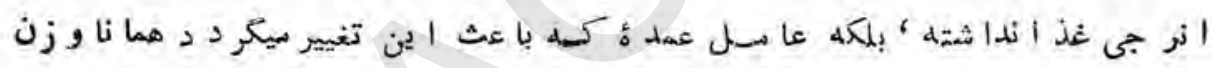

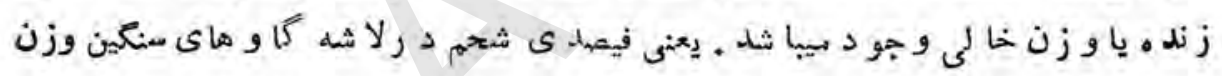

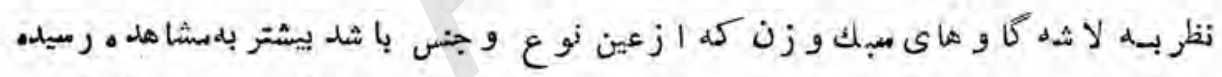

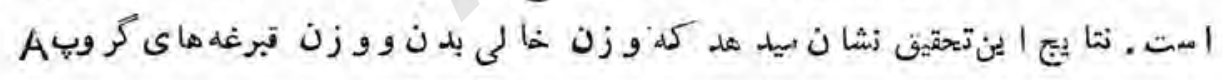

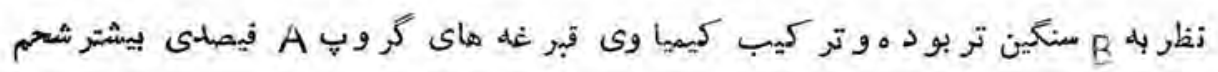

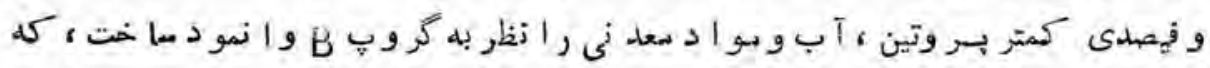

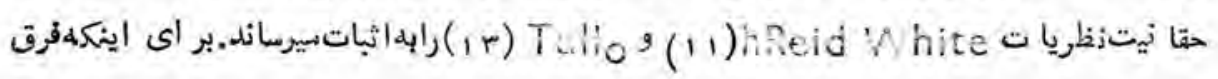

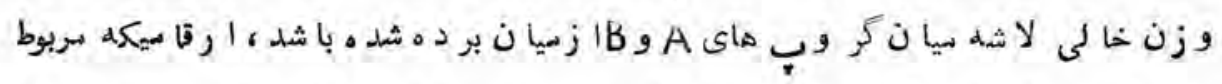

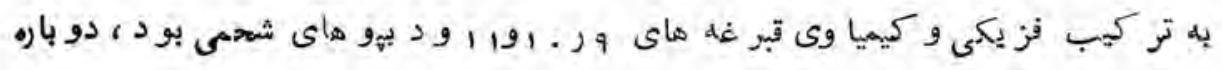




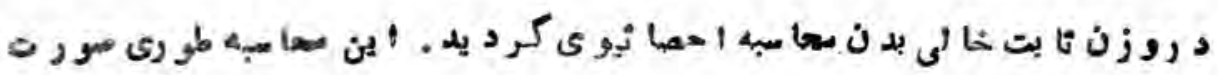

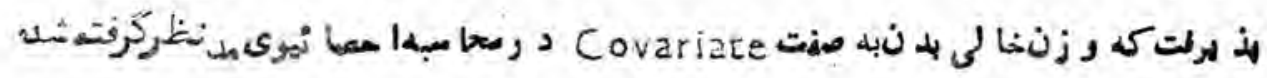

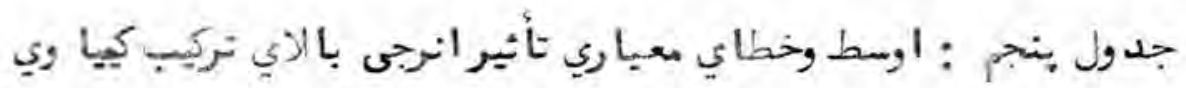

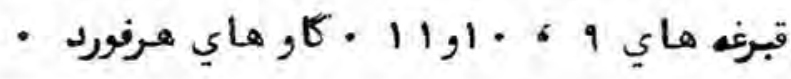

\begin{tabular}{|c|c|c|c|c|c|}
\hline فيصدي & فيصدي & فيصدي & . & تعداد عاوها & كروت ها \\
\hline$\varepsilon, 0$ & $1 \mathrm{r}$, & $r 9,8$ & $\varepsilon q, r^{*}$ & & A $=25$ \\
\hline ד ار & 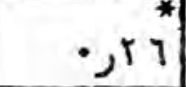 & 1,50 & $1,1 \pi$ & $r$ & $\pm s e$ \\
\hline $0, r^{*}$ & $1 \wedge, r^{*}$ & גرrr & مُ & & B $-2,5$ \\
\hline . & 0 & $1,5 \varepsilon$ & • 97 & & $\pm s e$ \\
\hline
\end{tabular}

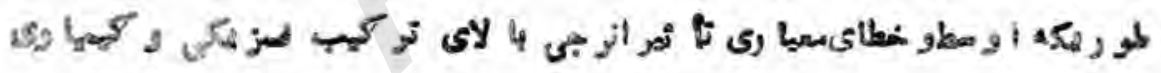

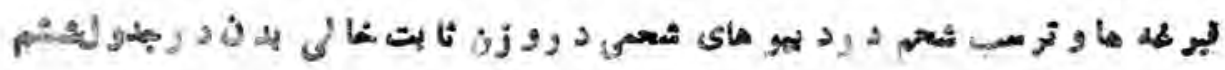

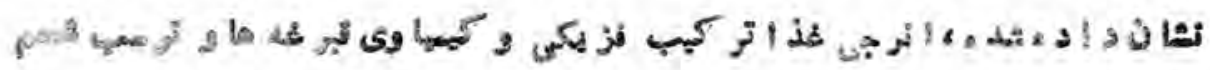

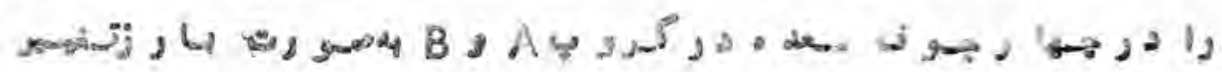

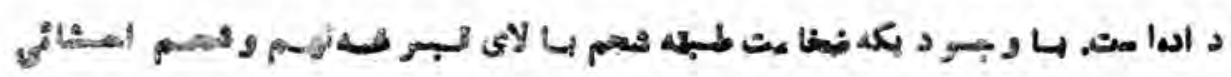

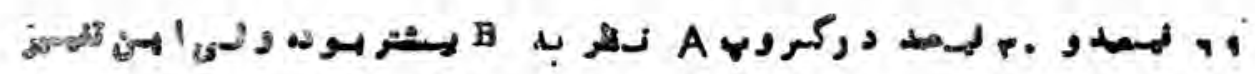

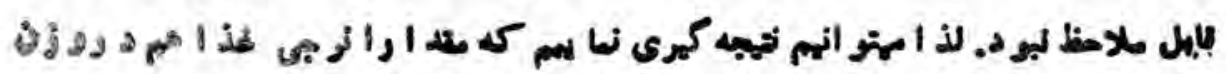
$(r A)$ 


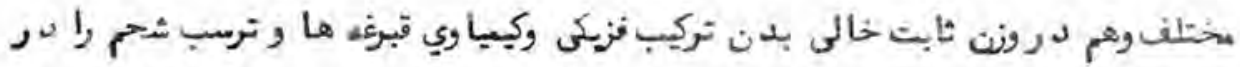

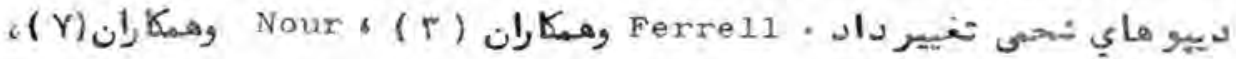

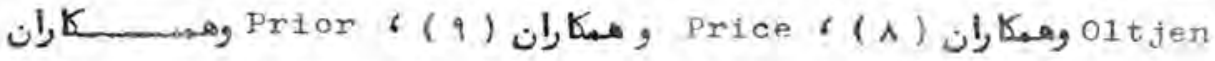

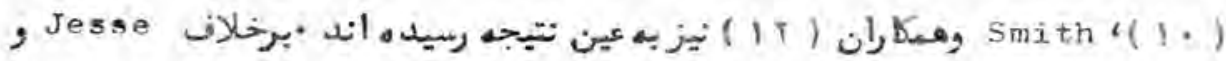

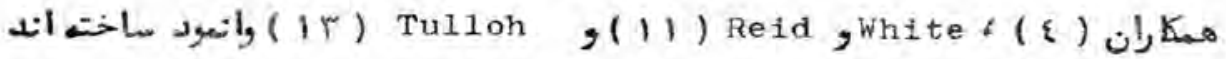

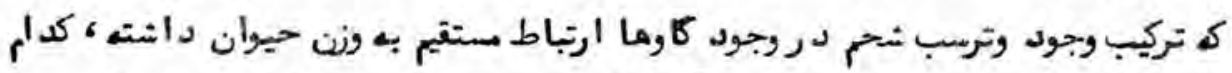

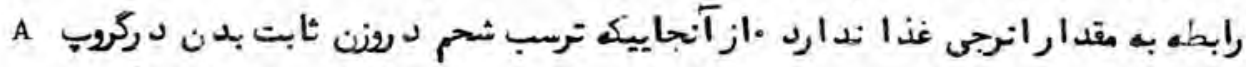

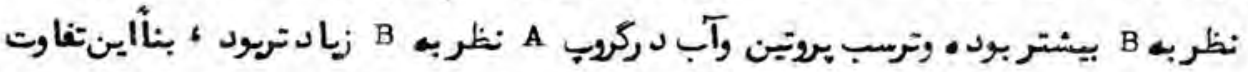

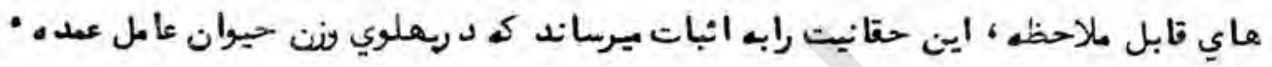

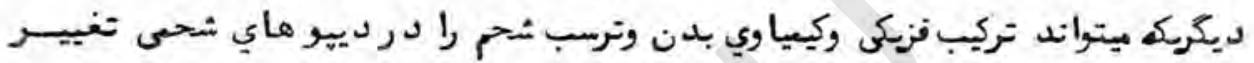

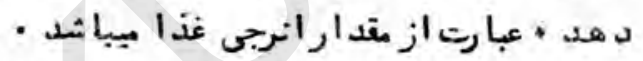

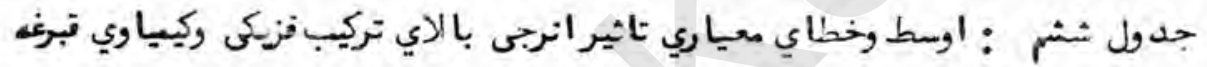

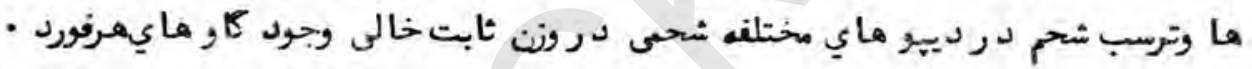

\begin{tabular}{|c|c|c|c|c|c|c|c|c|c|c|}
\hline \multicolumn{3}{|c|}{ ليمبواي شحمى (كيلر } & \multicolumn{3}{|c|}{ تركيبكيمياوي(فيصدي) } & \multicolumn{3}{|c|}{ تركيب فزيكى (يكلوكرام) } & \multirow[b]{2}{*}{ هاد رهركمرتح } & \multirow[b]{2}{*}{ لموب ها } \\
\hline & t & إوم:تأ & | ششحم & يروتين & ب & & ستخونه & مضلد & & \\
\hline 7 & ז'ره & $v_{0} \cdot$ & $r \cdot j^{*} \mid$ & ג, 17 & $\{\wedge, 0$ & $\varepsilon i^{*}$ & 1,9 & 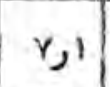 & $\gamma$ & $A=2$ \\
\hline & $0 \leqslant \leqslant$ & $+\infty 1$ & $3, \leqslant 0$ & 9 & 1,17 & ; &., 0 &., 10 & & \\
\hline ) & ز & 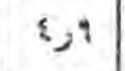 & $r t, \gamma$ & 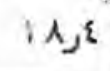 & | & $r, N$ & ונד & $y_{0} 0$ & & B \\
\hline &., 00 & $\cdot, \pi r$ & $\mid 1,1,1$ &.,$\pi y$ & $1,\{9$ & $\mathrm{sud}$ & $Y$ & . & & \\
\hline
\end{tabular}

$$
\text { * }(\mathrm{p}<\cdot, 0)
$$




\section{REARRENCES:}

1- AO C. Official Mctiods of Anatysis, (14.is Edicicn). Ssoci tion of Official salycical Che nisc. Wishington LC. (1970).

2- Atkinson, T-Fowler, V.K, Garton, G. A. and Laugh, A. Arapid mathod for live caresse detarmation of lipid in animal tissue. Analyst London, 97: 5:2 (1062).

3- Ferrel, C. L., Kohimier, R. H., Crouse, J. D. and Glimp, H. Inelowence of dictary energy, protein and biological type of steers upon rate of gain and carcess characteristics. J. Anim Sci . 46, 255. (1978).

4- Jesse, W. G., Thompson, G. B., Clarke, J. L., Hedrick, H. B., and Weiner, K. G., Effect of ration energy and slaughtior ewght on composition of empty body and carcuss gain of beef cattle. J. Anim. Sci. 43, 418 (1975).

5- McDonald, P.. Edwards, R. A., and Greenhalgh, J.F D., Animal Nutrition. 3rd ed., Longman, London. PP 432-435. (198i).

6- Nie, H. E., Hull, C. H., Jenkins, J. G., Stienbrenner, K., and Bent, D. H., SPSS. Statistical Facage for the Social Sciences 2nd ed. McGrawhiil. New York. (1975). 
7- Nour, A. Y. M., Thonney, M. L., Stouffer, J. R., and White, W. R. C. Jr. Muscle, fat and bone in serialeey slaughtered large dairy or small beef cattle fed corncrcorn silage diets in oneof the two location. J. Anim. Sci. 52:512. (1981)

8- Oltgen, R. R, Rumsey, T. S., and Putnaw, P. R. All forage diet for finishing beef cattle. J. Anim. Sci. 32: 327. (1971).

9- Price, M. A., Butson, S. and Makarchian, M. The influence of feed energy level on growth and carcass traizs in bulls of two breed types, Can* J. Anim. Sci. 64: 3.3 (198 ).

10- Prior, R. L., Crouse, J. D., Harrison, V. L., and Eaile, C. A. Elfazepam and Syriovex -5 influence on growth and carcass characteristics of steercs fed two dietary energy levels. J. Anim. Sci. 47:1225. (1973).

II_ Reid, J.T. and white, O. D. The phenomenon of compenstargy growth. Cornell Nutrition Conference. p 16. (1977);

12- Smith, S. B., Prior. R. L., Ferrell, C. L. and Mersmann, H. J, Interrelationship among diet, age, Fat deposition and lipid metabolism in growing steers. J. Nutrition 114: 153, (1984),

13- Tulloh, N. M. The carcass composition of sheep, cattle and pigs as a function of body weight, 1 n symposium on carcass composition and appraisal of meat animals, ed. Tribe, D. E. PP 5-30, (1964), 


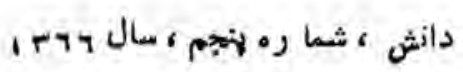

اوه هis

لو هيا لى م م موج

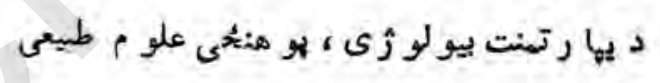

امكانات برورشوكسترش بادام زمينى

(A رافغانستان (Aarachis hypogae L.)

مقده هـ :

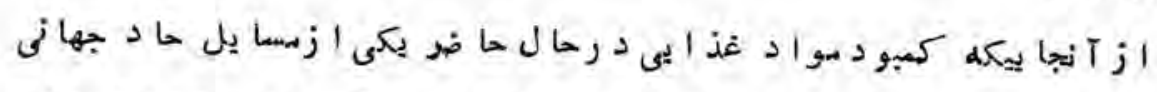

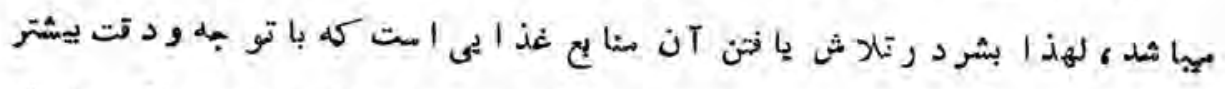

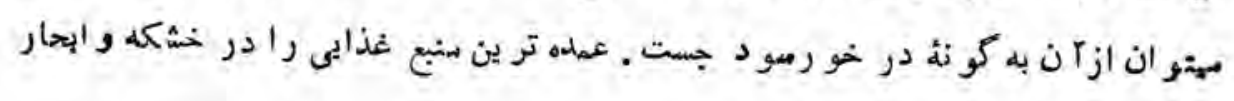

$(n+)_{i}$ 


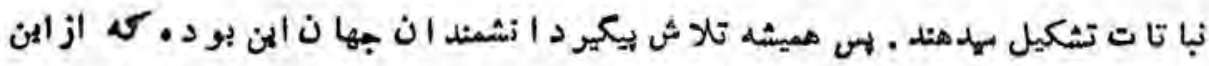
هنا بع سرشار تا سد ا سكان أ استفا ده به عمل آ يله. ازجمله نبا تات بهم ا قتصا دى و فا بـل توجه يكى هم باد ا م زمينى سيبا شد كسم

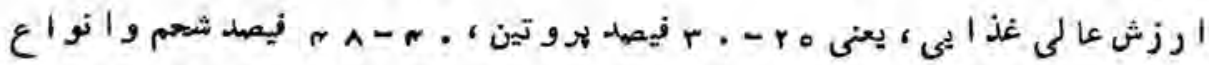

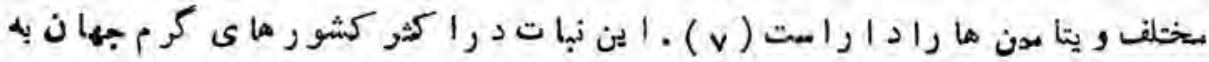
يميا نه وسيع زرع شد. و به انو الع كو نا كو ن ا غذ يه به كا ركوفته ميشو د ( ) .

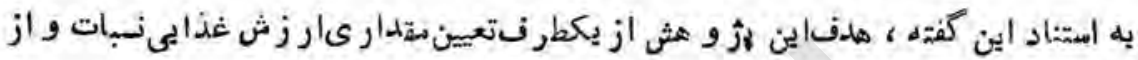

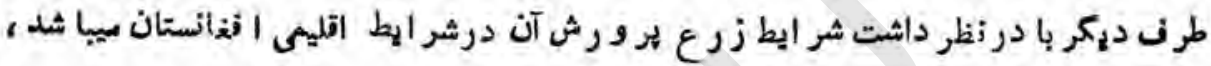

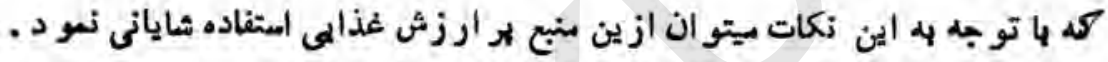

\section{: बis.}

بادام زمينى كه به و اسطه كارل لينه (Carolus Linnaeus) به نام اركيس ها -

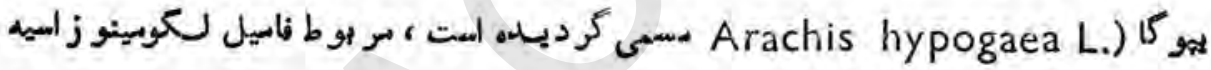
(Fabsaceae) Leguminosaceae

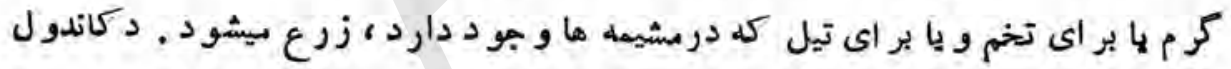

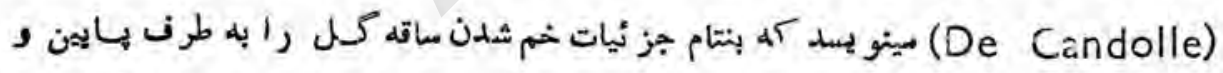

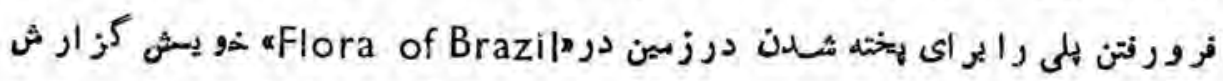

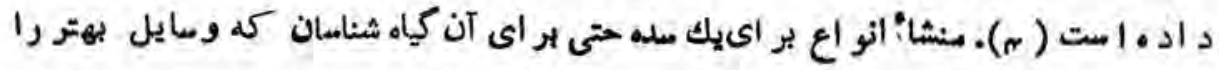
بر اي كشف آن به كار بردند ، مو ردمشاجره قر ارداشت . دكا ندول مينو يسد كه لينه بادام زمينى رادر مو رينام (Surinam) يـاكو يسانا

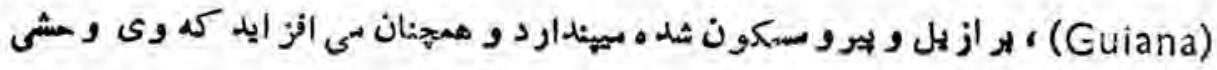


بو دن و يا زرع شدن آثر الشخص نكير ده أمت (م). اين نبات شايد ازحين به مبر زمين هند،

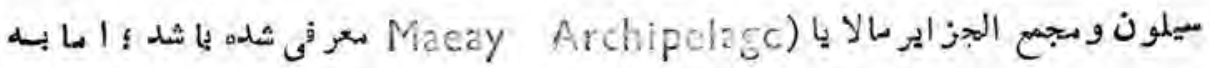

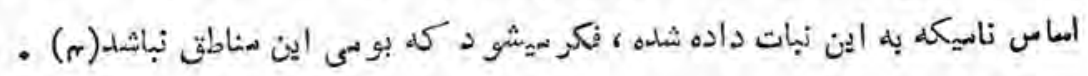

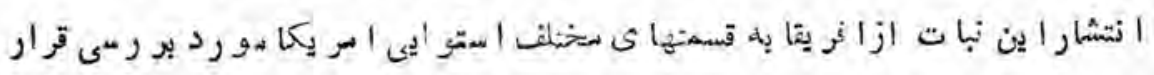

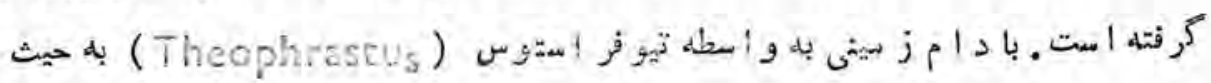

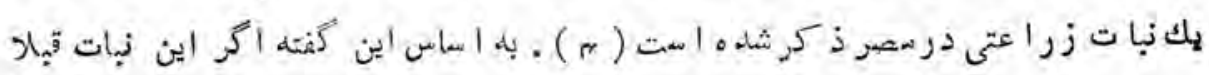

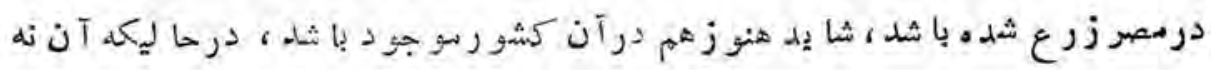

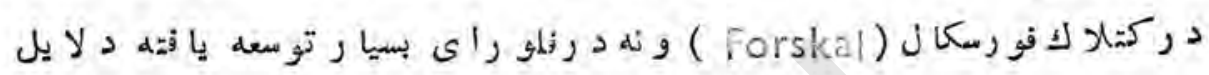
(Delile) Arachis hypogaea L.

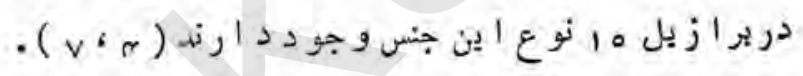

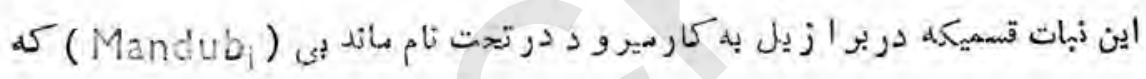

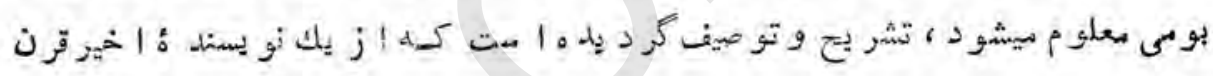

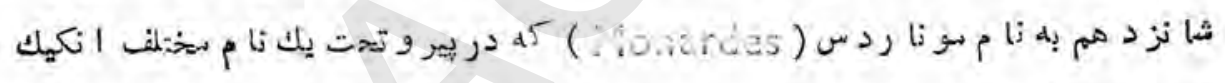

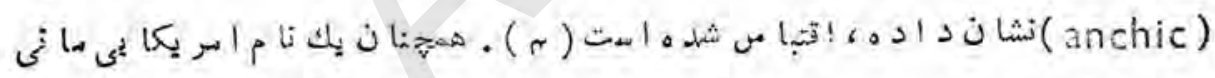

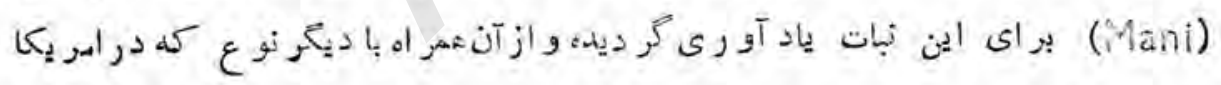

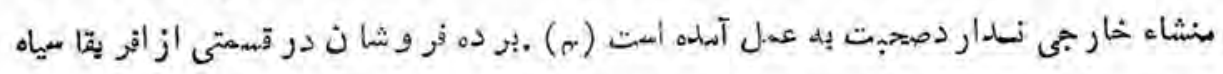

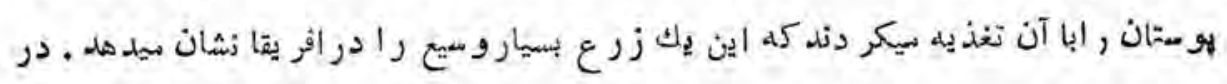

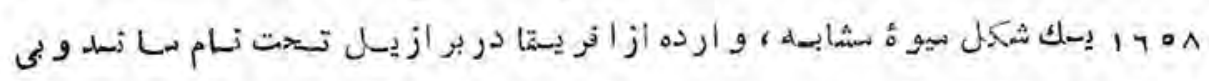
(Arachis ) (Mandobi )

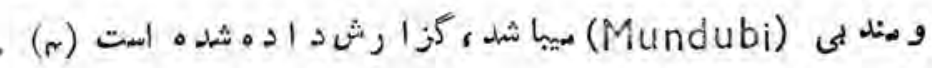




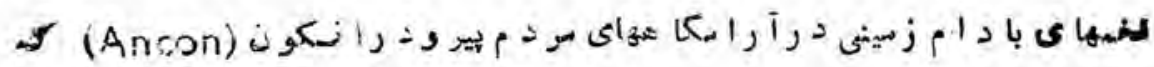

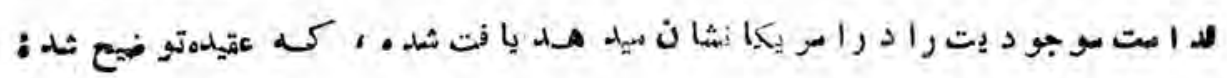

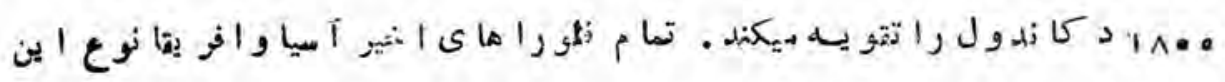

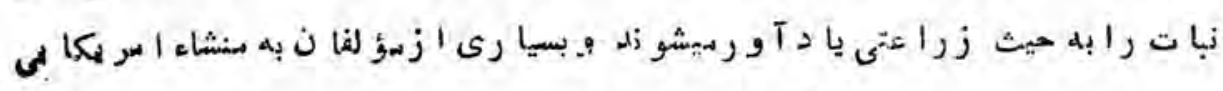

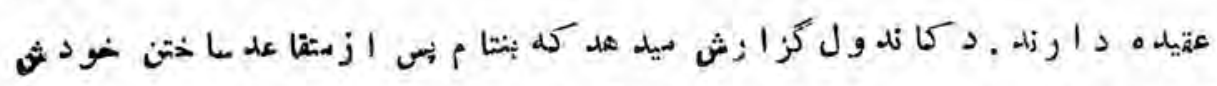

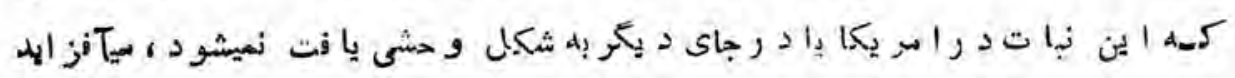

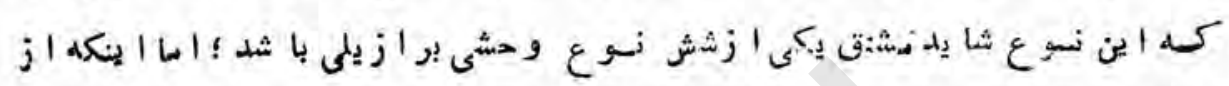

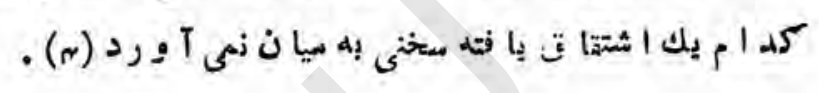

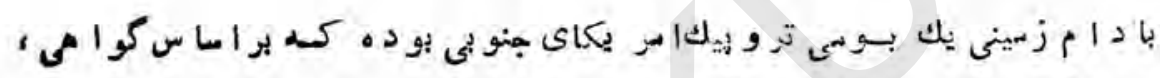

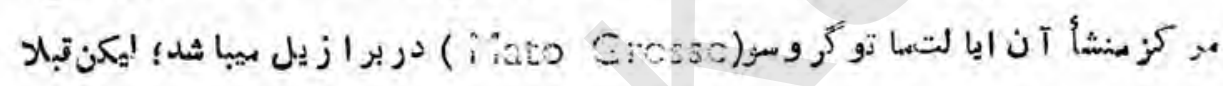

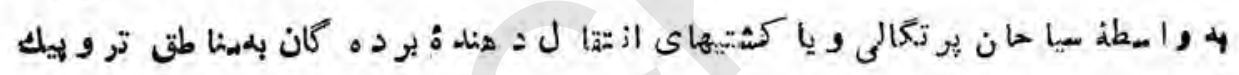

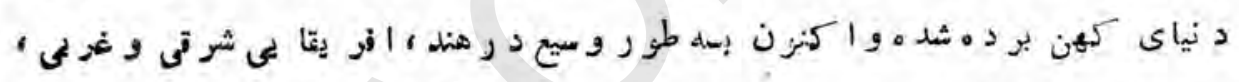

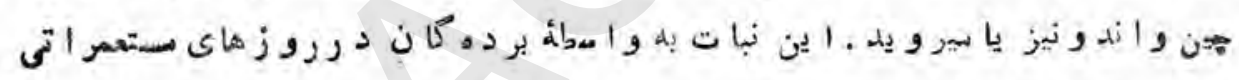

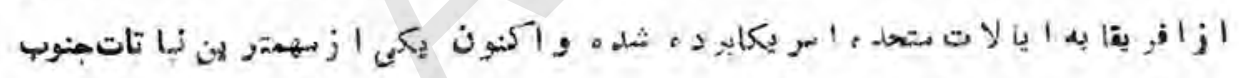

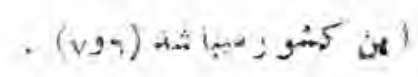

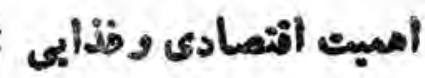

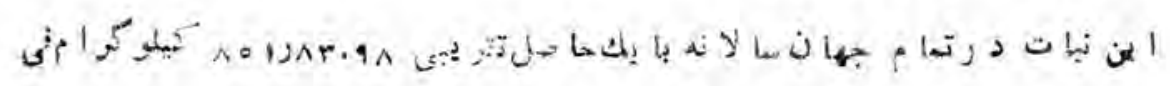

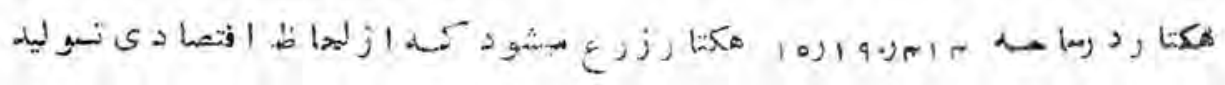

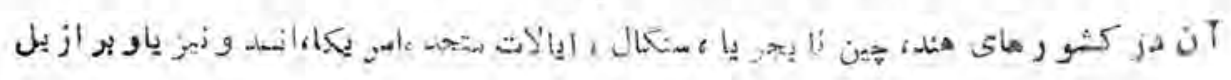

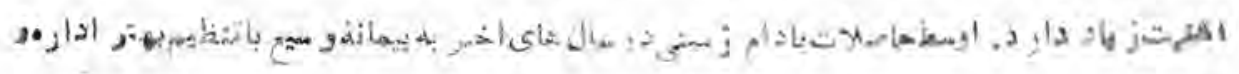




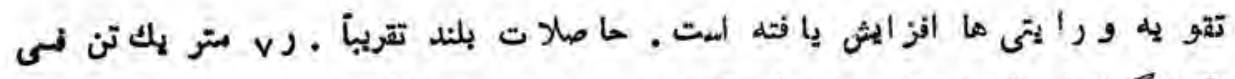

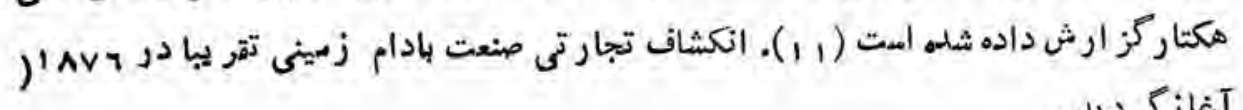
آغازكرديد

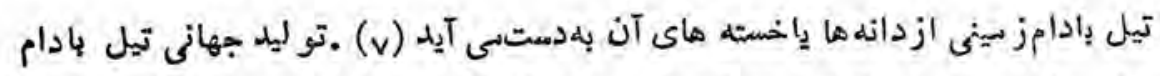

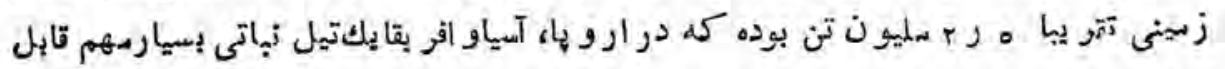

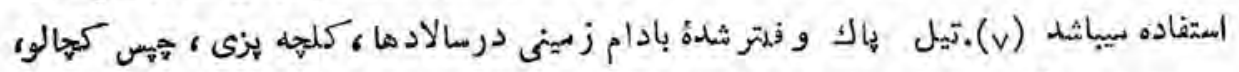

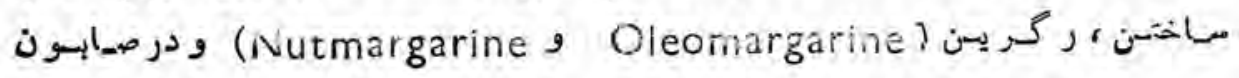

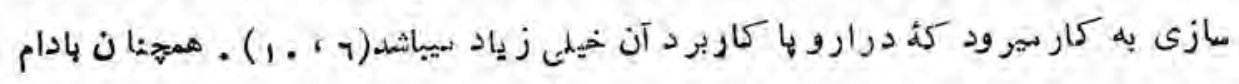

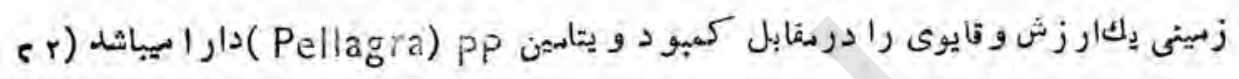

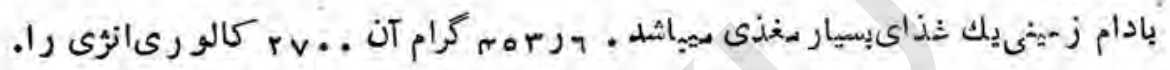

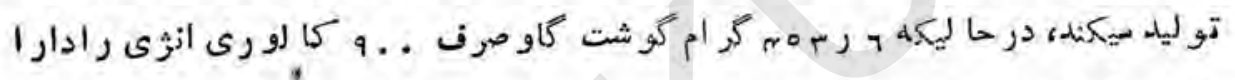

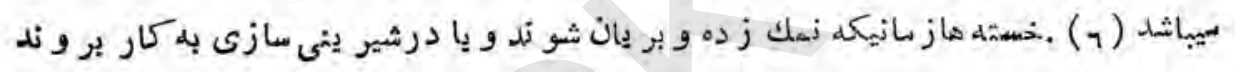

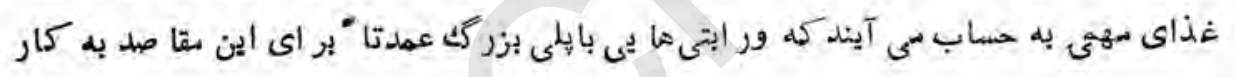

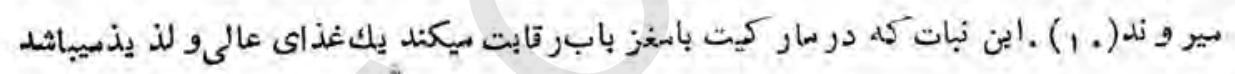

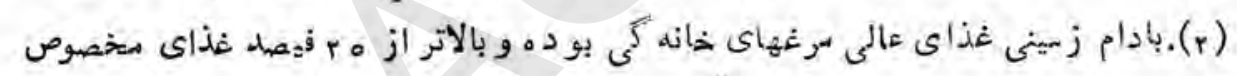

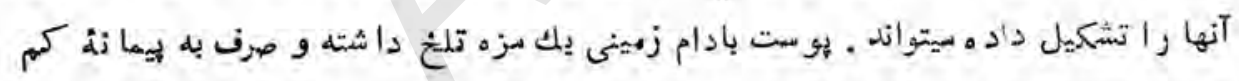

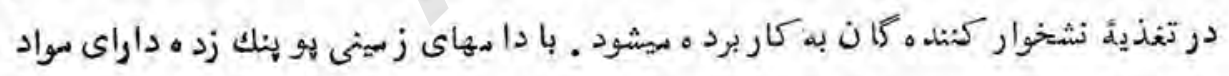

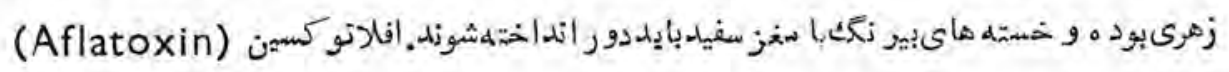

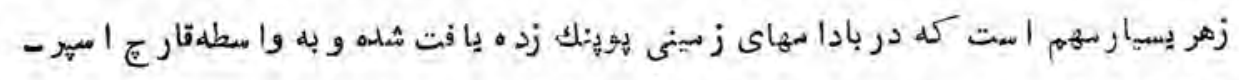

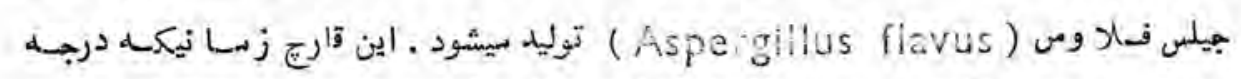

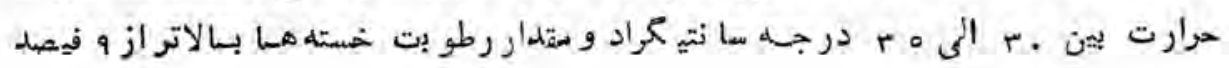

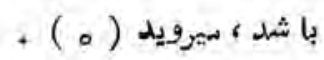




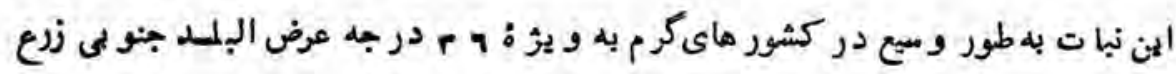
هيشود ( ب، ـ 1 ) . شر ايط بسيار رينا مب اقليهى بسراى آن ، اعندال بسارند. كى در ائناى نمو، ازدياد تابش آنتاب و درجة حرارت نسبتاً بلمند بميا شد ـ نبا تات ازشروع شكوفه تا دو ههته قبل از جمع آو رى حا صل ، ضرورت به رطوبت كا في خاك دارند ( v ) . بادام زمينى

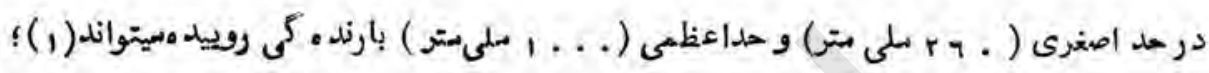

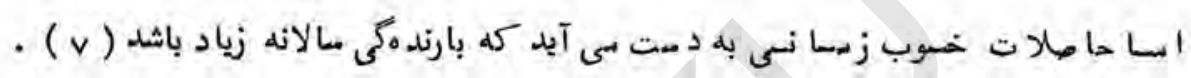

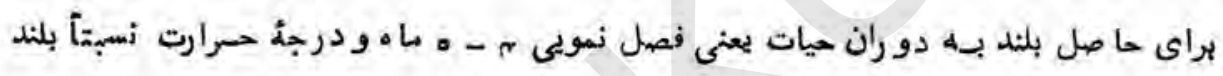

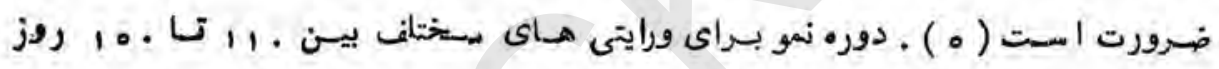
تغيير دارد (v) (v)

حاصلات ز باد بادام ز بينى دار ايى كيفيت عالى بر ایى خاكهاى لو م ريكى زاهكثى

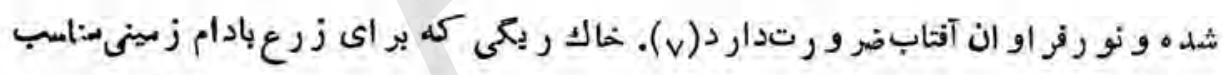

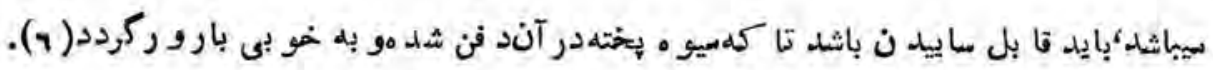

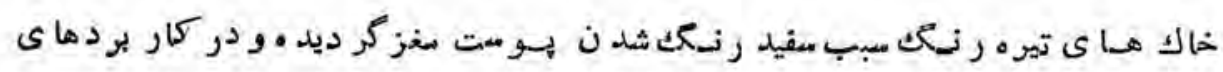
تجارتى از كيفيت آنسيكا هد.به هنظو رعلوفه اين نبات تقر يبا" با لاى هر نوع ماك بد ون

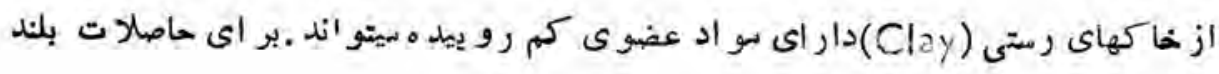

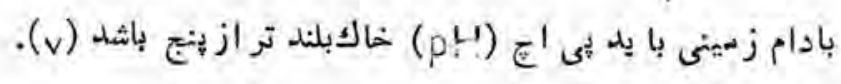


: تشربحسا ت نسباتصى

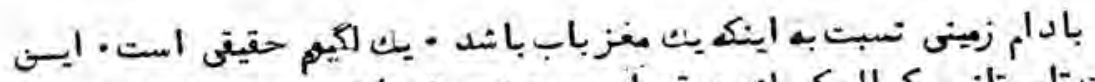

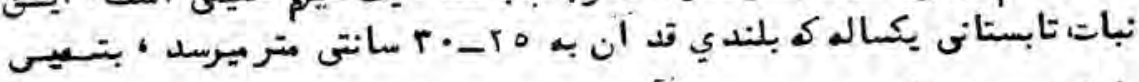

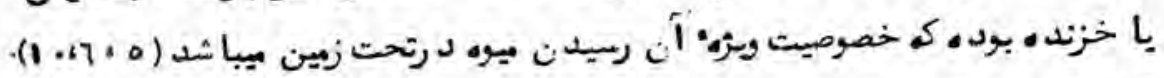

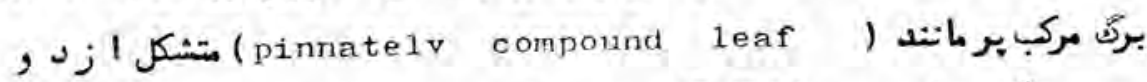

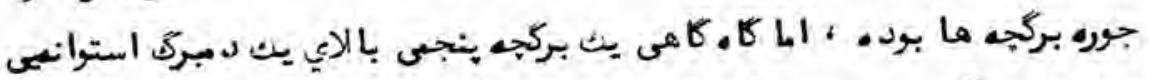

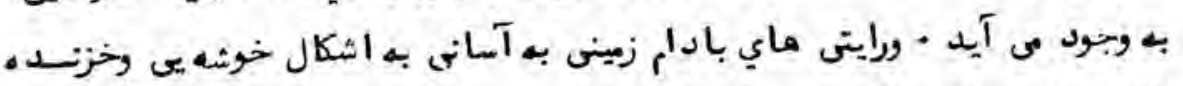
ازهم فرق ميشوند ك بعضى از ورايتى ها بلى بزرك ويرخى ديكريلى كوجلثراتوليد

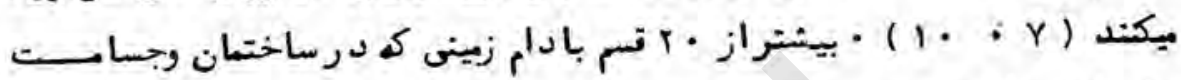
كلى فق دارند • ميرويند

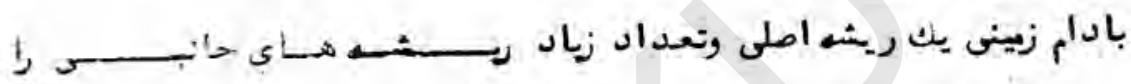

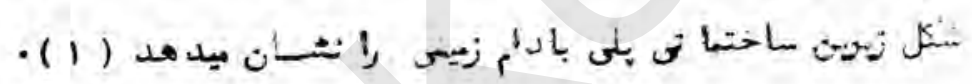

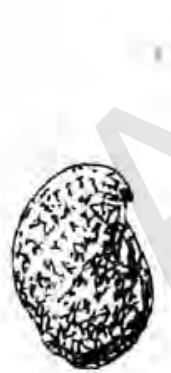

1

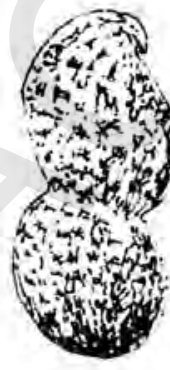

2

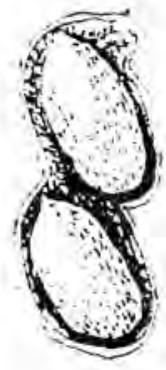

4

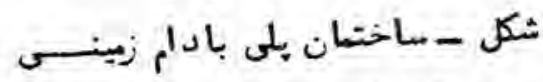

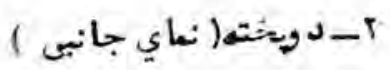

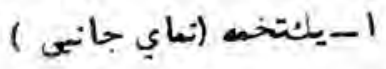

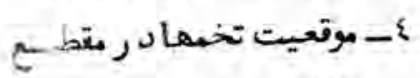

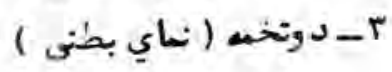

- طولسى

( \&ิ) 


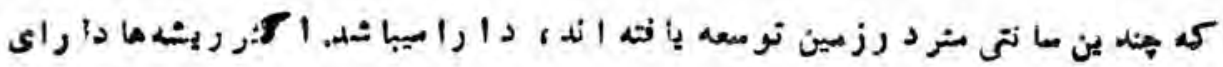

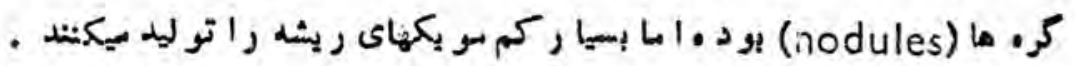

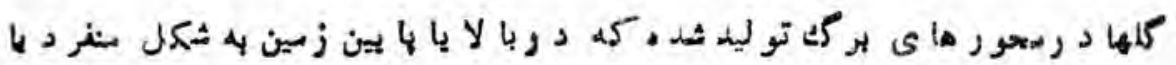

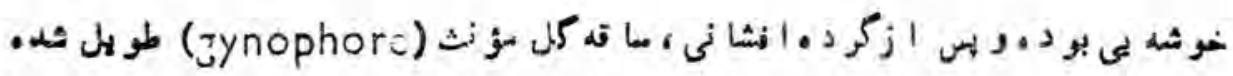

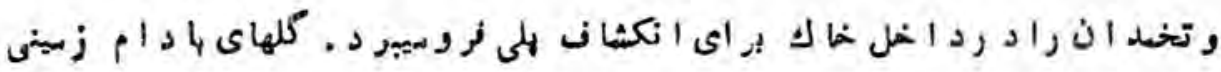

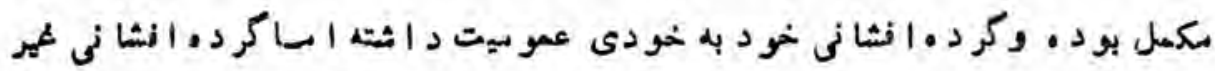

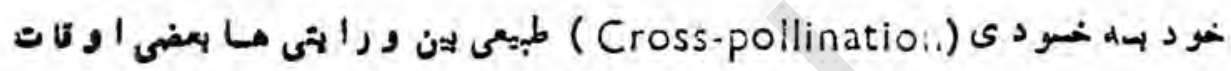

نيز ا نهجا مريذ برد مير

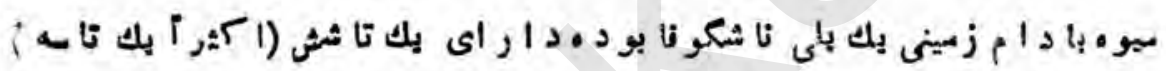

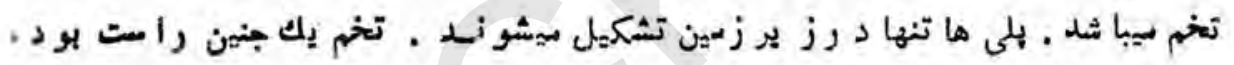

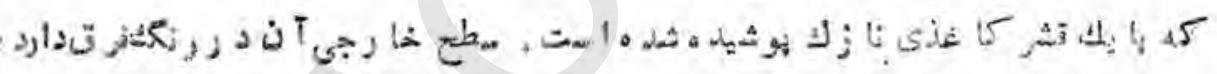

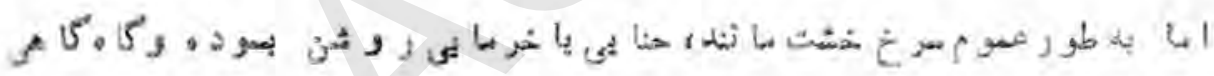

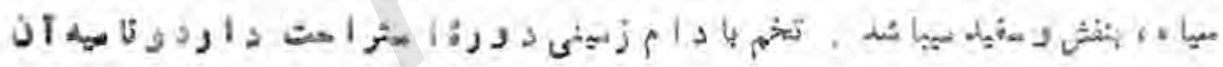

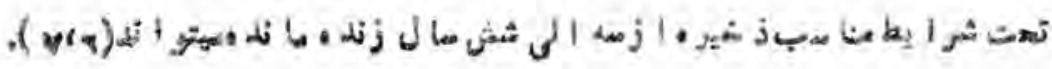

$: \log \sin ^{2}$

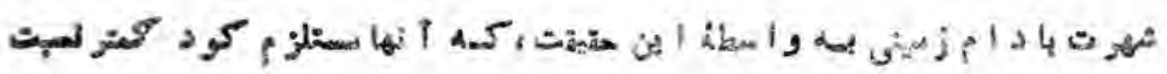

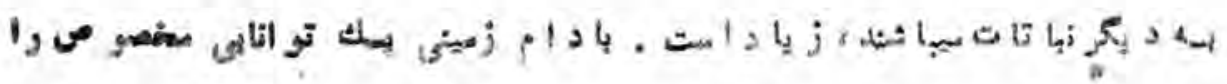

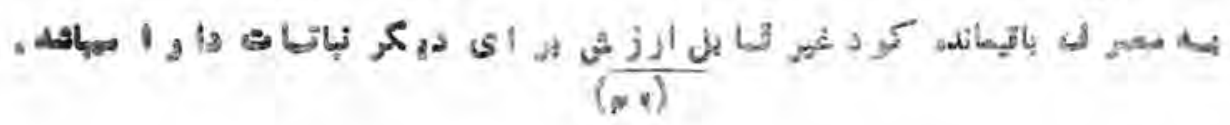




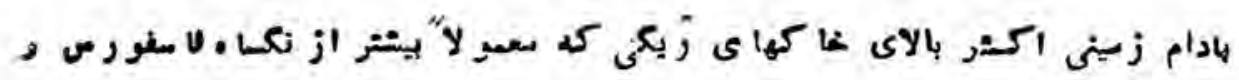

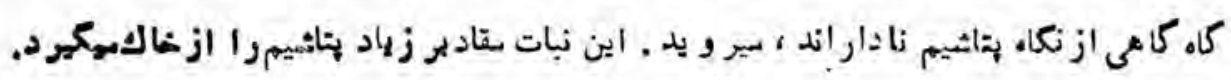

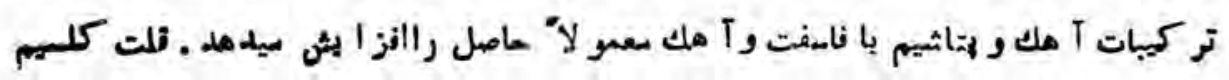

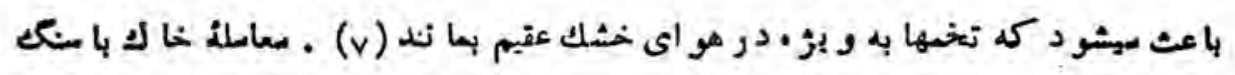

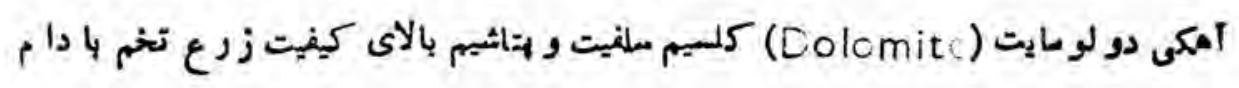

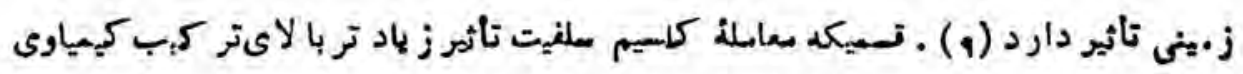

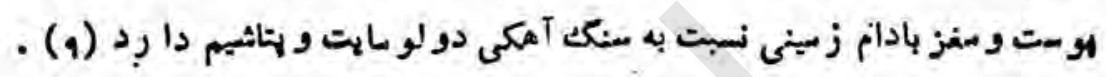

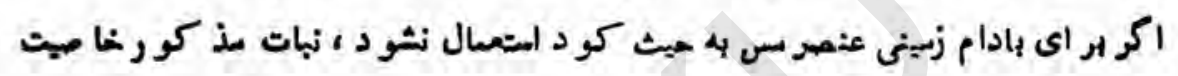

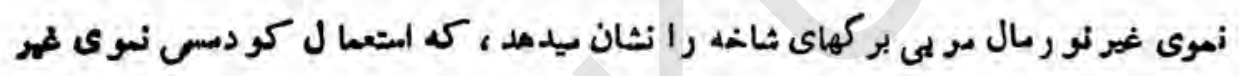

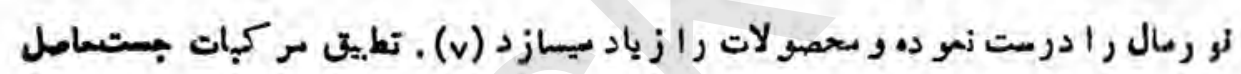

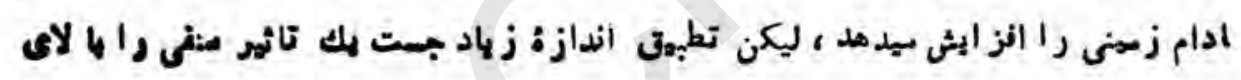

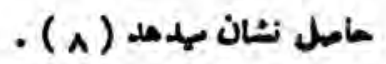

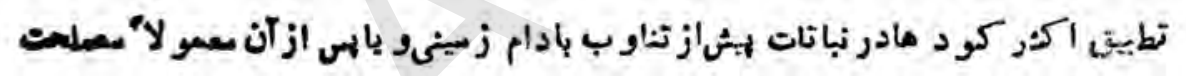

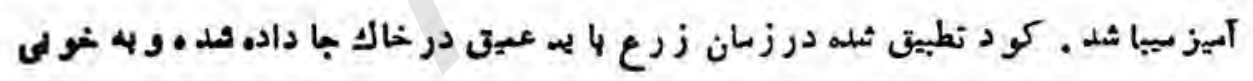

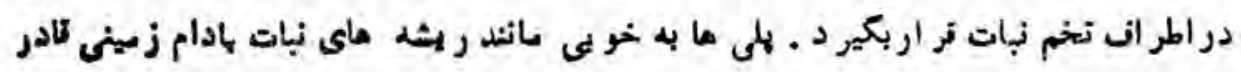

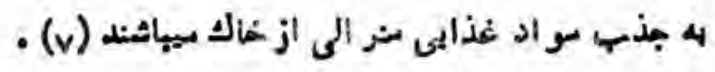

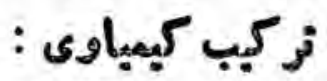

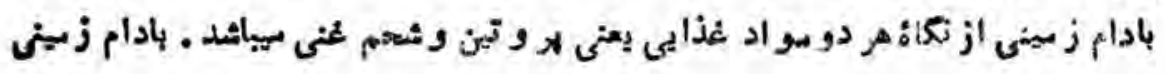

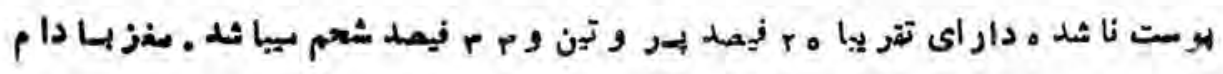

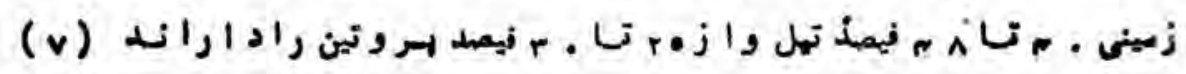

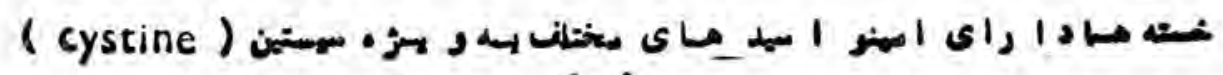
(..) 


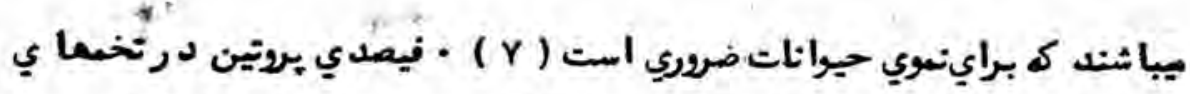

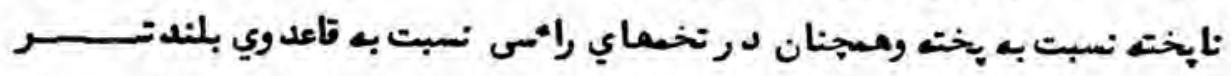
مياشــ (1乏)

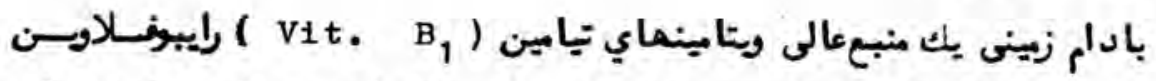

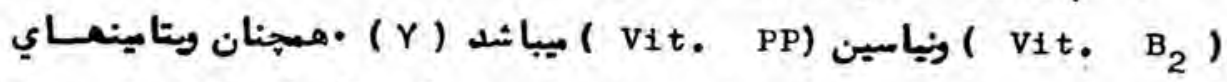

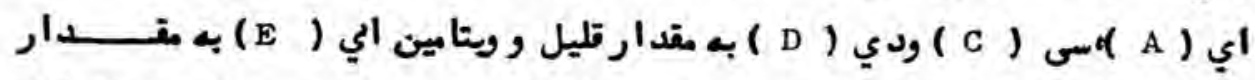

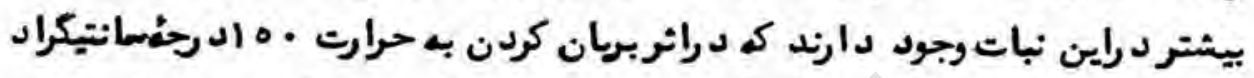

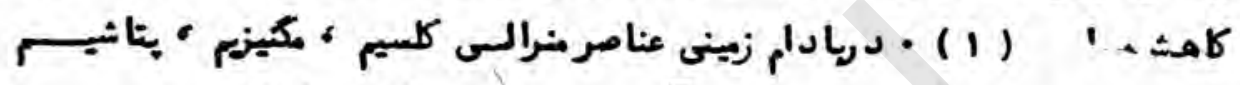

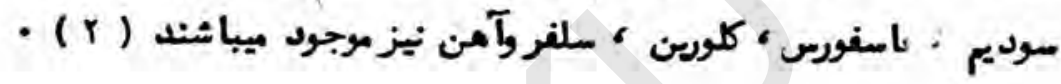

\section{ما دوو עמטمـL}

نمونه بادام زينى كه به نامعاي جلغوزه باكستانى مر يلى ولى نيزثعرث دارد،

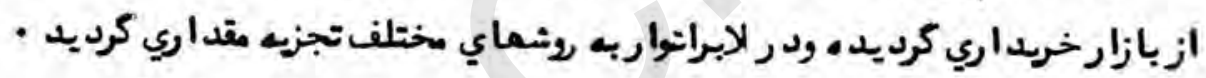

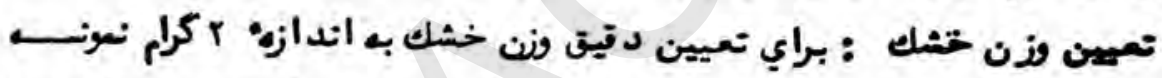

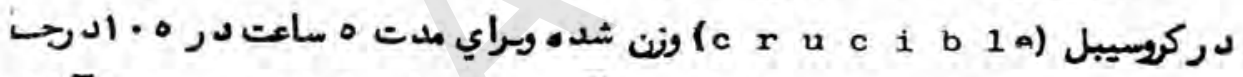

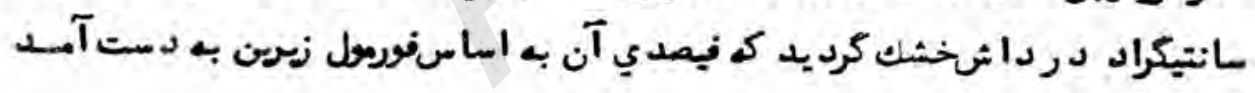
: (Ir6r)

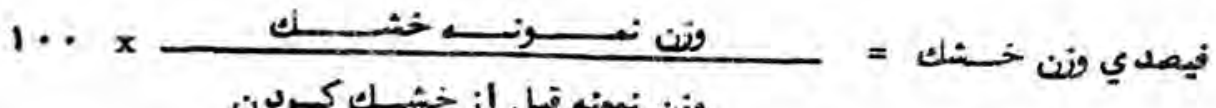

$$
\begin{aligned}
& \text { ونز نمونه قيل ازخشيـلك كـردن }
\end{aligned}
$$

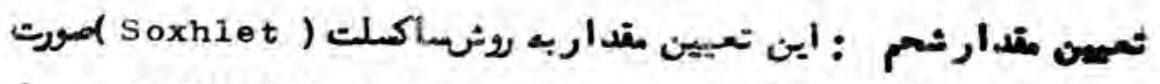

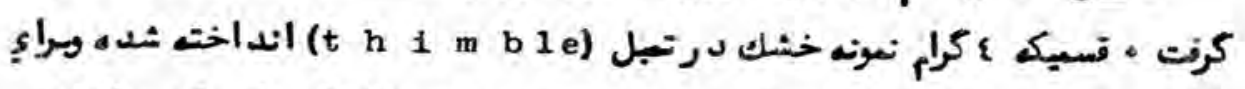

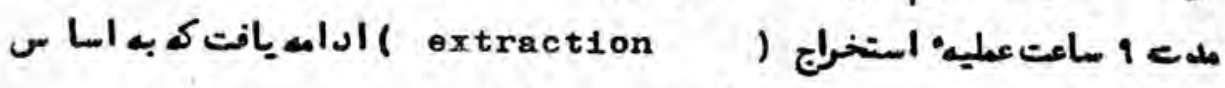

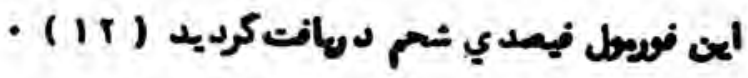




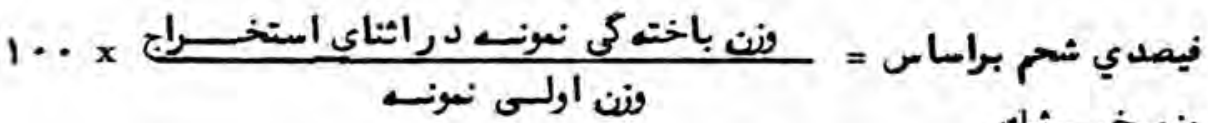

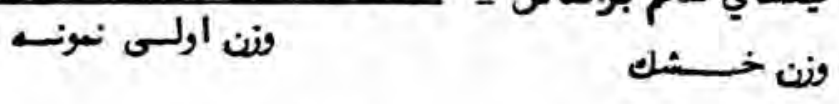

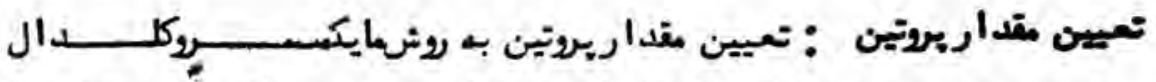

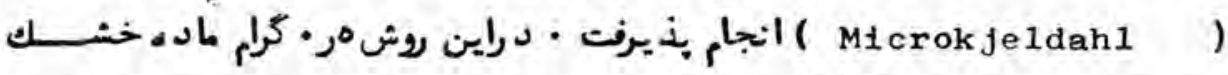

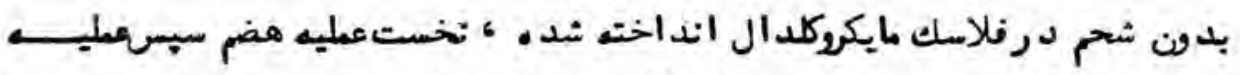

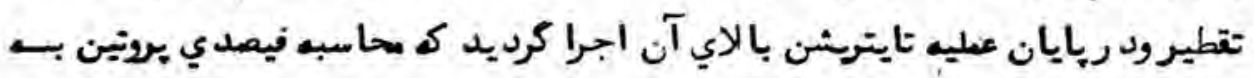

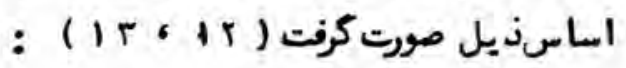
فيصدي نـايتروجـن فيصدي بوتين خام, = فيصدي نايتروجن تميعن مقدارخاكستر : براي تعيين مقدارخاكستر ب كرام نمونه خشك بــدون

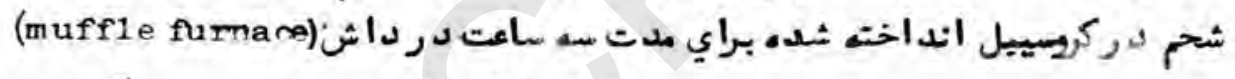

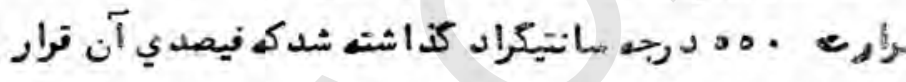

$$
\text { نيل حاصل شد (r) : 1r) }
$$

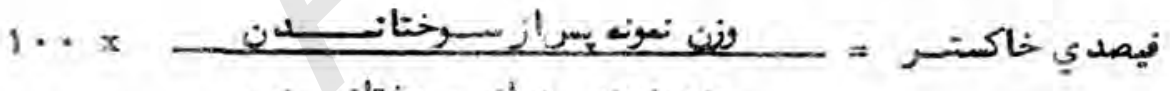

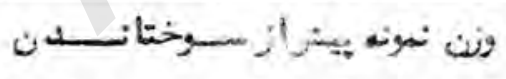

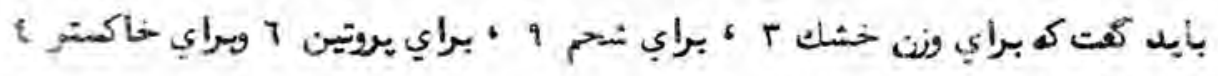

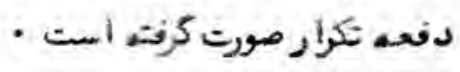

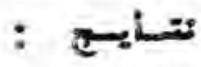

\begin{tabular}{|c|c|c|c|c|c|c|}
\hline اجسراي ديلز & خ خاكتيـر & ris & يروتين & إيت2جن & رطويت & ونت خشك \\
\hline $497 \varepsilon$ & $r, 5$ & $0.3^{\circ}=1$ & $\pi \lambda, 01$ & 2,67 & $\varepsilon, 1 r$ & 90,08 \\
\hline
\end{tabular}

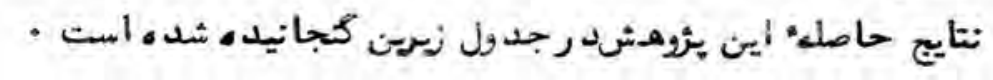


كسميكه در جدو ل به بمثا هلده ميو مدل فيصدى شتحم به درجه اول و ليصلدى لو و تين به درجه دو م در تر كيب بادام زبينى حصه دار ند، كم او لى اززخاه تو لهد انر زيى و دوبس ازنكاة. مادة معاختمانى سلو لها ارز ز غذايى فوق العاده دارد.

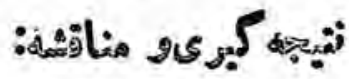

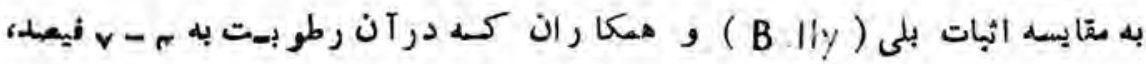

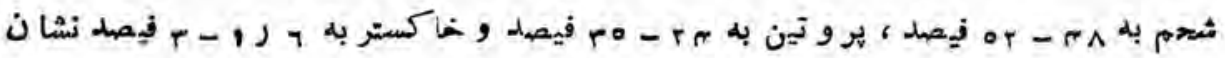

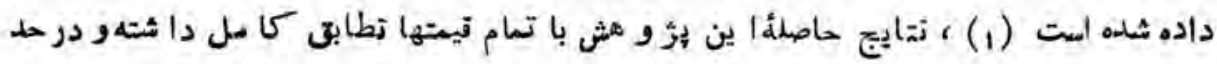
وسط قر اردار نله

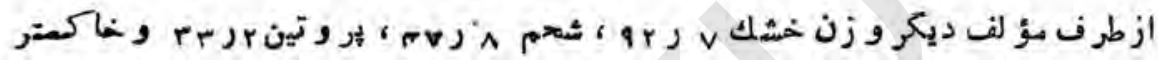

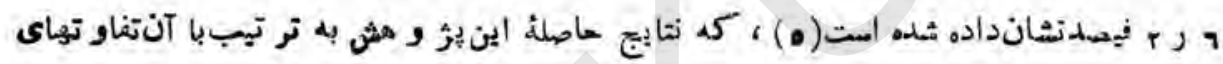

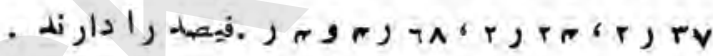

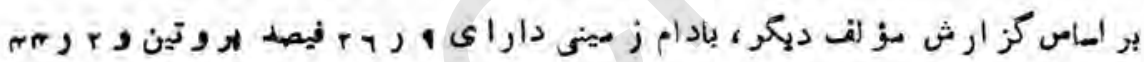

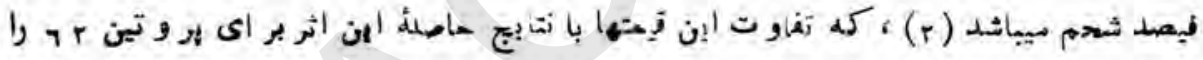

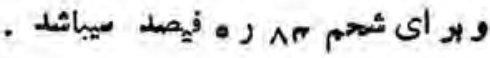

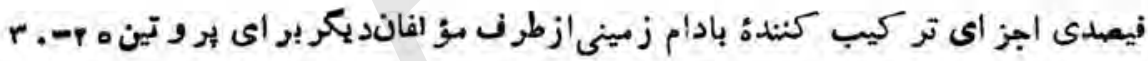

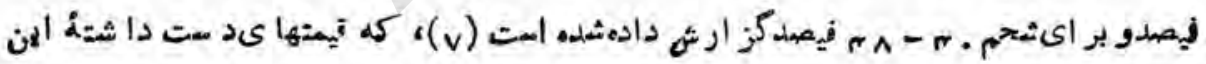

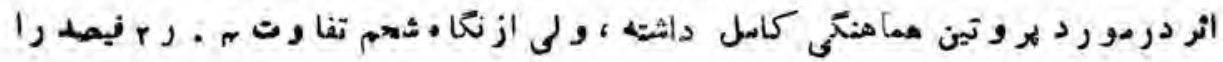

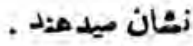

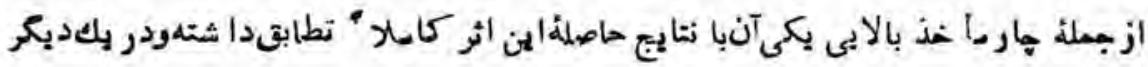

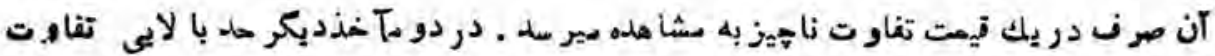

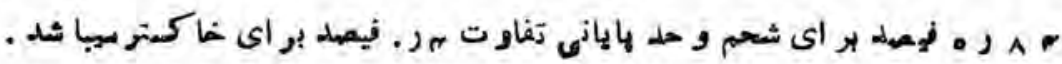




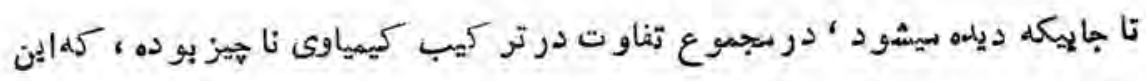

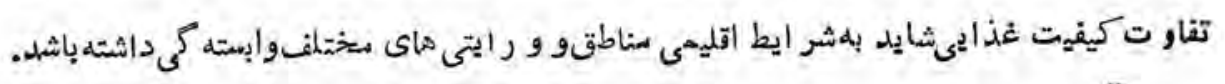
نظر به اين ار زش عالى غذابى بادام زمينى شر ايط زرع آن در بنا طق بختلفه جها ن

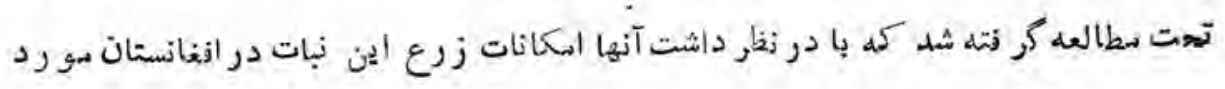

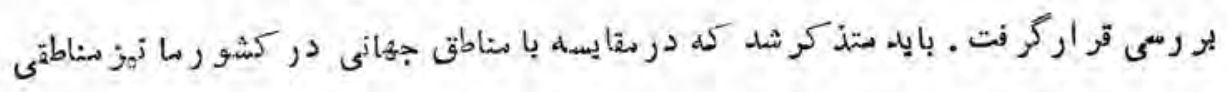

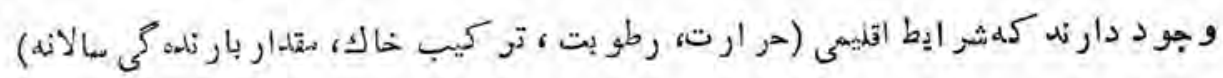

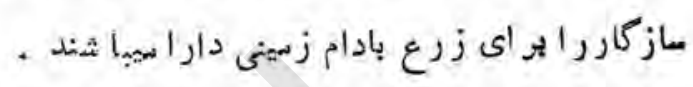

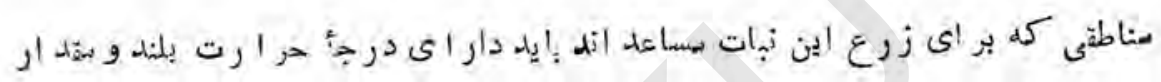

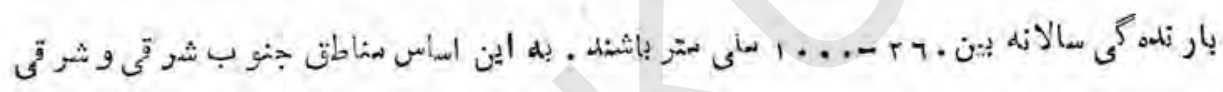

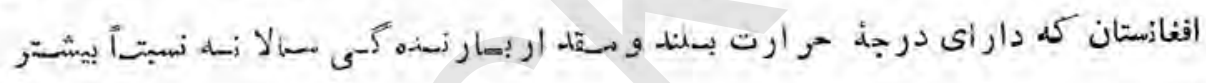
( )

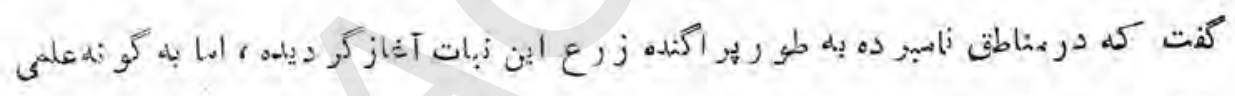
دراين قسمت كار صور رت نه كر فتله الست.

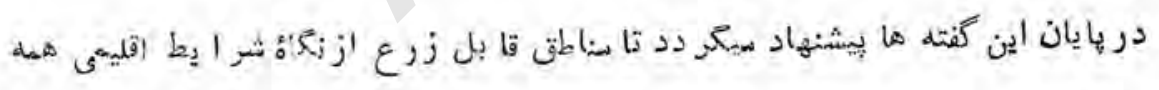

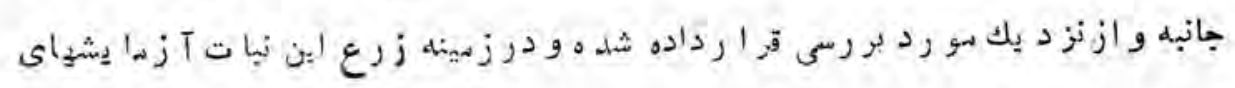

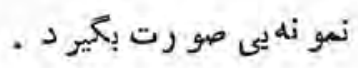




\section{REARRENCES:}

1) Bally, W. und andere. Oelpflanzen. Ferdinand Enke Verlag, Stuttgart, P. 1.8-30,15-196?.

2) Bush, C.D. Nut Grower's Handbook. Re ised Edition. Orange Judd Publishing Company, Inc., New Vork, . 22. 1953.

3) Chapman, HD. and PF. Praft. Method's of Analysis for Soils, Flants and Waters. Division of Agricultural Sciences, University of California, 60.1961 .

4) De Candolle, A. Origin of Cultivated Plants. Hafner Fublishing Company, New York, Pp.411-4.4. 964.

5) Goehl, B. Tropical Feeds: Feeds Information summaries and Nutritive Values. Food and Agriculture Organization of the United Nations, Rome, P. 139, 35, 35 . 1981.

6) Hill, F.A. Economic Botan . Second tdition. McGraw-Hill Book Compan, Inc., New York, P. 201,34, 34, 42,677, 686. 952

7) Martin, J.H. and W.H. Leonard. P.inciples o Field Crop Production. Second Edition. The Macmilla- Compan\%, New York, PP. $689-70$ ? 1967.

8) Quintana, R.U. and Other. Elfect of $\mathrm{Zn}$ fertilizers on nut yield and plant compos tion of peanuts (Arachis h pogaea L.) Agronom ${ }^{y}$ Abstraçt. J. Am. Soc. Agron., P. 225.970. 
9) Sullivan, G. ${ }^{\star}$., G.L. Jones, and R.P. Moore. Effects of Dolomitic Limestone, Calcium Sulfate and Potassium on Planting seed Quality of Peanuts (Arachis hypogaea L.) Agronomy Abstract J. Am. Soc. Agron., P. 55, 973.

10) Uphof, J.C. Th. Dictionary of Economic Ilants; Second Edition J. Cramer, New York, P.44. 1968.

II) Walsh, L.M. and J.D. Beaton, Soil Testing and Plant Analysis Revised Edition. S,S.S. of A, 17c. Wisconsin, PP.3־2-323. 1973

12) Wolfenden, JP.A. Laboratory Guide. Hedge \& Bell Pty Ltd. Melbourne, PP. $118-123,1982$.

13) Woodman, A.G. Food Analysis, Fourth Edition. McGraw-Hill Book Company, Inc. New York, PP. 37_43. 1341.

14) Young. C.T. and Y.P. Tai. Variations in percent protein of Individul seeds from five peanuts. J. Am. Soc. Agron. Vol. $66(3) ; 439.1974$.

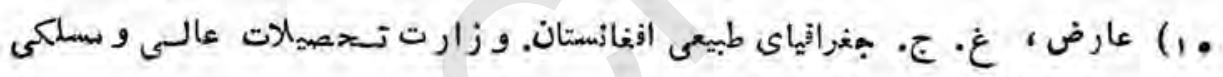

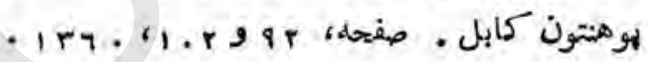

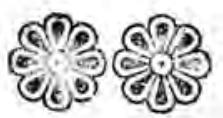




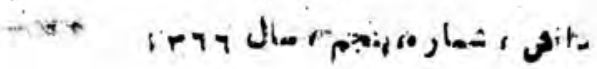

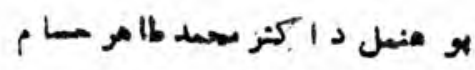

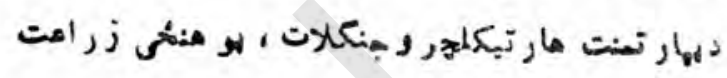

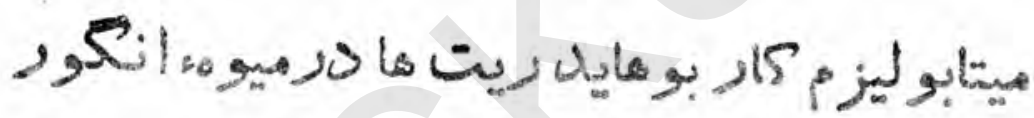

india

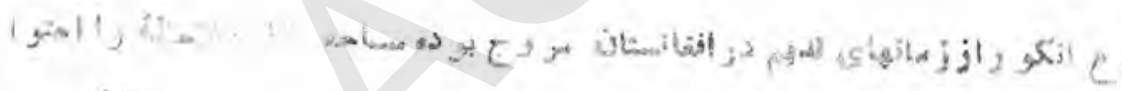

...

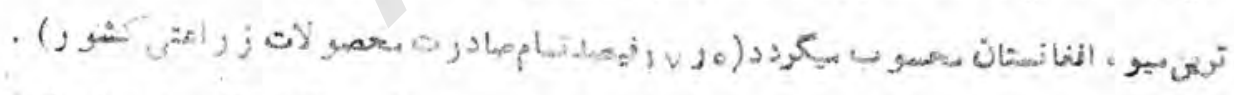

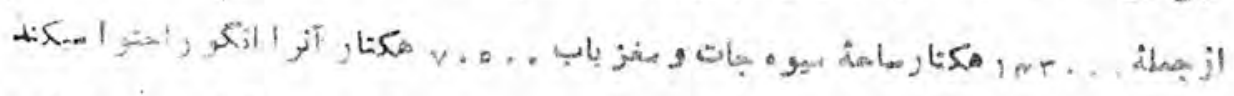

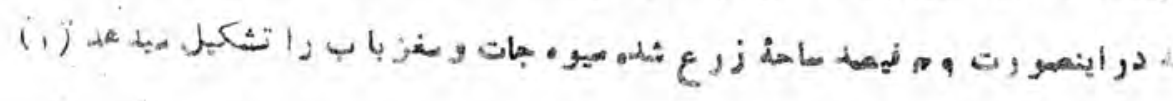

(०v) 


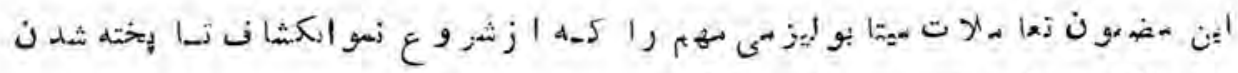

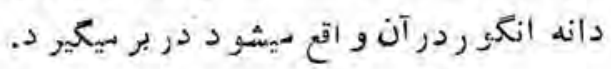

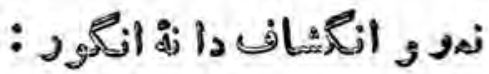

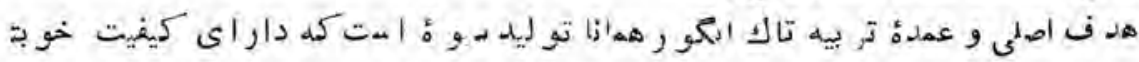

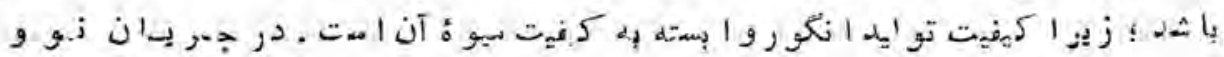

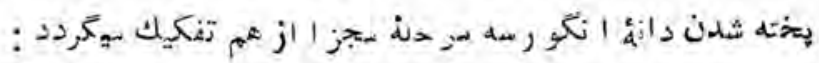

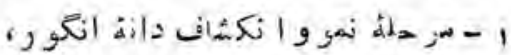

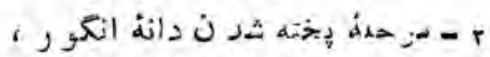

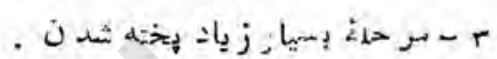

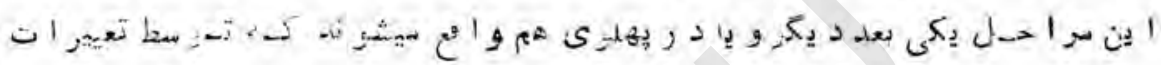

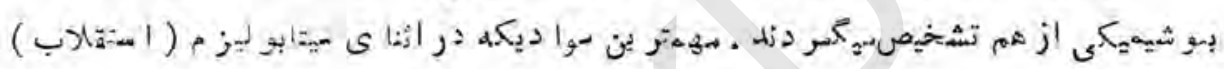

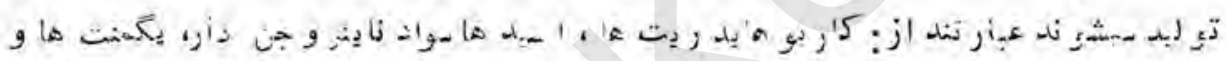

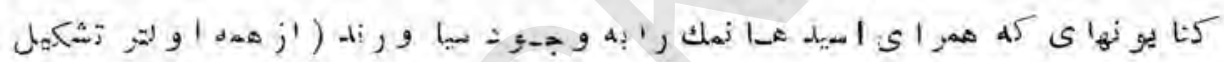

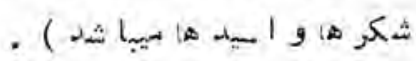

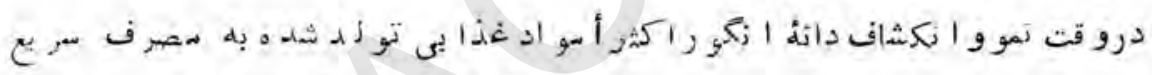

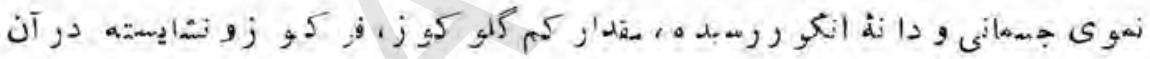

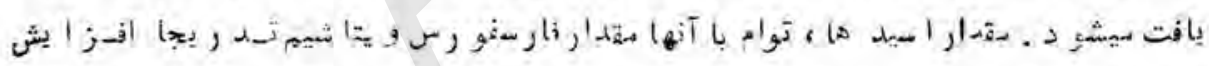

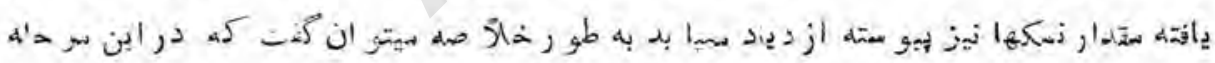

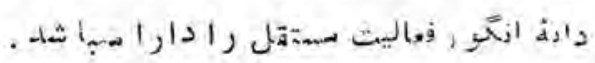

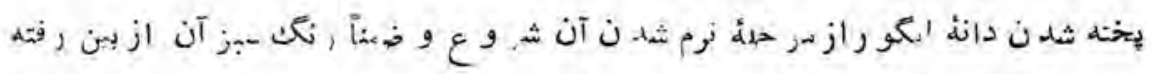

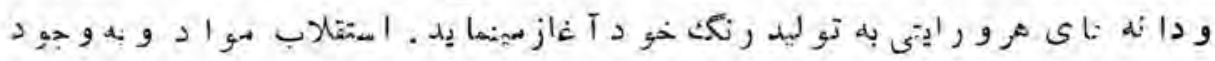

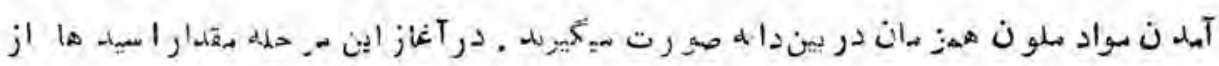

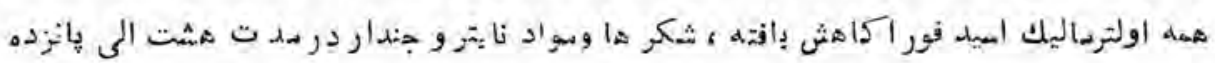

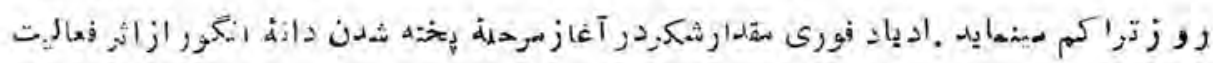




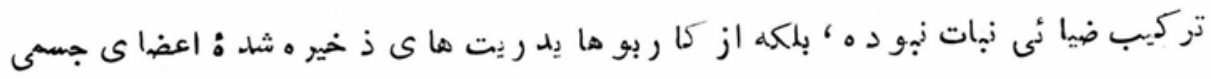

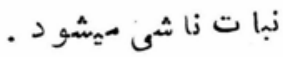

تر ا كم سو اد كار بو ها يد ريت و قتى صو رت سيكير د ، كله اسيد ها د ر اثر عملية تنفس.

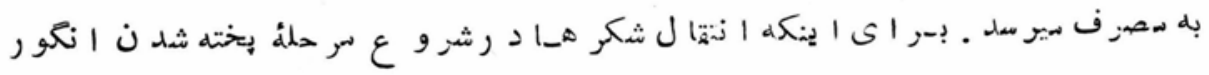

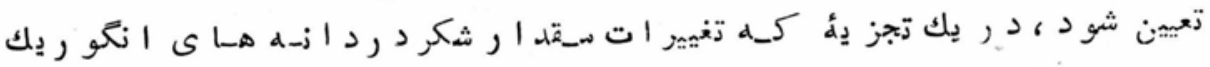

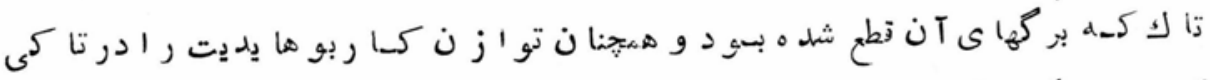

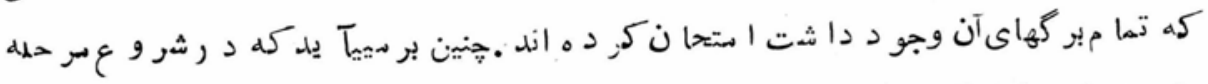

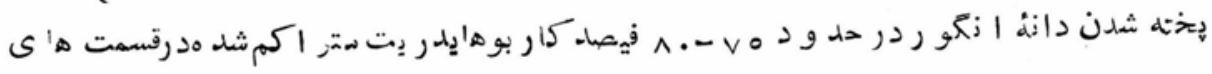

هو بي تا ك ا نكو رو جو د سيد اشته با شد (م) .

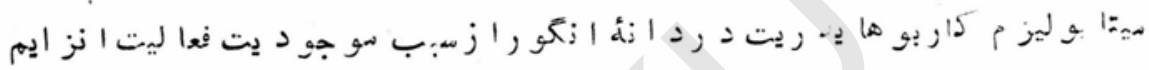

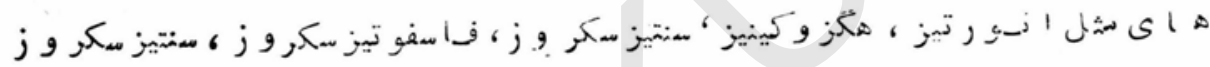

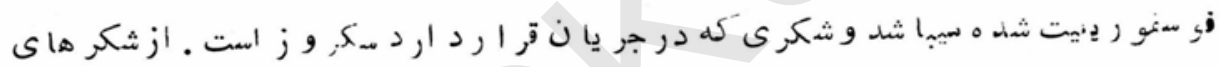

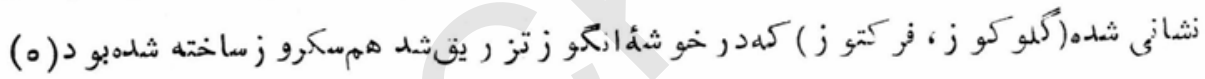

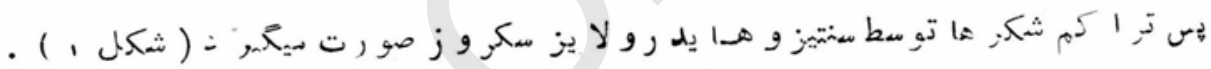

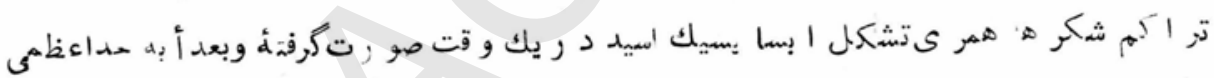

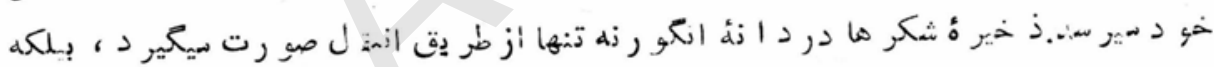

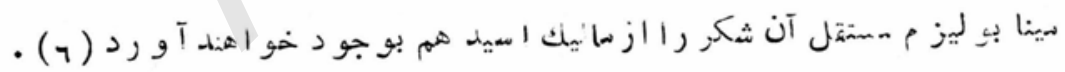

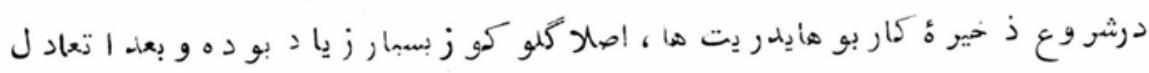

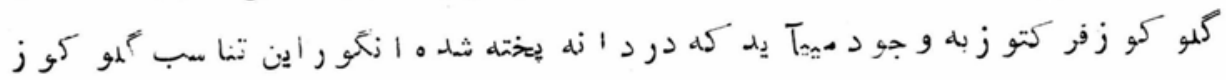

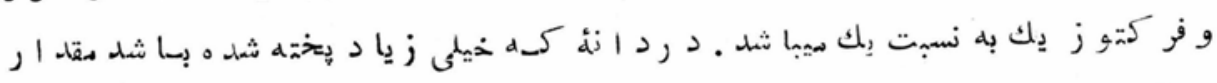

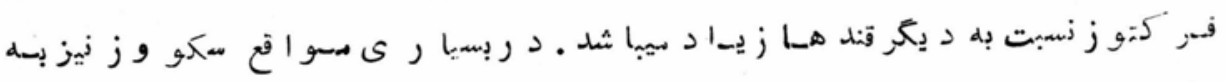

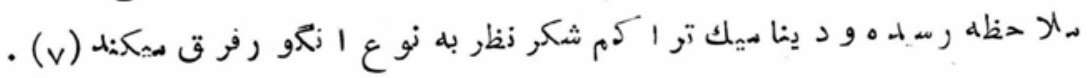

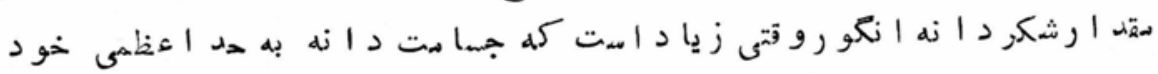

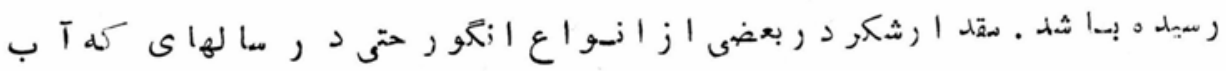

(०q) 


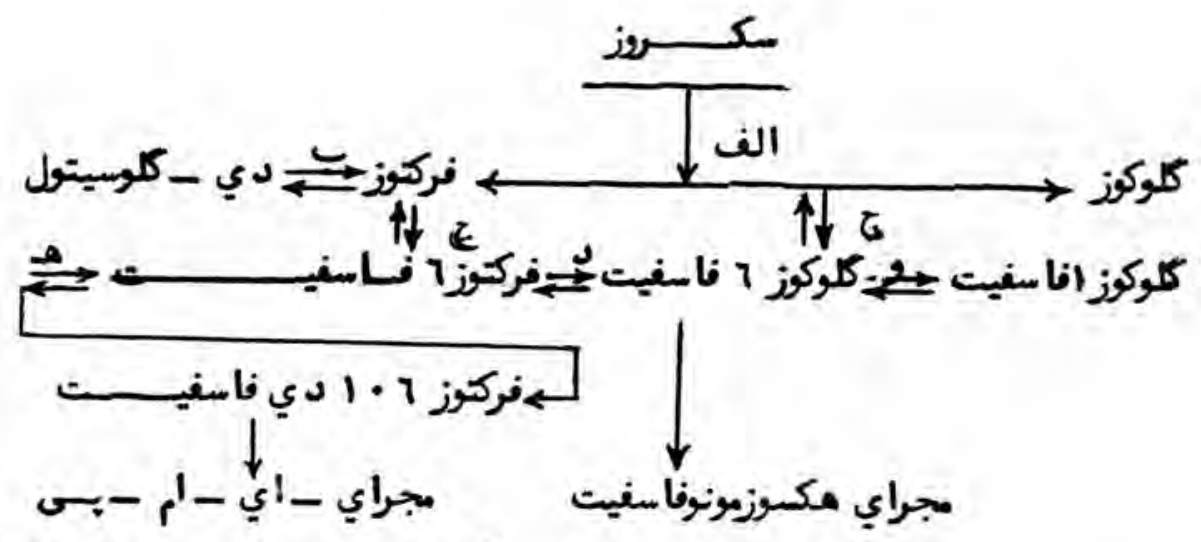

(ايدن -ميرهوف-بـرنسر)

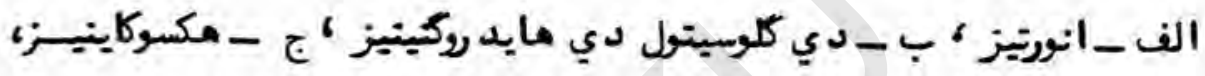

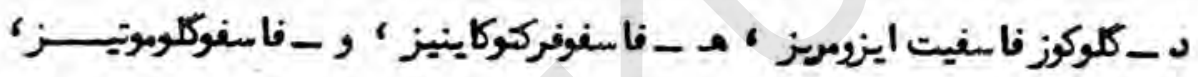

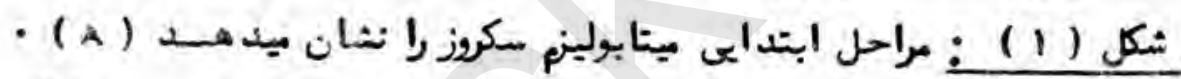

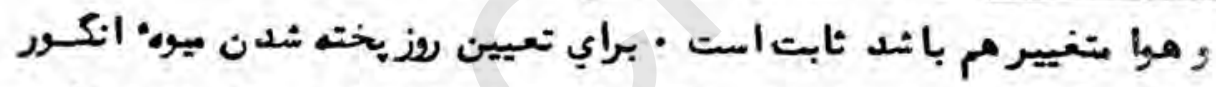

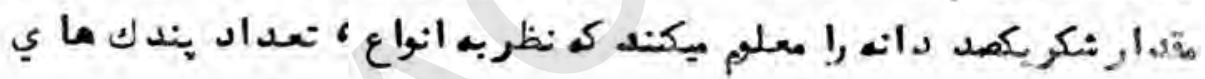

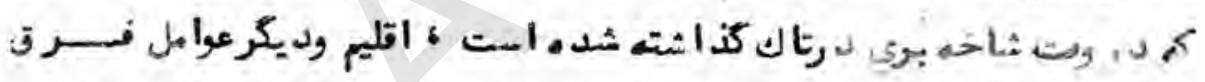

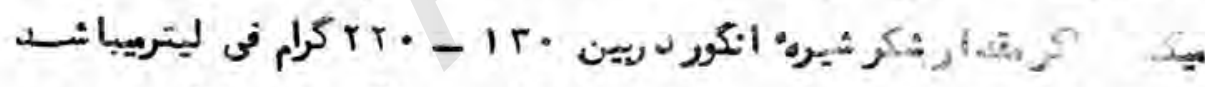

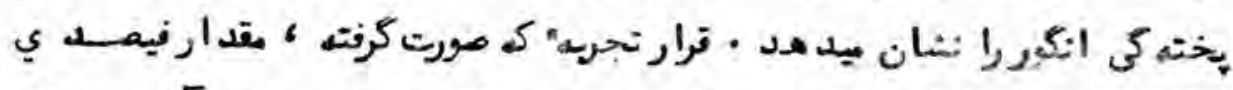

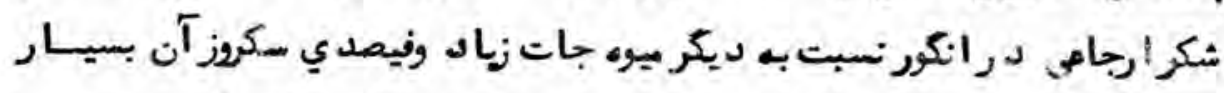

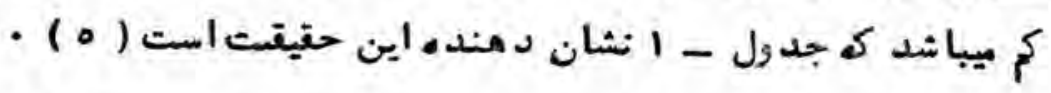

درجرا نه نمو وخته شدن دانه انكورد رمقدا راسيد ماي آن تغييسرات

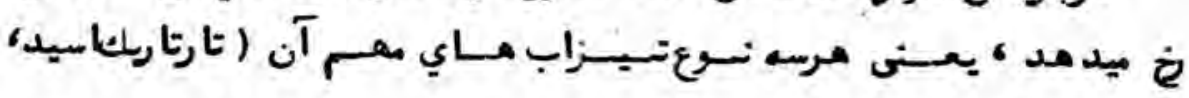

(1.) 
جدل ( 1 ) : مقدارثكردر شمرنت بعضى ازميوه جا ت معملى دروفـ

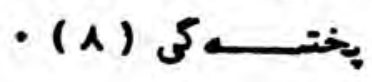

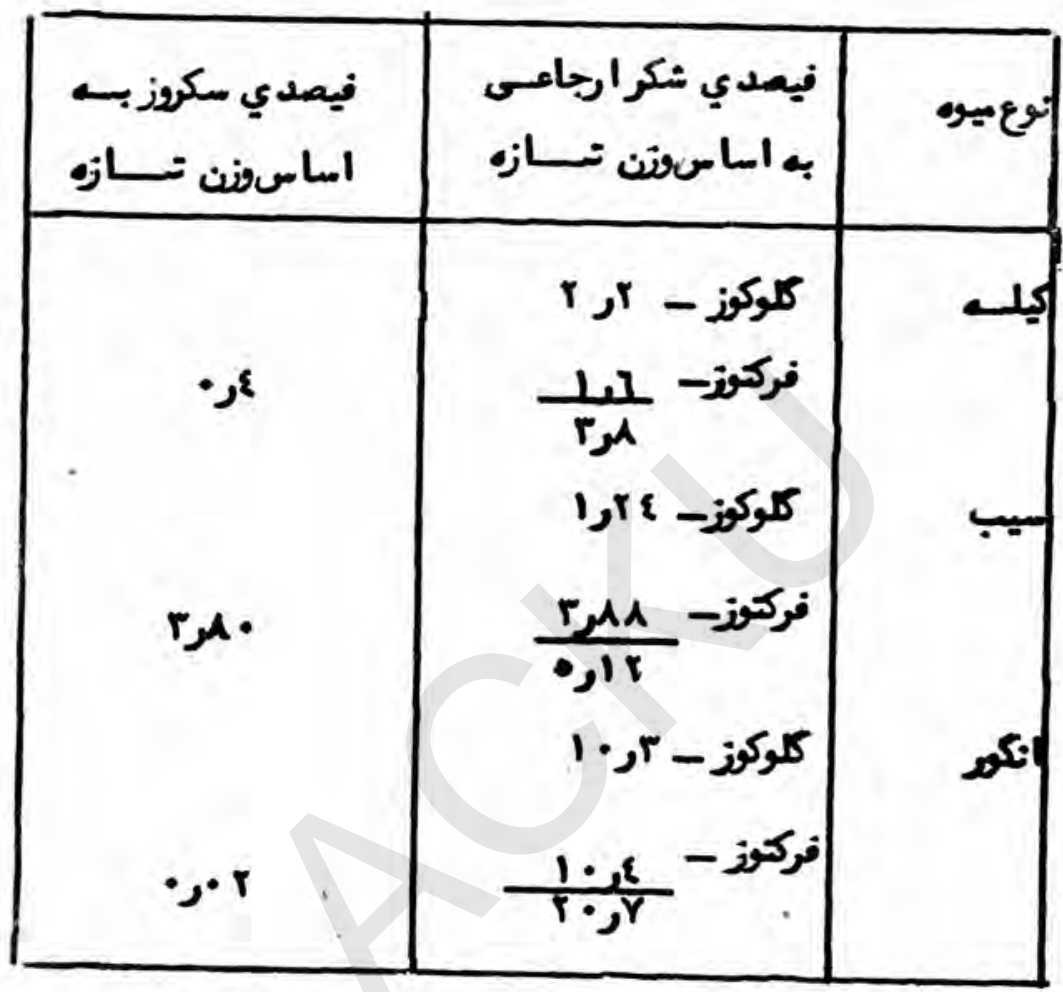

ماليك اميد ومتريك اسيد ) به تدريج تراك مينطايند • بمداء د رقت بختهـيه شدن دانه تيزاب ماليك اسيد فوراء ، تارتاردك اسيد به أمسته كى ومتردك اسيد

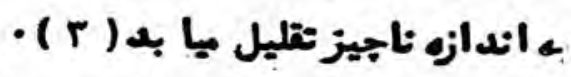

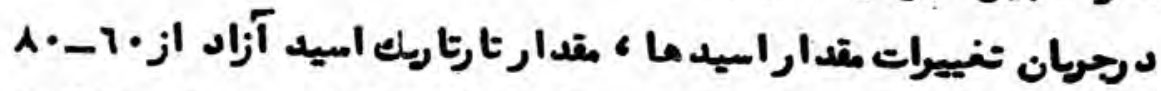

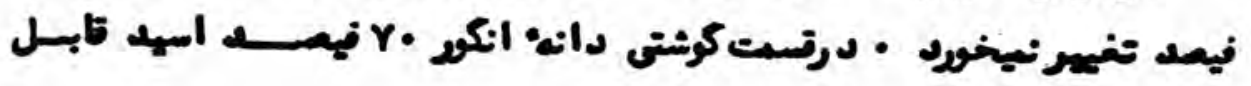




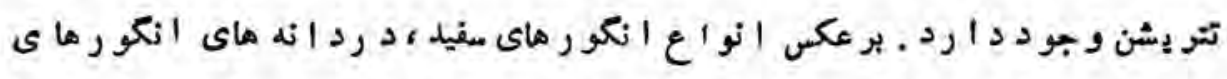

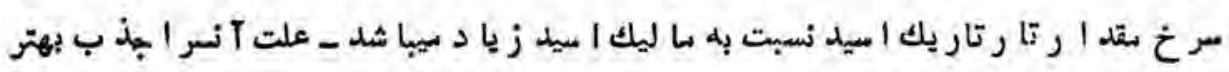

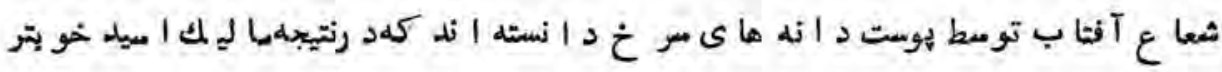

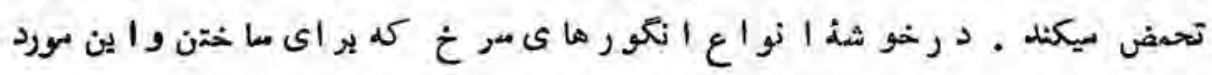

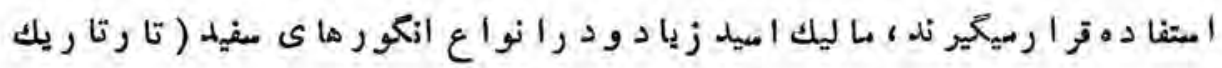

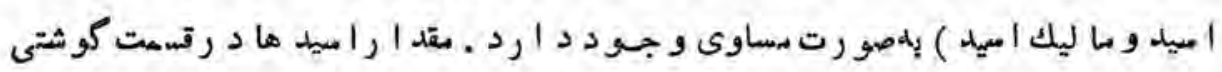

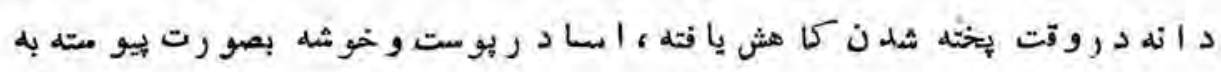

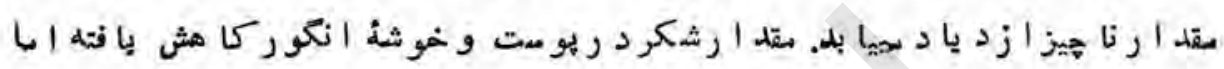

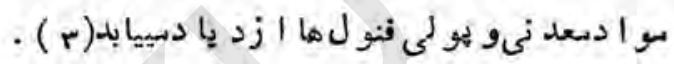

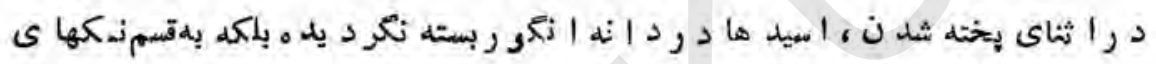

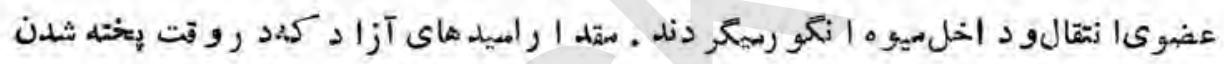

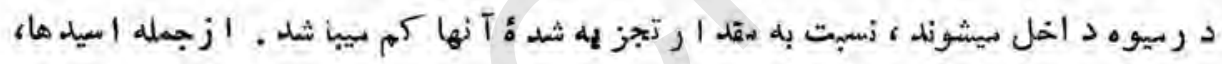

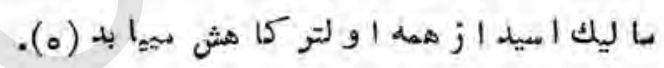

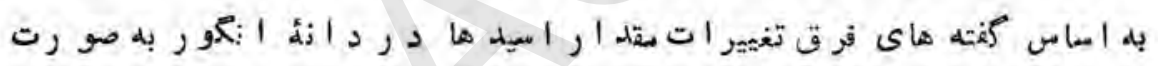

$$
\begin{aligned}
& \text { ذ يل خلا صله ميكر ددد : }
\end{aligned}
$$

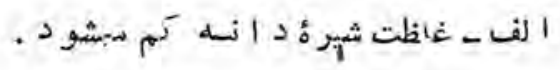

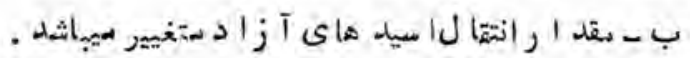

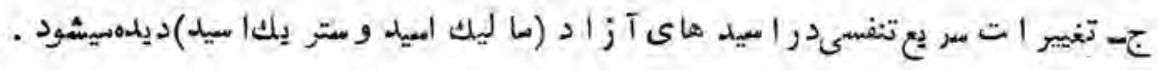

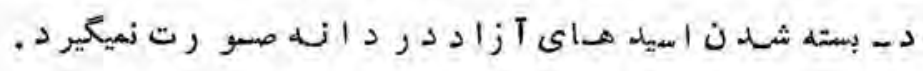

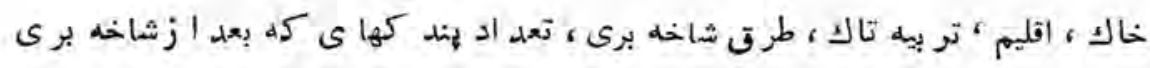

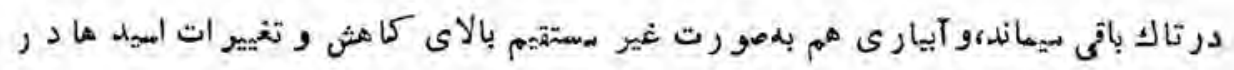




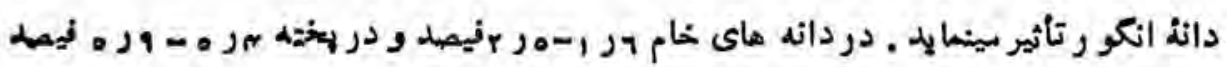

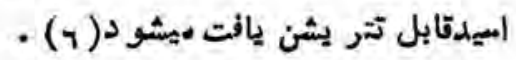

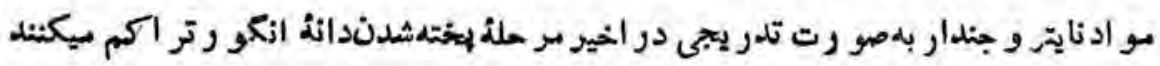

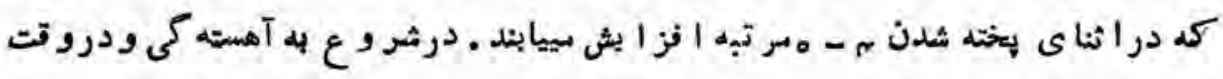
بخته شدن فو راتقليلمييا بد .دردانه هاى انكو رهم همين اميدهاى كحتوسط ديكر اعضاى

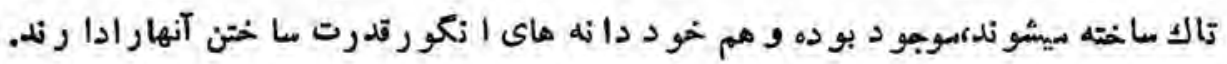

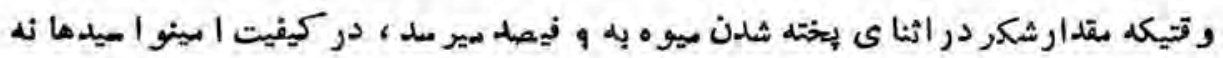

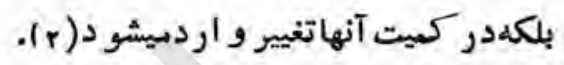

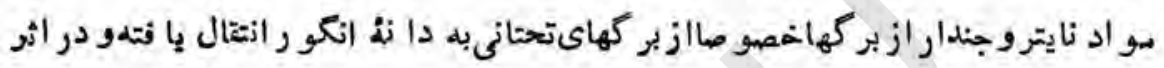

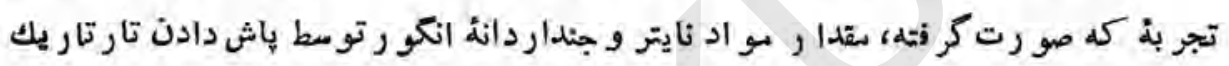

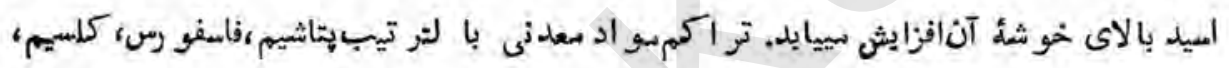

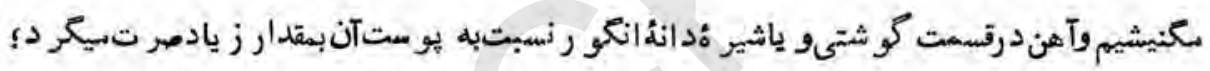

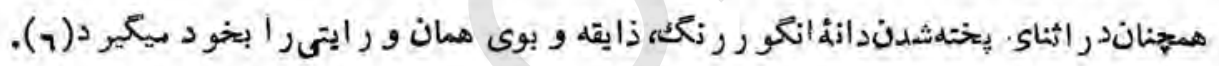

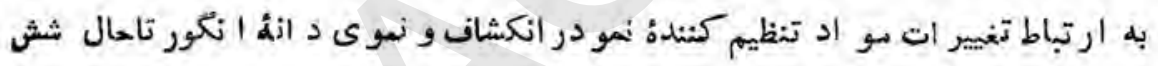

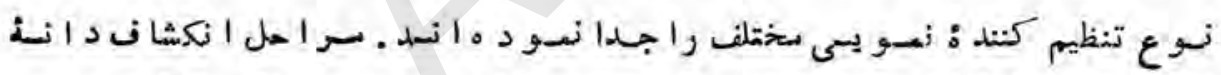

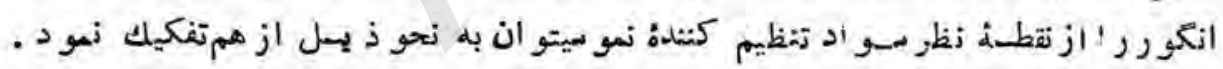

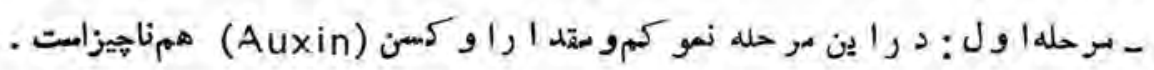

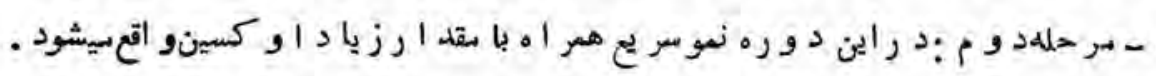

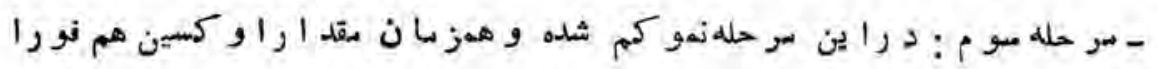
كا هث بيابد

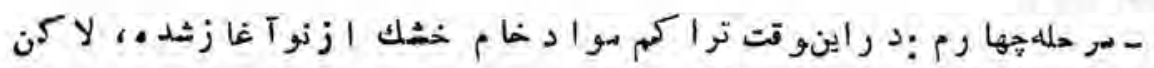

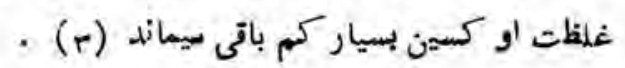




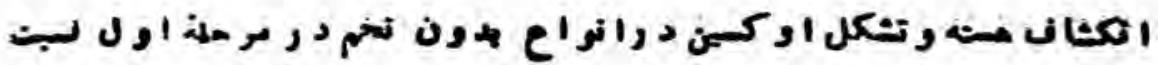

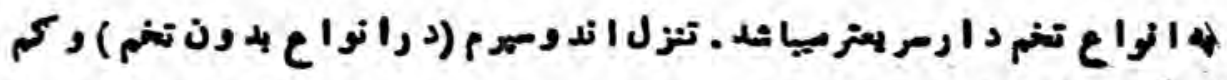

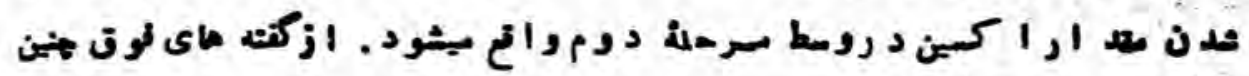

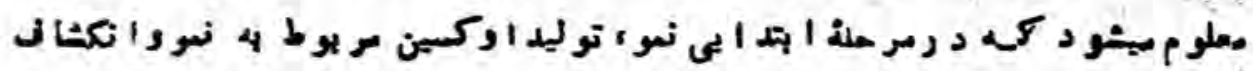

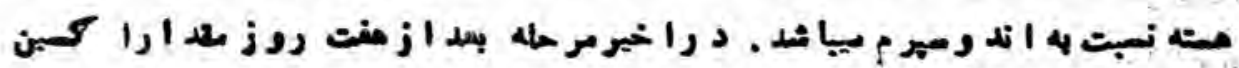

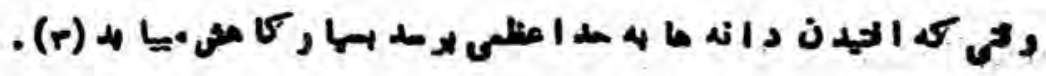

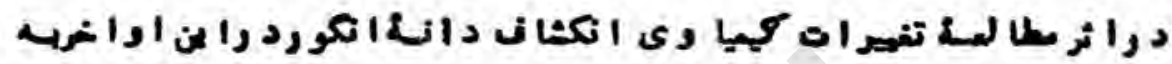

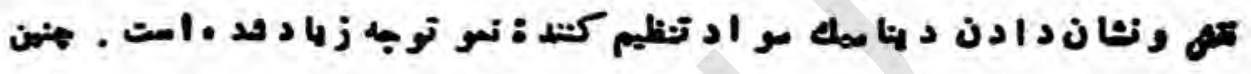

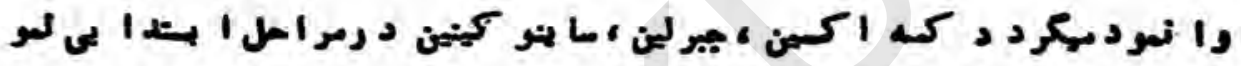

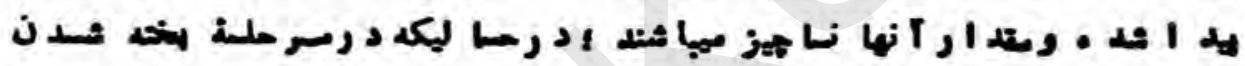

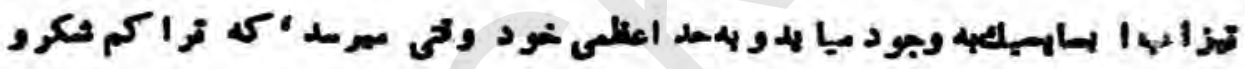

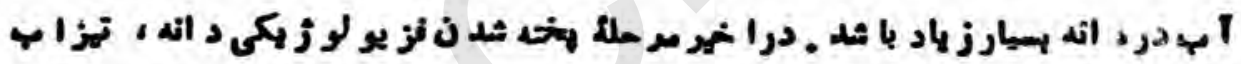

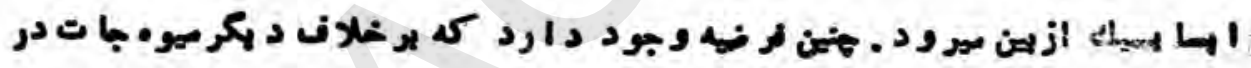

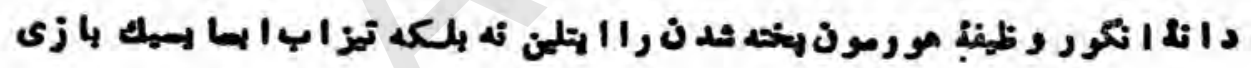

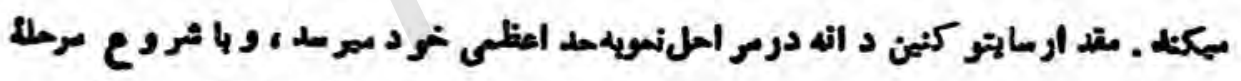

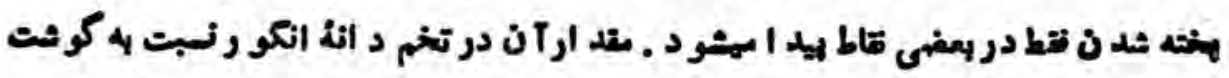

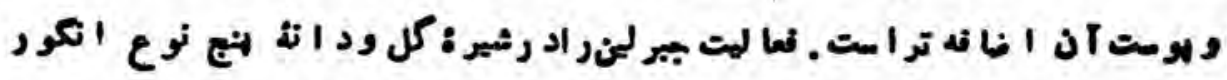

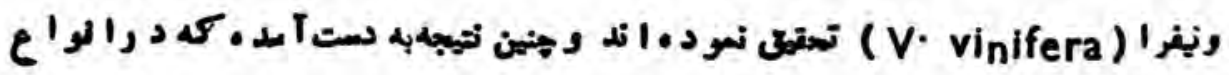

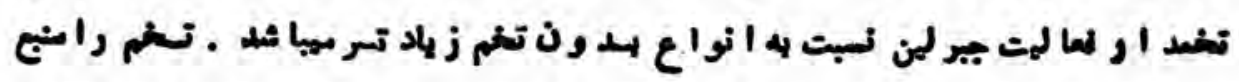

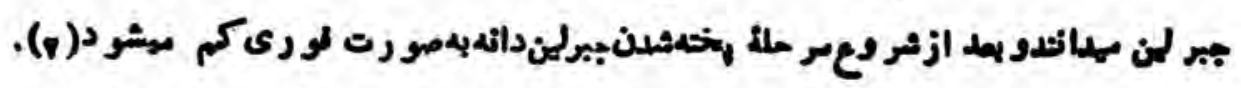

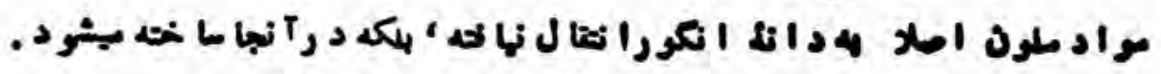




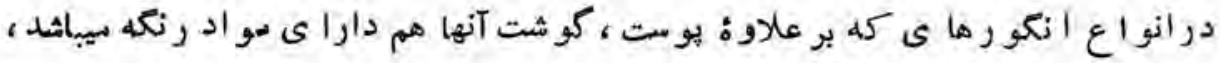

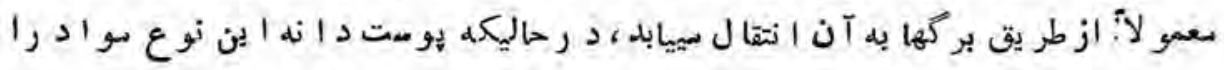
خود بلو جو دنيمآو ردد.

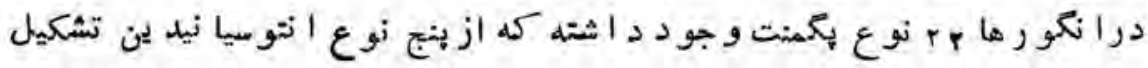

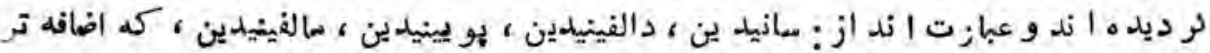

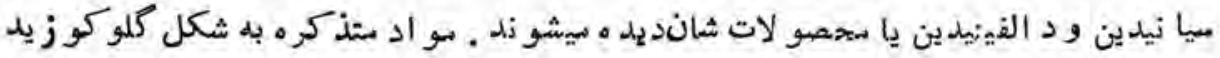

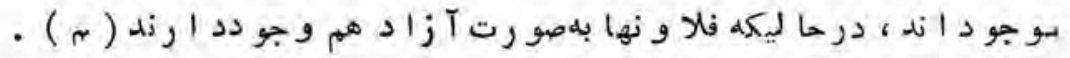

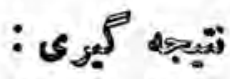

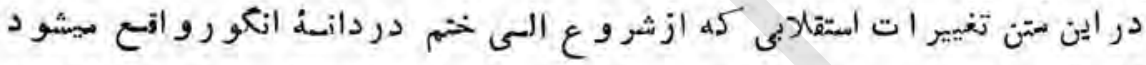

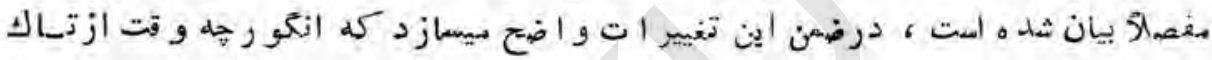

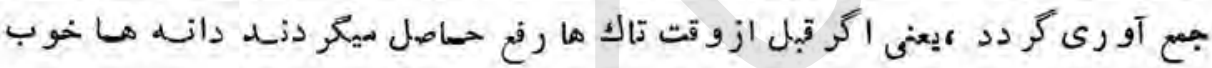

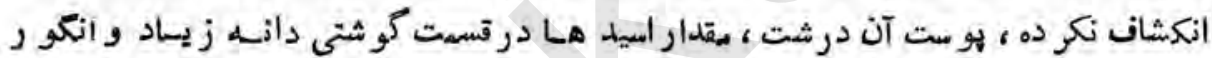

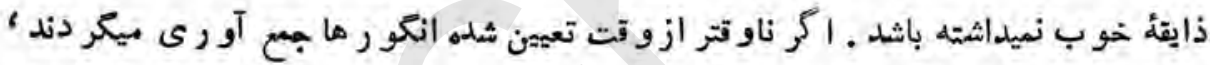

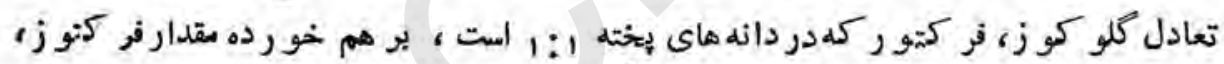

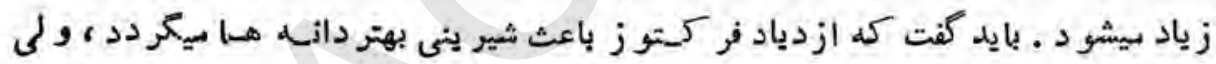

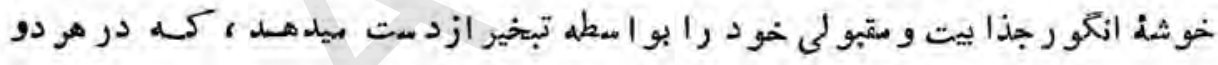

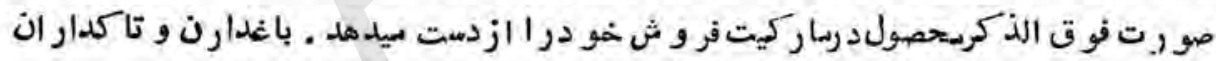

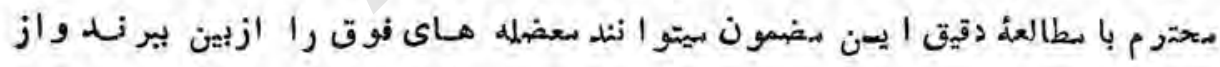

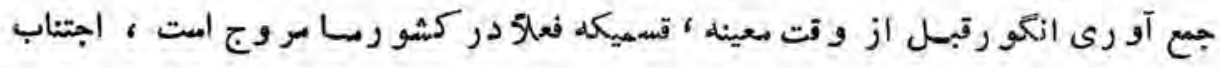

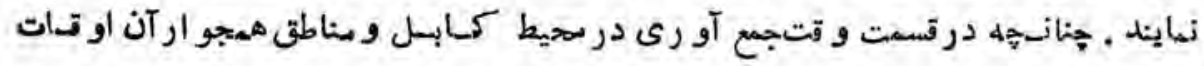

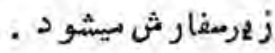

ا - و رايتى هاى زود رس از او اخز ماهجو زا الى او اخر ماه عر طان.

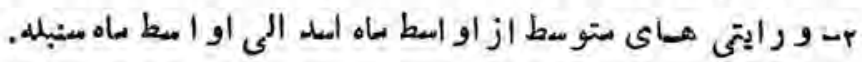

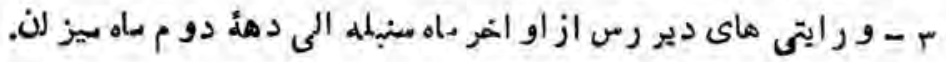




\section{REERRENCES:}

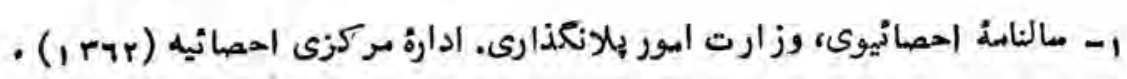

2. Csepregi Pal (1982): Aszolo metszese, fitotechnikai muvletei mezogazdasagi Kiado, Budapest 284-296 P.

3. Csepregi. P. Zilai, J. (1982): Szolotermesztes III. Fajtaismeret es Fajtahasznalat. Budapest 80-102 P.

4. Kozma Pal (1968) Csemegeszolo. M.zogazdasagi Kiado Budpest 224-245 P.

5. Kozma Pal (1983): Szolotermesztes, I Altalanos resz es a szolo szaporitas. Budapest $201-235$ P.

6 Vargas Ledezma, C. (1979): A furtterheles es a lombfelulet hatasa a magasmuvelesu szolotokek leveleinek asvanyi anyag osszetetlere es vesszoinek szinhidrattartalmara.

Akerteszeti doktori ertekezes. 158-182 P.

7. Winkler, A. J. (1929). The effect of dormant pruning on the carbohidrate of Visis vinifer-. Hilgardia 4: 178_194. P.

8. Bulme, A. C. (1970): The biochemistry of fruits and their products. Academic press London and New York. Volume I, 16-21 P. 399-705. P. 


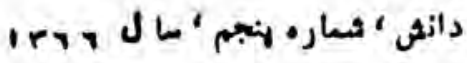

$$
\text { تو هنو ال عبيداله ا كبرى }
$$

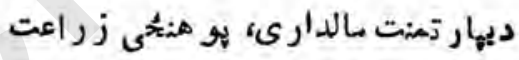

\section{منشأ نكامل وامريت اقتصادى اسب در افغانستان}

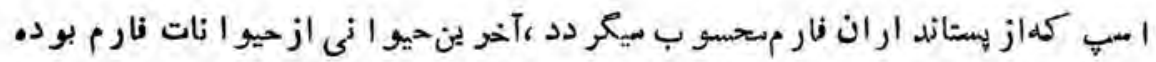

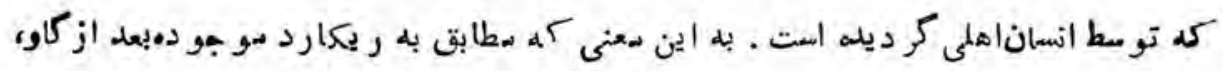

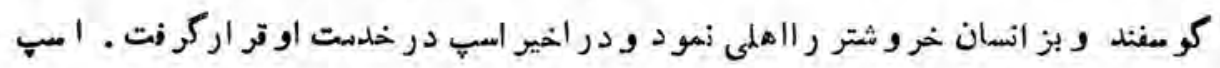

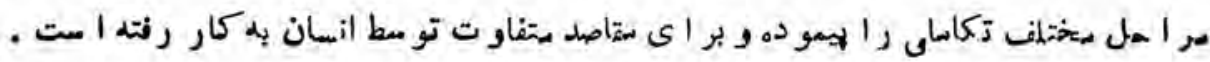


هعر فسى اسب و اهميت آن در افغانستان هـدف ايسن سضمون بو ده ' سو اد و بعلو مسات

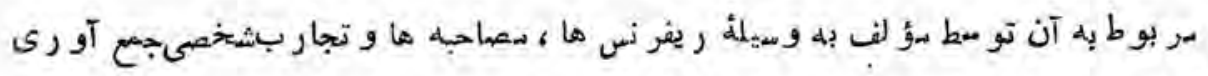

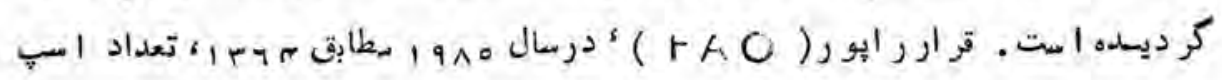

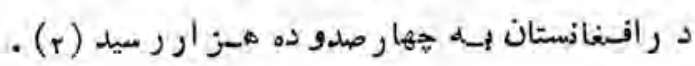

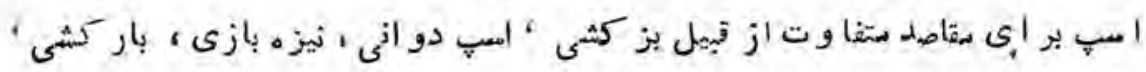

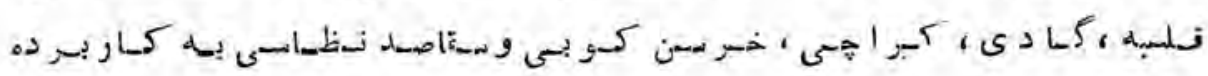

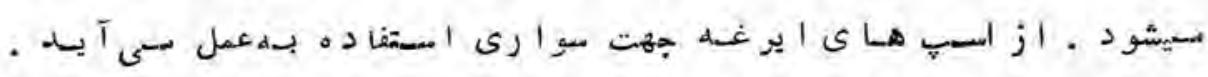

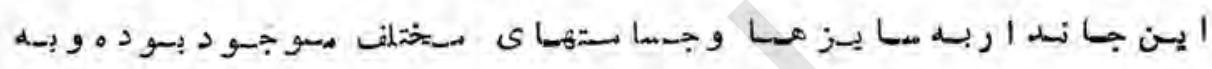

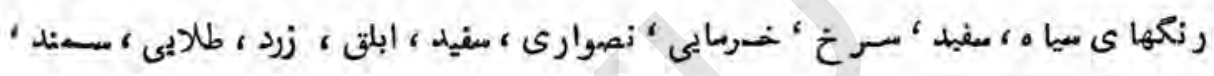
جكر ى و غير ه يافت بيشوند .

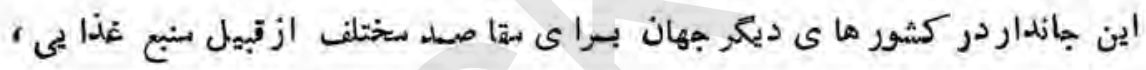

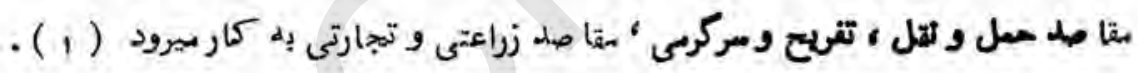
تكامل اسب:

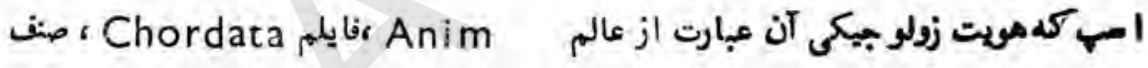

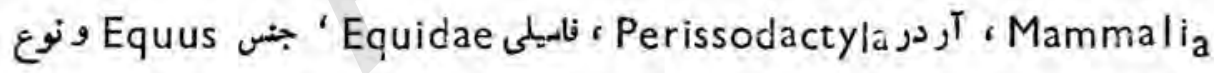

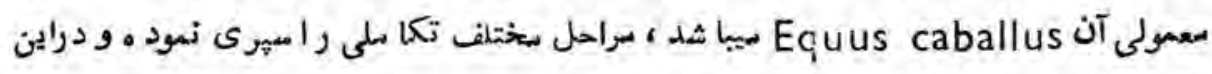

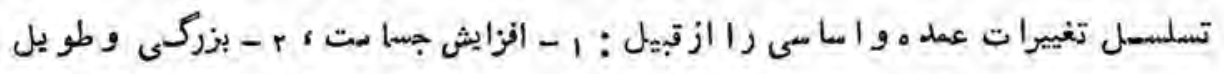

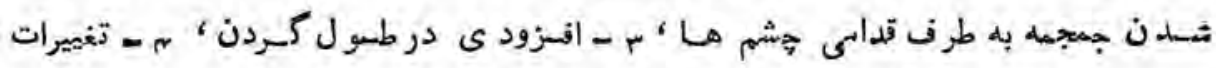

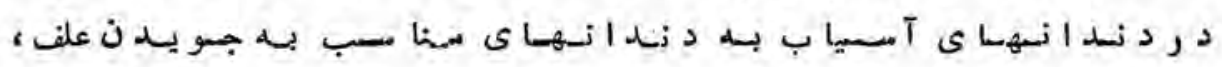

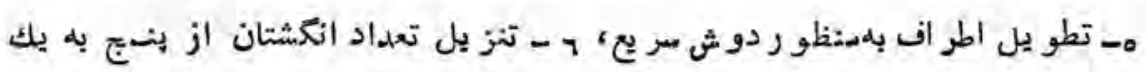

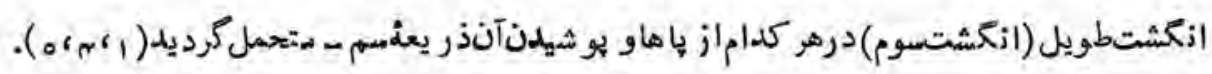




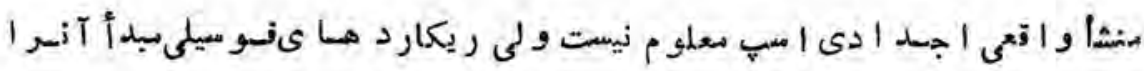
نشان سيدهل. در اين مرحلهاسب ديك حيو ان كوجك (Eohippus) Hyracotherium

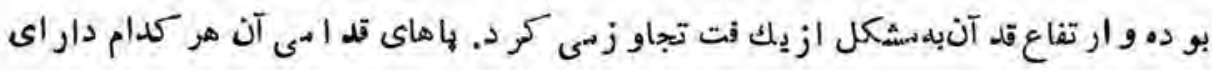

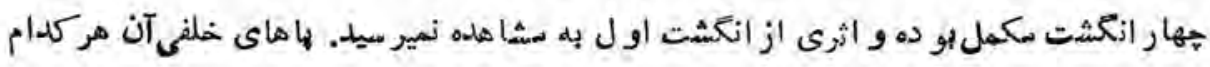

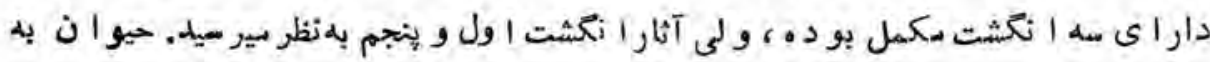

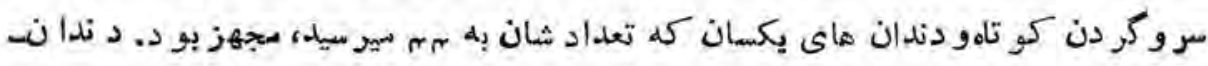

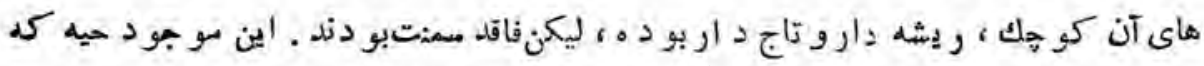

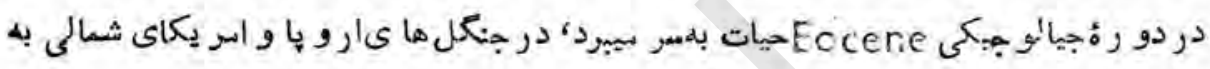

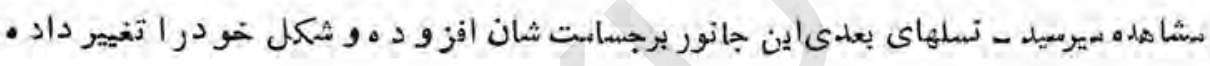

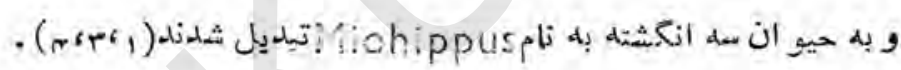

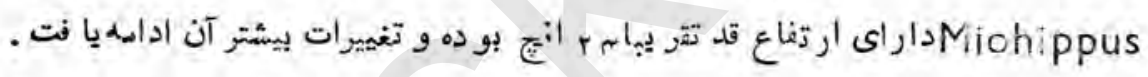

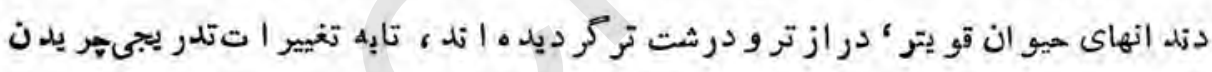

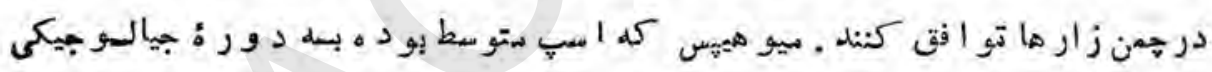
Oligoocene

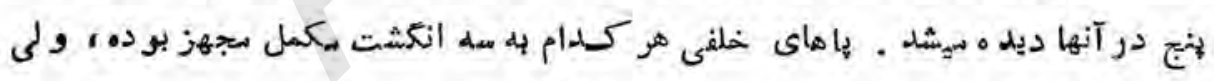
اثرى إز كدام انكشت ديكرى در آن نمايان نبو د ؛ هرسه انكشت به زبين تهاس بيكرقت ؛

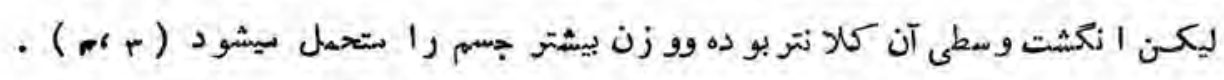

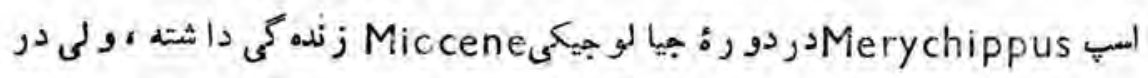

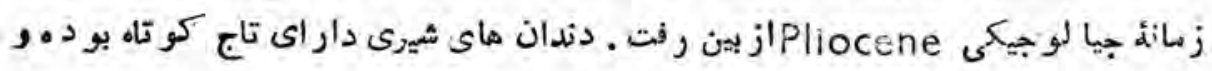

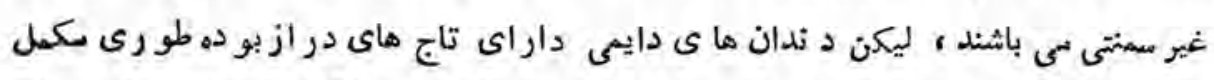

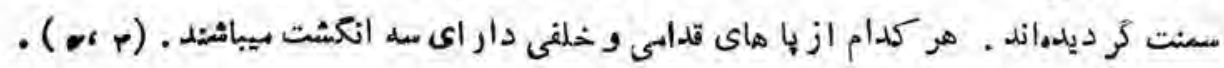




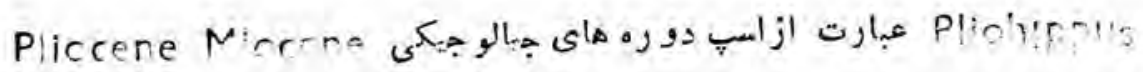

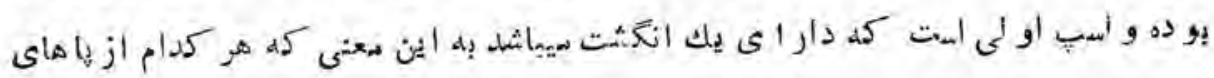

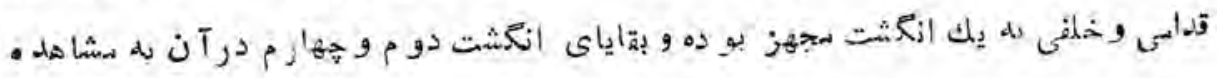

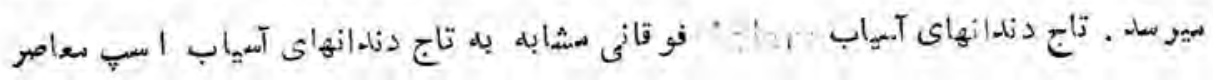

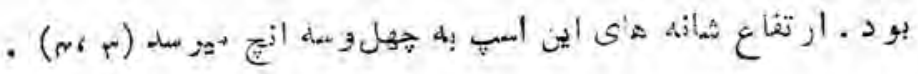

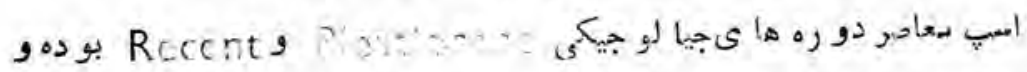

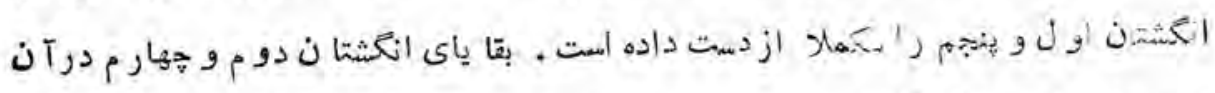

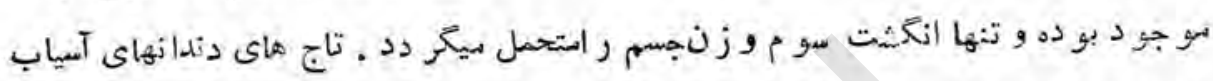

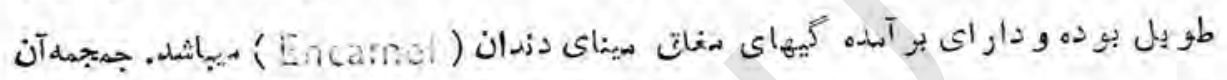

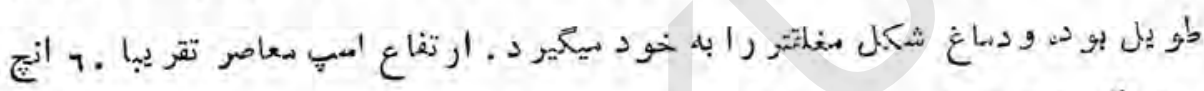

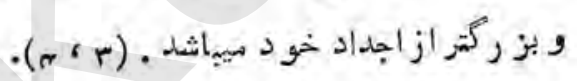

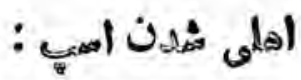

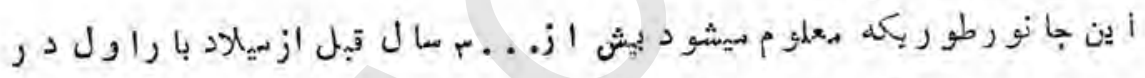

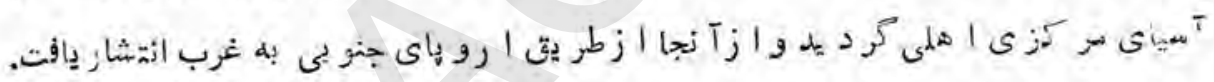

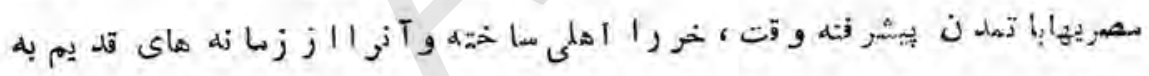

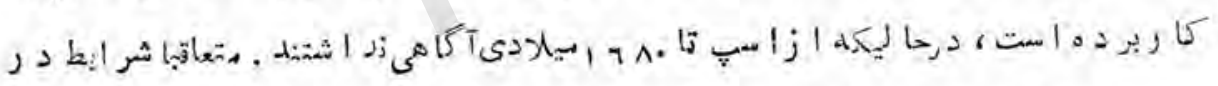

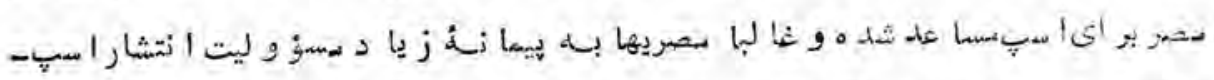

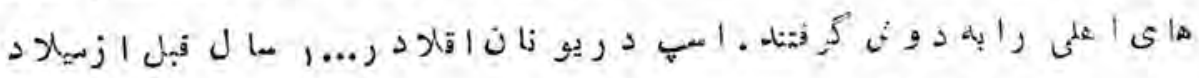

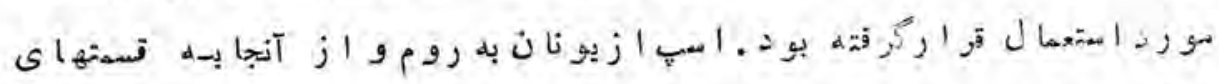

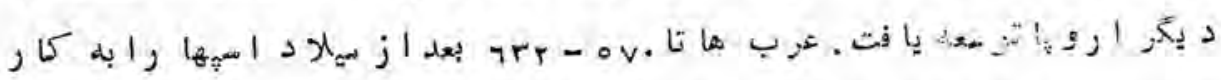

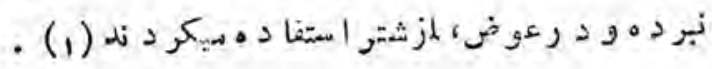
(v.) 


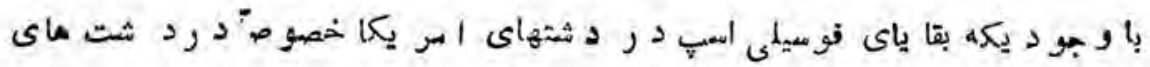

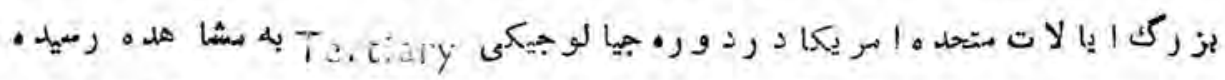

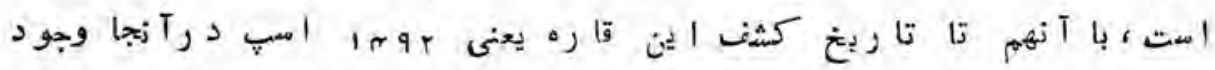

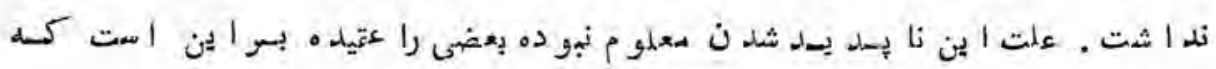

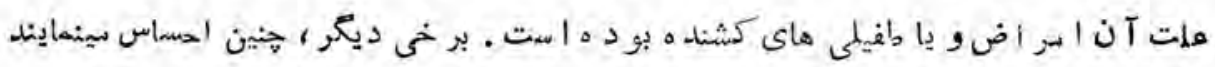

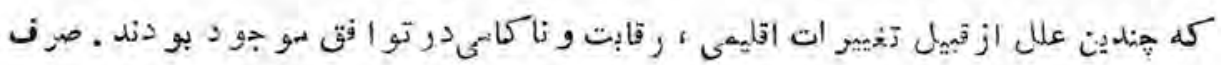

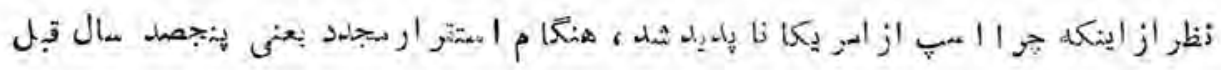

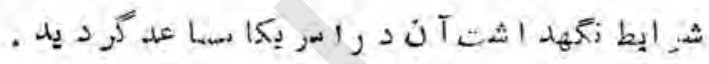

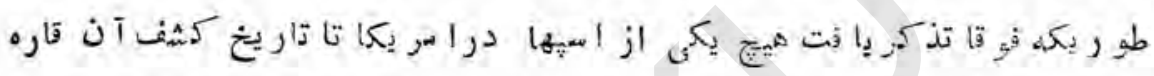

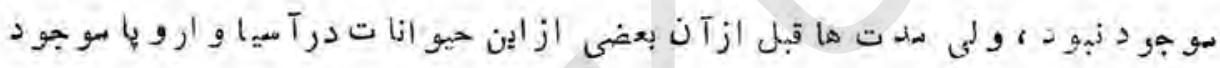

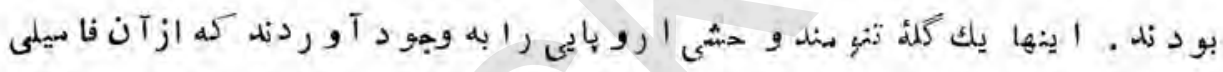

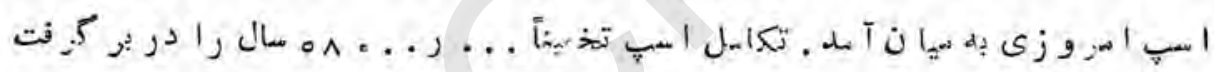

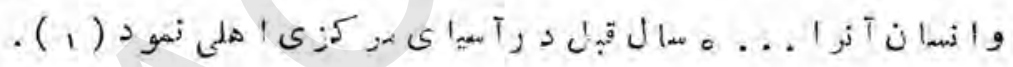

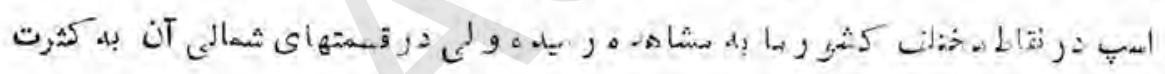

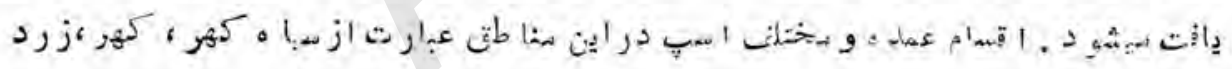

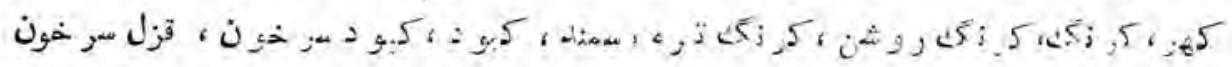

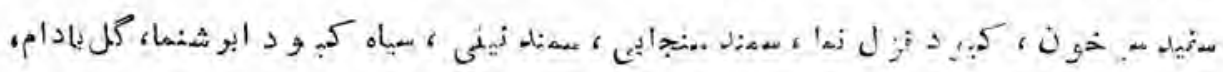

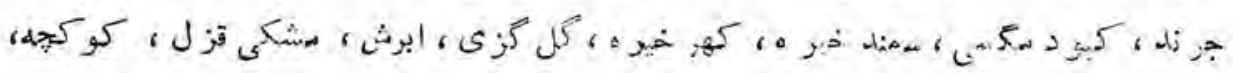

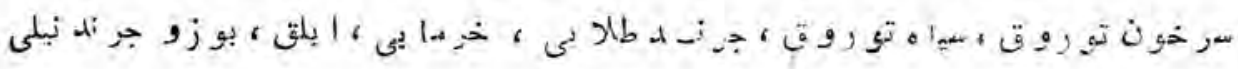

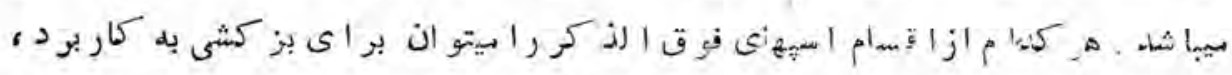

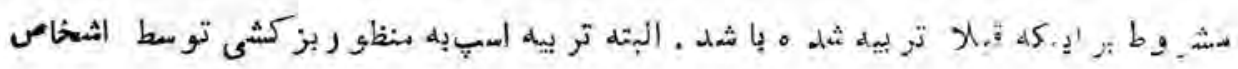

(vi) 
مبر ب صو رت بيكير د و هر كدام ازاقسام متذ كره اسب بيتو اند أير غه به بارا يد.

\section{:}

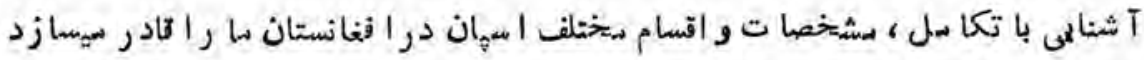

تا درآينده بر ایى اصلاح نسلها لى بو بى و ايجاد نسلهاى اختصاصى جهت دو ش ، بز كشى ،

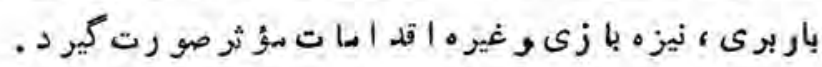

\section{REAERENCES}

1. Ensminger, M.E., Animal science, 6th. ed. The Intrstate Printers and Publishers, Inc, II inos, 969, P? 077-1087.

2. FAO, Froduction Year book Vo 39, 1985.

3. Stiles, K.A., Hegner, R.W. and Boolootian, A., College Zoology, 8h. Ed. Amerind Publishing Co. Pvt. Ltd. New Delhi, 1570. PP. $465-4=7$.

4. Storer, T.I. and Usinger R.L. General Zoology 4th ed, Mc Graw-Hill Book Company, N.Y., 1965. PP. 49- 50.

5. Villee, C.A., Walker, Jr. W.F. and Smith, F.E, General Zoolog, 3rd. ed., W.B. Saunders Company, Philadelphia, 1968. PP. 659660 . 


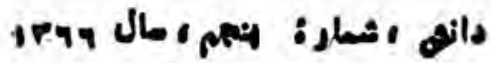

هو مثدوى عبد الننى تاج

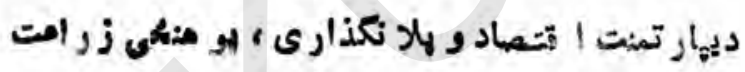

تحليل موللديت كارتوليدى دززراعث

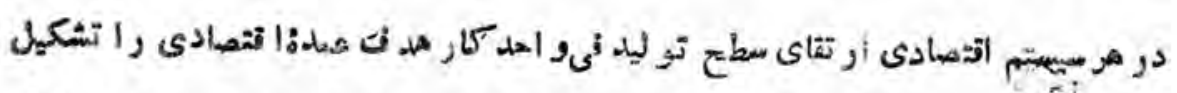

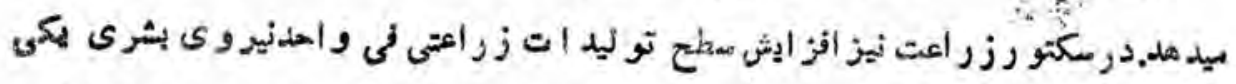

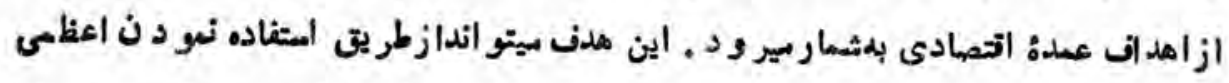

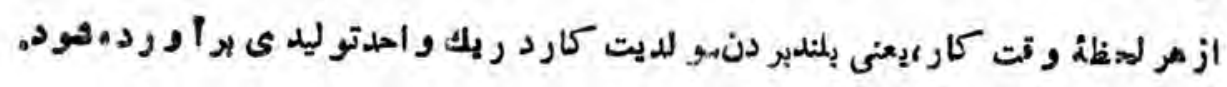

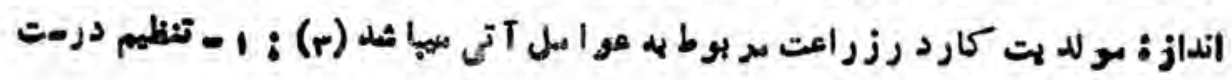

$$
\text { (vr) }
$$




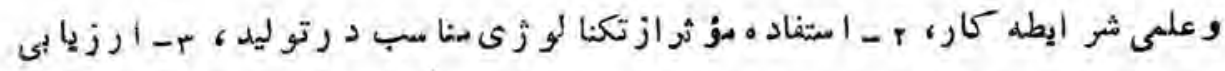

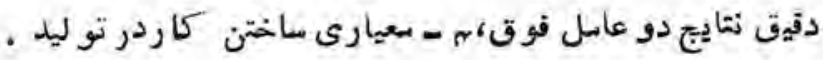

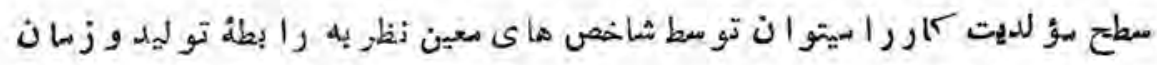

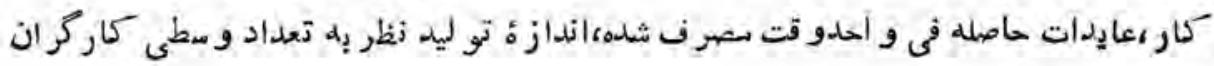
در زمان بعين وفيره تعيين نمو د.

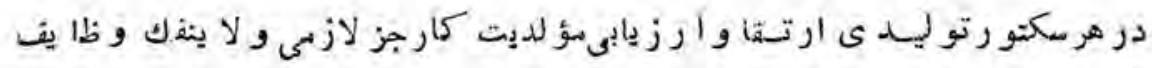
تصهلىهاى تو ليدى به شهار بير و د. روش و شاخص هائ تعيين كنندأهئ لديت كار ورياست -

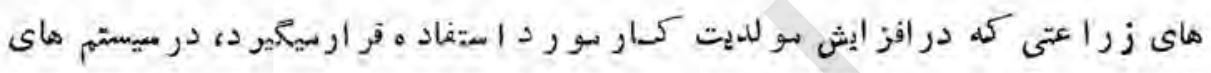
مختخف اقتصادى ازمهد يكر تنا وت دارند .

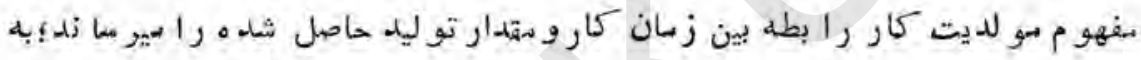

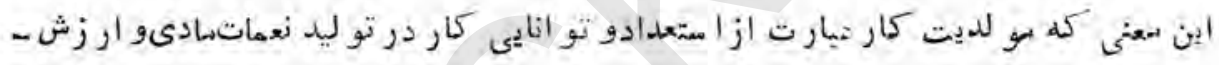

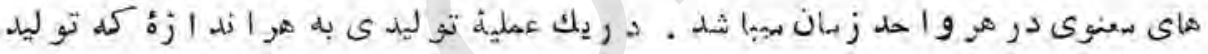

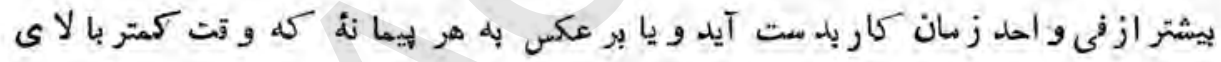

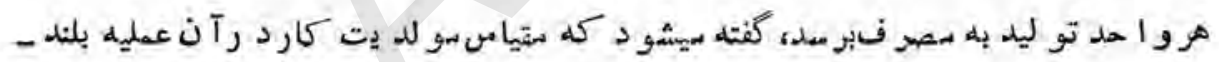
تر است (r) عملية تو ليد سجصو لات زر اعتى درنتيجه كار بجسم و كار ز نده صو رت بيكير د. كار

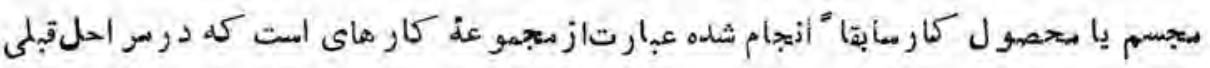

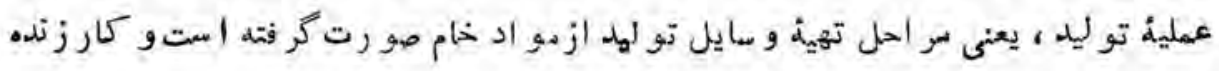

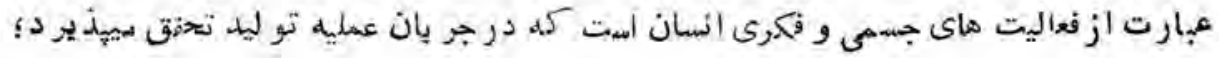

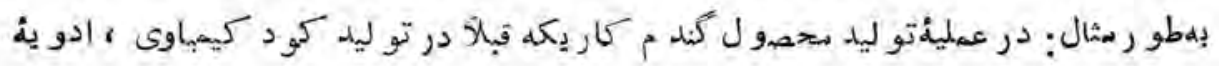




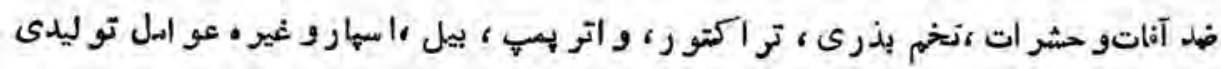

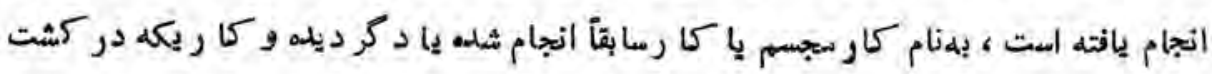

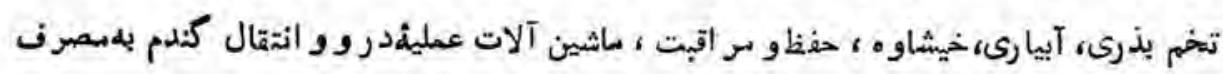

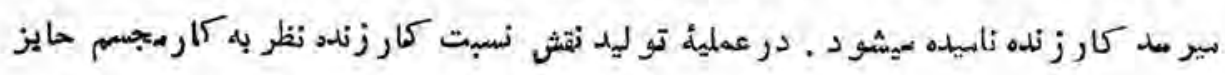

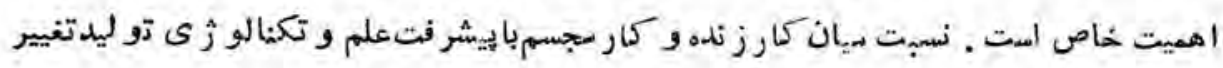

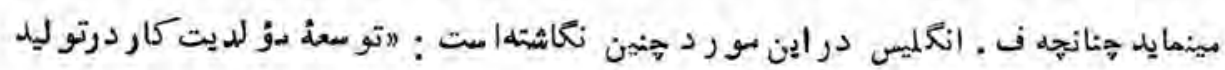

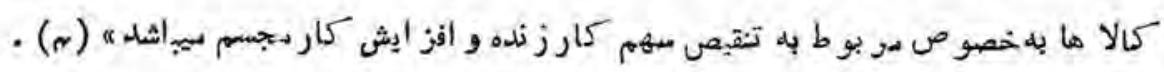

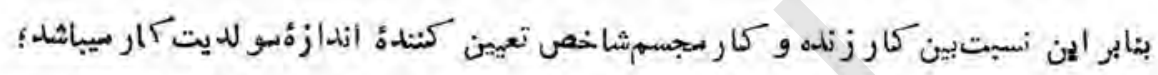

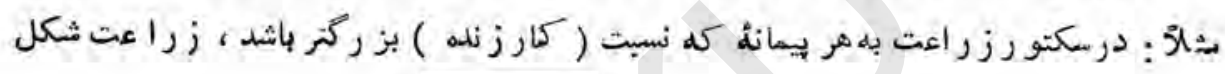

$$
\text { مان }
$$

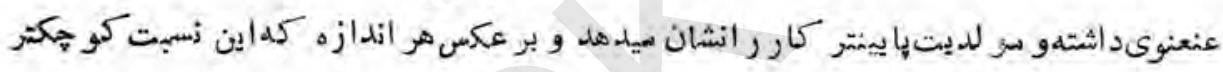

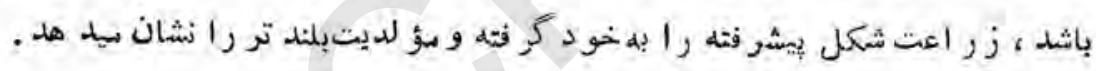
بر اى تعيين آهنكة رشد سؤلد يت كار و صر فه جو بى ازو تت بلصو رت كل ، تخغين

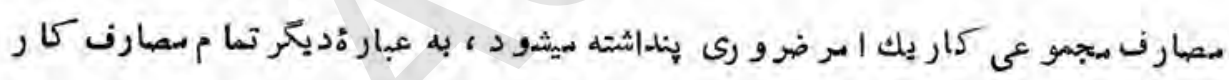
ز زنده كمه جهت تو ليد نحصول جديد صو رت ميكير دو و مصارف كار سجسم كله بهثكلو مايليل تو ليد بو رد ابتفاده قر ار بيكير د بايد دانسته شو د ـ تعيين سصارف سجمو عى كارصرفبر اى تعيين آهنكك رشد سؤلديث كازخر وى نبوده، ، بلكه ا سام خو بى را براى تعيين ارزثر شحصو لات ز راعتى نيز تشكيل بيدهد . به ادادئ نظر يات اقتصاد دانا ن كلا سيك (ديو يد

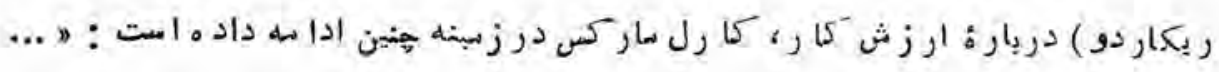

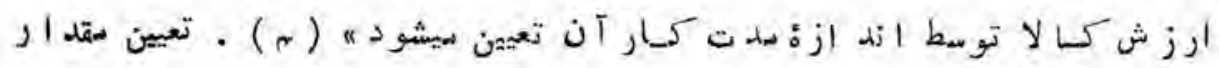


مارفخدمات اجتماع براي اراثه نسبت بيت رثته ماي مربوط نيز لازم وداراي

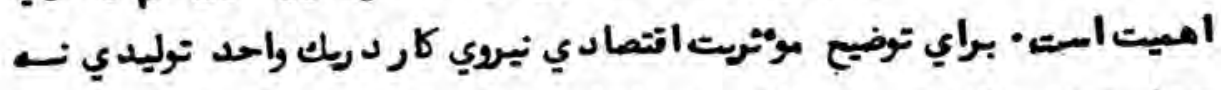

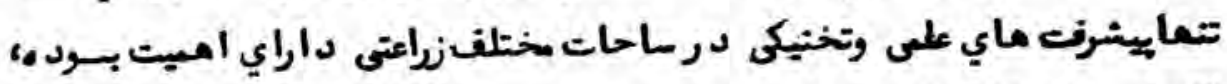

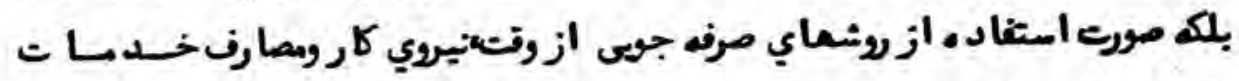

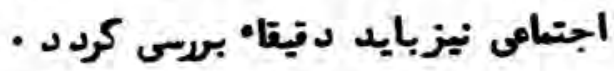

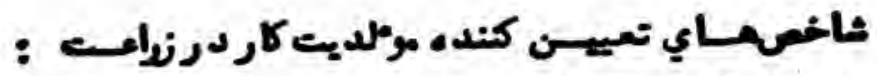

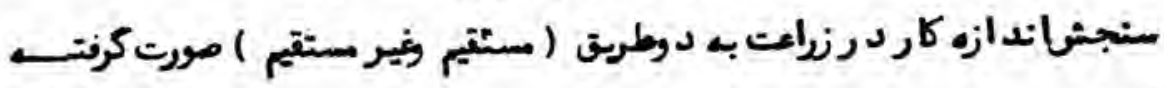
ميتواند

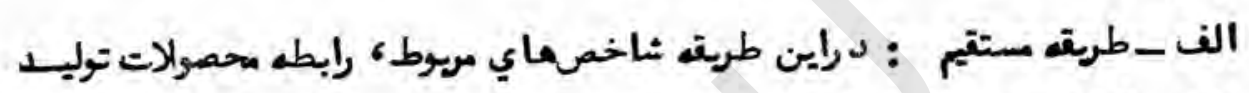

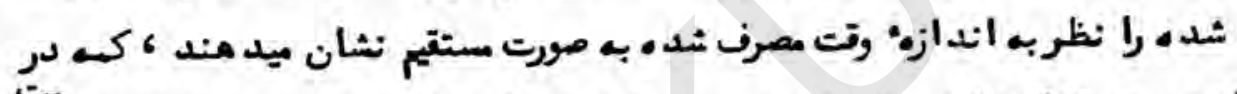

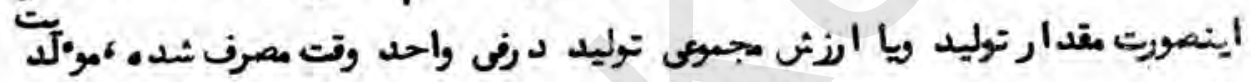

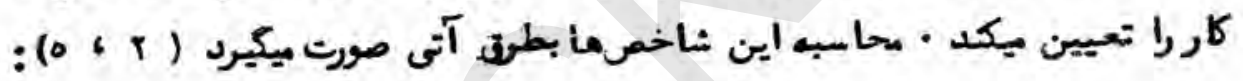

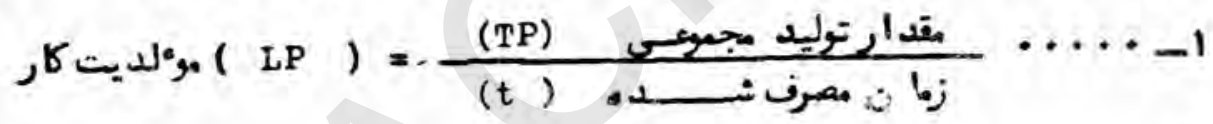

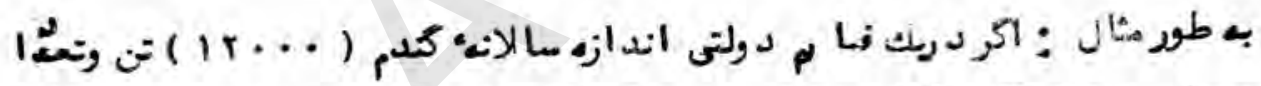

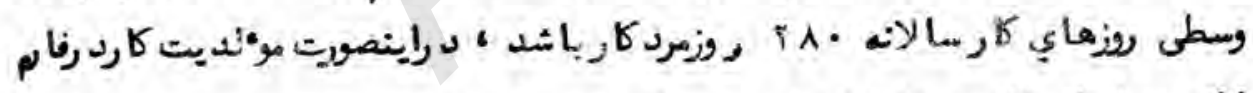

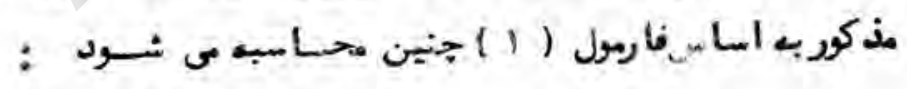
(LP )

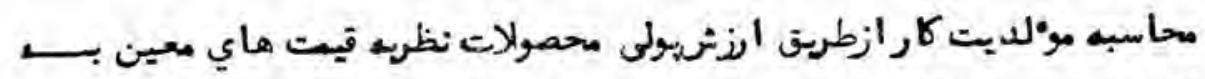

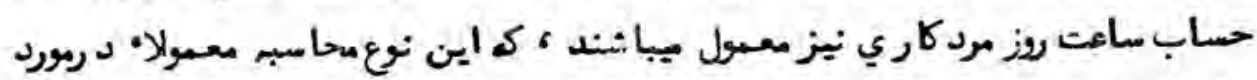

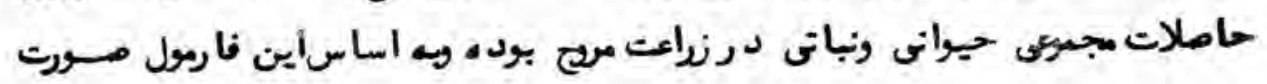




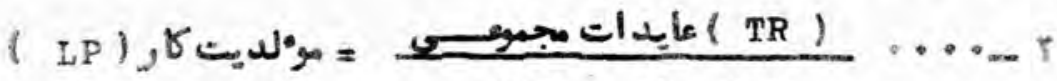

$$
\text { زمان مصرفكار }
$$

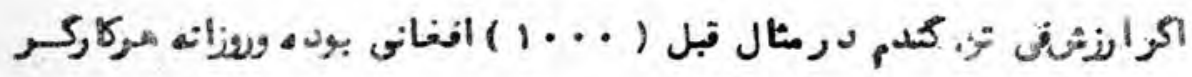

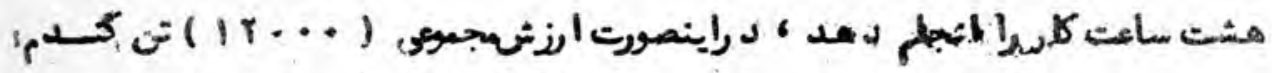

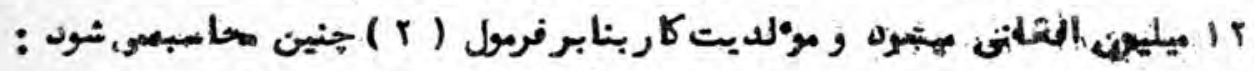
)

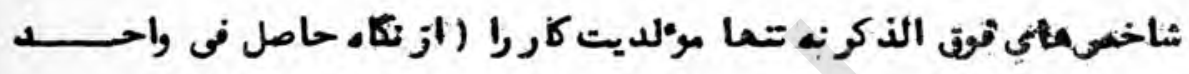

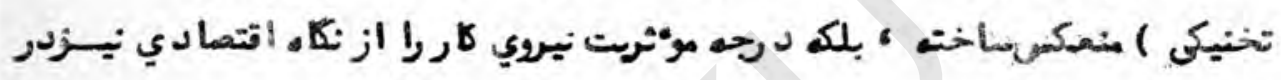

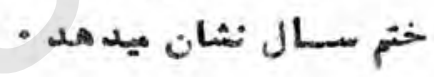

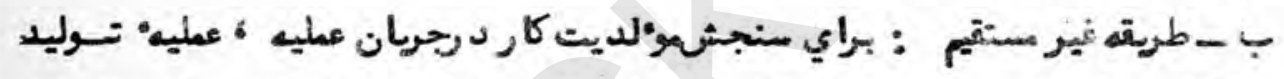

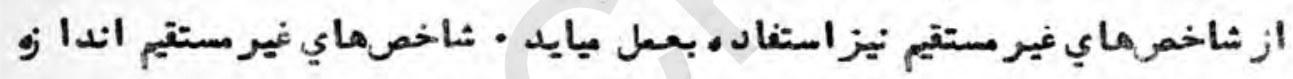

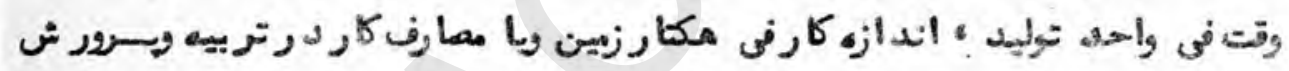

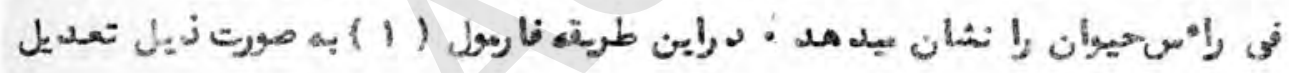

$$
\begin{aligned}
& \text { : (1 S r ) }
\end{aligned}
$$

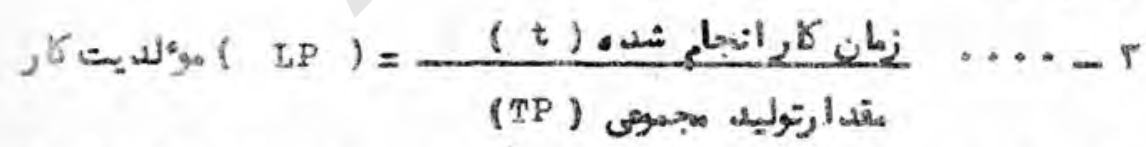

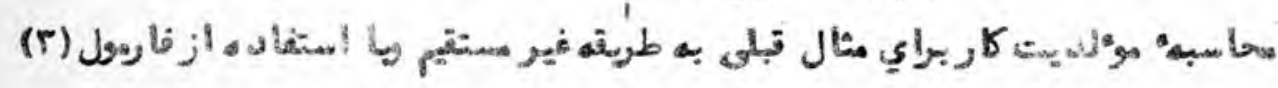
:

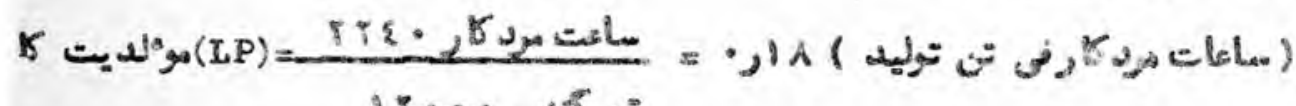

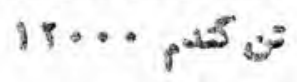




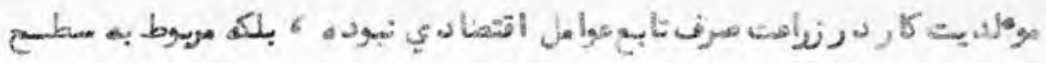

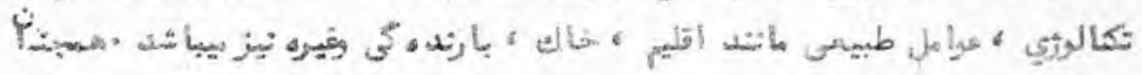

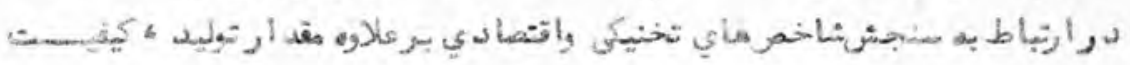

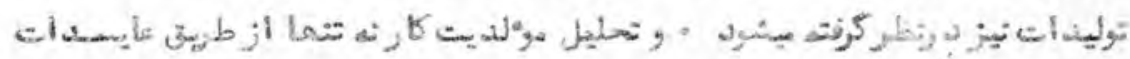

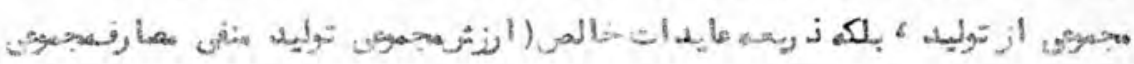

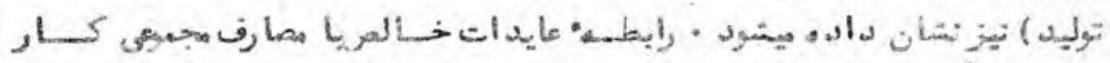

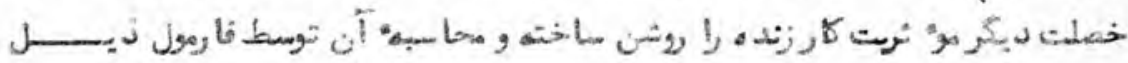
: مورت ميكيرد (1)

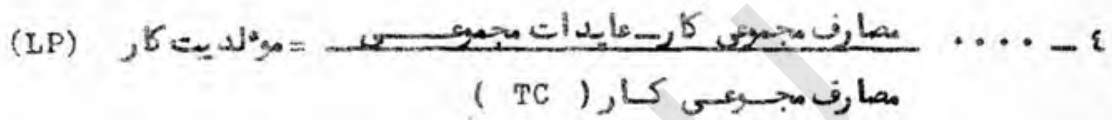

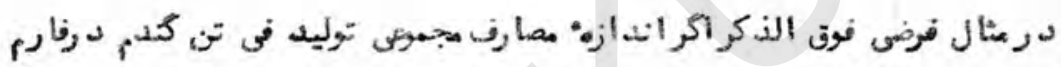

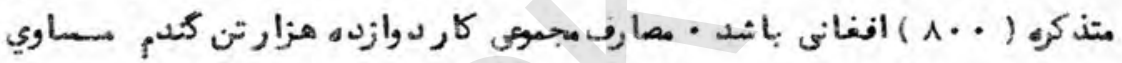

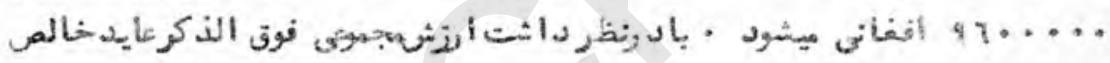

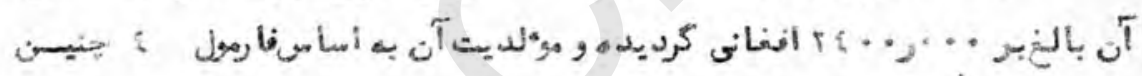
: A

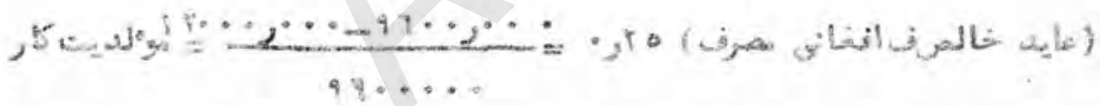

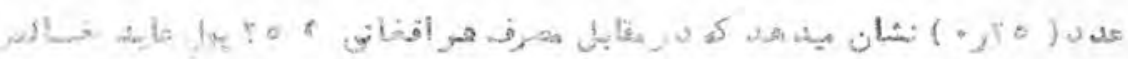
-

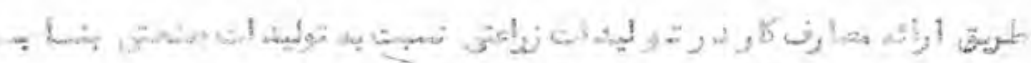

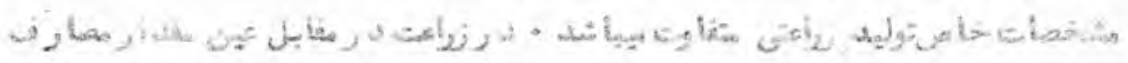

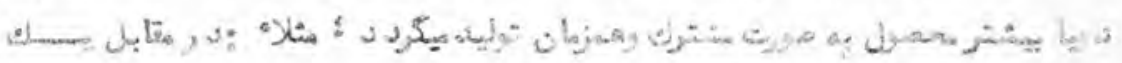

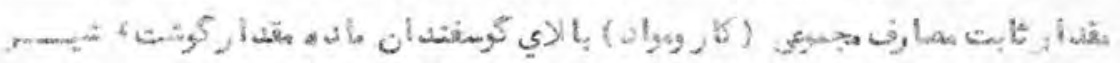

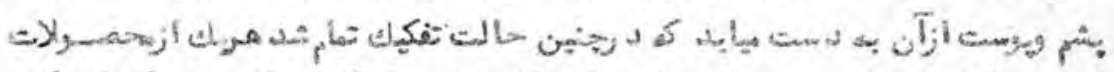

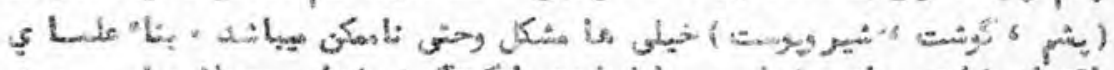

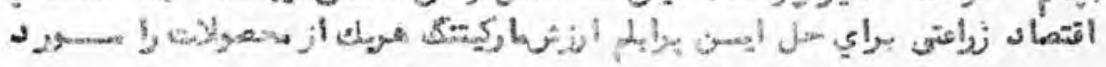




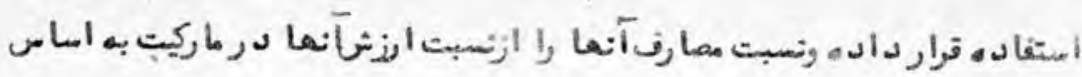

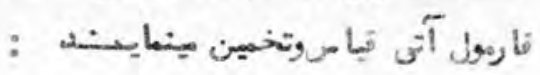

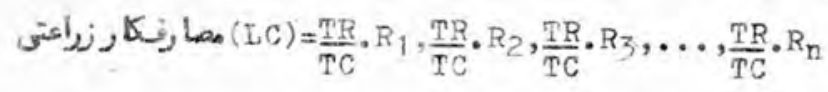

$$
\begin{aligned}
& T R=\quad \text { ع }\left(R_{1}+R_{2}+R_{3}\right) \\
& R_{1}=\text { ع } \\
& R_{2}=0 \\
& \text { R } \\
& \text { TC = مصارف مجموعى } \\
& \text { طرق أرتقأه وبلند بردن مولديمت ار : }
\end{aligned}
$$

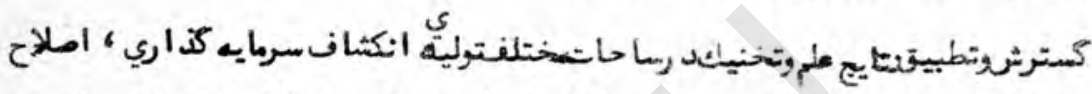

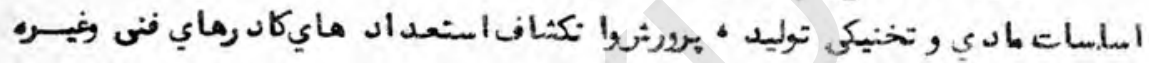

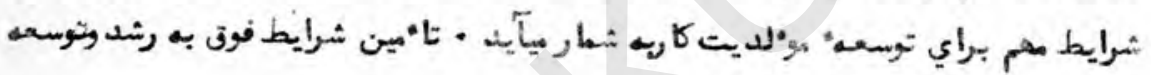

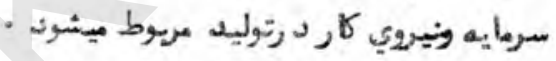

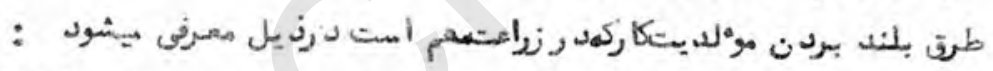

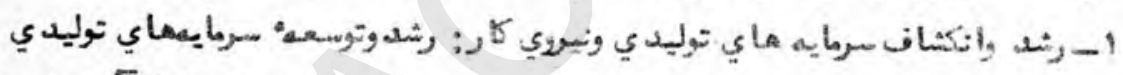

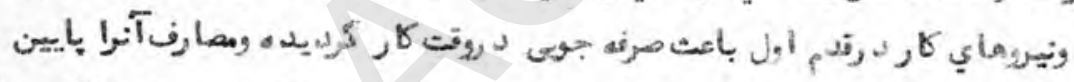

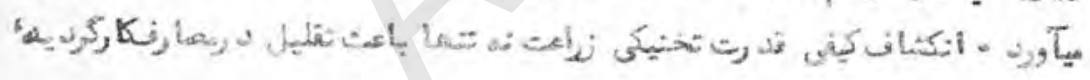

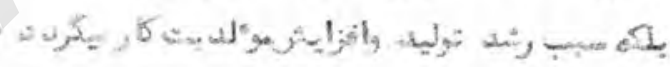

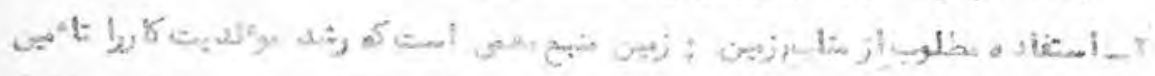
Crescest

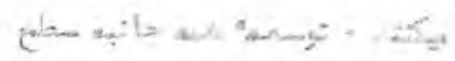
定

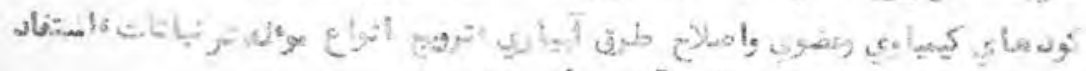

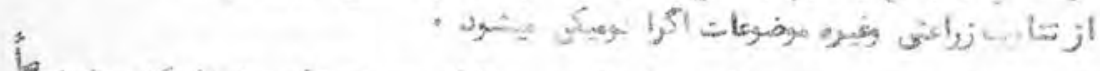

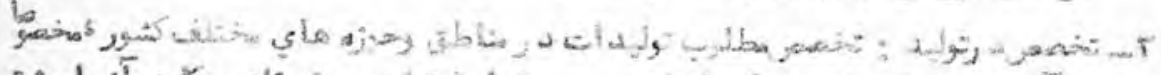

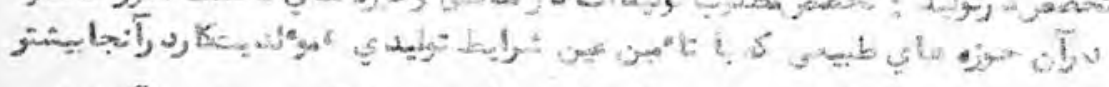

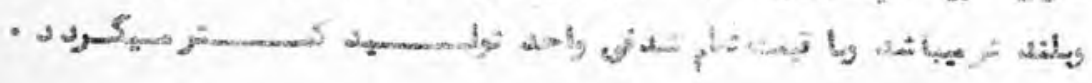




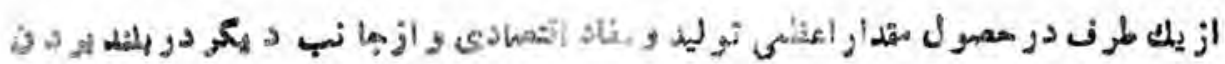

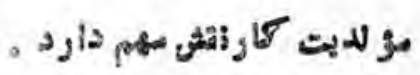

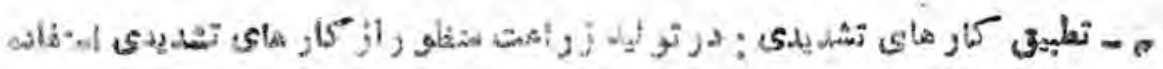

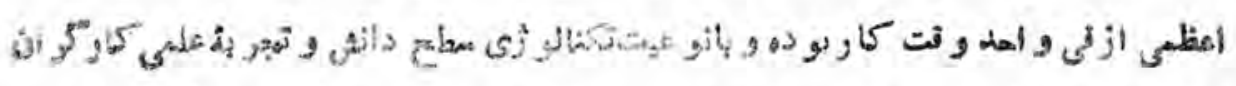

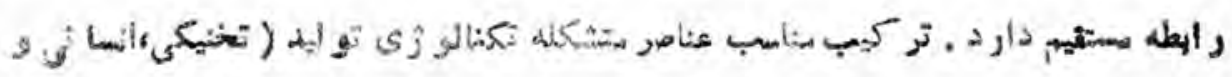

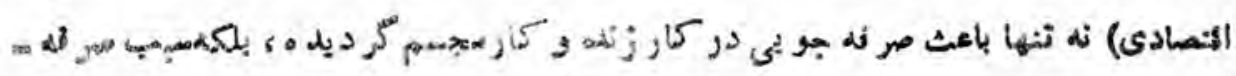

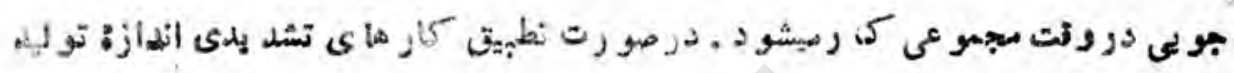

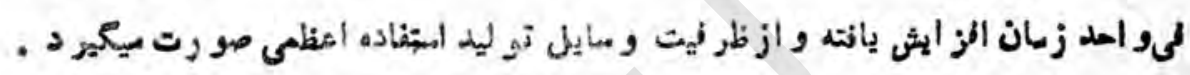

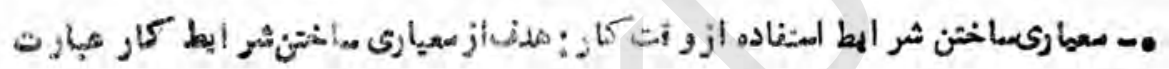

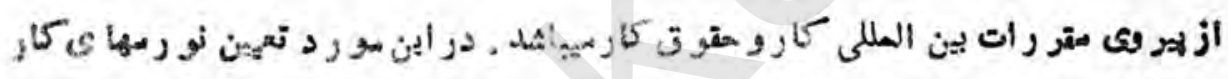

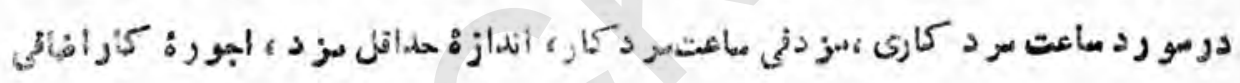

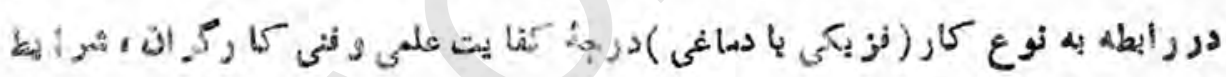

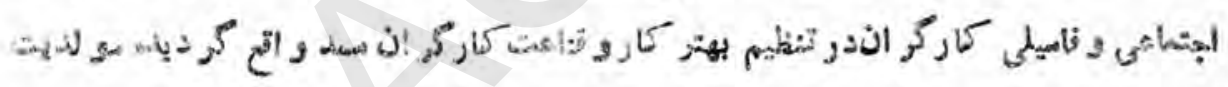

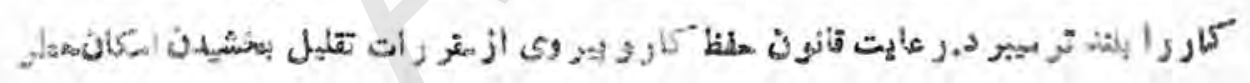

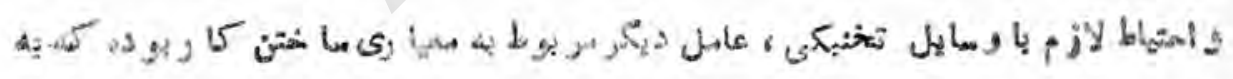

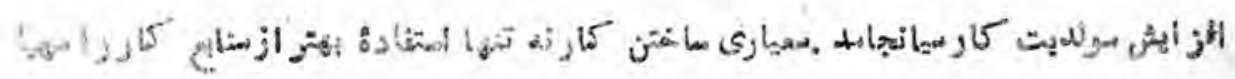

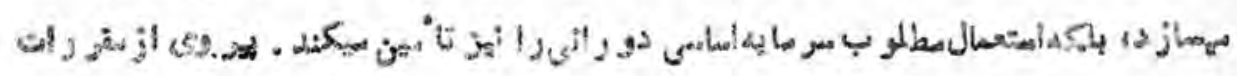

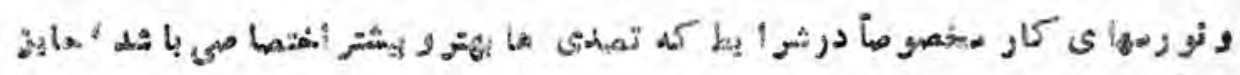

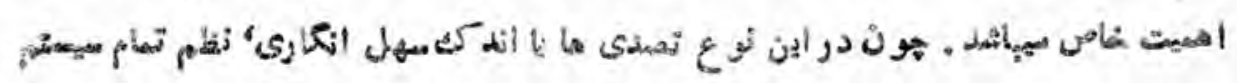

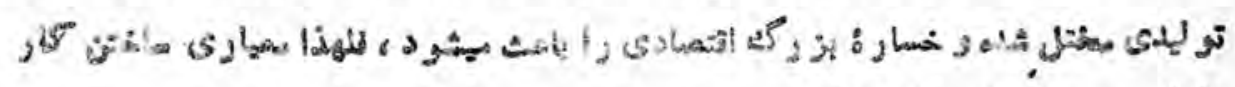

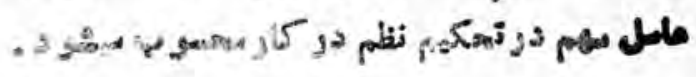




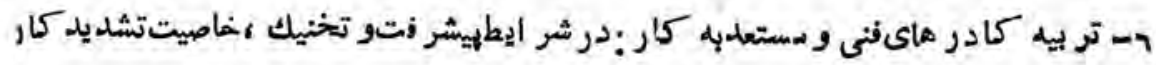

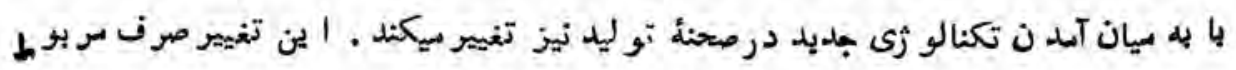
هه انكشاف لزز يكى و 'ير وىعضالت نبو ده، بلكه باا ستعد اد هـاى فكرى و كيفى نيز رابسطه دارد ـ بنابر اين تر بيه كمر هاى فنى و رشهد استعد ادهسا به هنظو ر امتفاده هؤثر از علو م وتخيك بيشر فته و عصرى ع عامل مهم و اسعاسى به شمار سير ود .

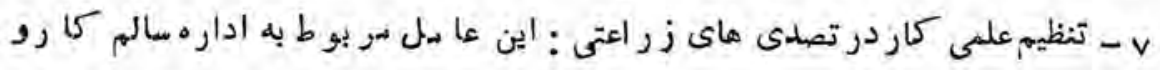

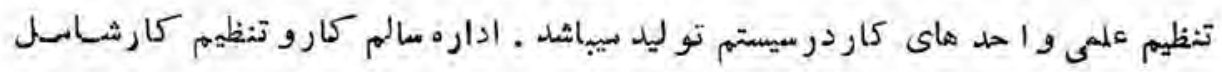

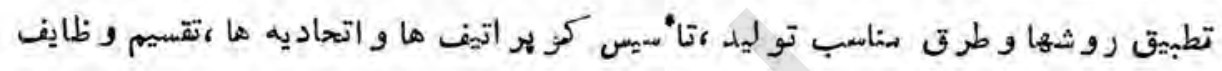

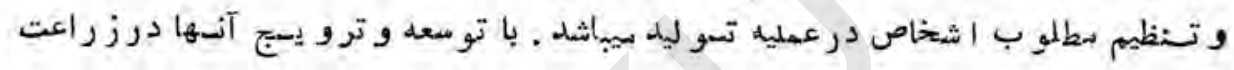

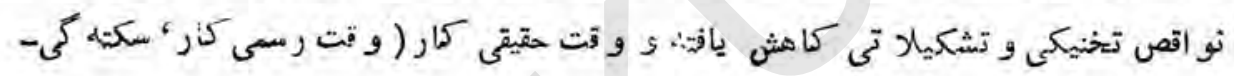

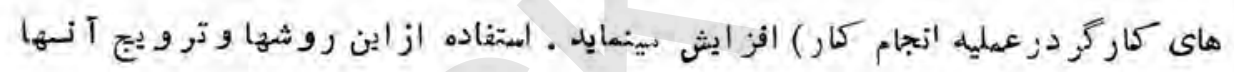
بين دهاقين اسر حتمى درطر يق رشد سو لديت كار مخستو ب بيشو د .

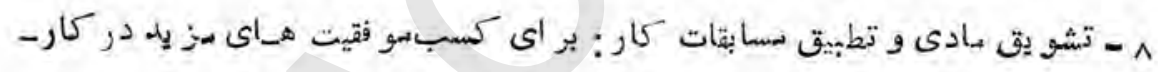

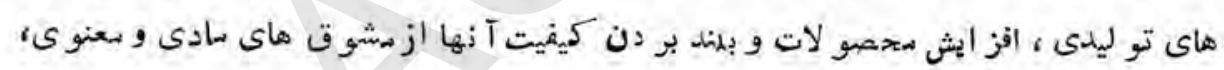

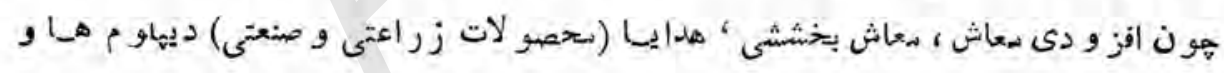

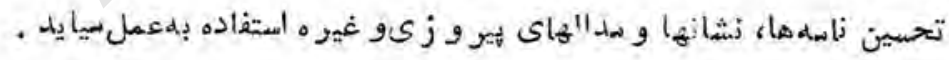
تطبيق سمابقات ك'رعامل د ديكر است كلبه حيث مسشوق كاركر ان و ميحر ك ذوق كار

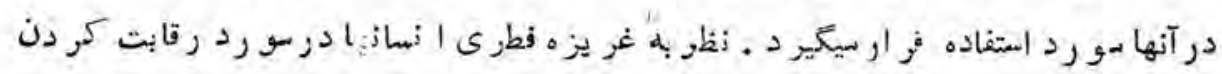

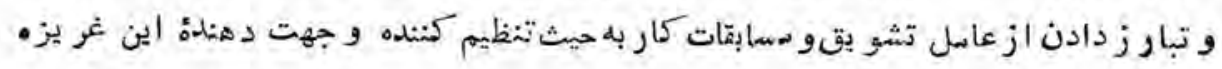

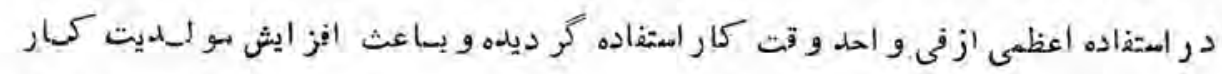

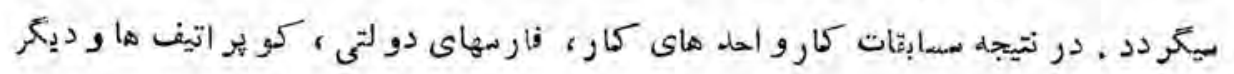




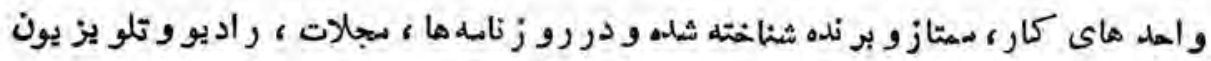

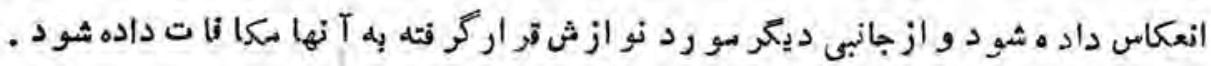

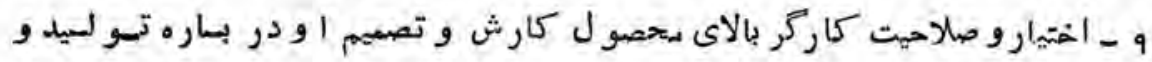
تخهيص هنابع در عمليه توليد عاسل ديكر است كمه بـاءث بلند بردن هو لـديـت كمار و و مخهمو صأباعث بلندبر دن درجه كيفيت محصيو لاتز ر اعتى سيشود د.

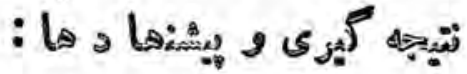

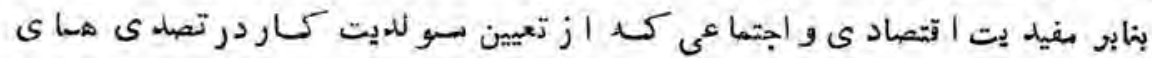

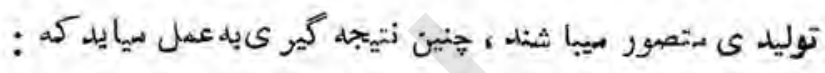

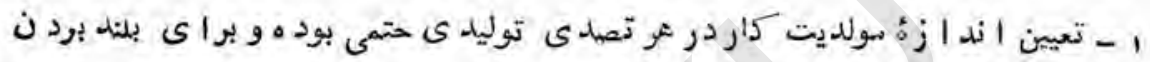

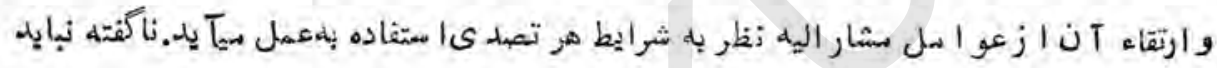

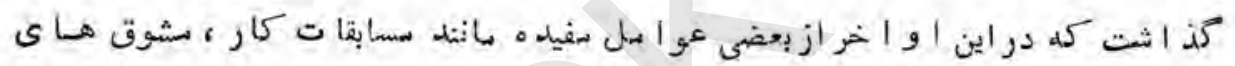

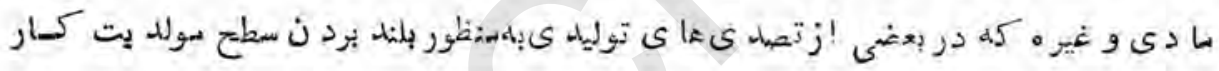

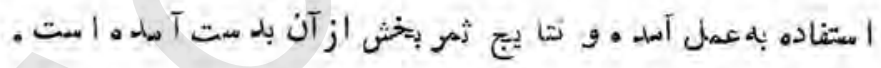

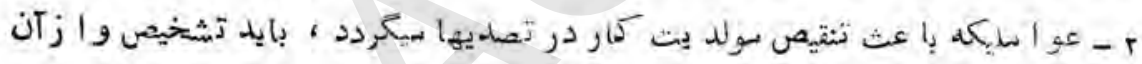
جلو گير ىبله عمل آيل.

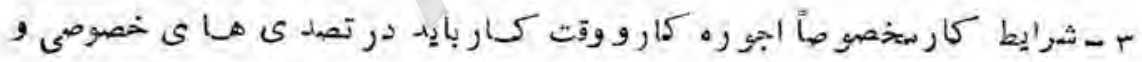

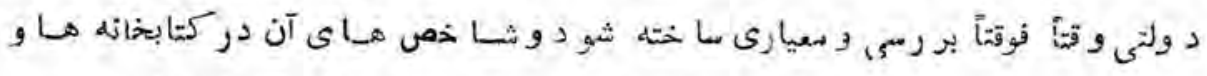

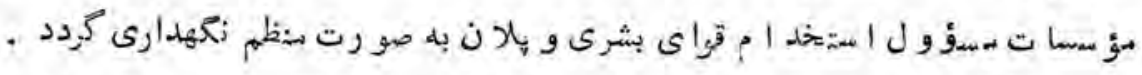

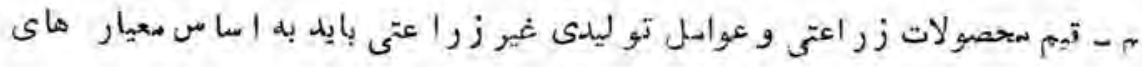

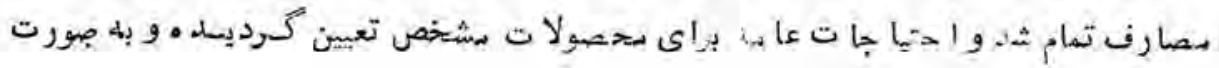
جدى كنتر ول شود . 


\section{REARRENCES:}

1. Debrenin, B.A. and others. Ekonomika Organizas e and Planerovania Fla erovenia Selskokhaziaestvennova Proeizvodstsa.

"Kolos" Moskova, 980. pp. 160, 241.

2. Dobrenin, B.^. Ekonomika Selskovokhaziaestva " Moskova, 978. pp. 171-74.

3. Emelinov, A.M. Ekonomika Selskovokh iaestva. Ekonomika 198?, p. '86.

4. Marks, K. and Angels F. vol ' $5,6, ; 69,86$.

5. Copovich. E. B. "Ekonomika Selskovokhaziaestva" "Kolos" Moskova, 975, pp. 54, 49.

6. United Nations i L O. Measu ing Labor roductivit, inetrnational Labor Office, Geneva, 969, p 18,37 . 
دازش ، شماره تيخجم ، ميال ب דبr

لو هاند د كتو ر احمل رشاد روشن

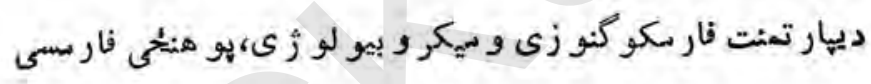

\section{تحقيق فارمكو كنوستيك نبات بوى مادراث شش ناحية افغانستان}

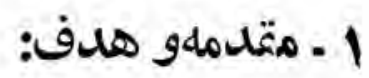

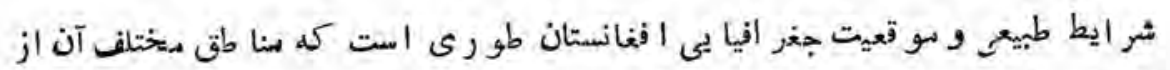

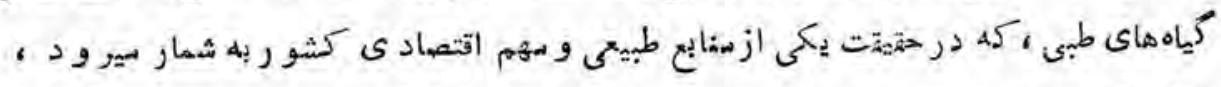

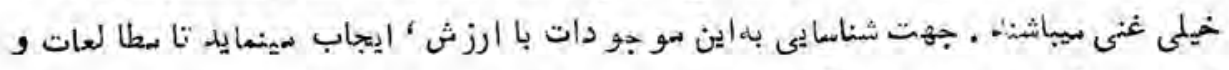

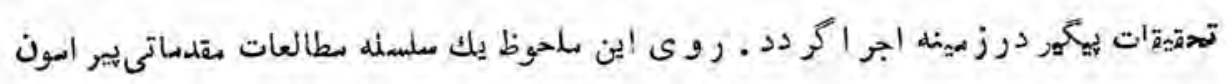

$$
(\wedge \kappa)
$$


واتات الغانستان تو سط دانشمندان خارجى (0)و افغانى انجام شده امت؛ إسا درمو رد نباتات طبي انغانستان سطالعات بسيار ريحدو د صو رت كر نته اهت ـ بنابر ان ، تعداد ز يادى از نباتات

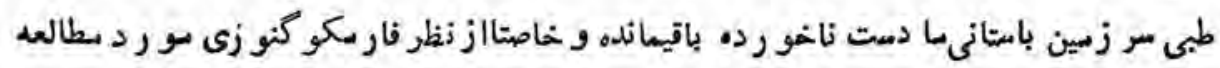
تر ارنكر فته اند.

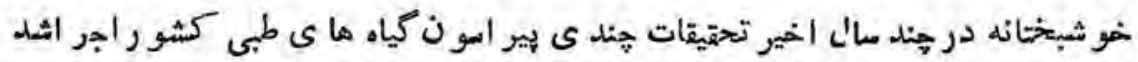

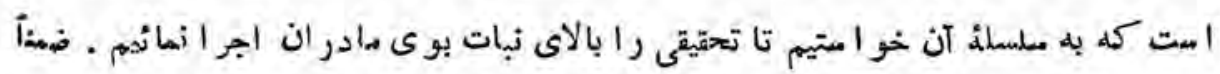

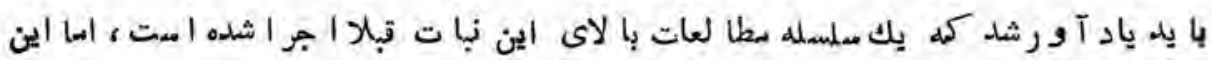

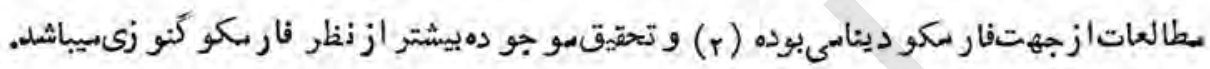

\section{ن}

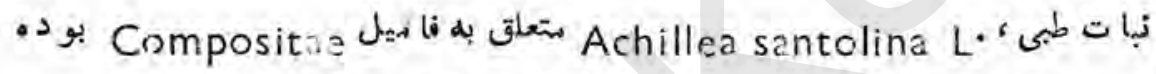

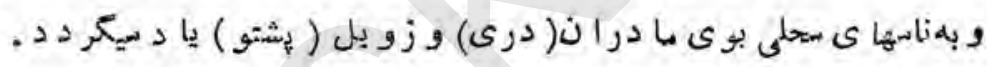

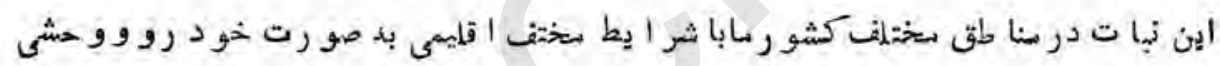

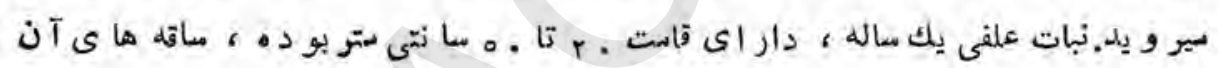

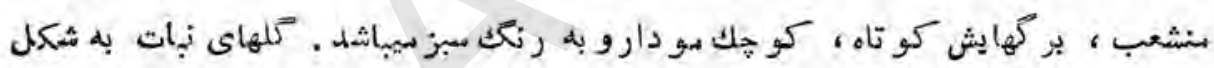

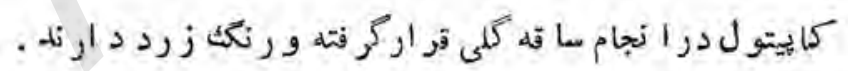

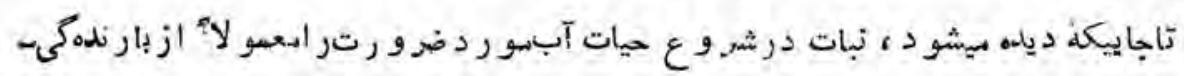

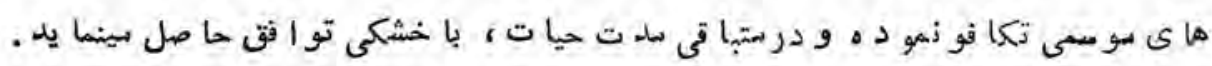

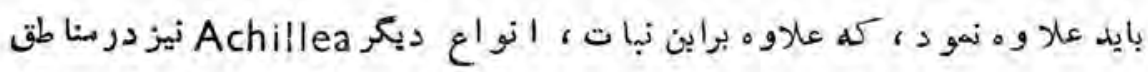

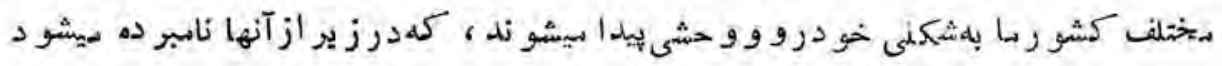

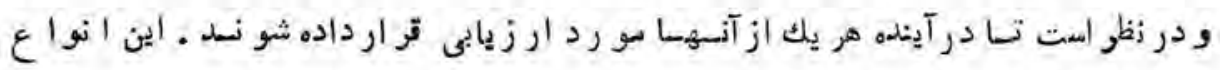

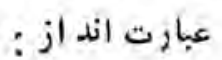


( : دركندز(. Achillea biebrsteinii Afan

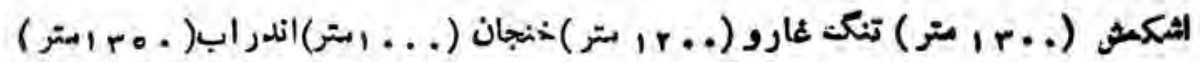

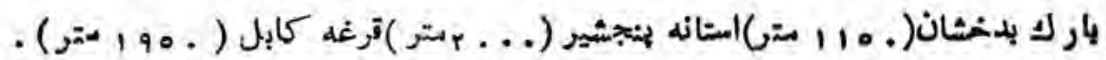
بد خشان (. Achillea filepondula Lam كندهار ( Achillea Lebtnpinylla A itch (: Achiliea micranta wild(MB) (ه : Achillea millifolium !.

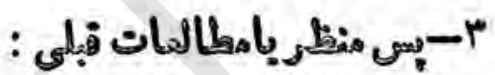

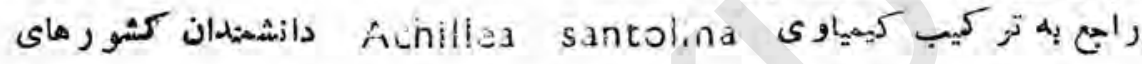

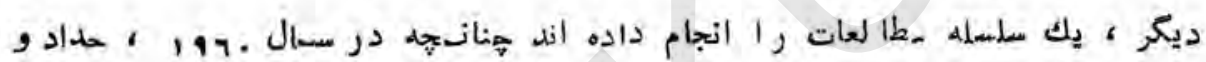

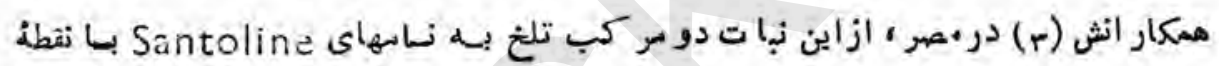

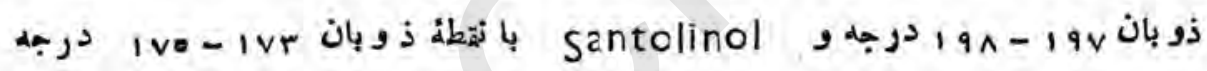

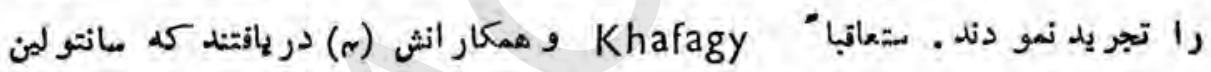

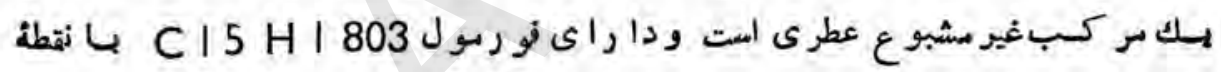
ذو بان بتذ كر ه بيباشد.

در كشو رما تحقيقاتعلدى هله جانبه از نظر فار مككوكنو زى بالاى بو ى مادر انصو رت

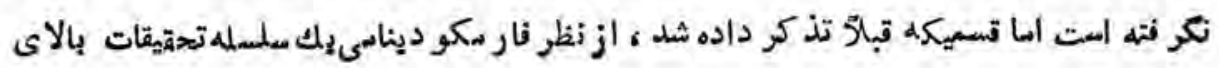

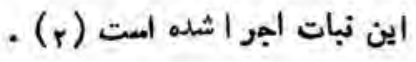

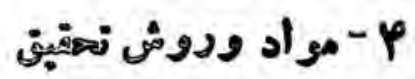

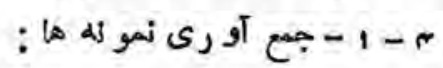

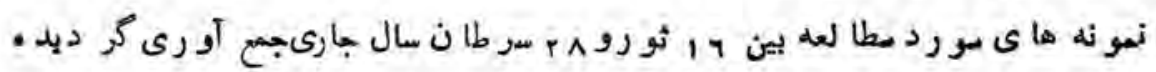




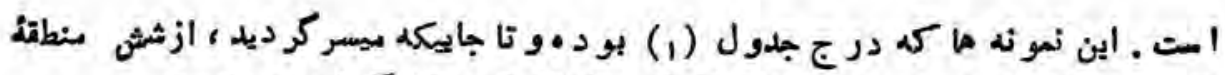

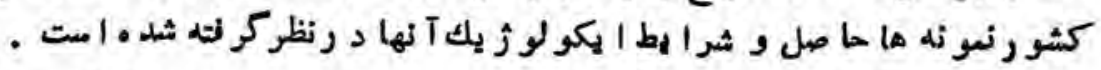

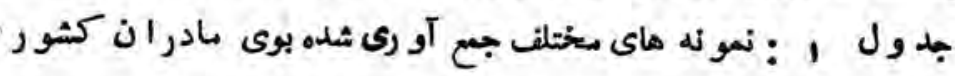

ثرا بط ا يكو لو ز يك

$$
\text { ازمطاع بحر به هتر }
$$$$
\text { مسمل جمع آورى }
$$

نمو نه

زمينها ى مز روعى - مد ثمت

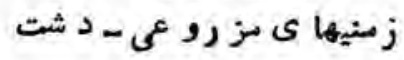

$$
\text { د شتح تهنه }
$$

زمين هاى مزرو عى ـد شت لت

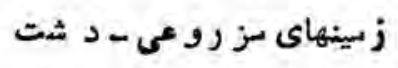

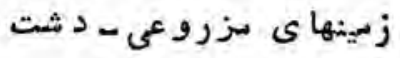

110.

r...

ryas

$17 .$.

$1+7$.

190.

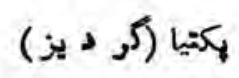$$
\text { با بيان }
$$$$
\text { بند المير }
$$

مر ب

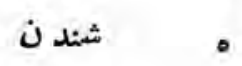

قر غه كا بل

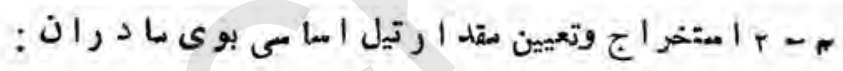

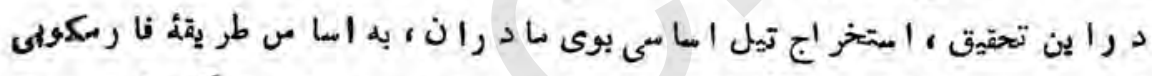

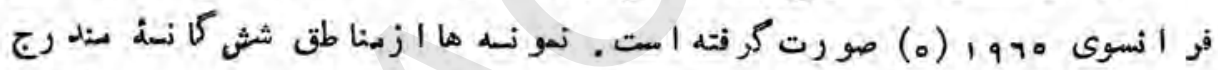

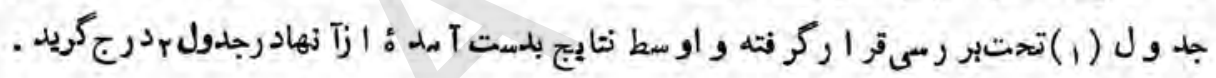

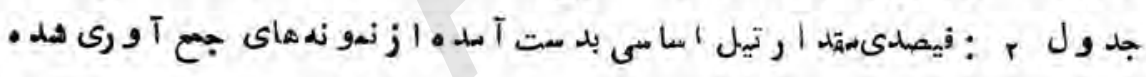

| اوسط فيصلى مقده ا رتيل اساسى

$$
\begin{aligned}
& .11 \\
& .11 \\
& . / 40 \\
& .11 . \\
& .1 \% \\
& .10 .
\end{aligned}
$$

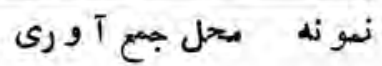

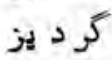

با ميان ل

م ات مر ات

بند اسير

مر غن كا بل

يو ه:تون كا بل

$$
\text { i }
$$




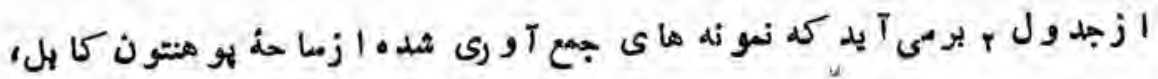

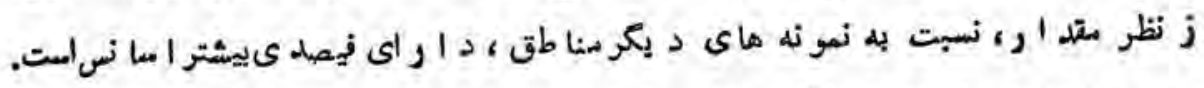

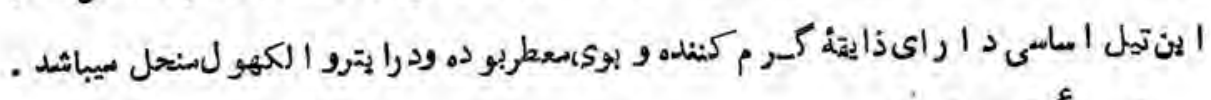

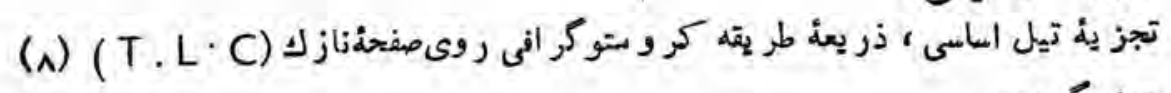

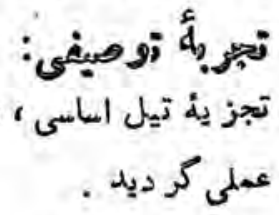

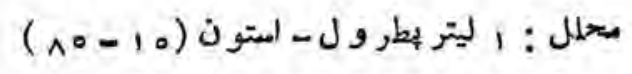

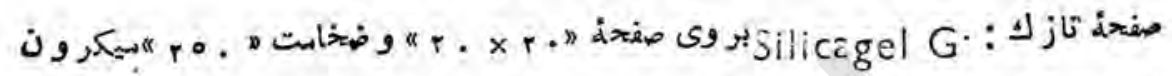

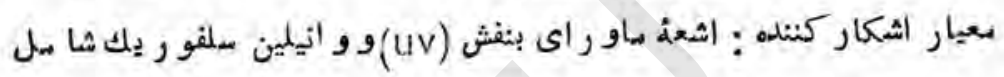

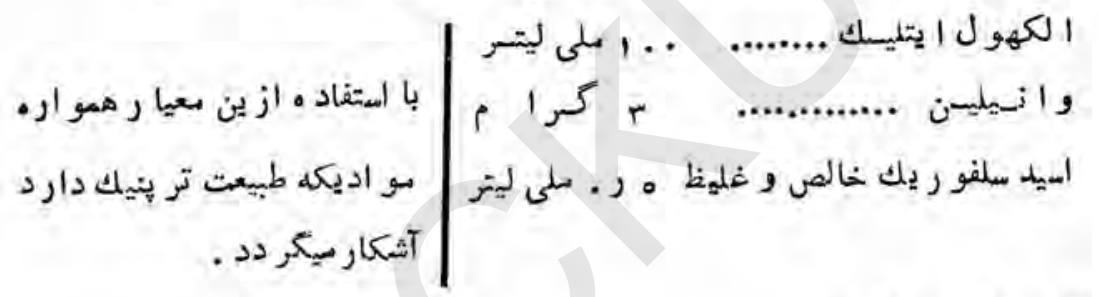

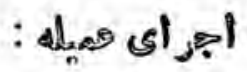

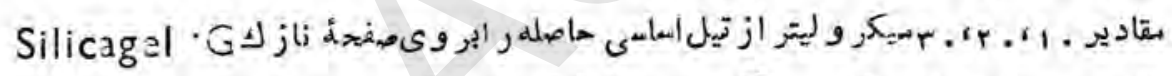

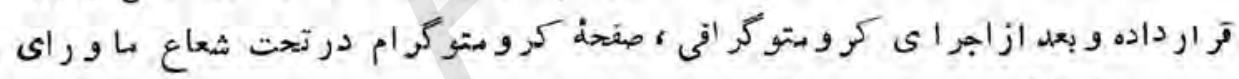

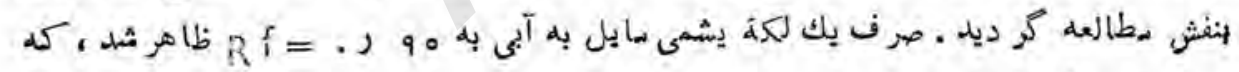
هنو زمجهو ل باقيمانده است.

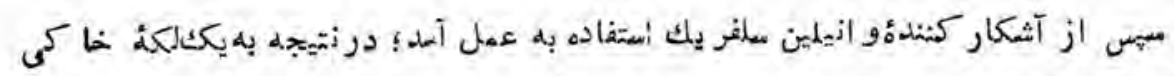

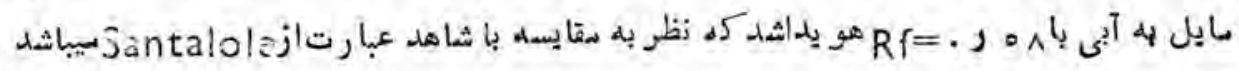

$$
\begin{aligned}
& \text { ت }
\end{aligned}
$$

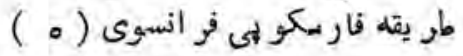

$$
\begin{aligned}
& \text { اوسط حاصله : : } \\
& \text { (^^) }
\end{aligned}
$$


T- تميين مقدار حاكستر

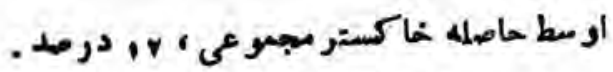

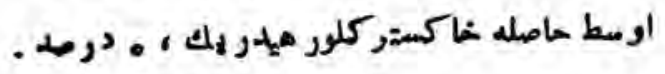

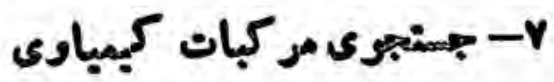

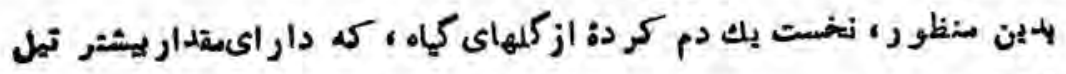

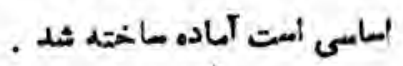

1 ن

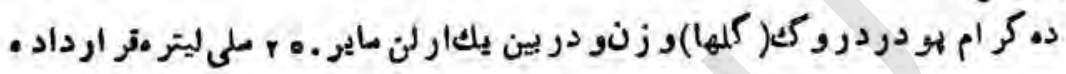

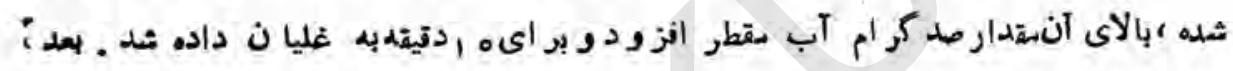

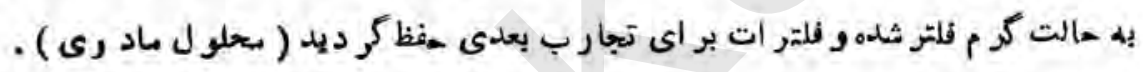

- - - جستجوى لو كوانتوسيا نها: (

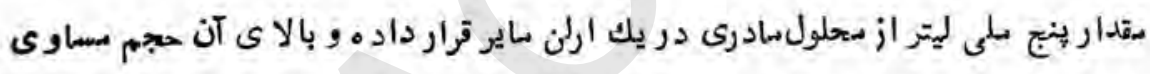

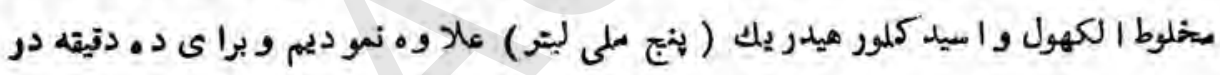

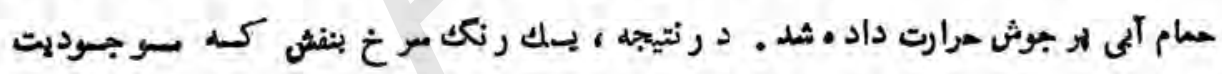

Leuco-onthocyanes

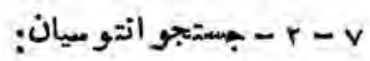

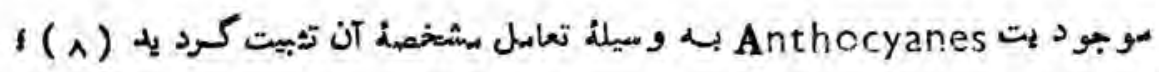

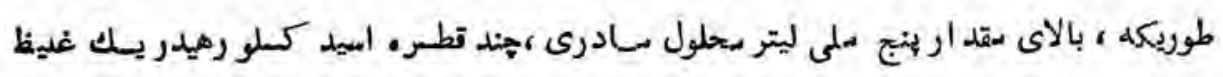

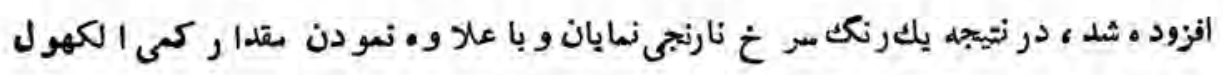

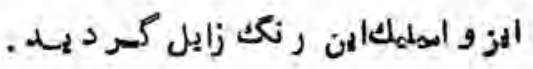

(A) 


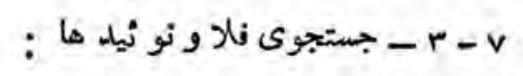

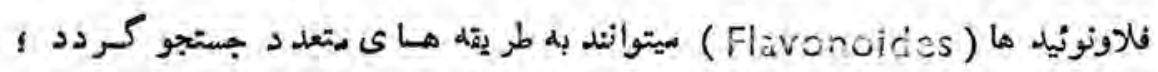

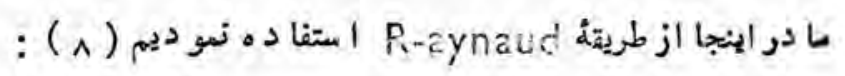

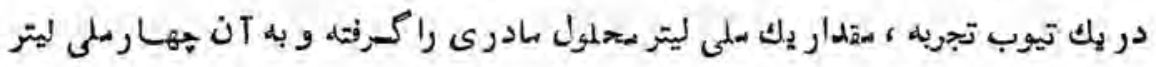

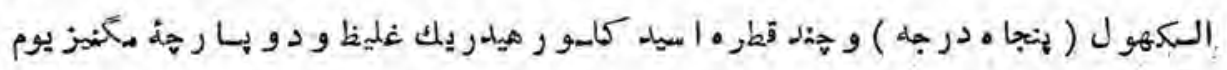

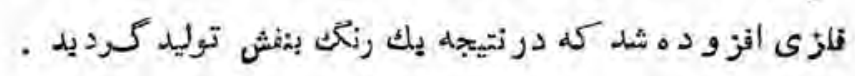

$$
\text { : }
$$

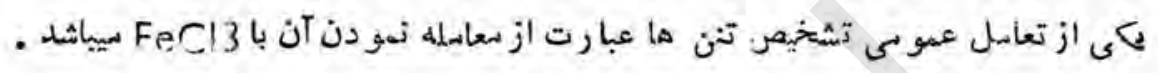

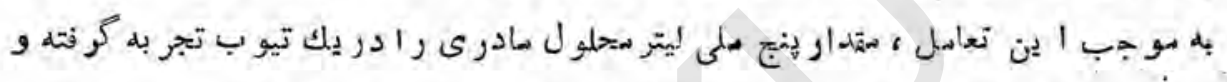

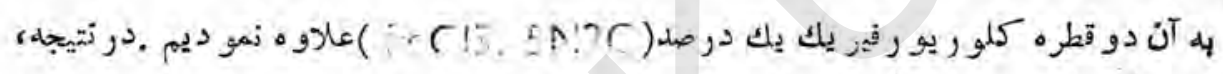

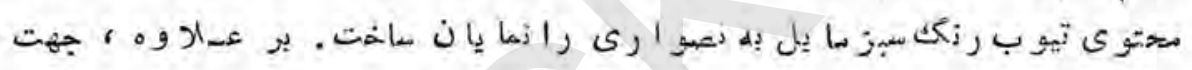

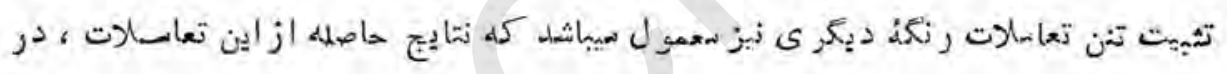

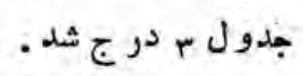

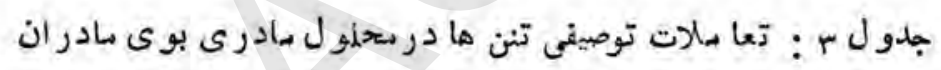

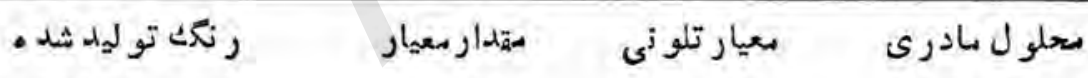

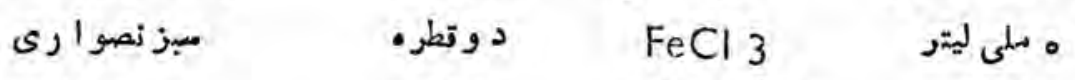

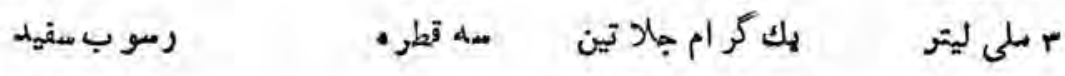

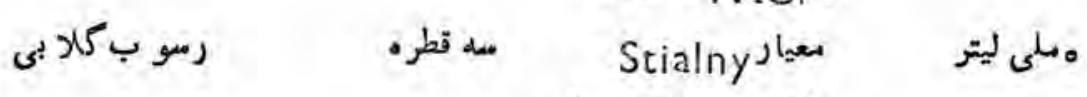

$$
\begin{aligned}
& \text { (دوحجنم فو رمول) } \\
& \text { ( }
\end{aligned}
$$

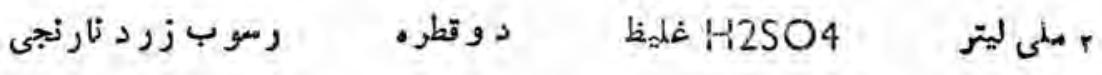




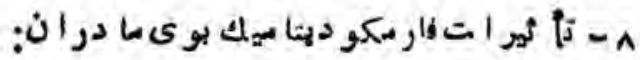

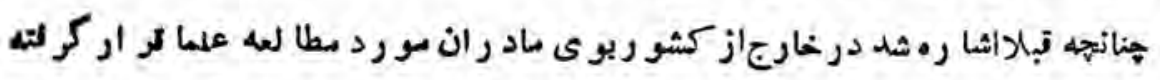

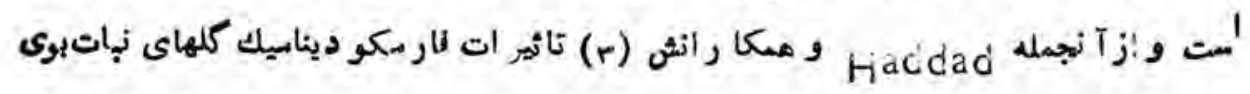

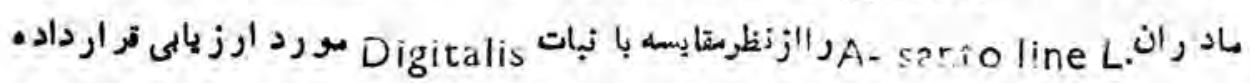

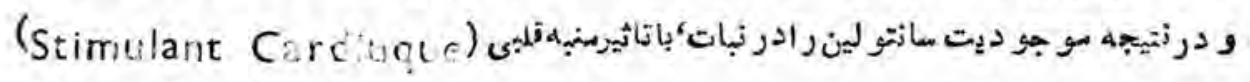

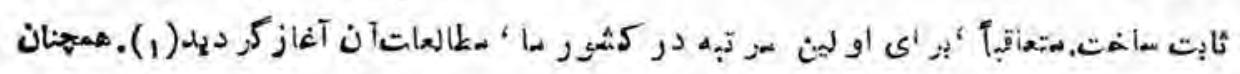

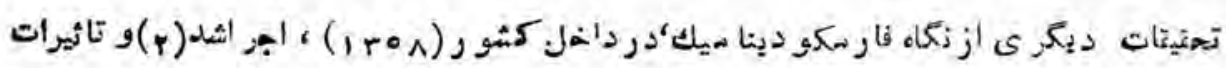

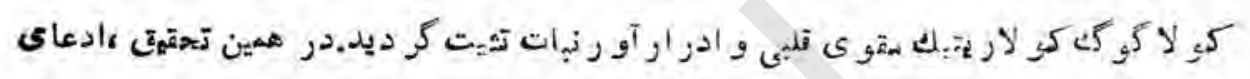

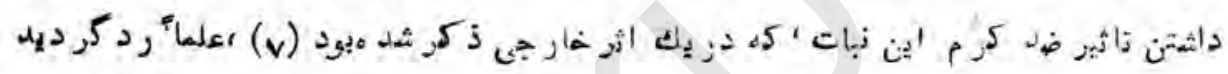

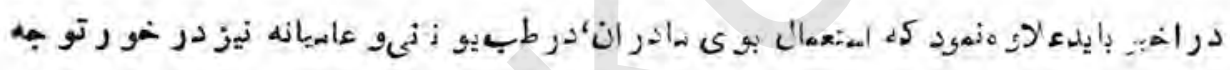

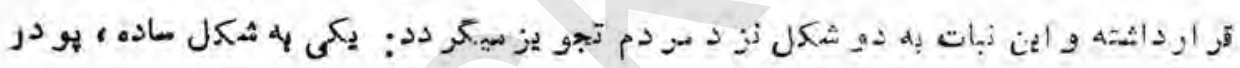

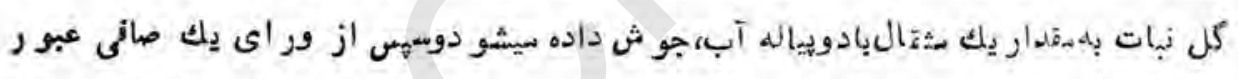

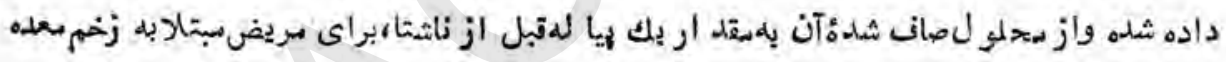

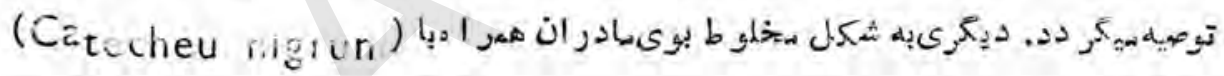

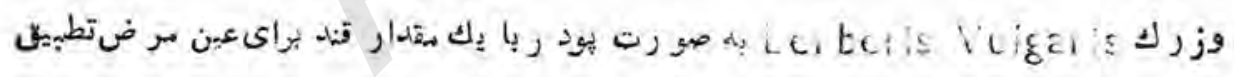
سيشود د.

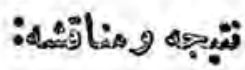

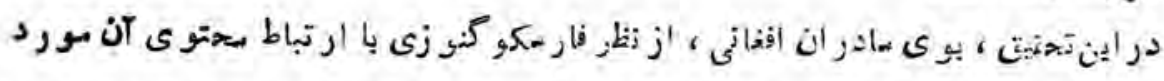

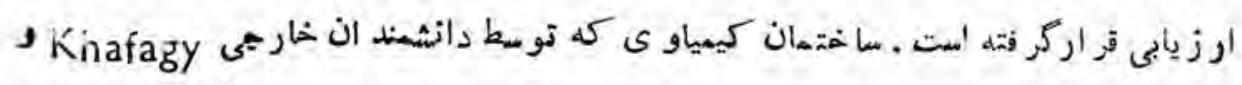

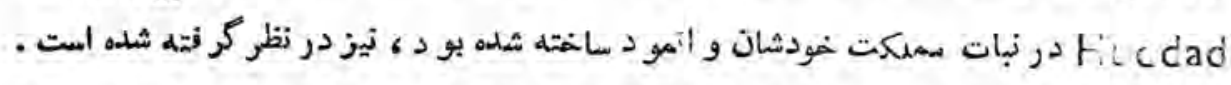

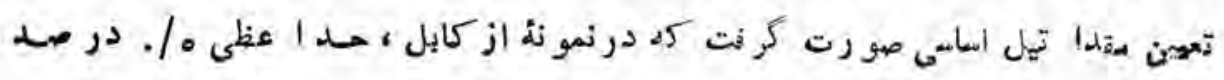




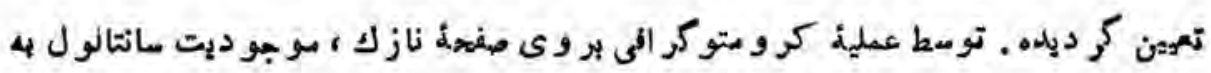

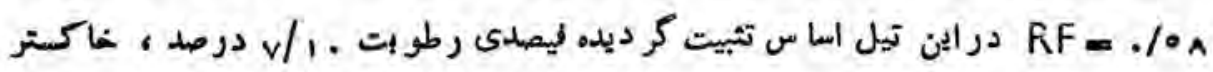

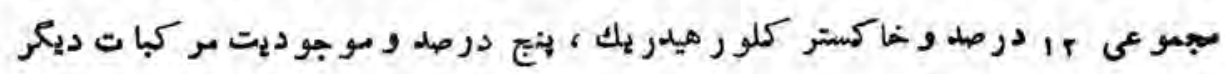

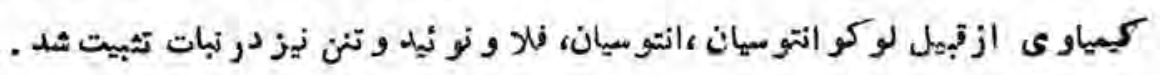

\section{REFERENCES}

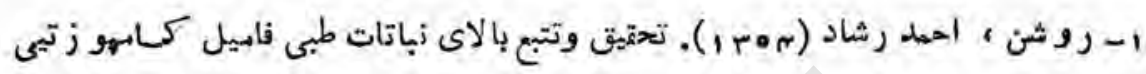

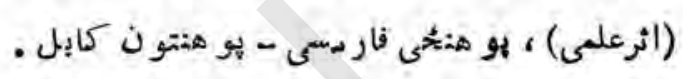

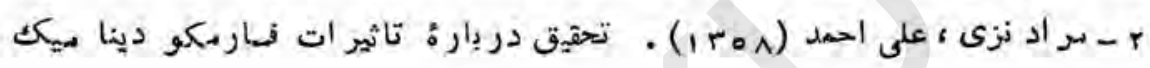

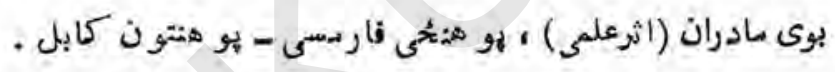

3. Hacdad D.Y. Khafayy S.M. and Faxatin 1. (1960). J. Pharm. sci., United Arat Republic Vol. 75, quoted From Annual Index of the reports on plants chemistry in 1965, PP. $45-50$, Birokawa Pub. Co. Tokyo Japan, 1967.

4. Khafagy S.M., Lilda A.M., Fatatry E.L. and Samir A., Prilliminery Caracteresa of Santoline, bitter principle of Achillea Santolina L. growing in egypt, after C.A. Vol. 64, No. 7. 1966. 9997 c.

5 Kitamura S. (1960). Flora of Afghanistan, Kyotu University Publ. 6. Pharmacopee Francaise, (1965), VIII edition, Paris.

7. Pelt J.N., Hayon J.C., Younus M.S. (1965): plantes medicinales et drogues, Bull. Soc. Pharm. Nancy No. 66, 16-61.

8. Randerat H.K. (1966). Thin Layer Chromatography sec. ed., Gaucier Villars, Paris. 
9 Raynaud Y., (1970). Contribution a l'etude batanique et bloshemilque Anemone hepatica L., Lyon.

10. Rechinger K.H. (1955). Symbolae Afghanicae. Compositae. Tom II,

II. Unani system of medicin In India, (1987). Central Council for research in Unanl medicin Rakmo enterprise, Naiwara, New Delhi. 


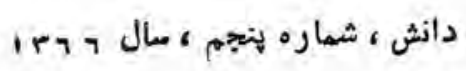

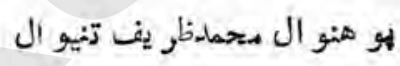

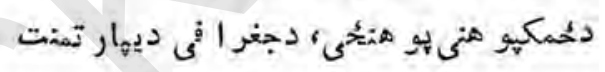

دننكر هارولايت دير اختيايى مروزى خيرنه

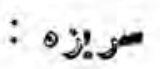

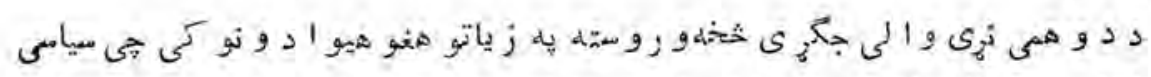

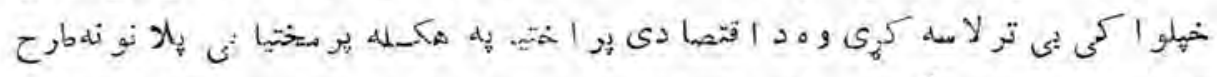

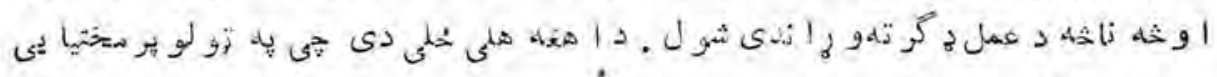

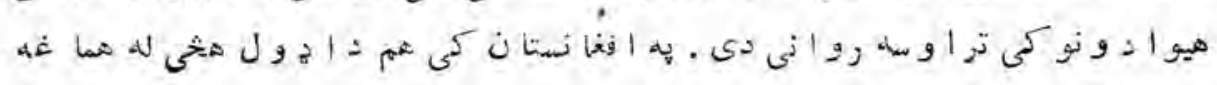

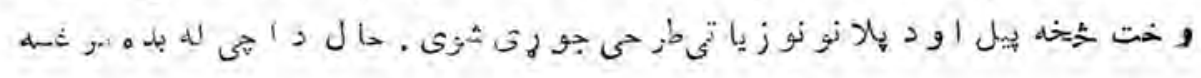

$(9 \pi)$ 


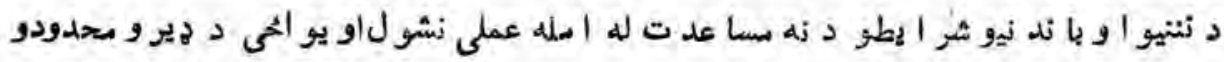

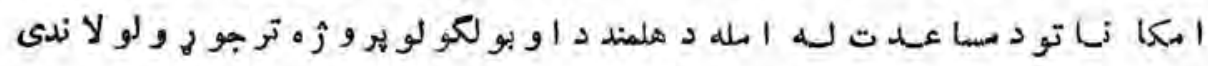

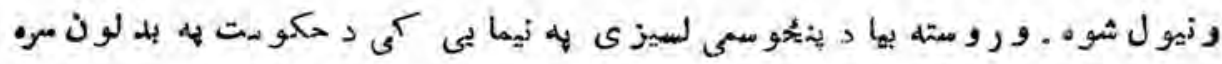

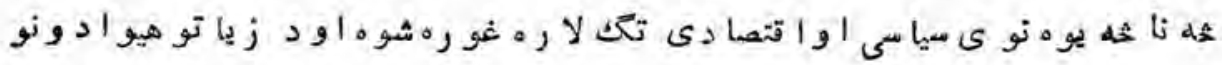

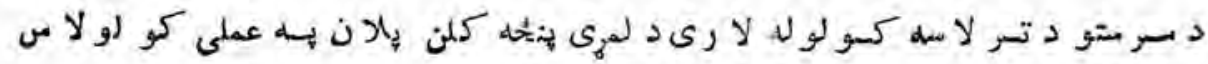

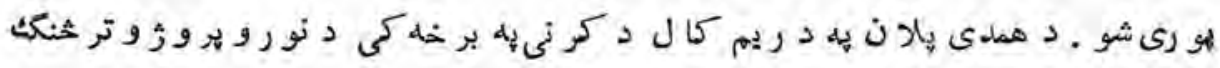

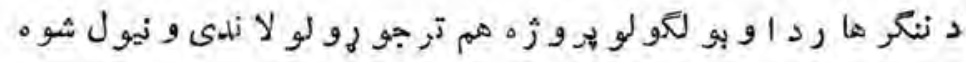

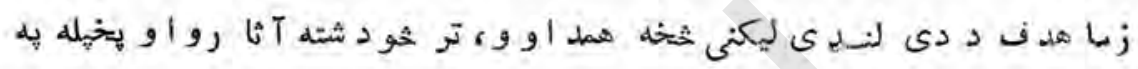

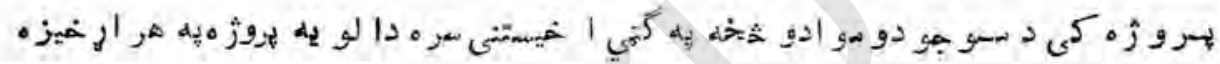

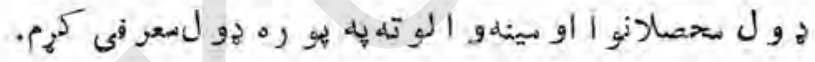

\section{:}

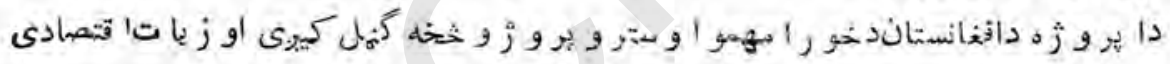

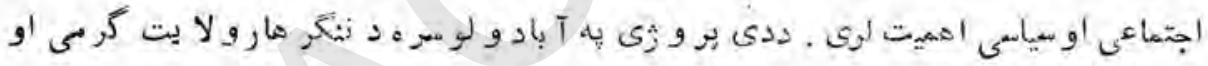

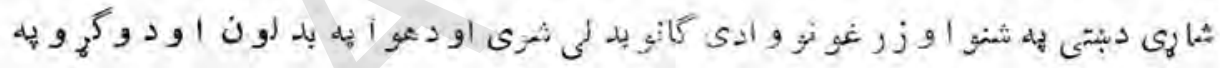

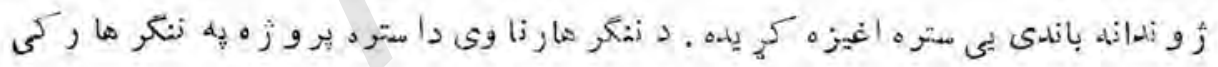

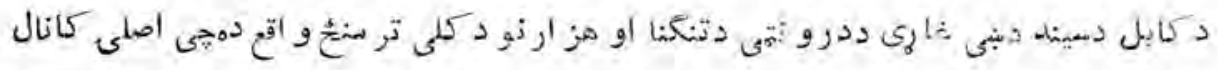

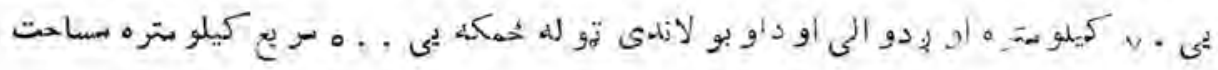

$$
(r-q r) \mathrm{s} J
$$

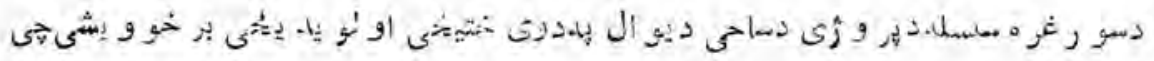

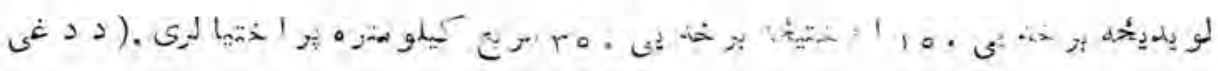

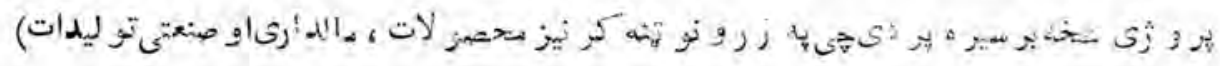




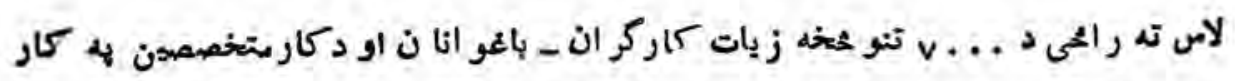

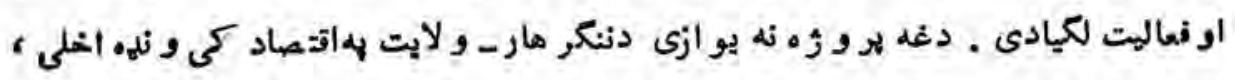

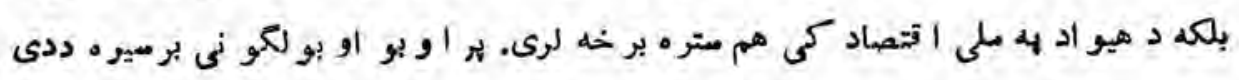

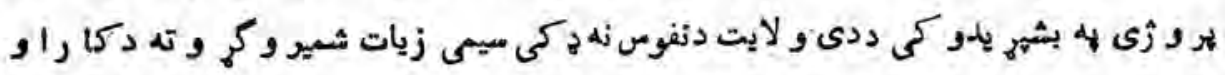

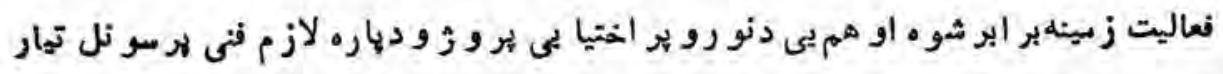

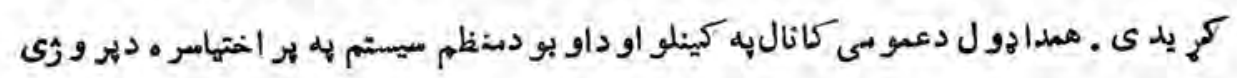

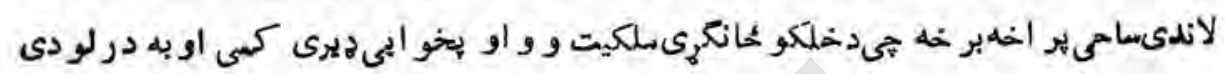

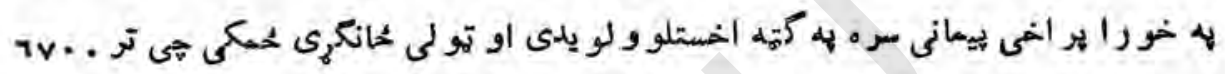

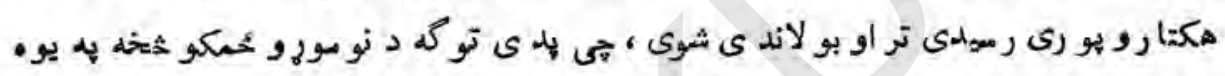

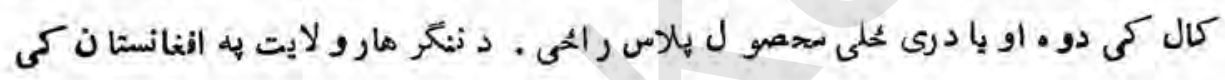

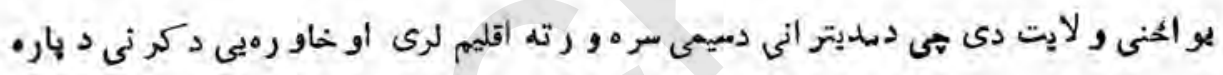

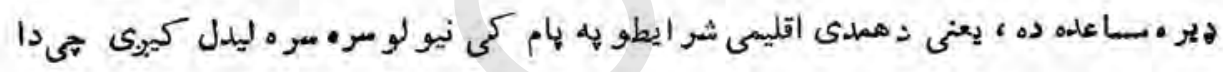

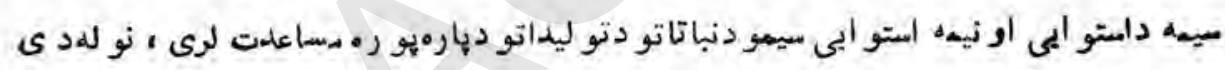

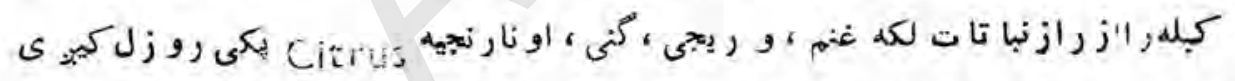

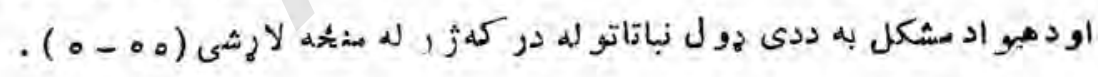

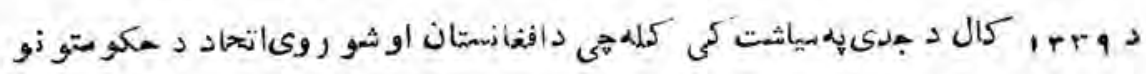

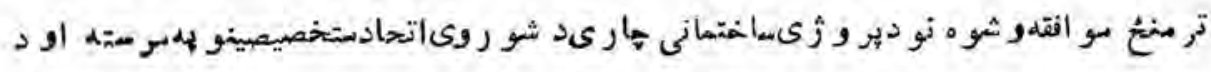

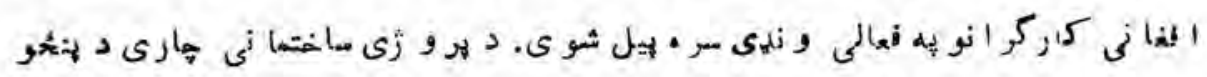

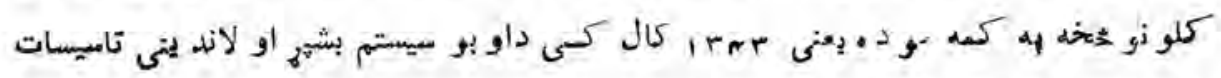
: vos 


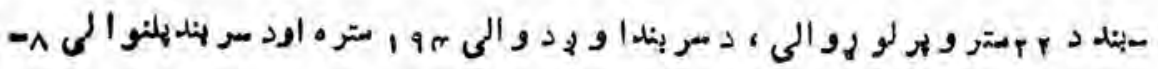

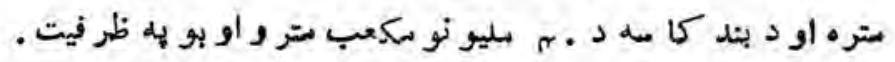

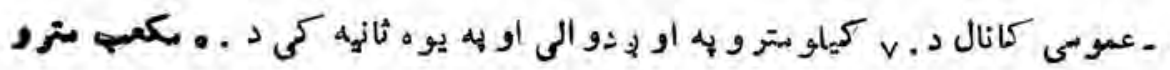

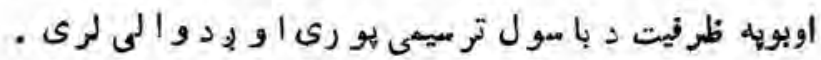

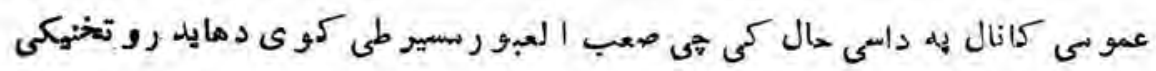

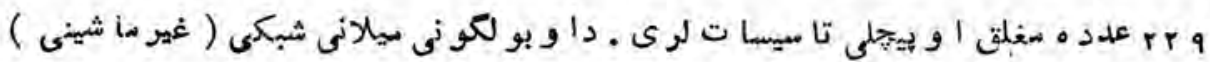

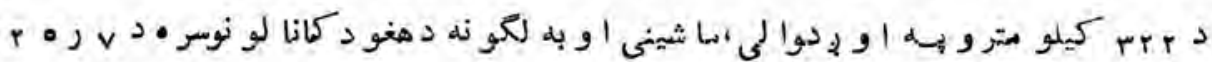

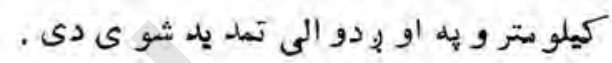

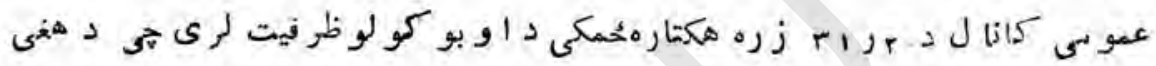

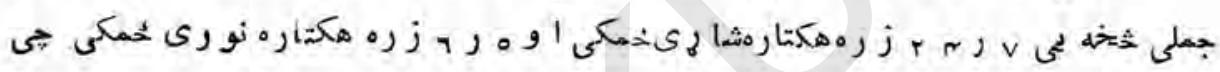

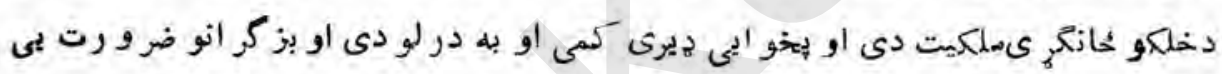

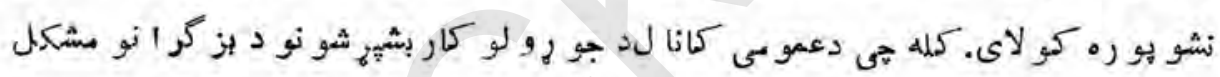

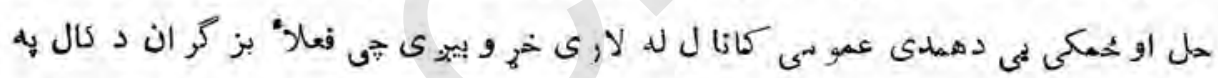

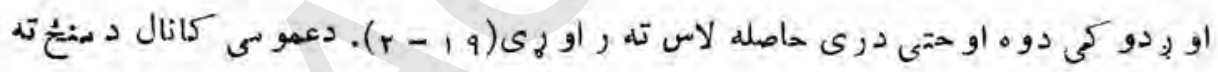

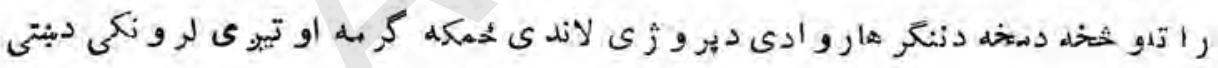

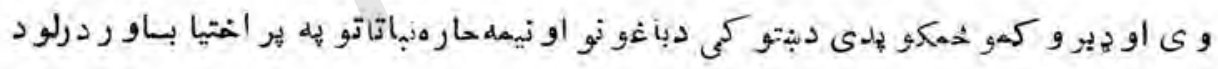

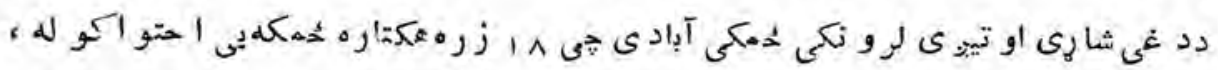

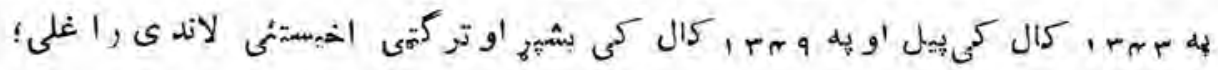

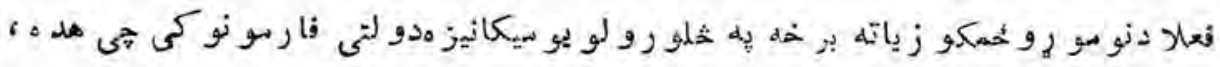

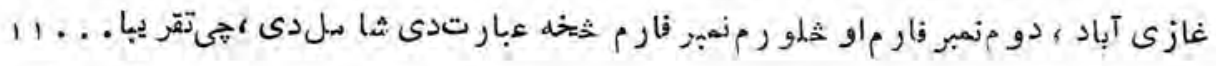

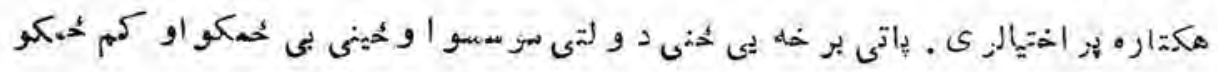




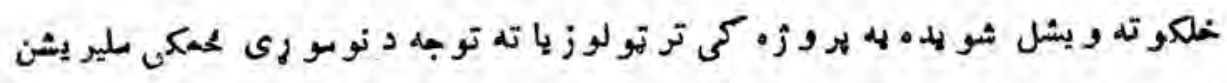

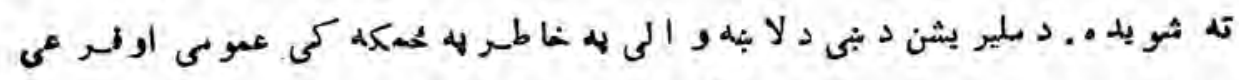

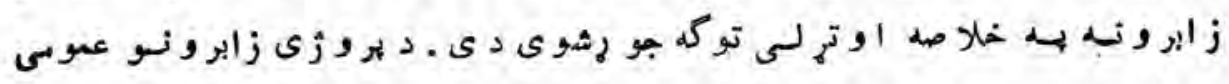

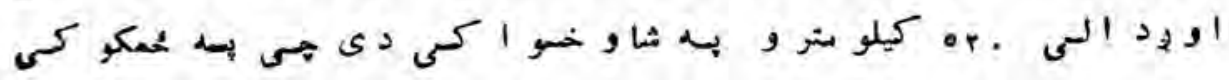

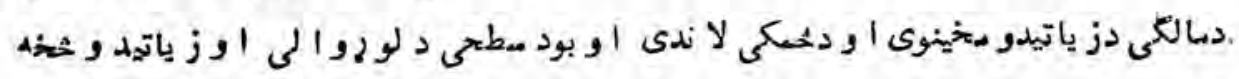

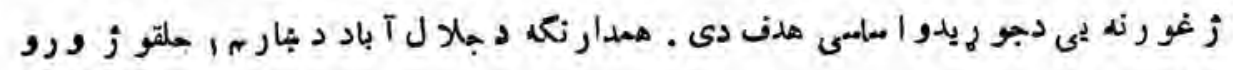

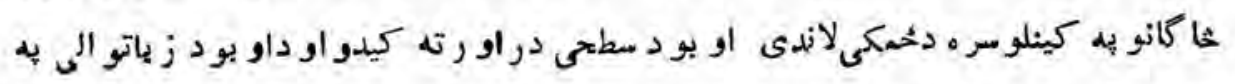

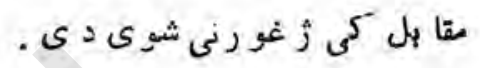

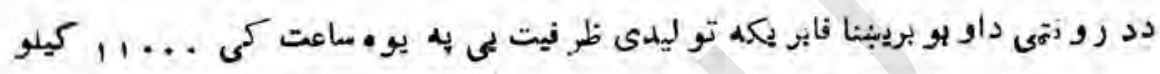

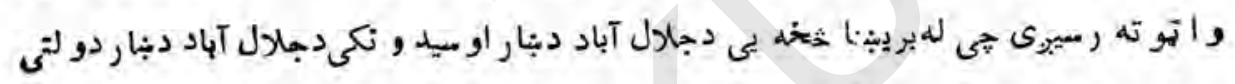

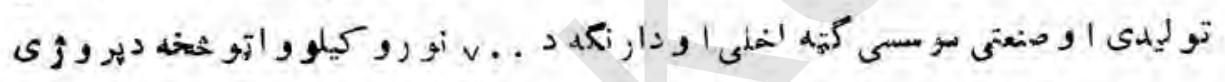

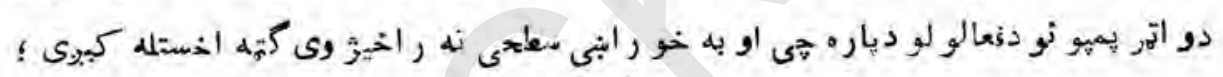

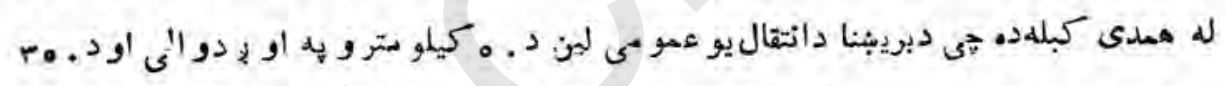

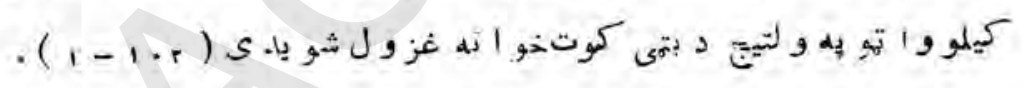

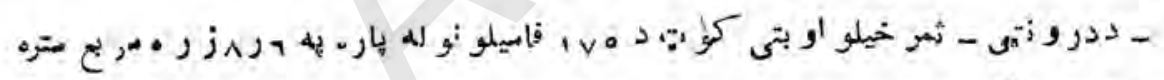

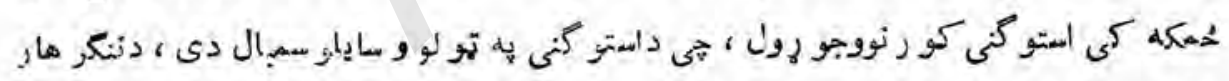

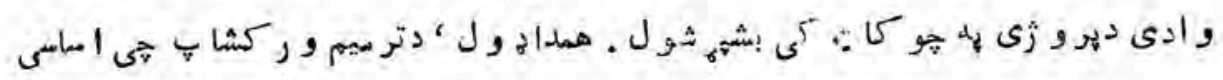

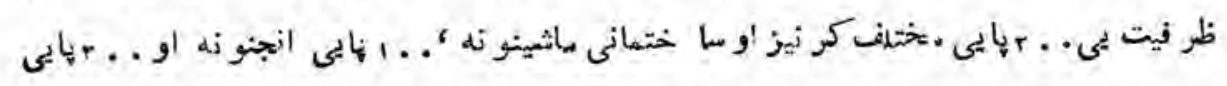

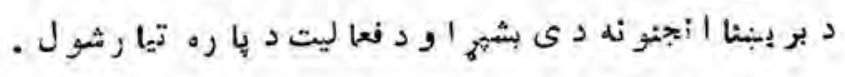

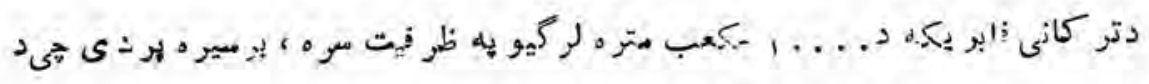

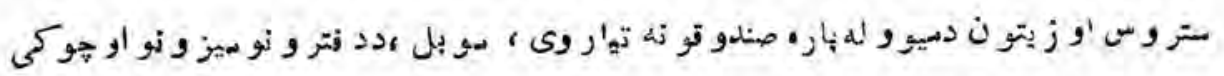




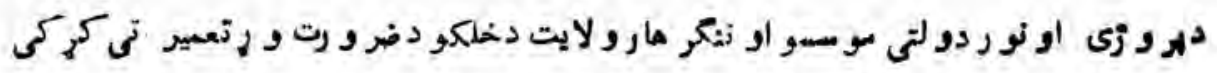

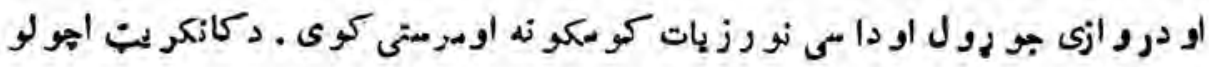

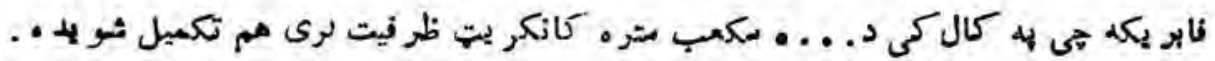

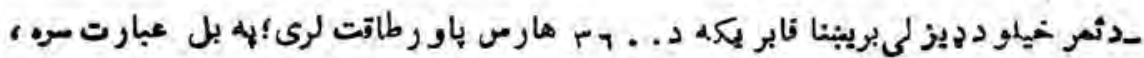

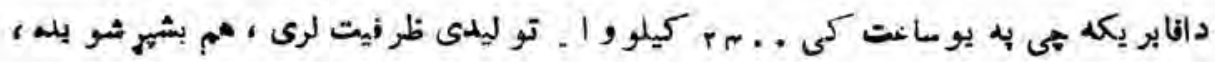

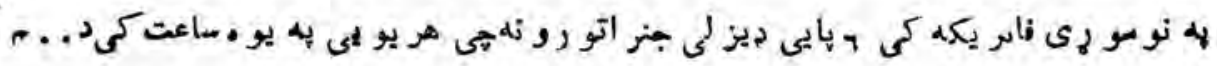

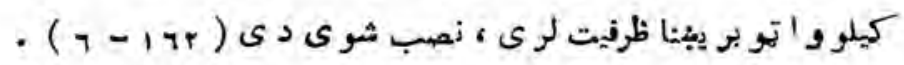

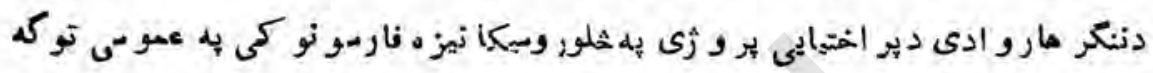

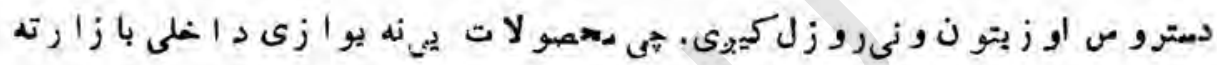

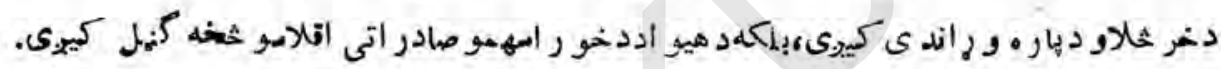

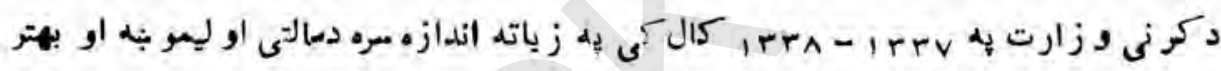

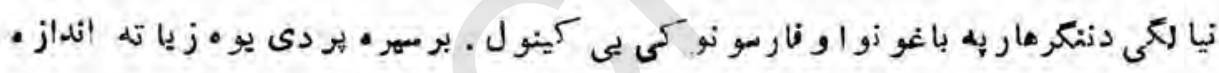

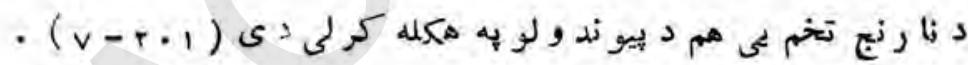

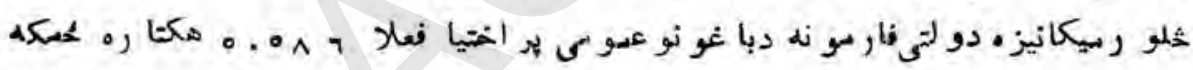

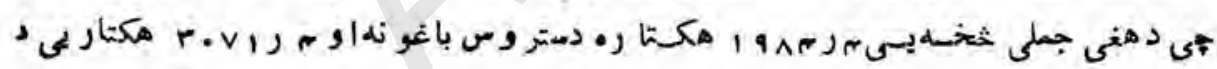

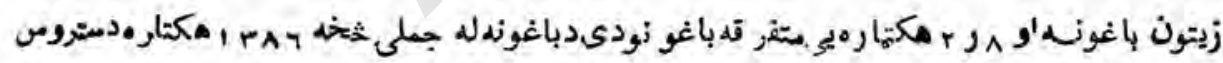

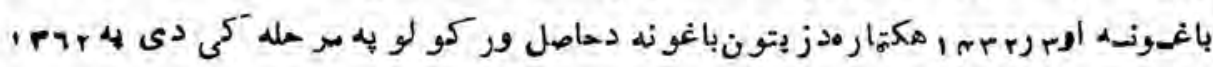

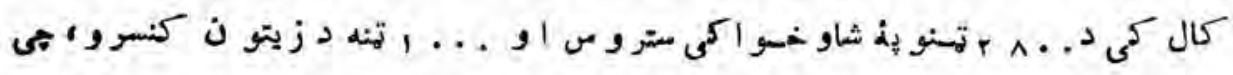

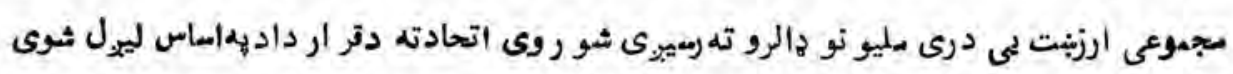

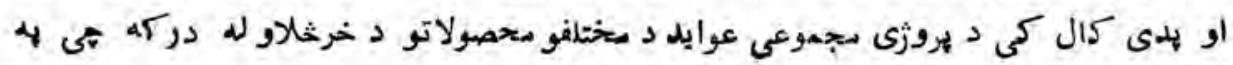

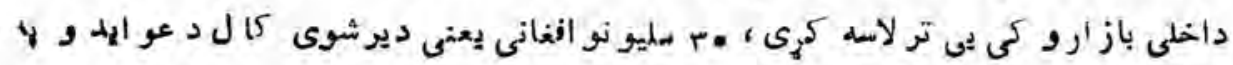

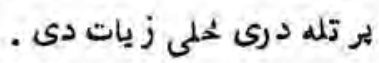




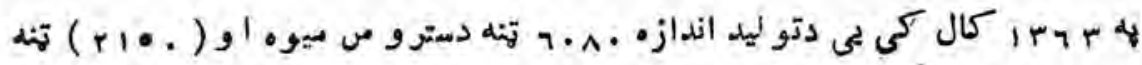

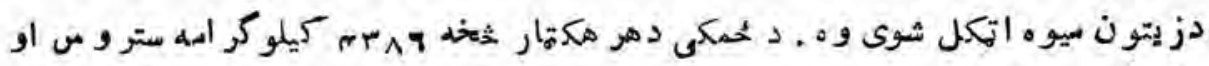

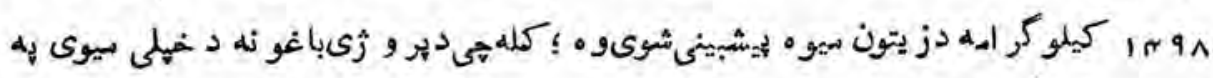

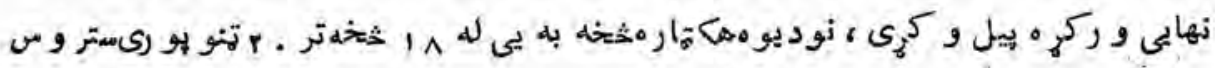

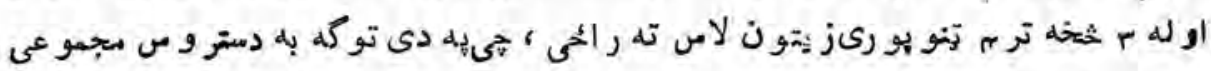

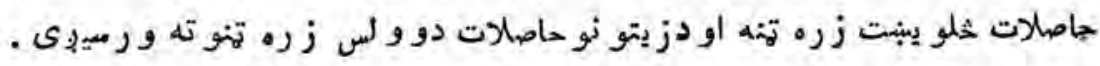

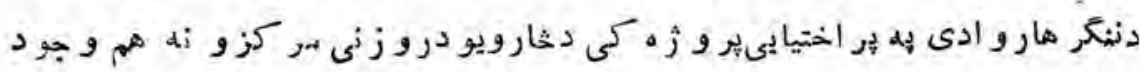

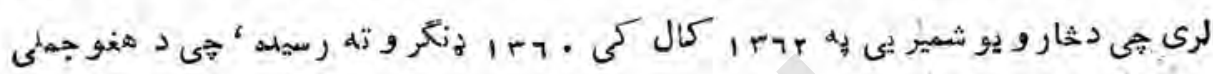

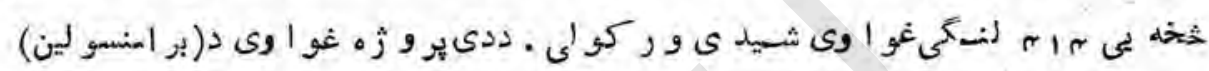

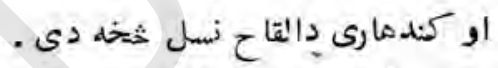

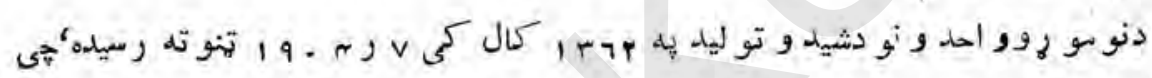

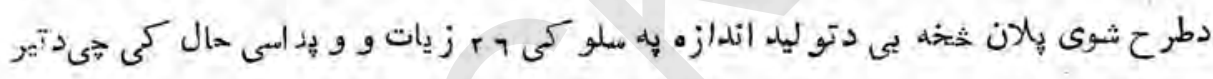

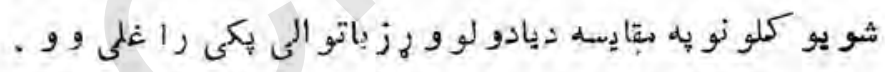

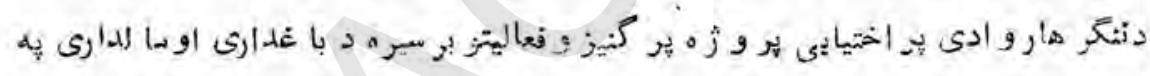

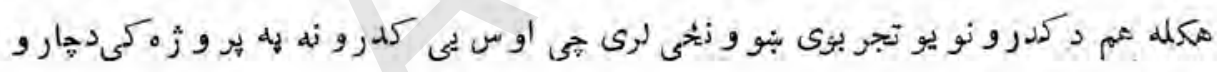

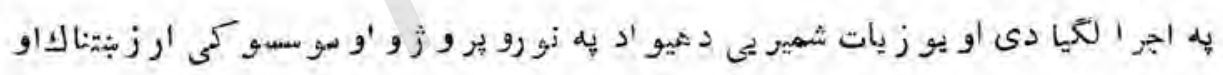

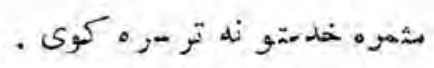

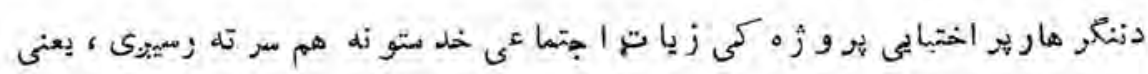

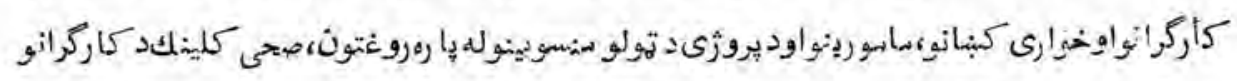

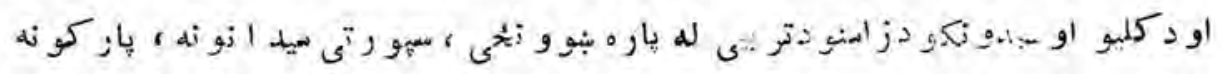

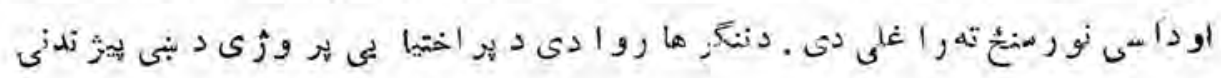

$$
(1,)
$$




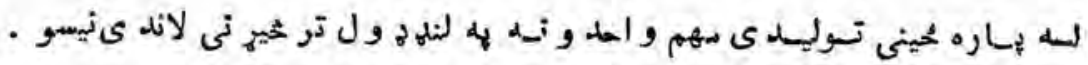

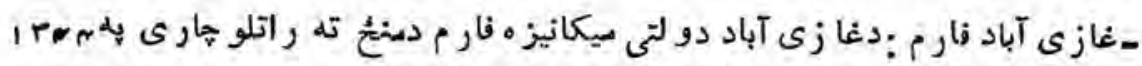

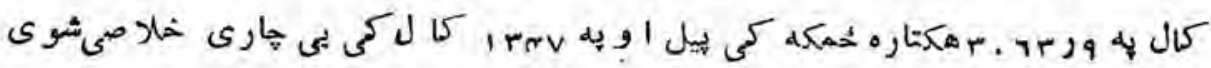

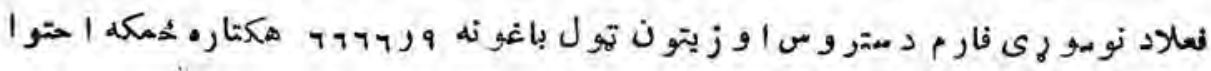

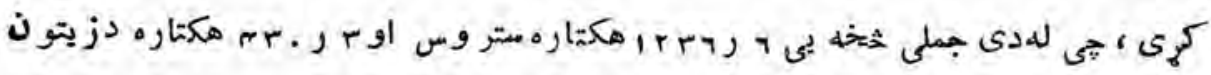

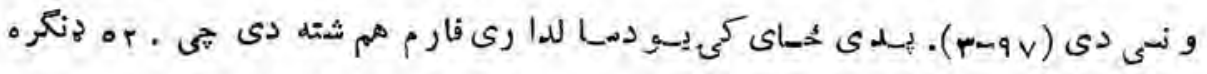

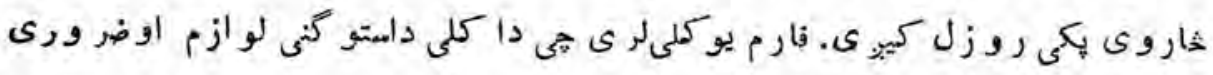

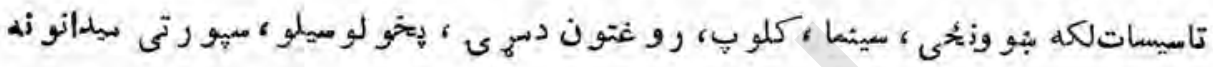

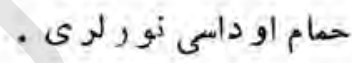

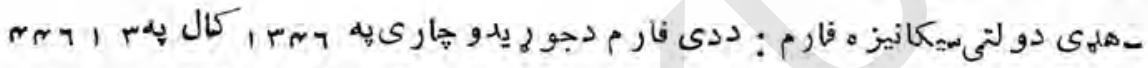

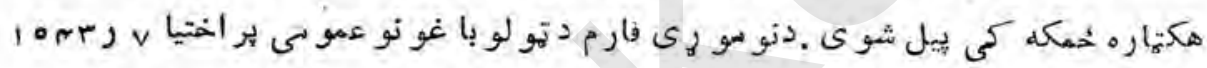

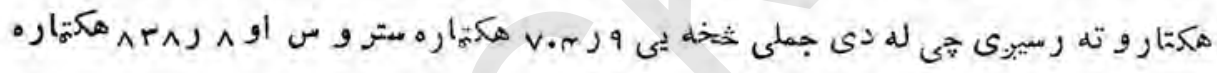

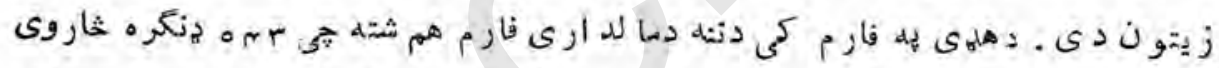

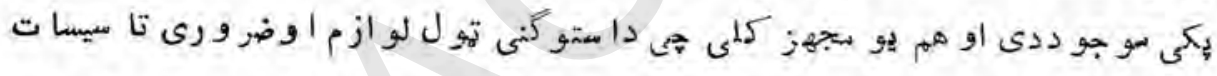

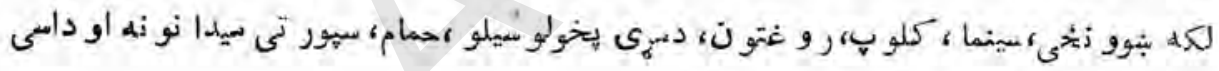

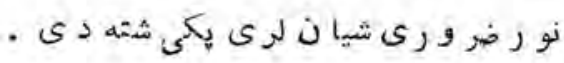

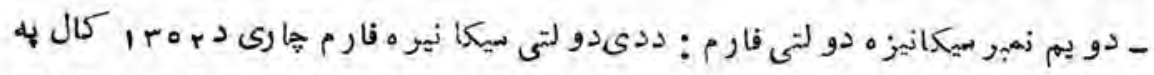

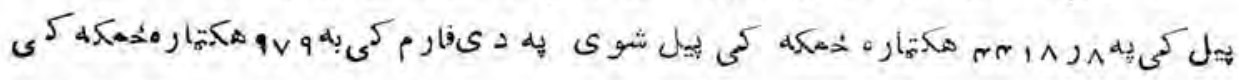

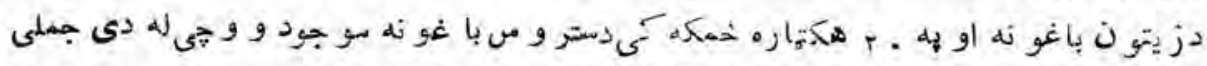

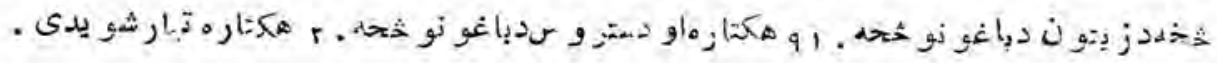

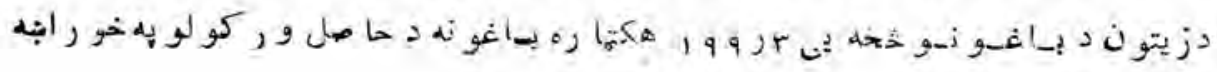
. $c 20$ 


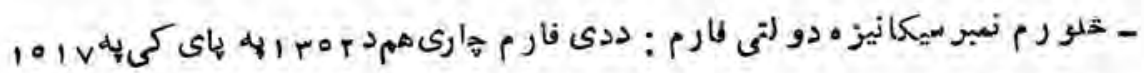

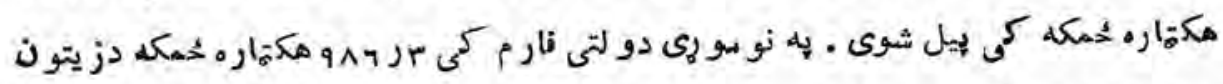

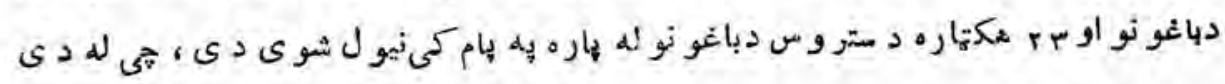

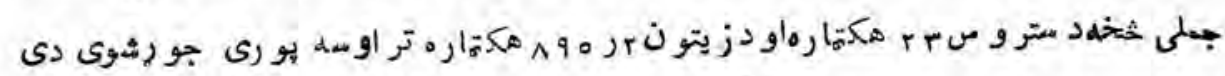

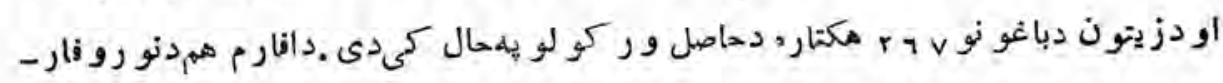

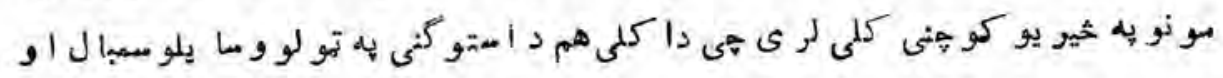

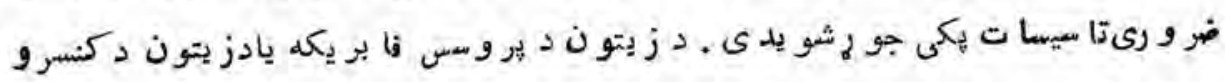

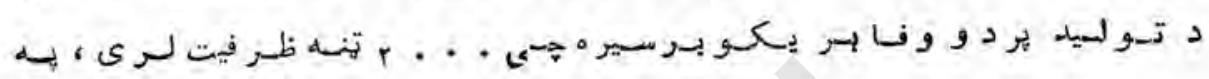

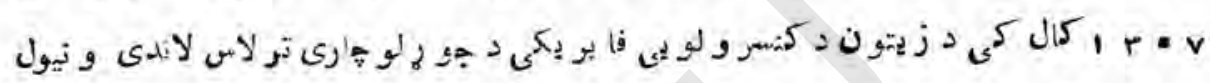

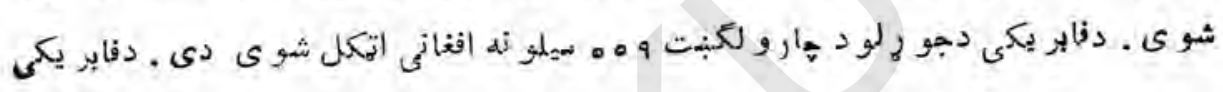

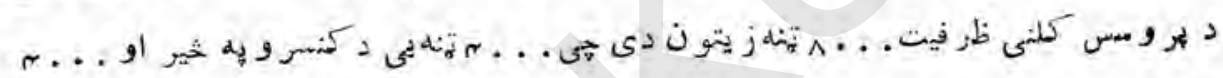

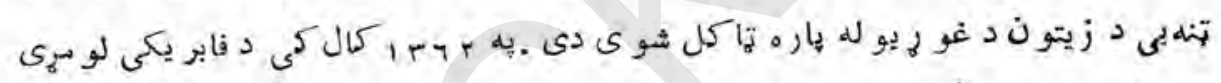

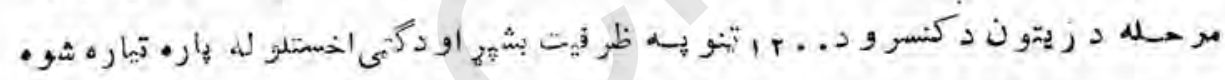

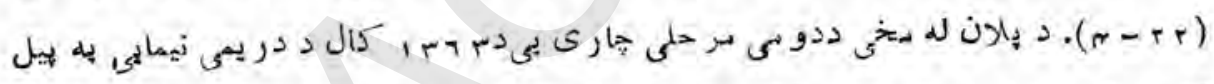

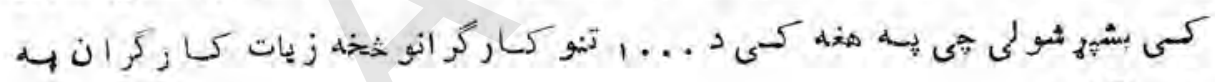
هار و لكيادى.

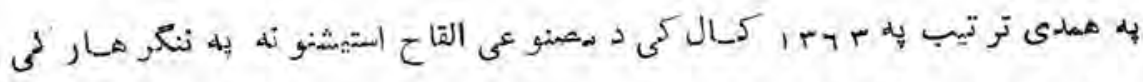

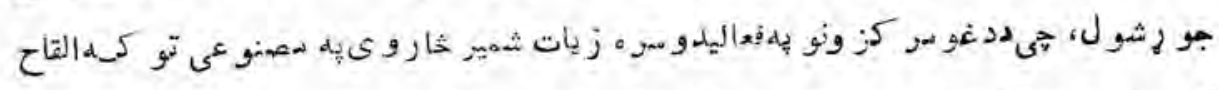

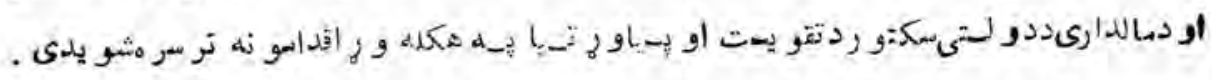

:

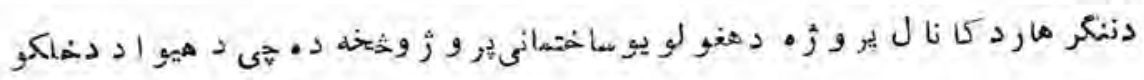

$$
(\ldots+)
$$




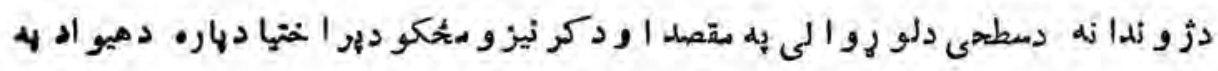

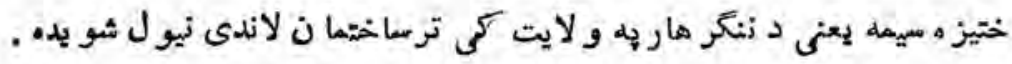

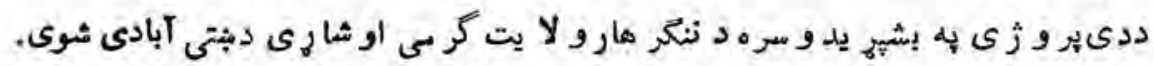

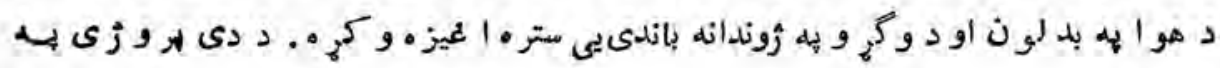

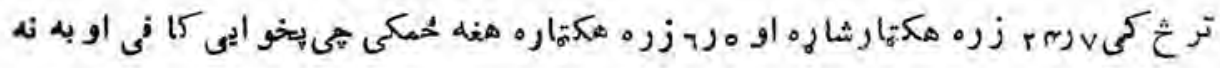

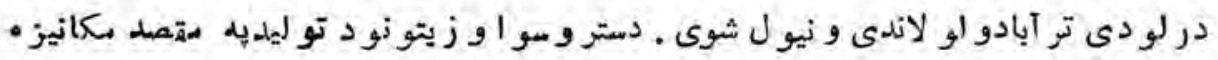

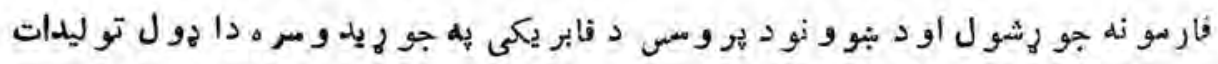

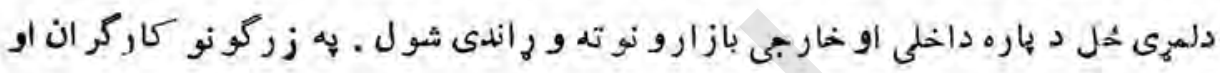

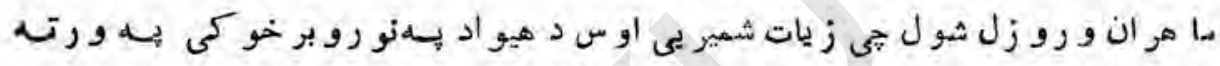

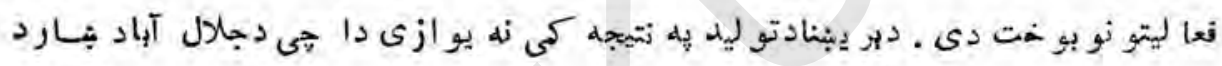

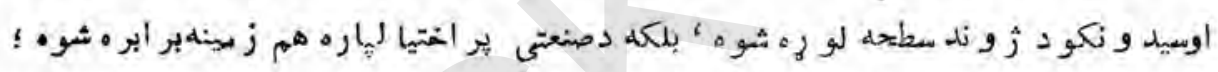

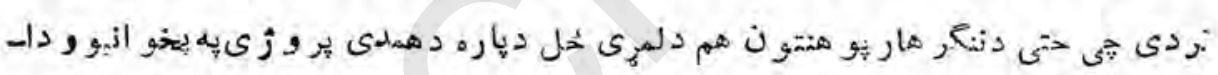

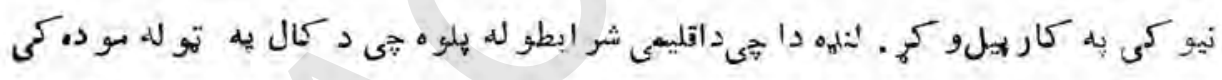

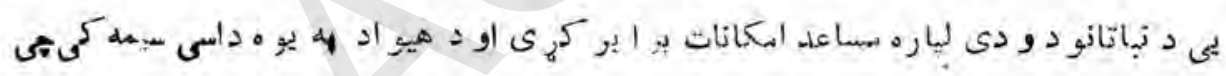

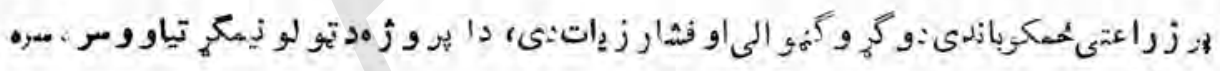

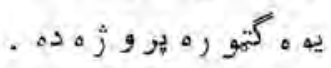

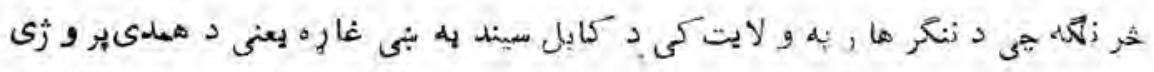

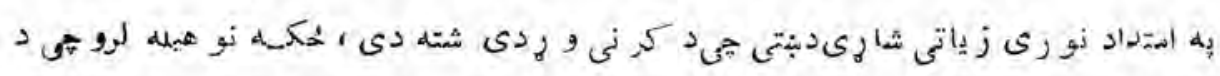

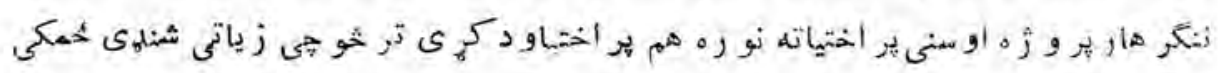

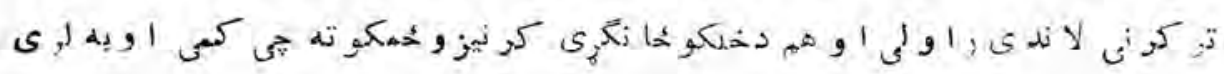

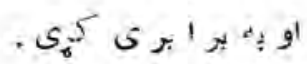




\section{ماخذونه}

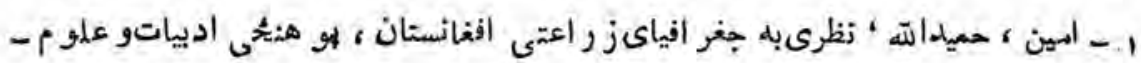

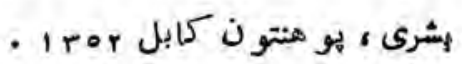

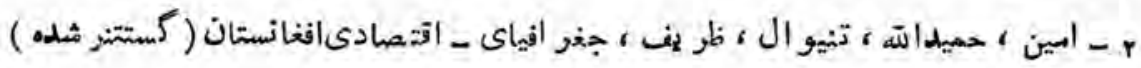

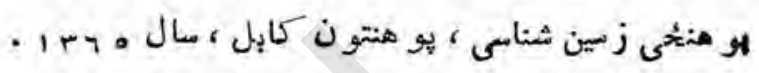

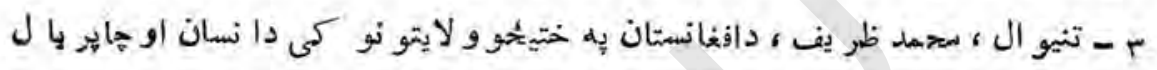

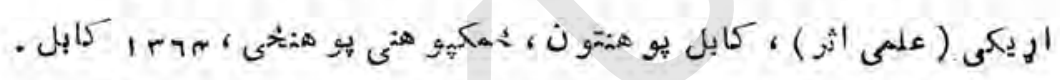

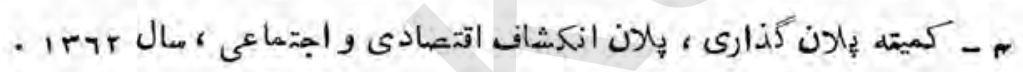

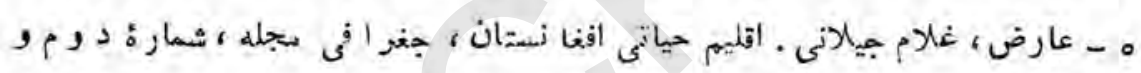

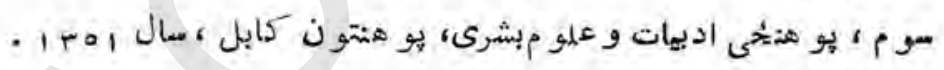

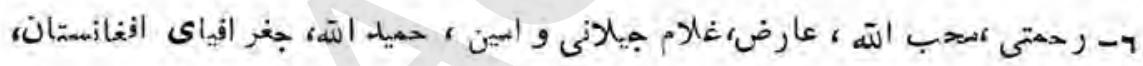

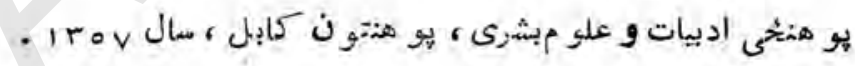

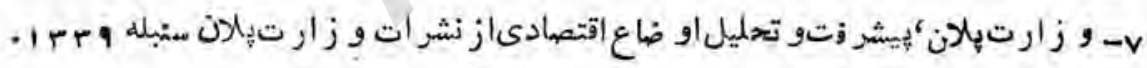




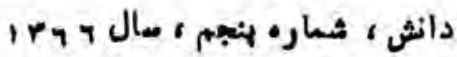

دو كتو رو. و. و ز يابكين ، دو كتو رايكو يشن ن. 1،

بو هنمل ش ـ ا ـ جو يان و هو هثيار ع . دمتسب ز اده.

نورم ونايايلارى جريانات سالانه آب

هر دريا هاى افغانستان

مقل : (1)

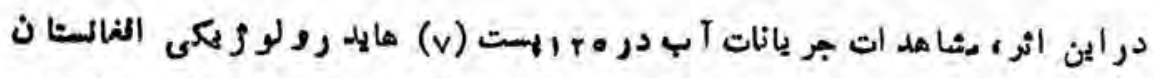

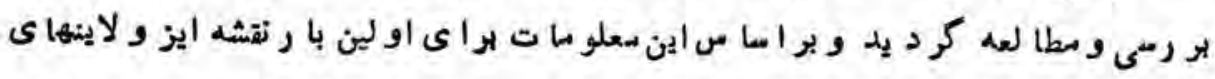

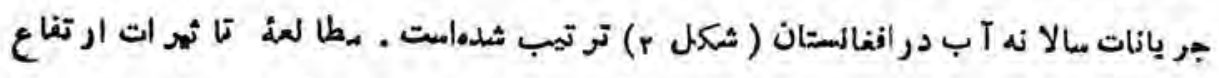

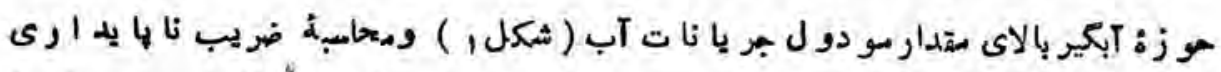

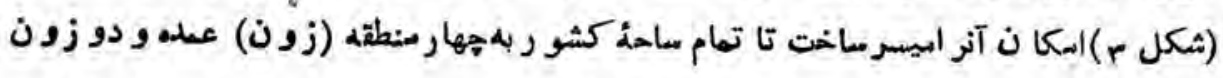

$$
(1 . \bullet)
$$




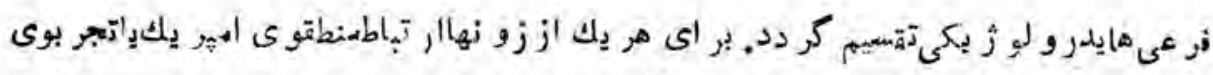

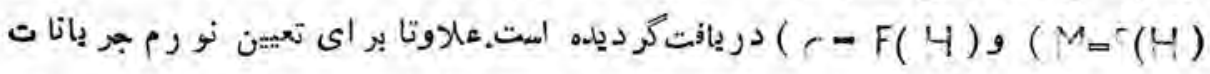

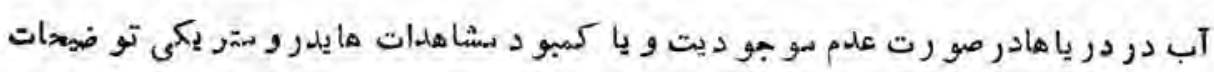

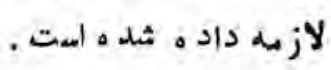

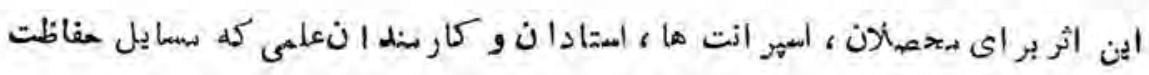

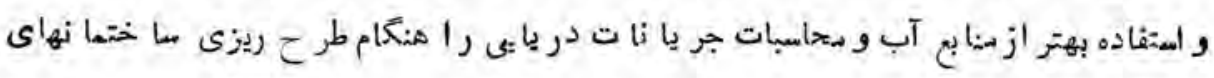

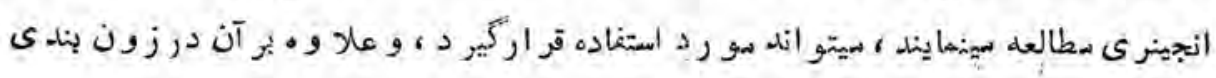

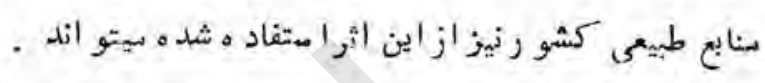

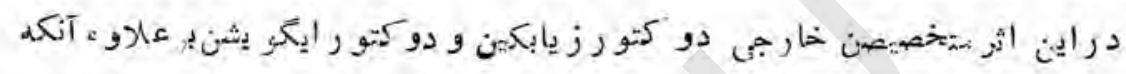

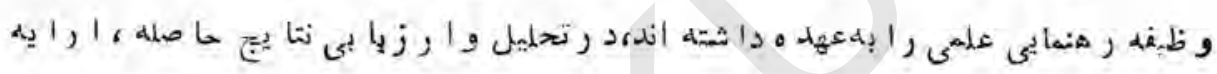

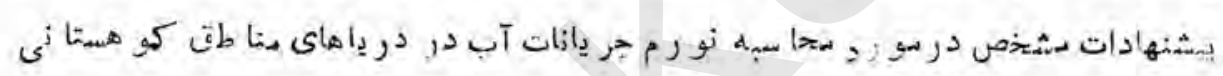

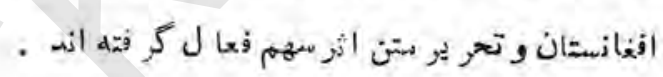

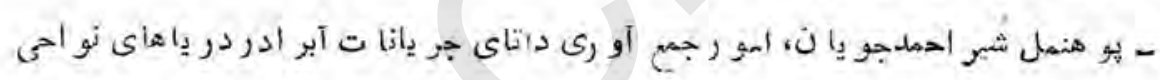

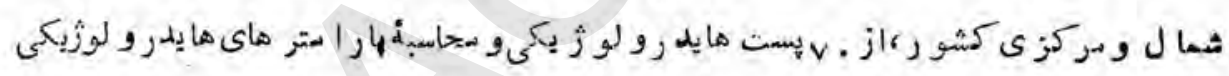

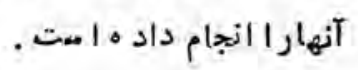

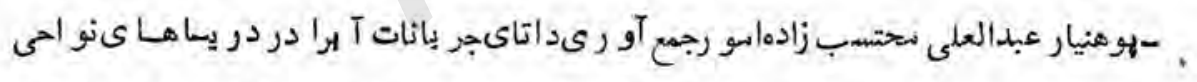

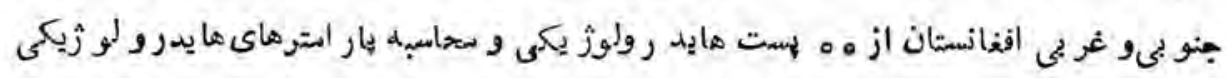

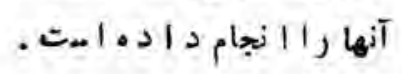

\section{: فำ}

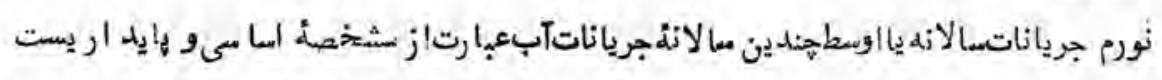
كمه قابليت جريانات آب دردريا ها و وبوتنسيال منابع آب بك حوزه ميا سيطقه را تثبيت بينمايد. 
علاوتا" زو رمجر يا نات آب از جمله بعيار هاى عمله: هايدر ولوزيكى ميبا شد كله به كمكك

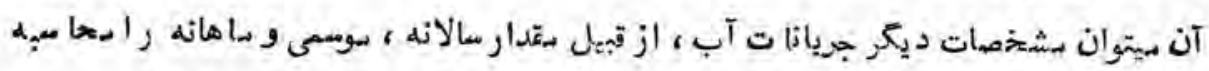

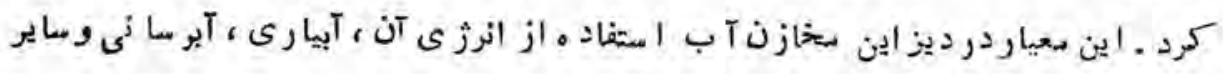

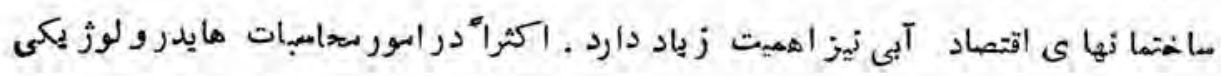

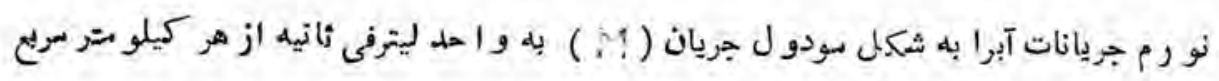

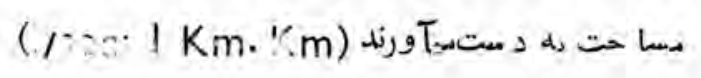

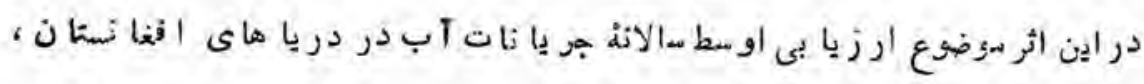

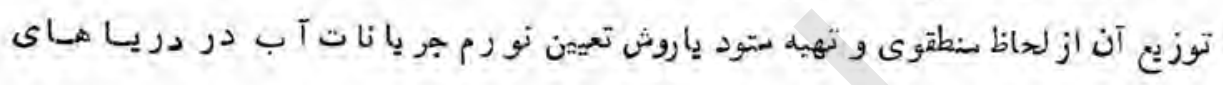

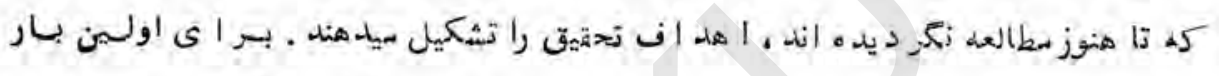

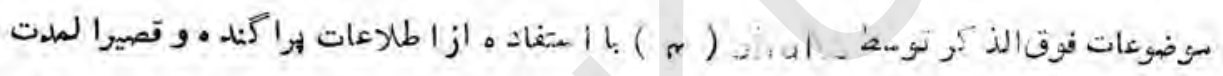

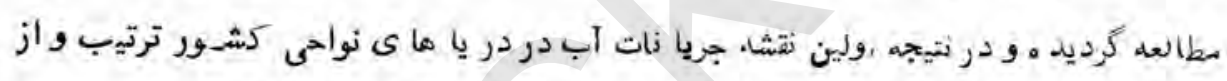

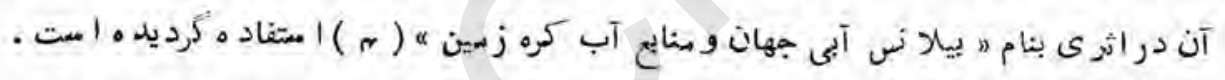

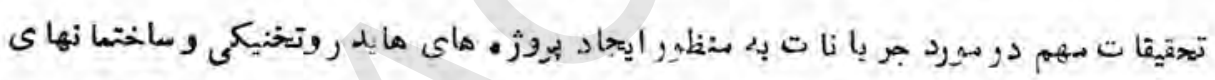

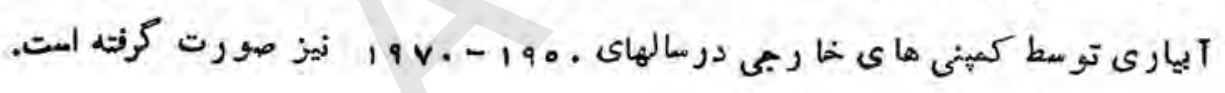

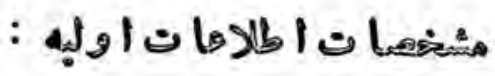

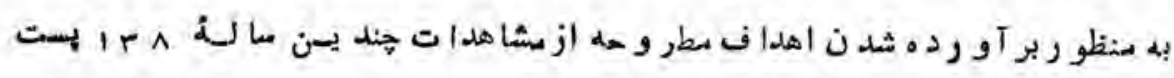

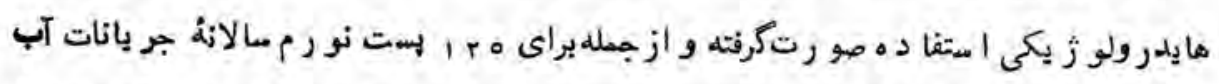

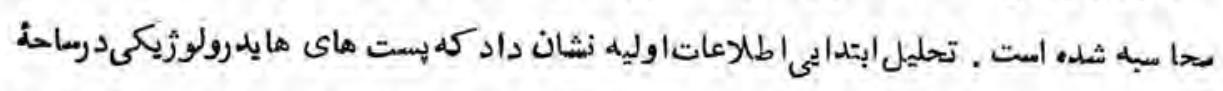

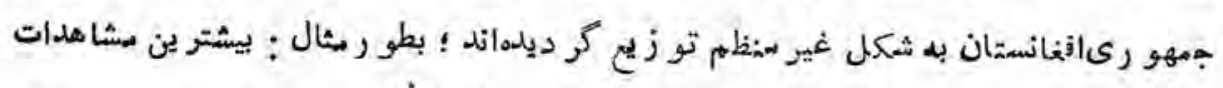

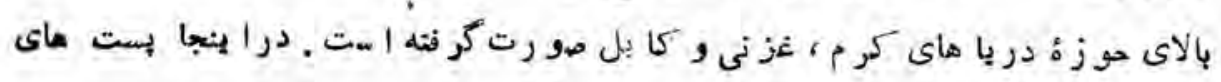




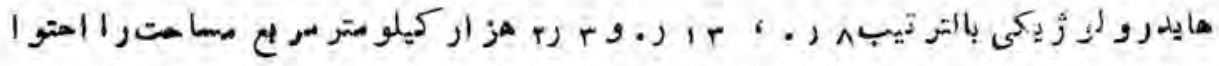

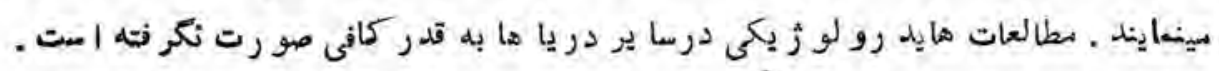

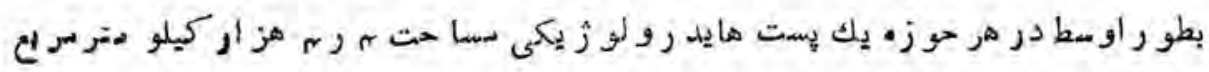

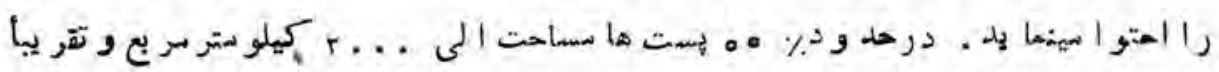

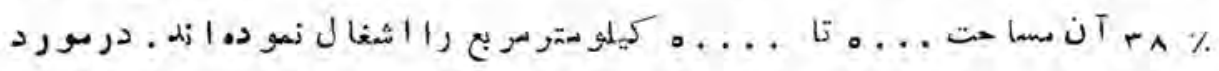

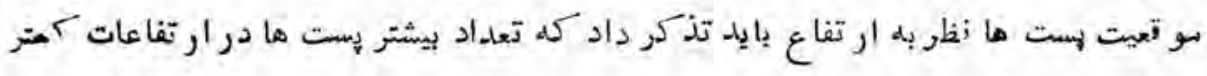

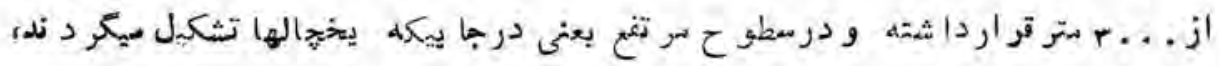
هثا هذات صو رت نميكير د.

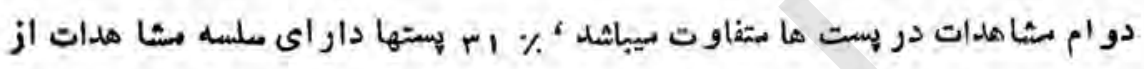

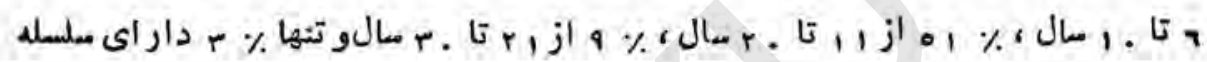
مشاهدات بيشتر از ـ ب سال ميباشد.

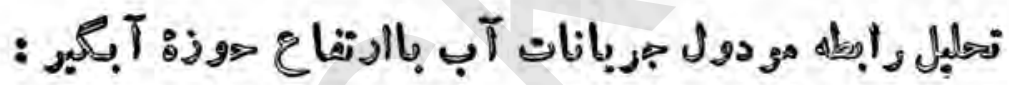

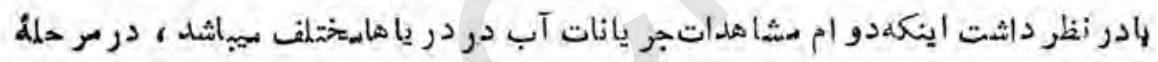

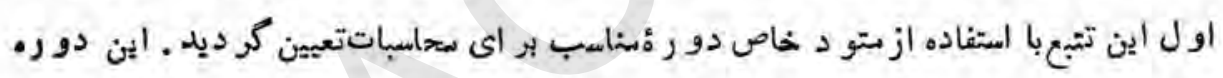

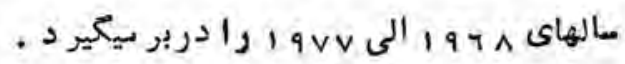

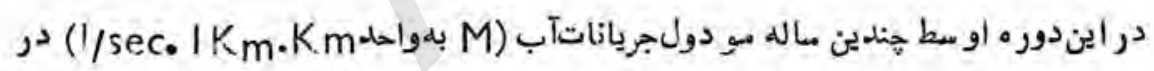

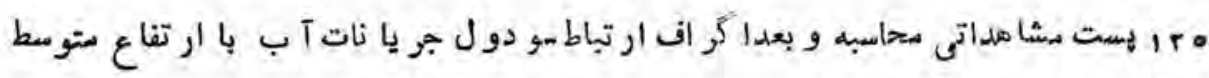

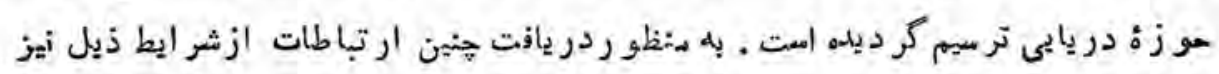
به شكل تخمينى استفا ده شده است :

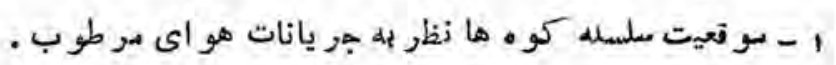

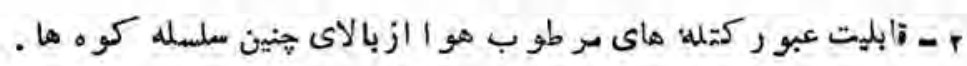



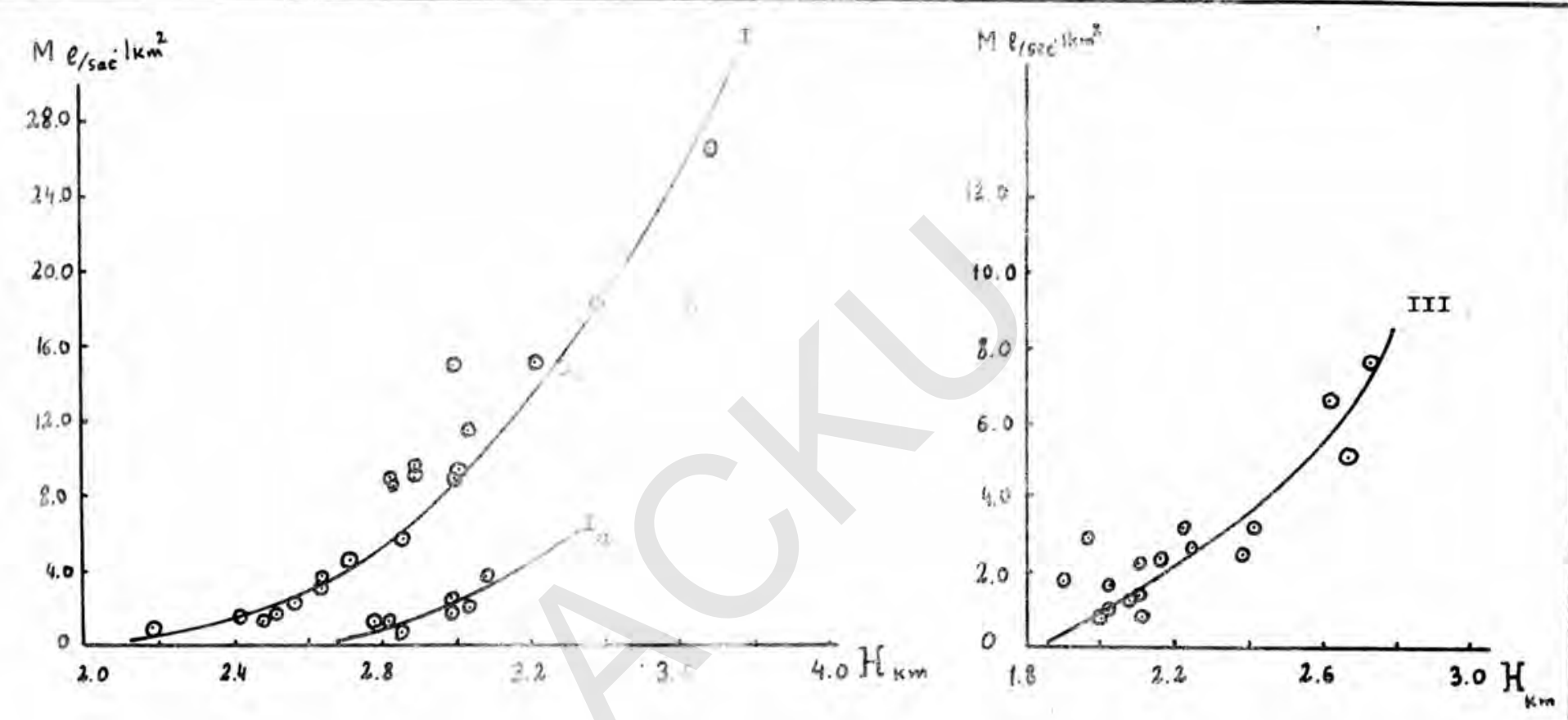

شكل 1 - ارتباط مود ول جريان با اوبط ارتخاعحوزه آبكير 


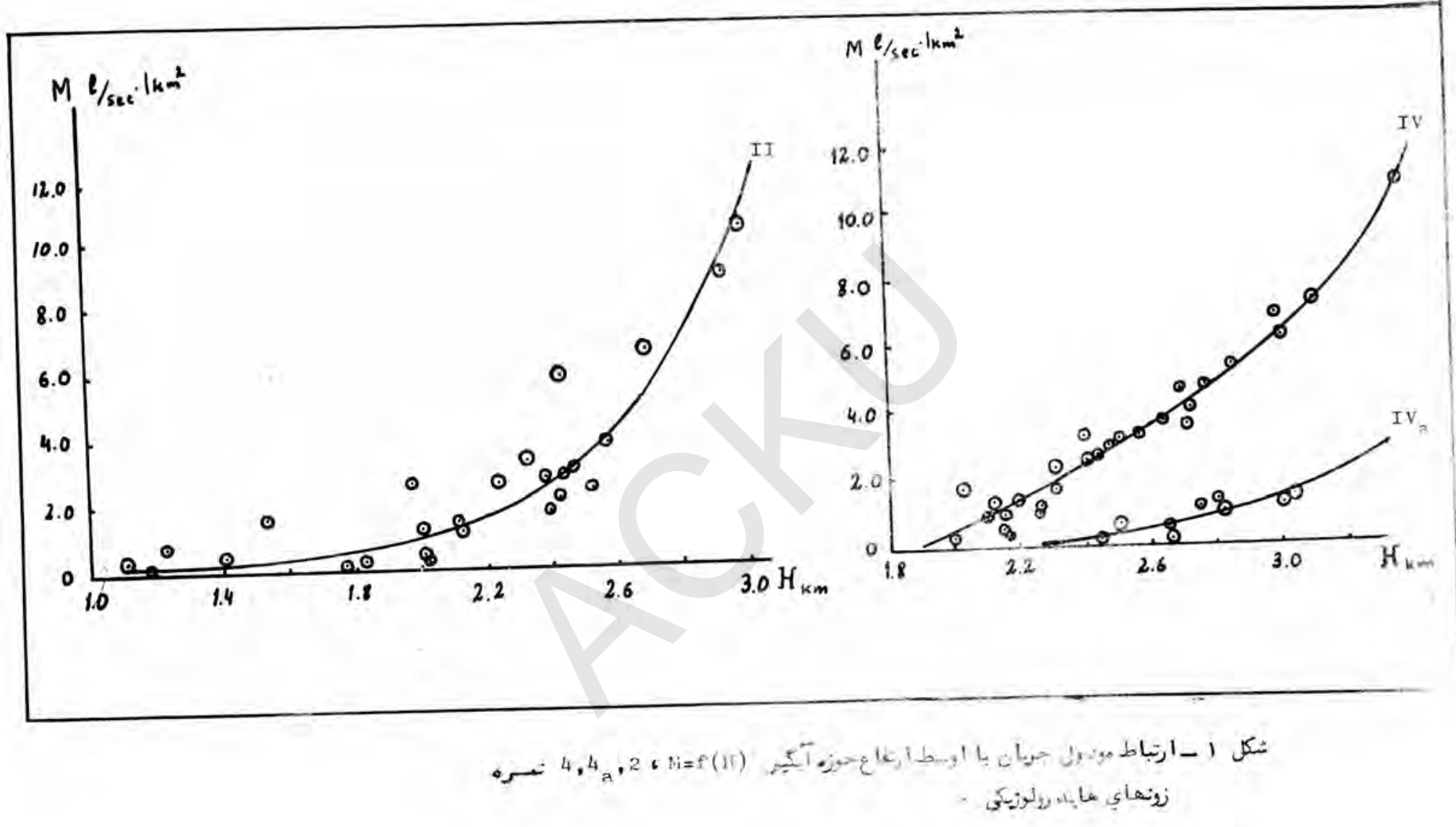

$$
\text { (1) })
$$




\section{•r- يكما ن بودنير وسم مانى ميناتيكى

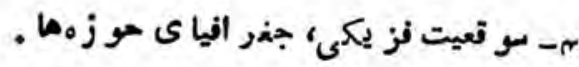

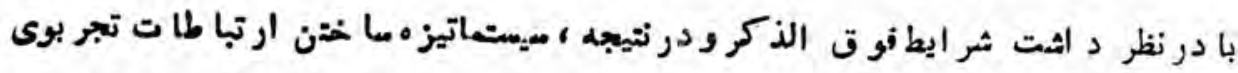

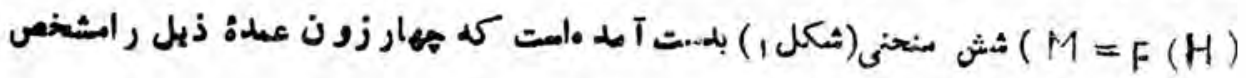
سيسا زنه :

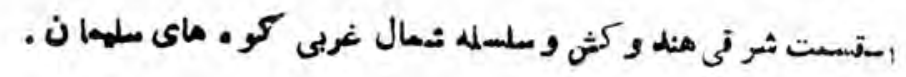

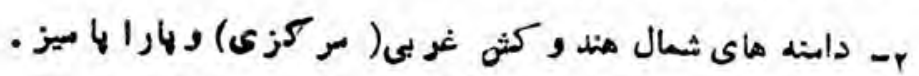

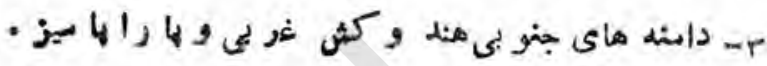
.

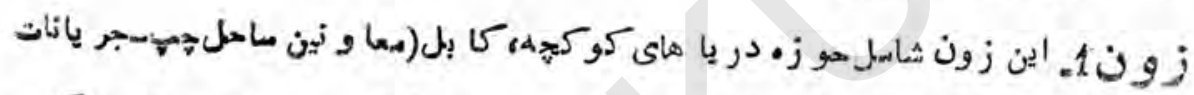

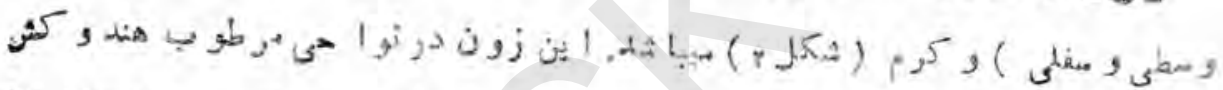

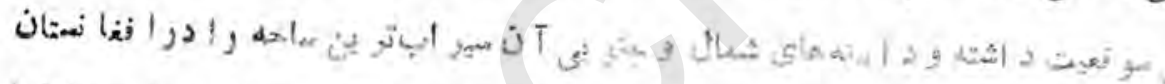

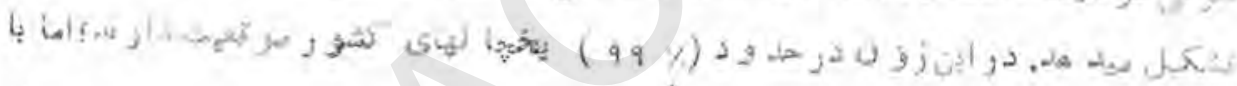

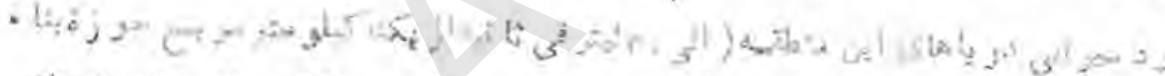

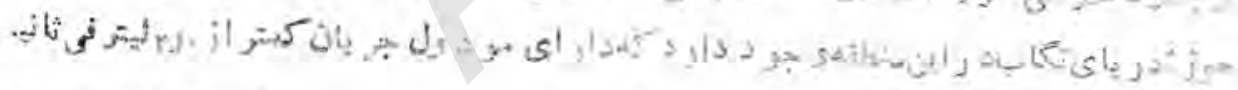

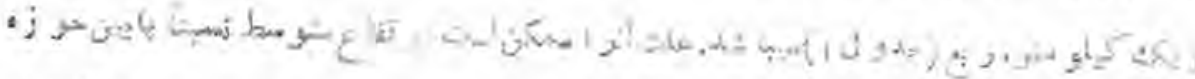

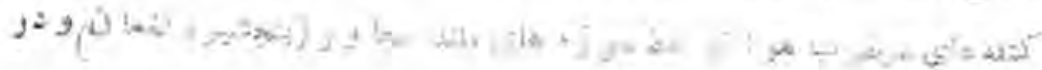

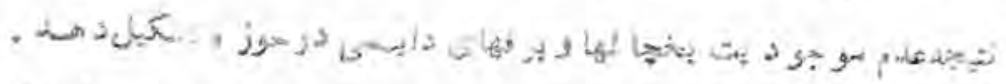

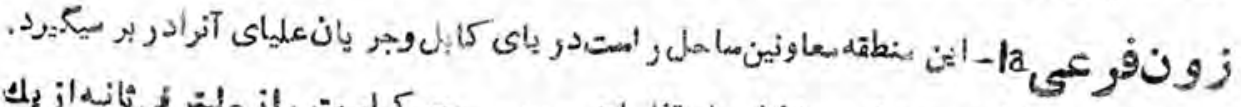

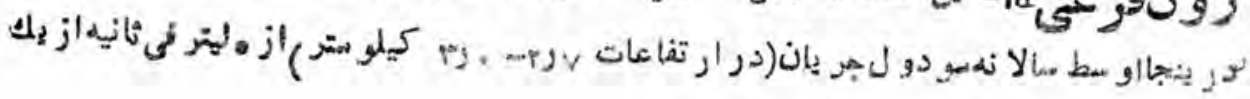

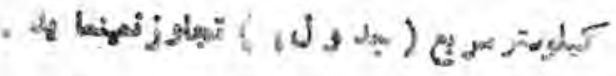




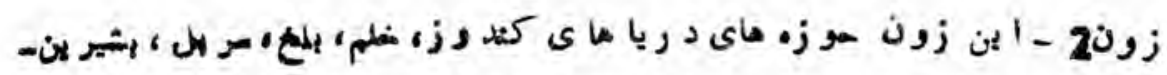

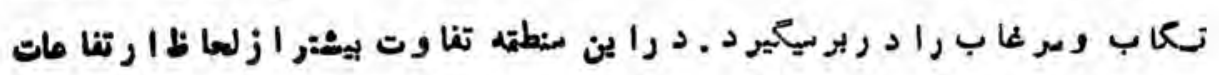

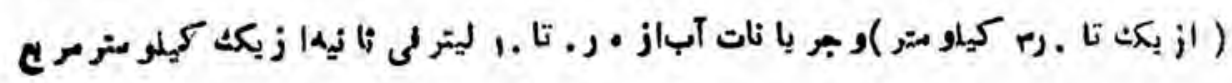

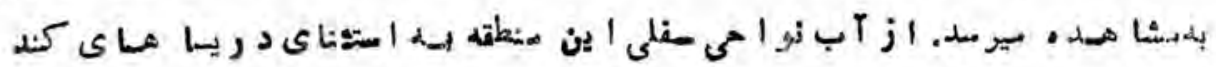

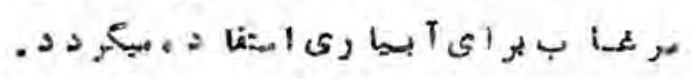

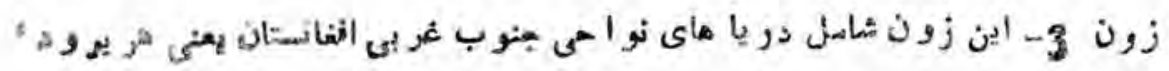

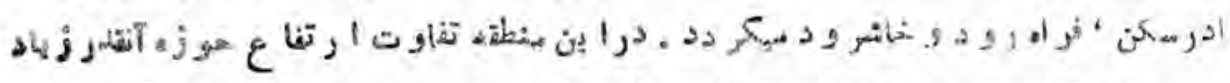

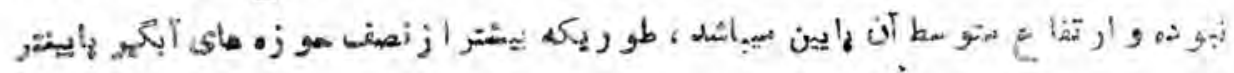

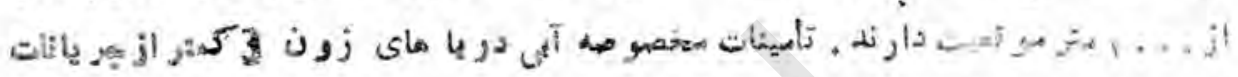

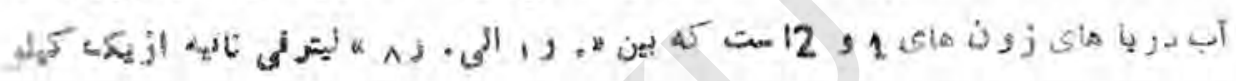

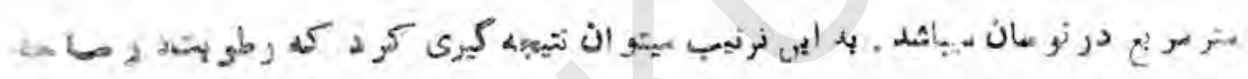

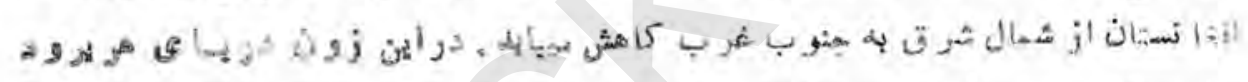

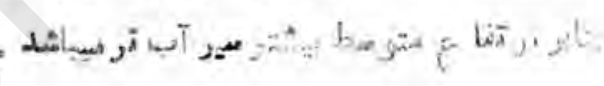

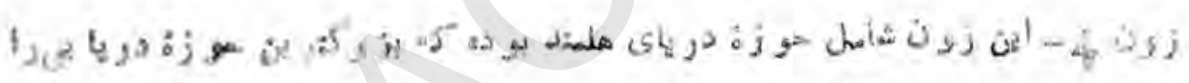

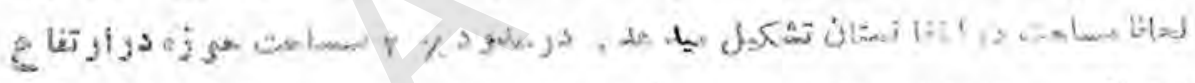

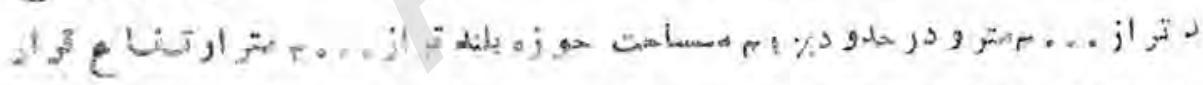

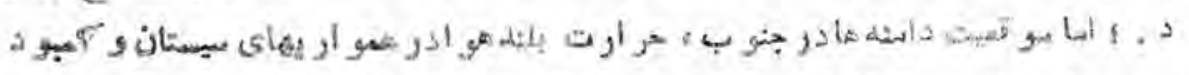

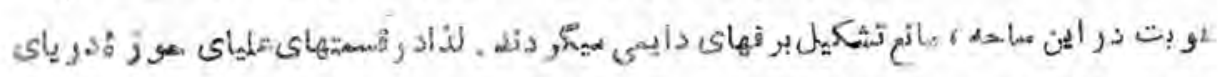

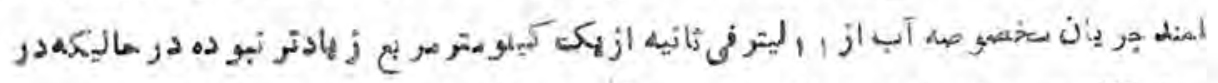

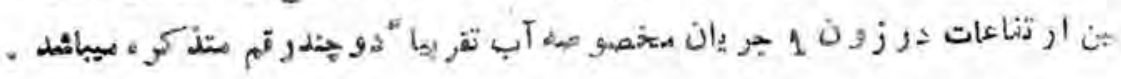

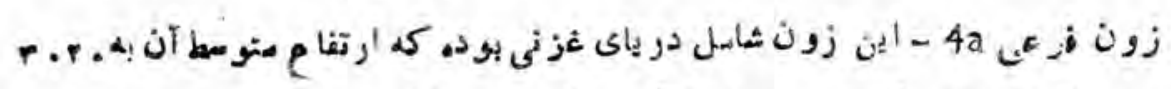

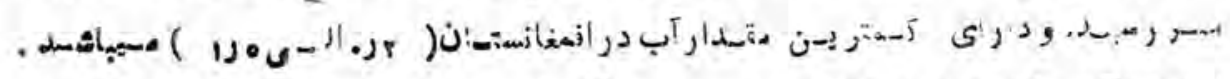

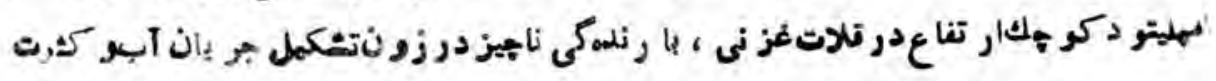
(11, 


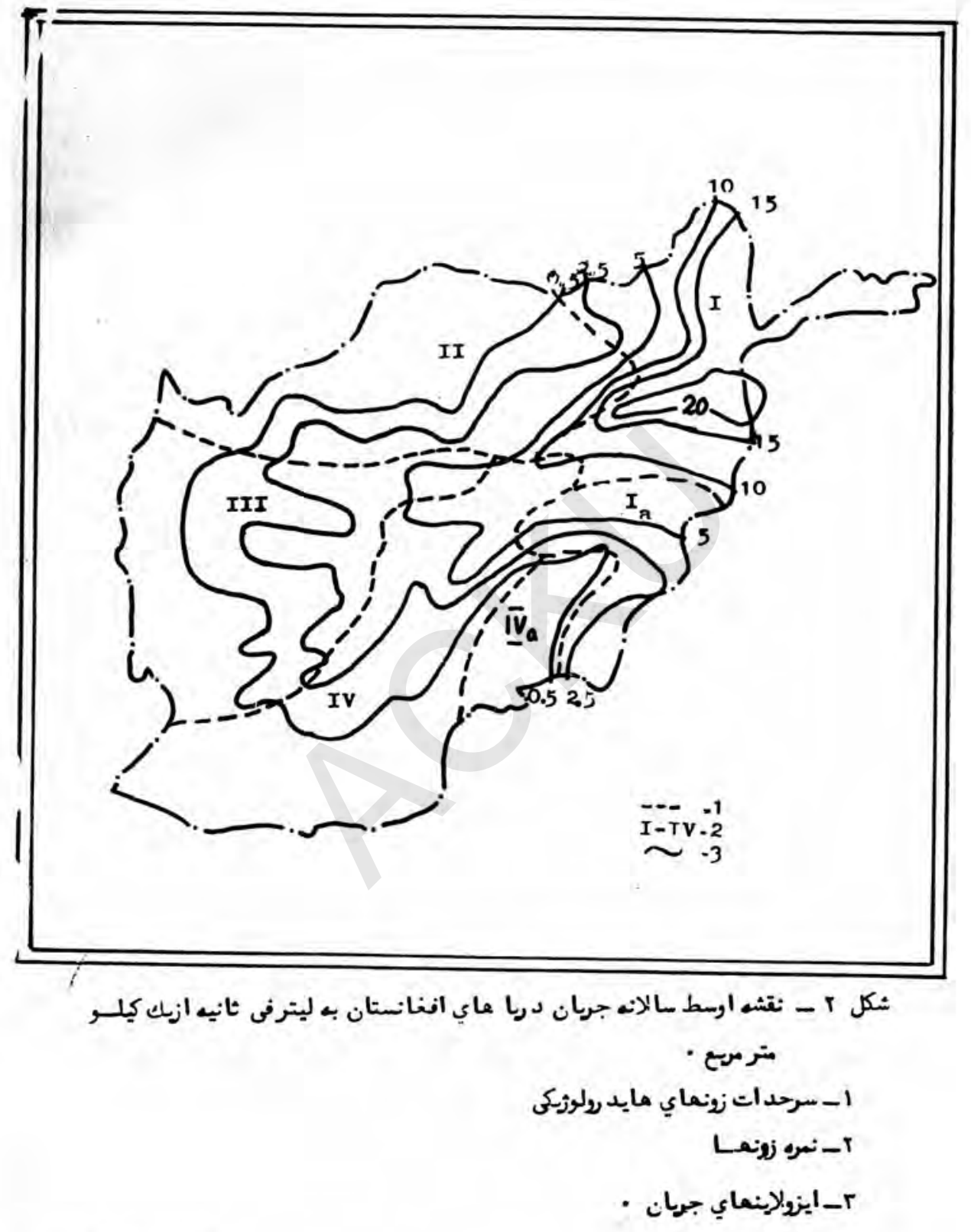


موجوديت كله ماي خشك مرا د راينجا مانعتجعع وحفي برف براي مدت طولانى ميكردن.

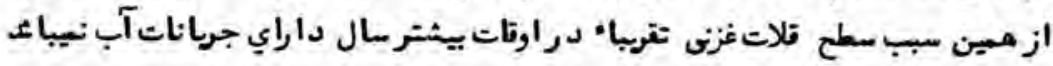

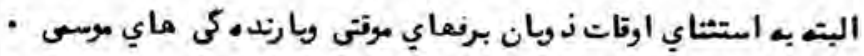

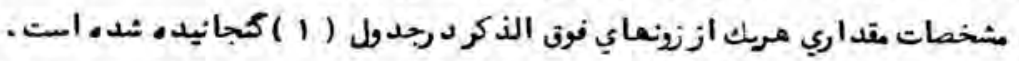

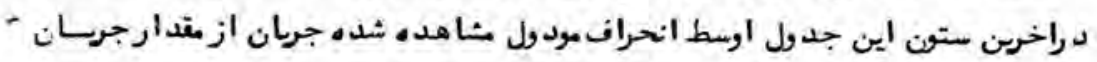

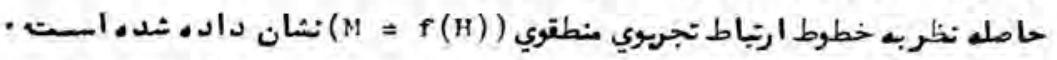

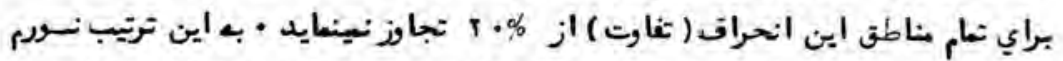

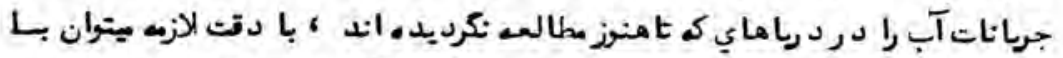

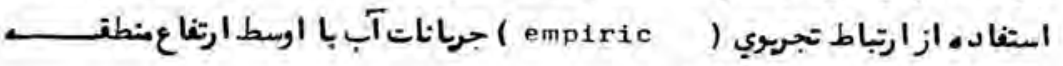

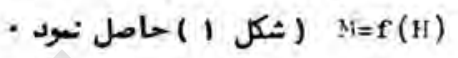

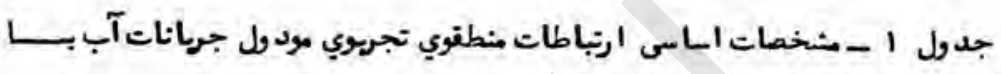

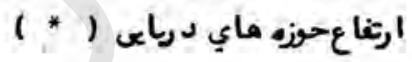

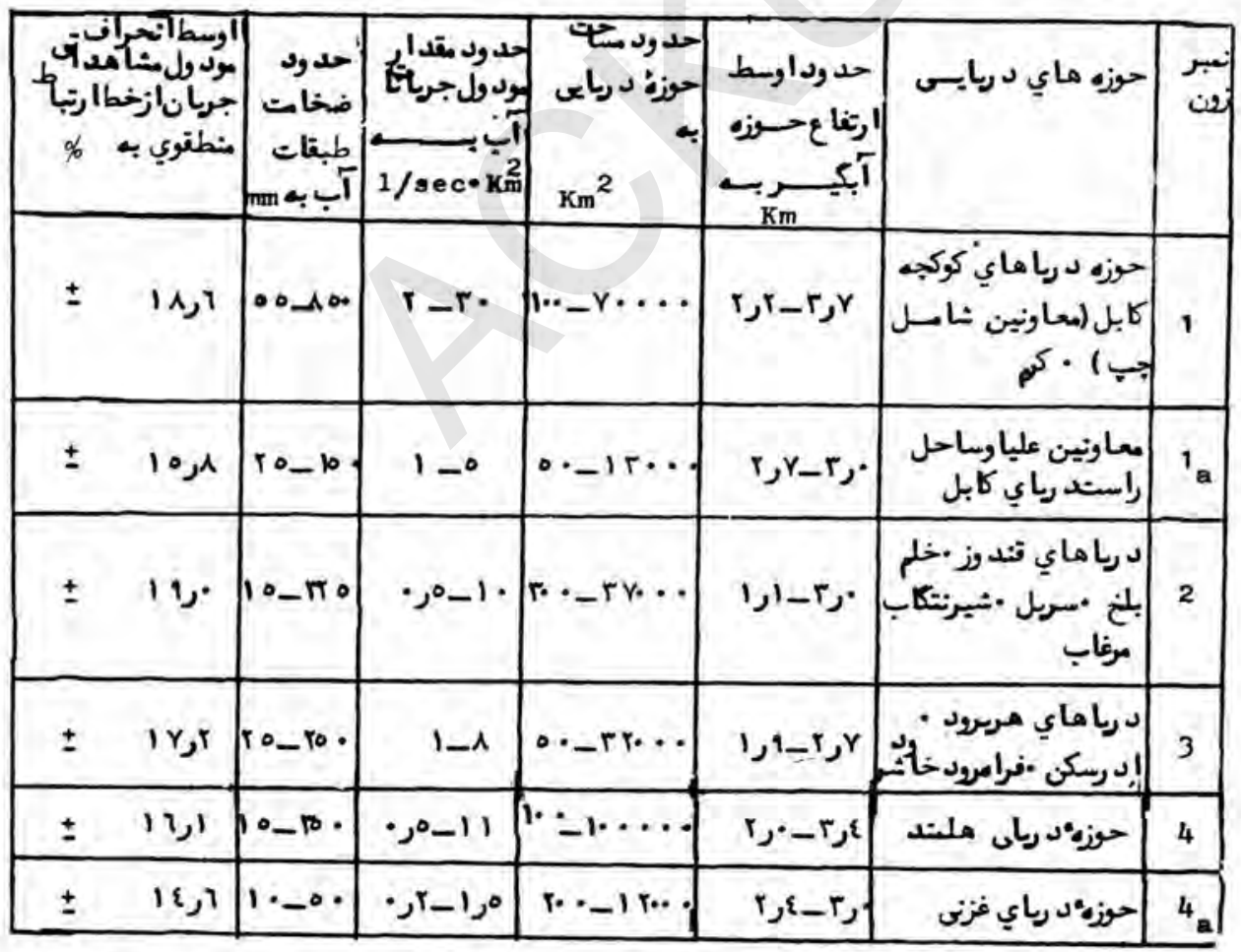

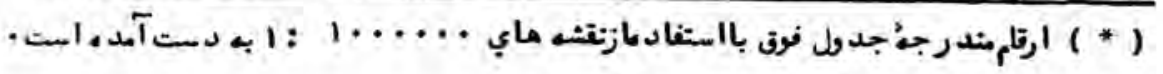




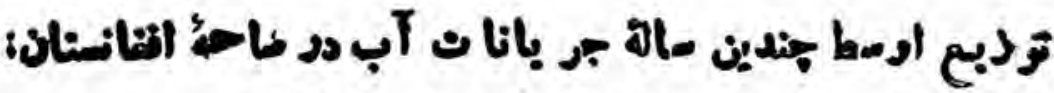

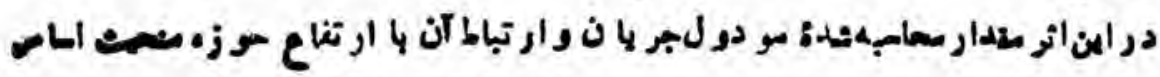

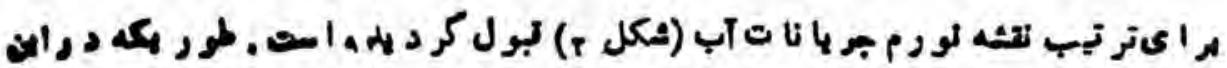

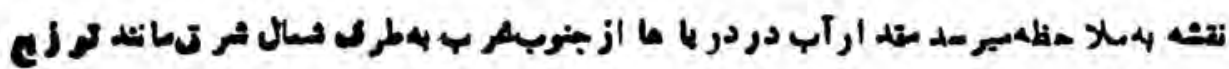
- 4

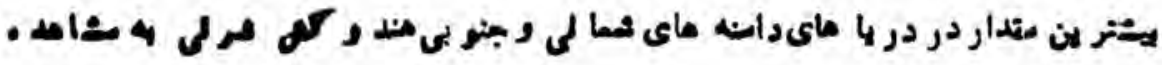

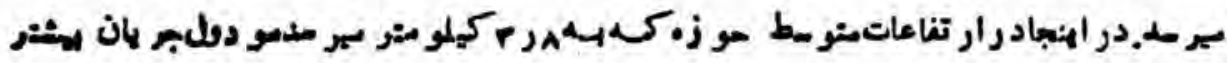

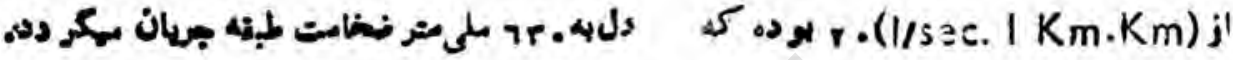

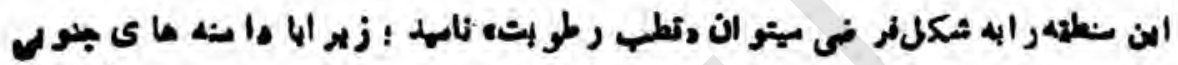

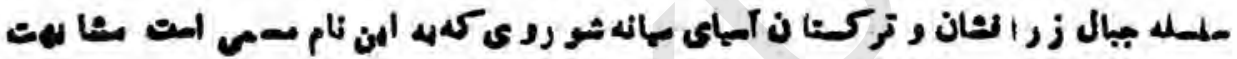

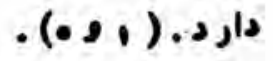

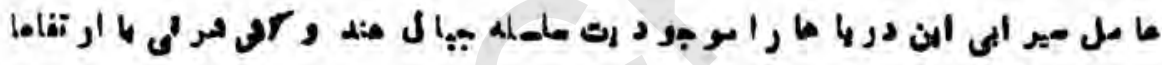

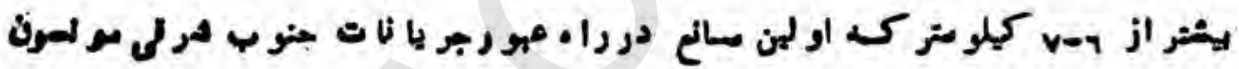

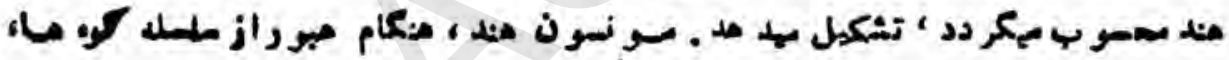

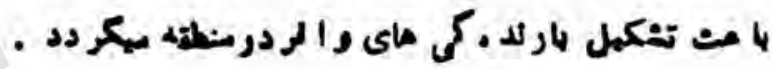

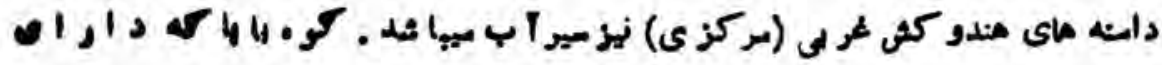

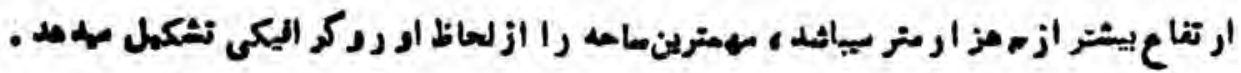

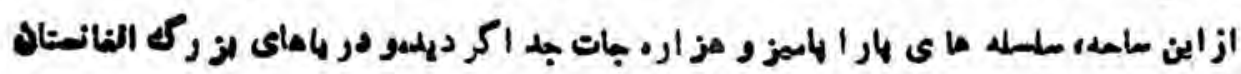

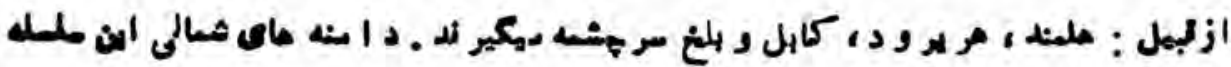

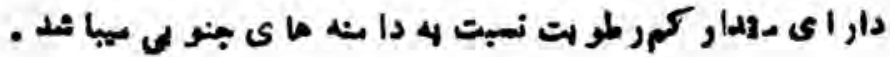

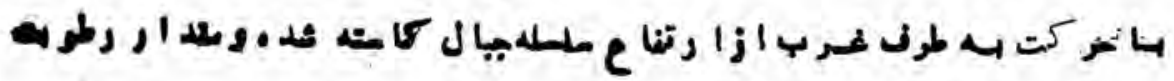




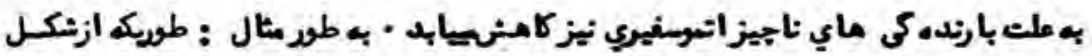

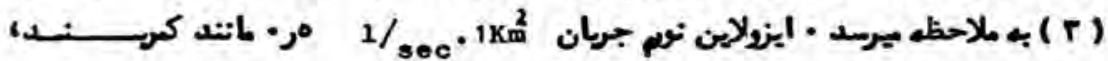

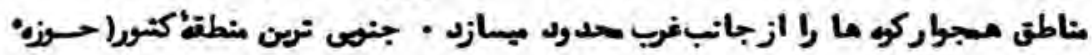

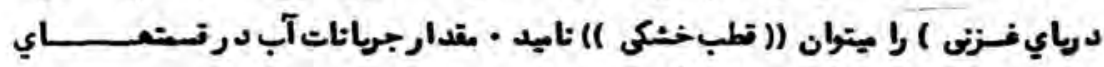

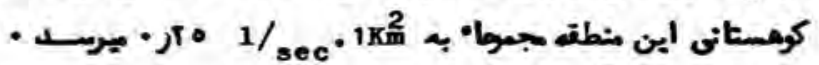

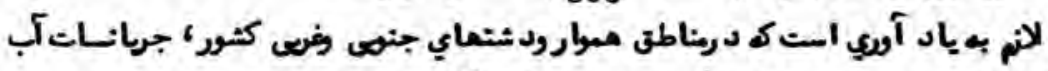

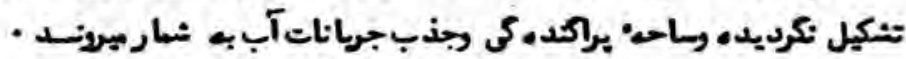
:

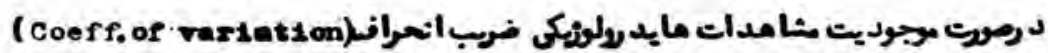

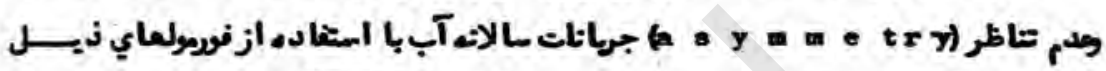

$$
\begin{aligned}
& c_{v}=\sqrt{\frac{\sum_{i=1}^{m}\left(k_{1}-1\right)^{2}}{n-1}} \cdots \\
& c_{s}=\frac{\sum_{i=1}^{n}\left(k_{1}-1\right)^{3}}{n \cdot c_{v}^{3}} \cdots
\end{aligned}
$$$$
\text { (T) : ماسبع يكردد }
$$

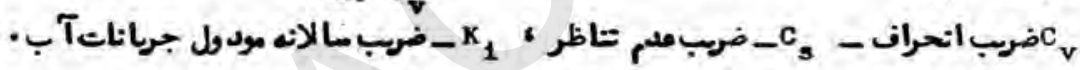

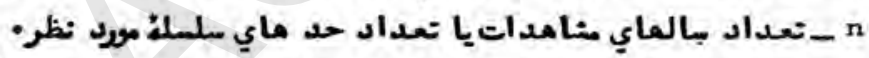

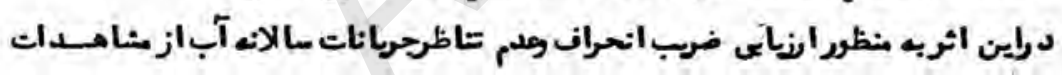

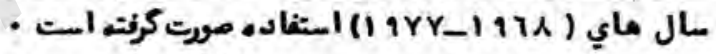

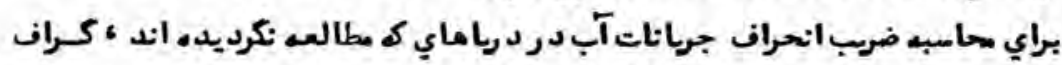

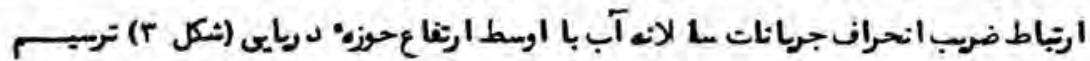

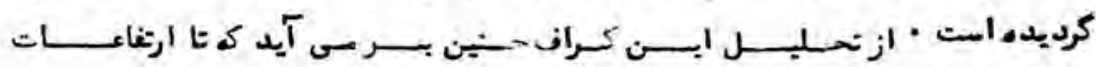

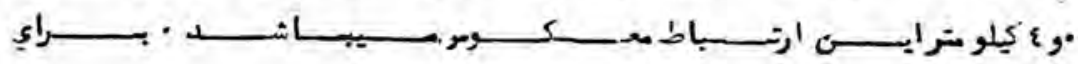




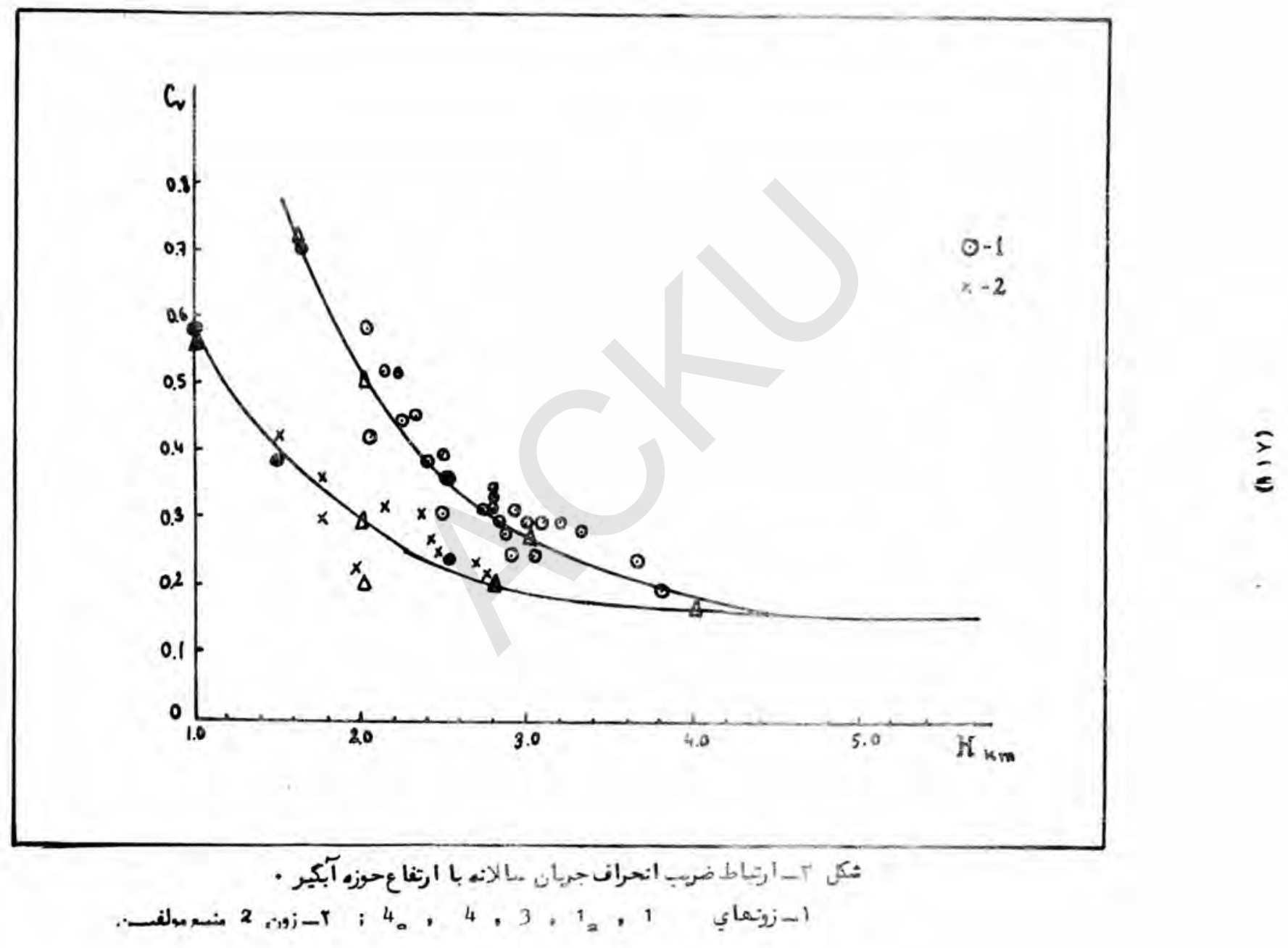


ارتغاعات بيشترارتباط بدست نيامده است ـ الما ضرب انحراف را مولنين مساوي بهما ا و.

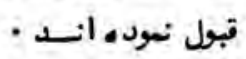

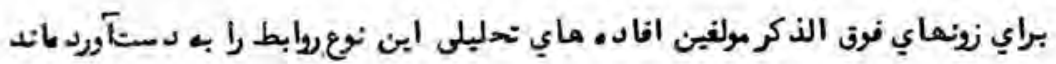

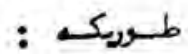
براي نونهاي را دارا ميباثـند :

$$
\begin{aligned}
& c_{v}=\frac{42700}{\mathrm{H}^{1,49}} \\
& c_{v}=\frac{355}{\mathrm{H}^{0,93}}
\end{aligned}
$$

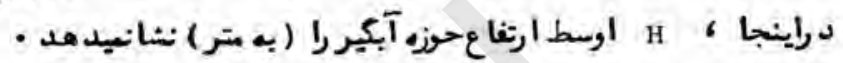

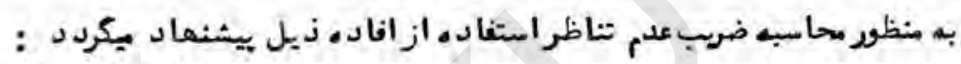
$\mathrm{C}_{\mathrm{s}}=2 \cdot \mathrm{C}_{\mathrm{v}}$

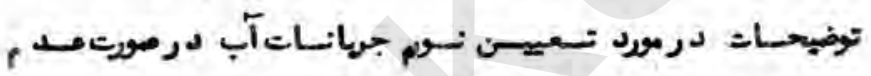

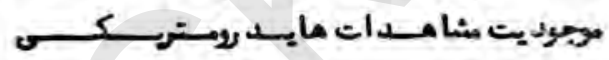

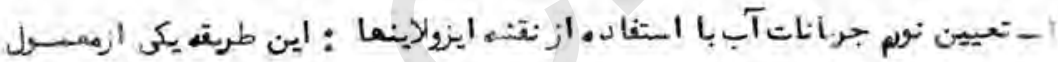

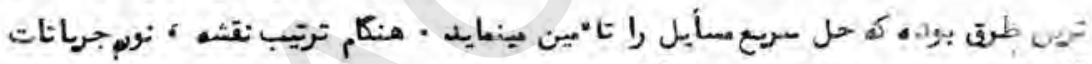

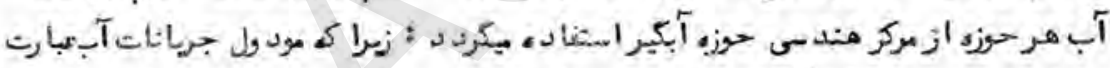

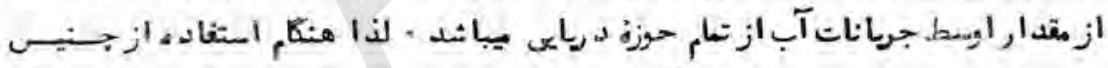

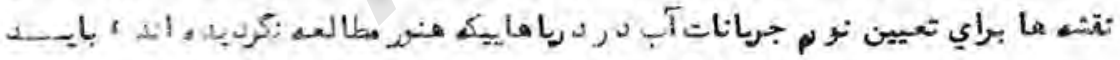

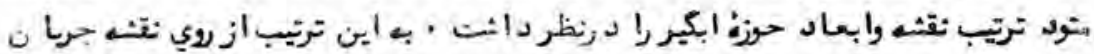

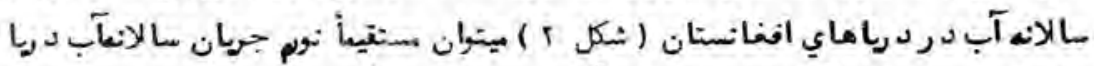

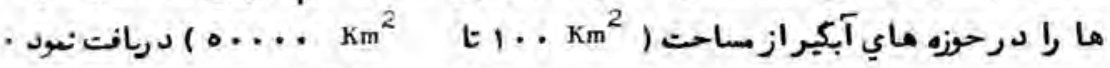

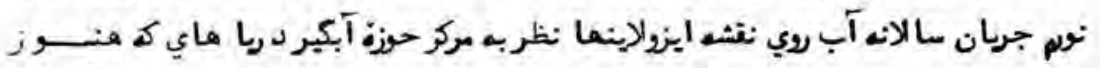

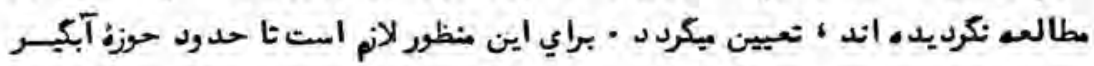

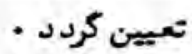

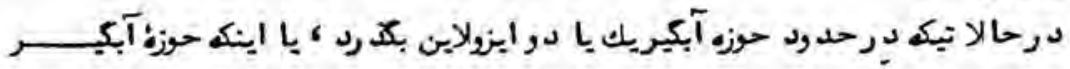

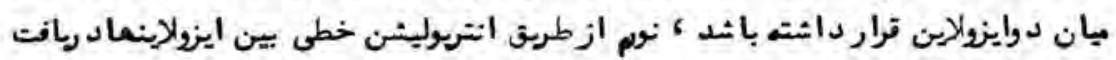




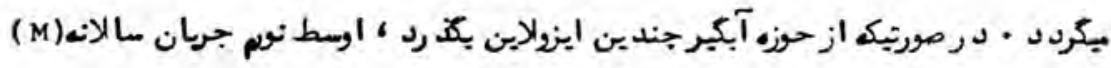
ازفورمل نيل بد ست ميآيد :

$$
M=\frac{M_{1} \cdot f_{1}+M_{2} f_{2}+\ldots+M_{n} \cdot f_{n}}{F} \quad \ldots(0)
$$

د راين فورول مقد اراومط مودول جريان يين ايزو لاينماي

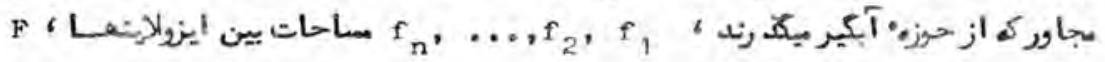

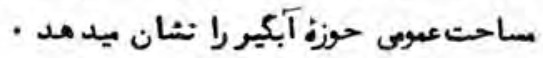

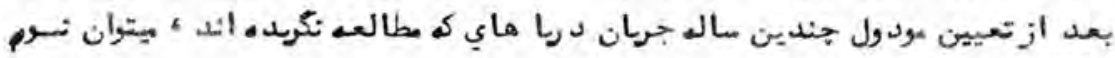

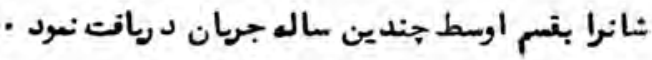

$$
\begin{aligned}
& Q=\frac{M \cdot F}{1000} \\
& \ldots \ldots+(1)
\end{aligned}
$$

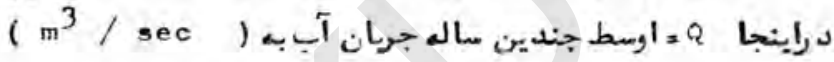

Y-_تعيين نور جراناتآب درد را ماي كومستاني كه مطالعه نكرديده اند

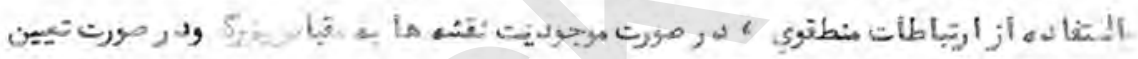

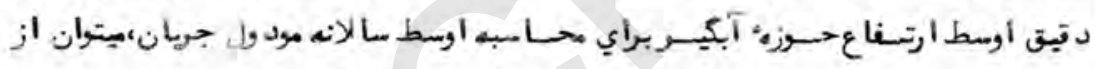

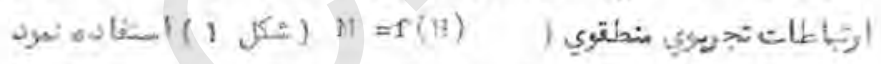

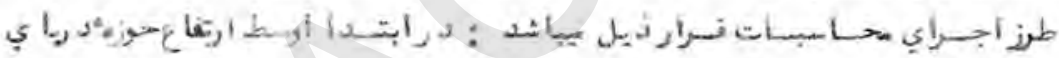

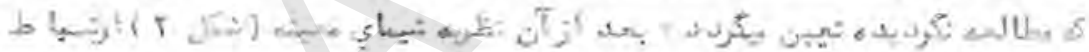

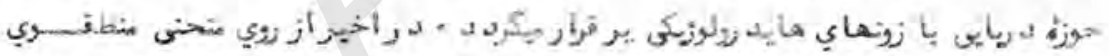

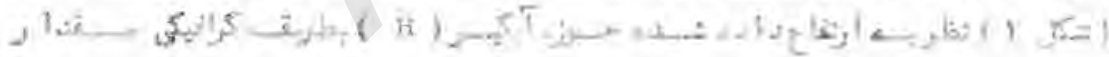

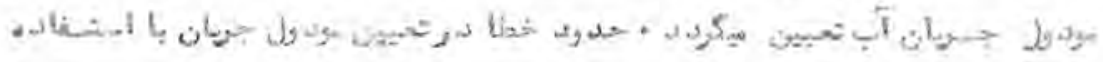

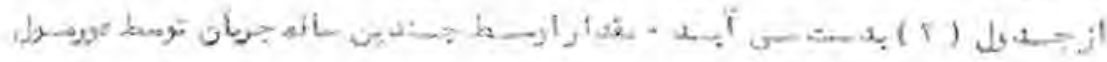

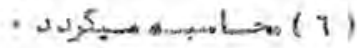




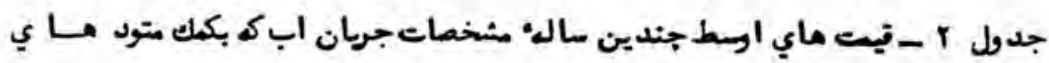
مختلف درافت كرديده است ( * )

\begin{tabular}{|c|c|c|c|c|c|c|c|}
\hline |انحراف & $\begin{array}{r}\text { r } \\
\mathrm{m}^{3} / \mathrm{sec} \\
\end{array}$ & مقدار & $\begin{array}{l}\text { ولجران } \\
1 / \text { sec. }\end{array}$ & مقدا' & 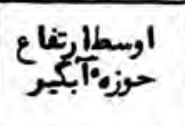 & ساحت & دراــنطقة \\
\hline$c_{v}$ & |نظنى | منه & نزفشربه & نظريك & & m & \begin{tabular}{|l|l|} 
\\
$\mathrm{Km}^{2}$ \\
\end{tabular} & \\
\hline ויוק• & $1 \& 4$ & IrA & אر & זניז & שוזץ & rTA7. & 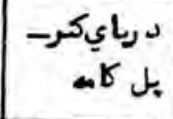 \\
\hline |rre & $10,$. & $10 x$ & ז & مر & ri.. & $\{\{10$ & دبلعرريكتر- \\
\hline •, זrA & 0 & 0 & זر. & זر. & $0-$ & $r 1$. & داريديارثـ- \\
\hline 0. & 5,0 & $r, r \varepsilon$ & קr & , 1 & $r+0$ & rir. & 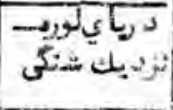 \\
\hline 0,00 & $\varepsilon$ & $\varepsilon$ & & • & 191. & 9 (19.5 & رئرئي خاثرى \\
\hline or & $1,0 \wedge$ & $1, .0$ & & , 5 & $11 \ldots$ & DYTD & it \\
\hline
\end{tabular}

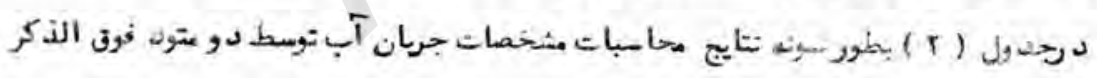

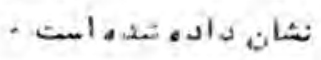

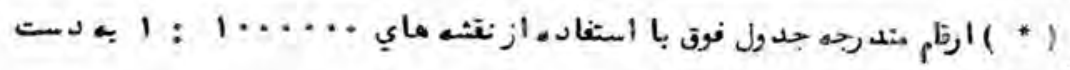

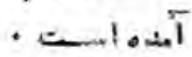




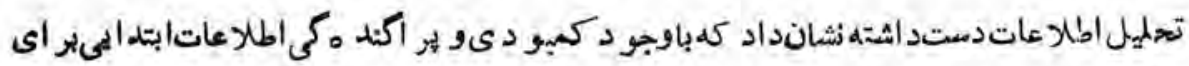

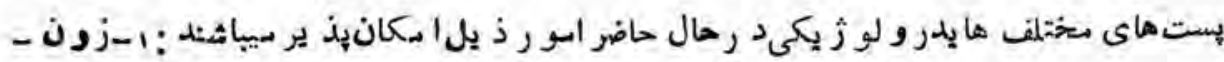

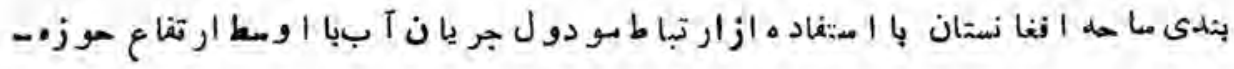

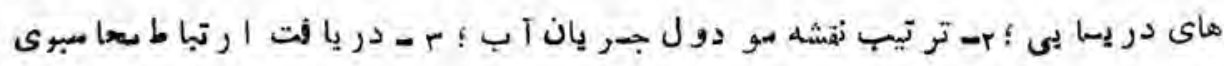

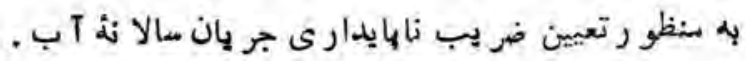

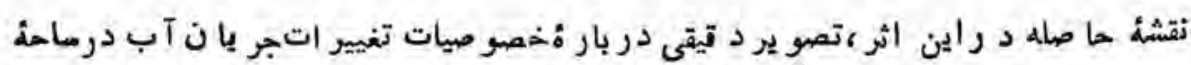

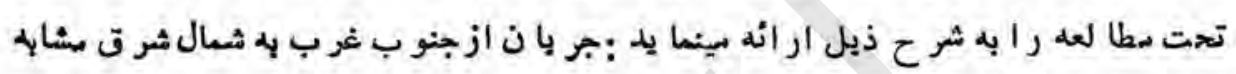

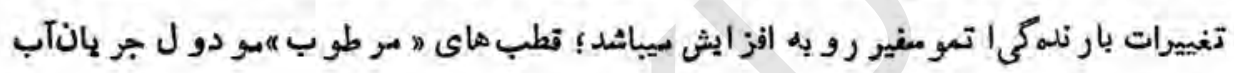

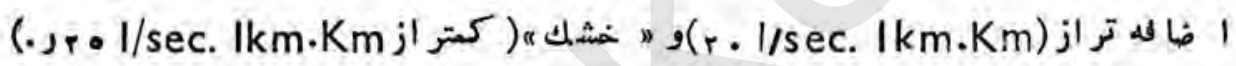

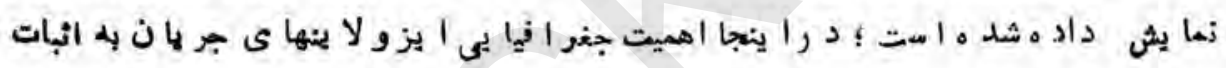

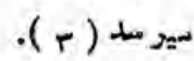

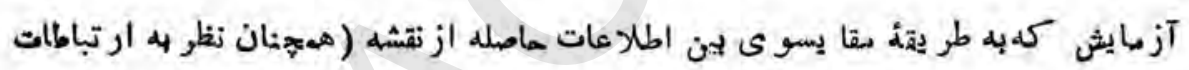

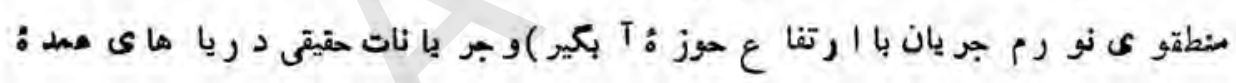

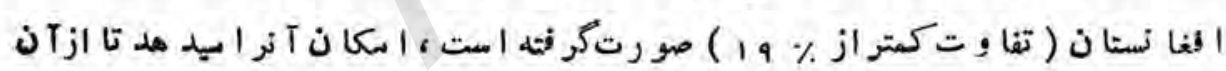

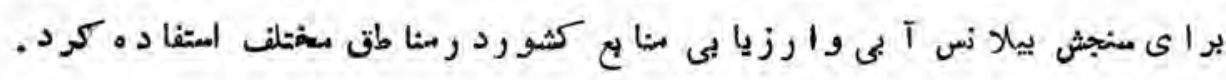

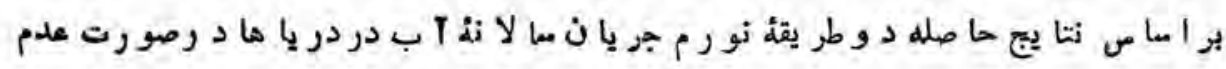

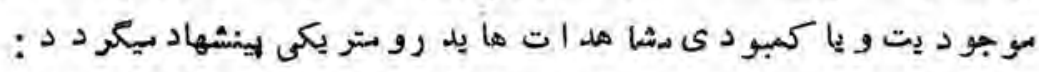

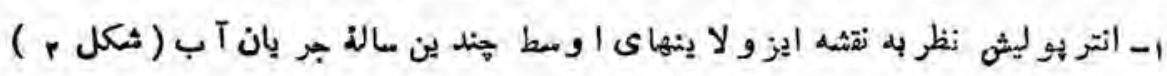

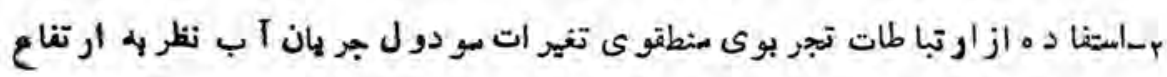

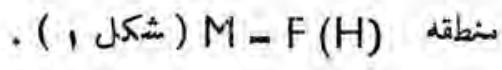




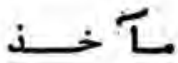

I. Водние ресурсы и воднуй баланс территорип Советского Солза.Под-ред.М.С.Протасьерв. -Л. : Гидрометеоиздат, І967. I99 c.

2. Гориков И.Ф. Гиярологические расчетн. - Л.:Гидрометиоиздат, I979,-с. 42-I57.

3. Зябкин В.В., Игошин Н.И., Абдул Али. Норма и измениивость годорого стока рек Афганистана. The sixth scientific conference abstracts of reports, Kabul, 1987.

4. Мировой родный баланс й водные ресурсы Земля. -Л.: Гидрометеоиздат, I974,- 638 с.

5. Цегапова 0.П. Генетический анализ и картографирование стоқа рзвешенных наносов рек Средней Азии.-Л.: Гидрометеолздат, I984, с. 6-49.

6. Шульц В.Л. Реки Аф̆ганистана. Труды среднеазиатското научно-исс,дедовательского гидрометеорологического института, выпуск 42/57/, I968,- I72 с.

7. Democratic Republic of Afghanistan,ministry of water and power "Hydrological yearbooks 1961-1978" Kabu1 1981. 


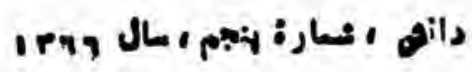

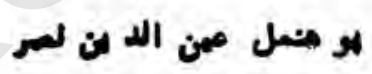

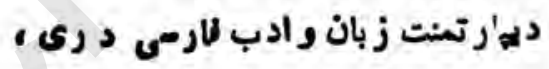

هو مثلث ز بان و اد بلهات

زبانشناسى وناصر خسرو

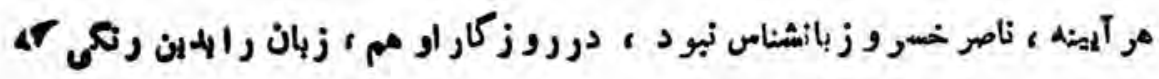

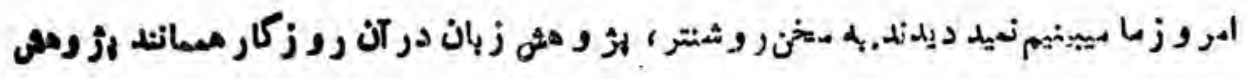

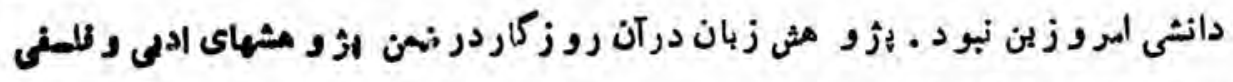

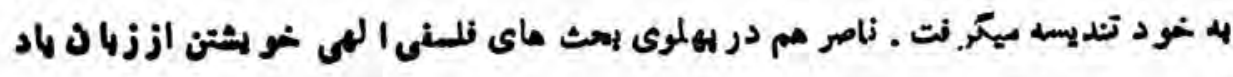

كردى بله ميان آو رده است .

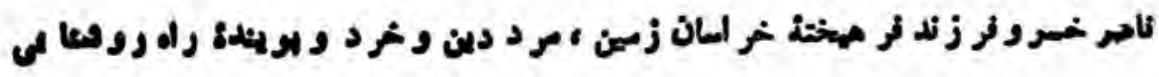
(ivr) 


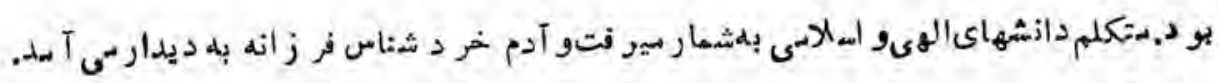

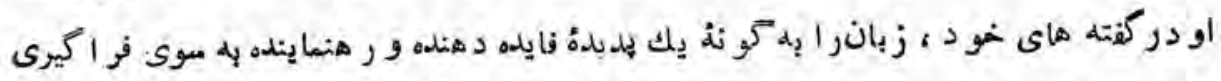

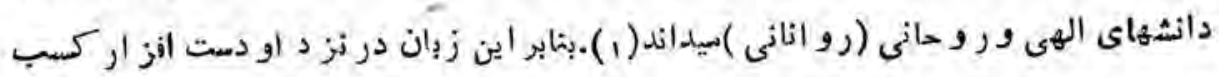

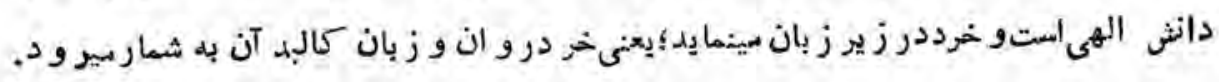

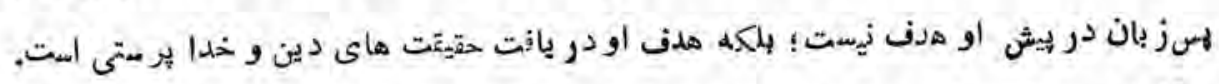

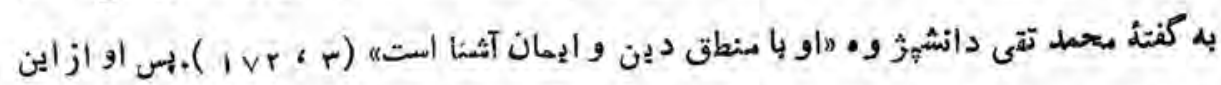

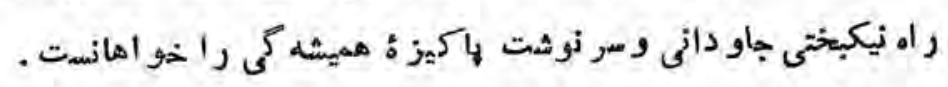

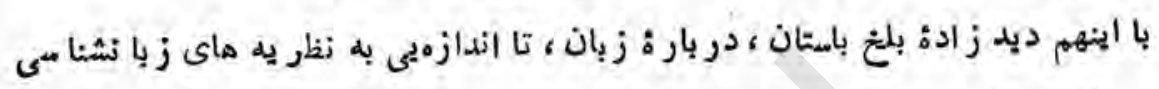

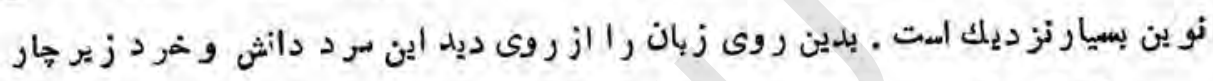

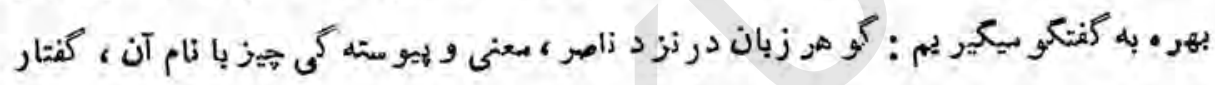

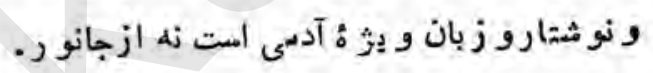

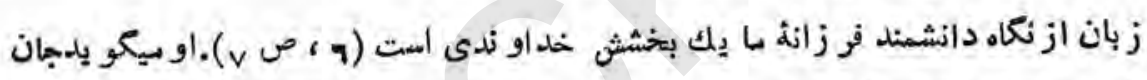

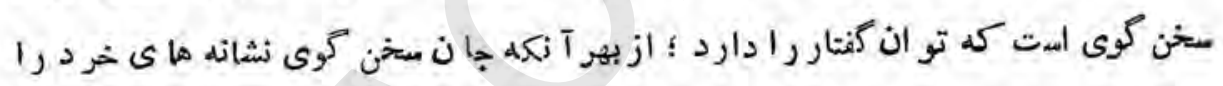

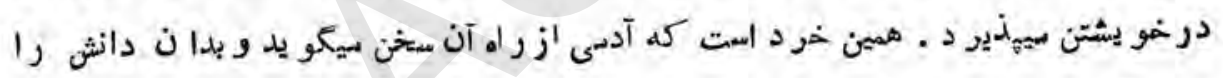

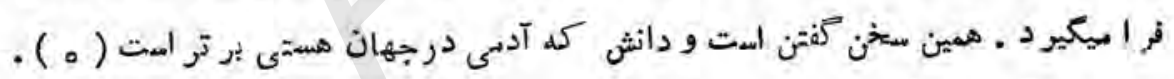

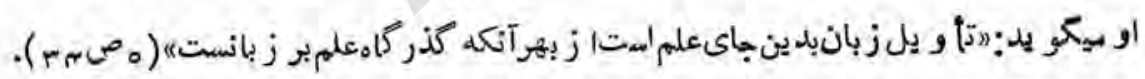

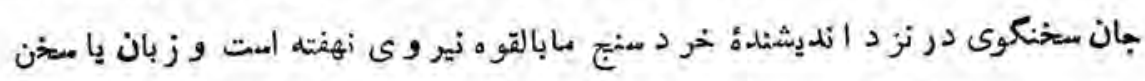

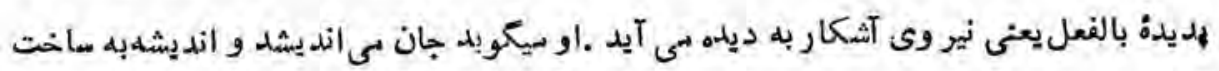

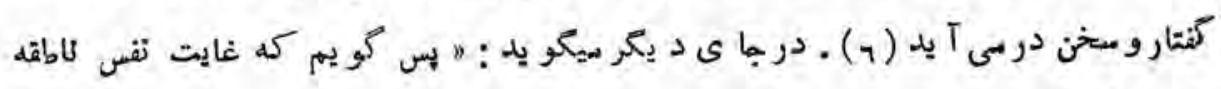

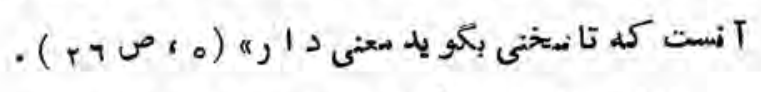

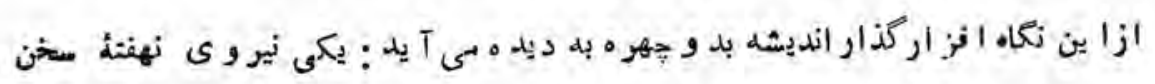




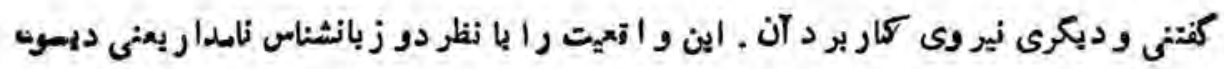

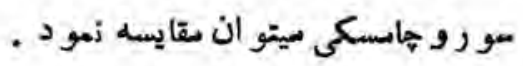
ديسوسو رتمام نماد هاى ذخير ه شلده در ذهن آدبى را كمه بر أى هملة جـامعل ز بسانى

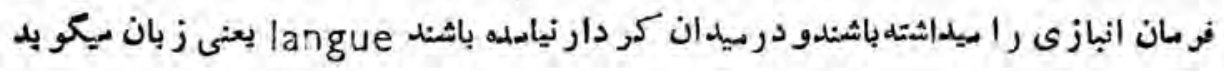

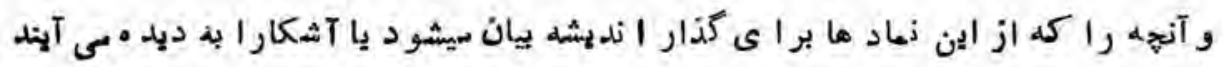

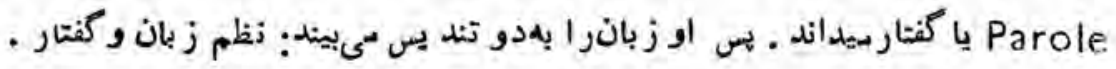

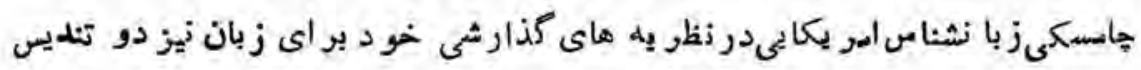

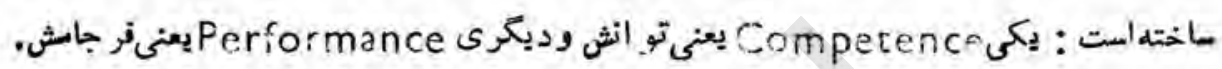

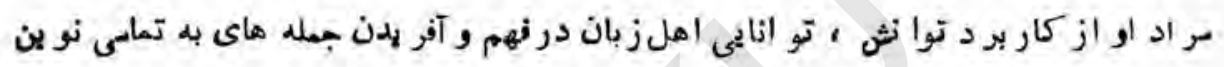

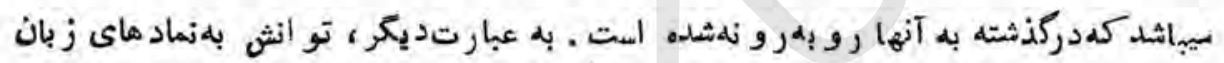

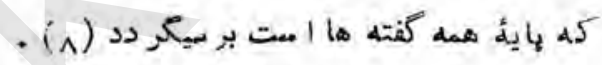

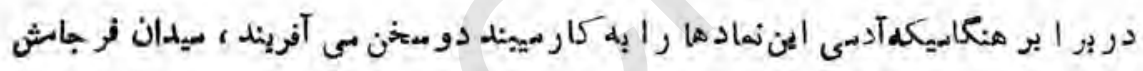

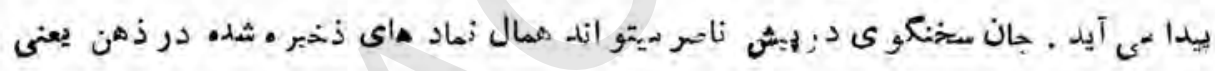

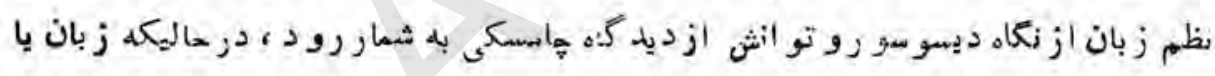

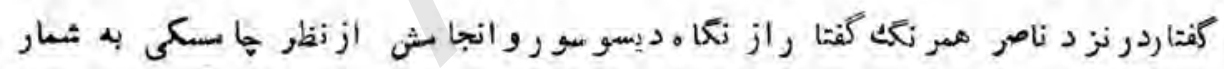

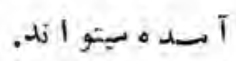

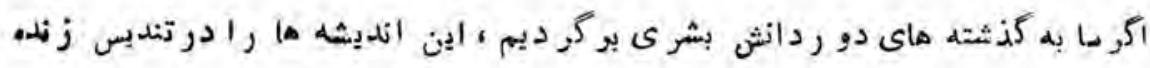

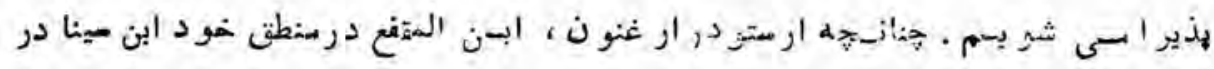

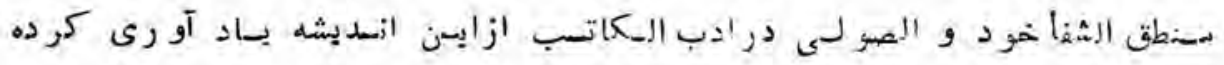

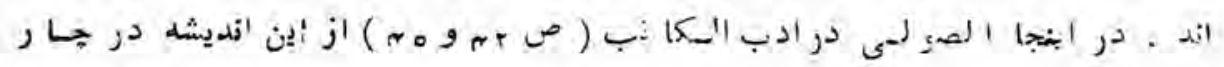

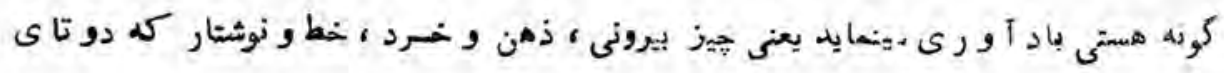




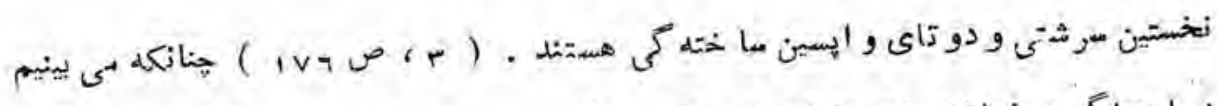

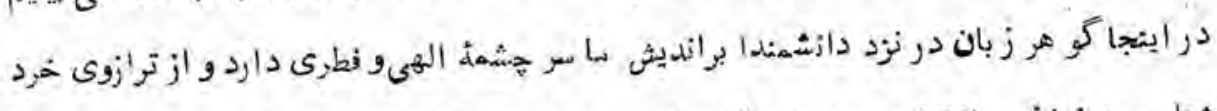

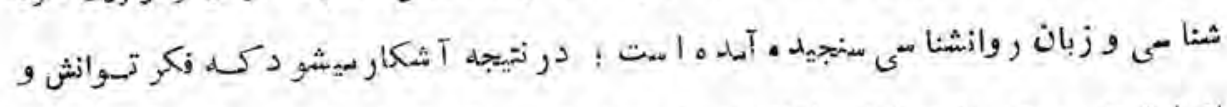

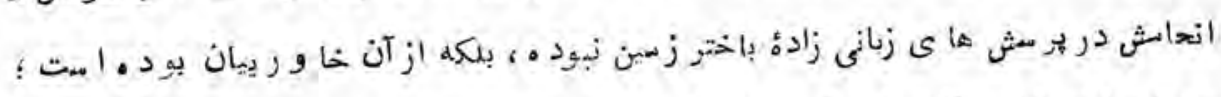

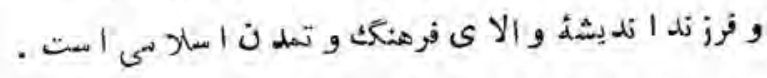

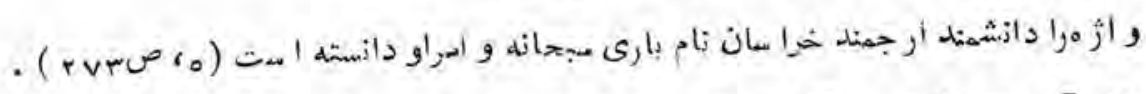

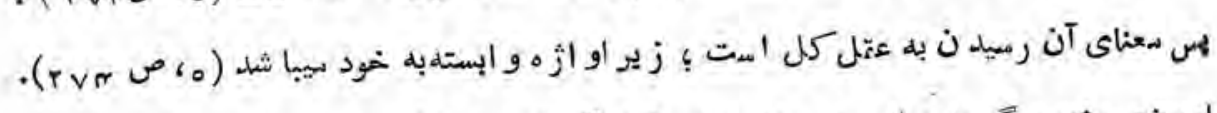

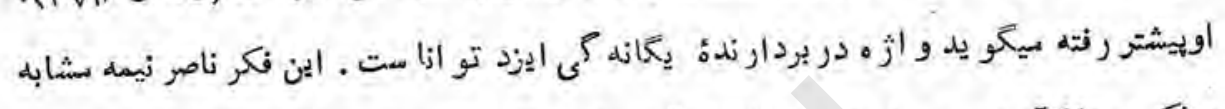

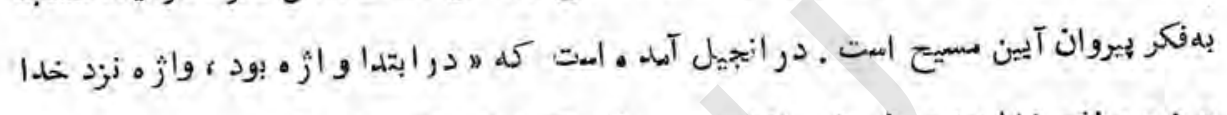

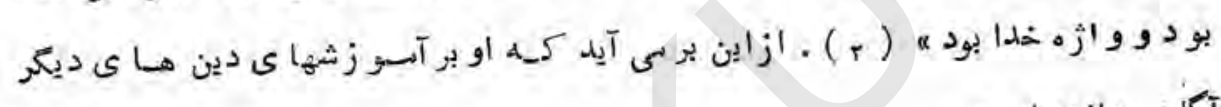

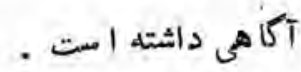

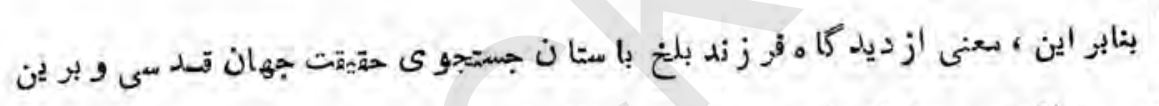

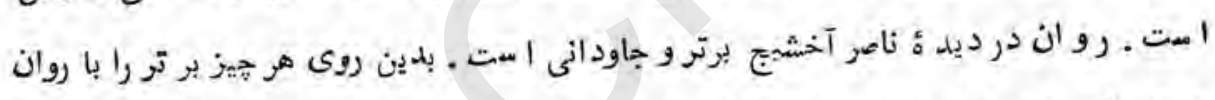

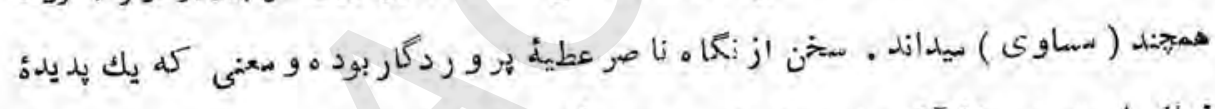

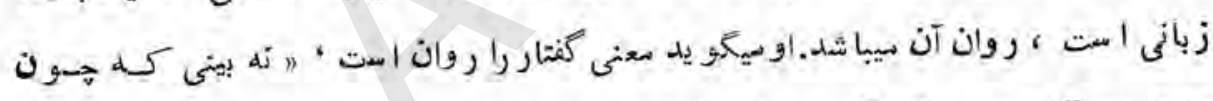

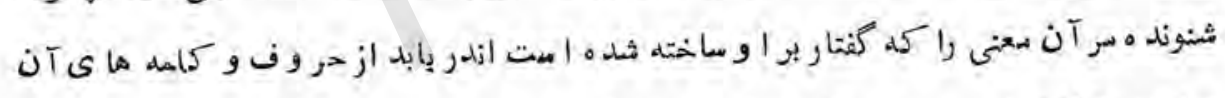

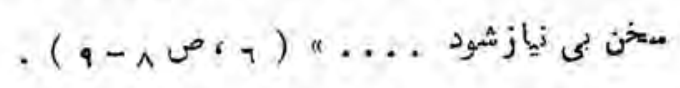

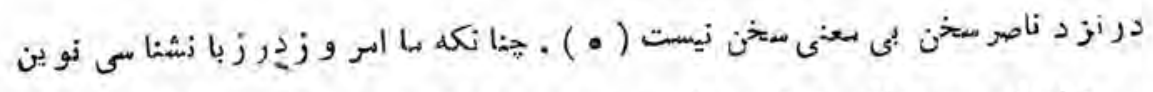

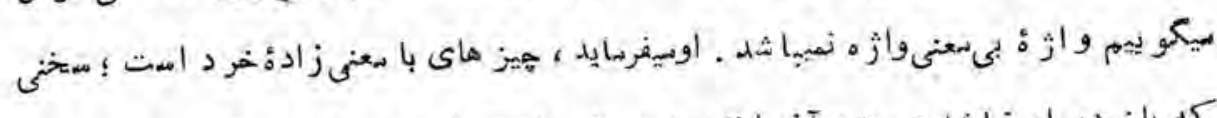

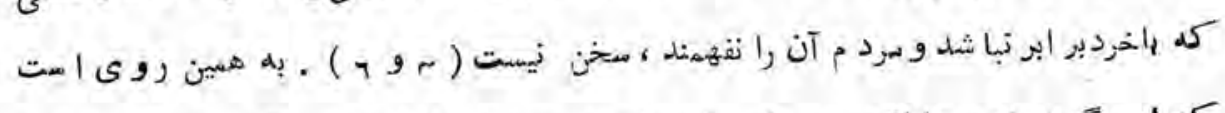

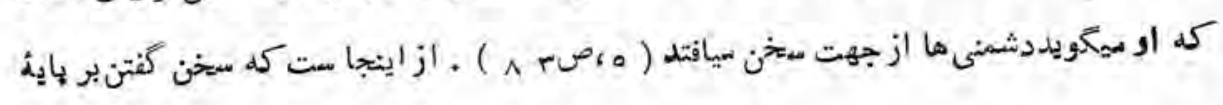




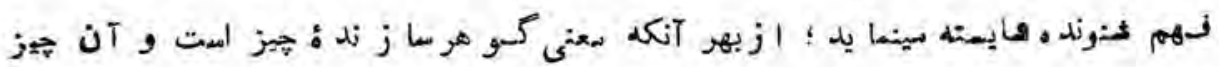

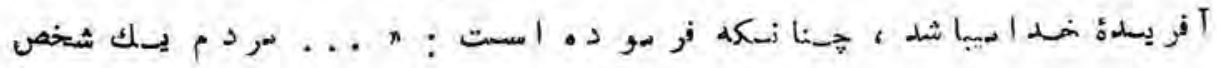

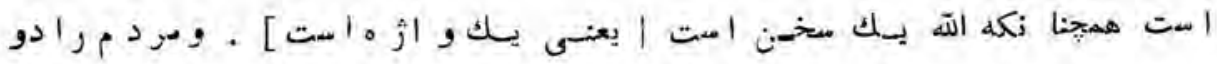

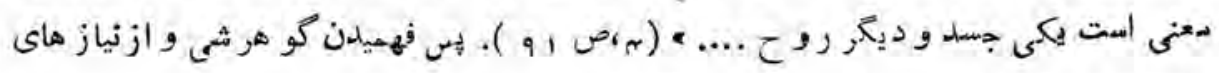

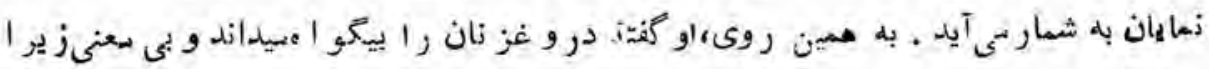

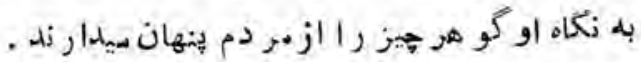

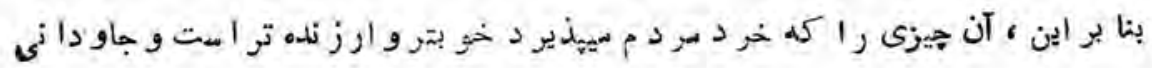

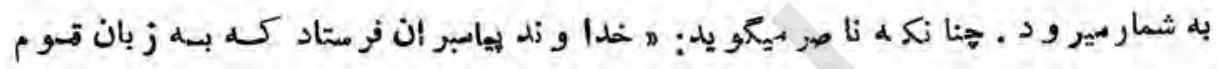

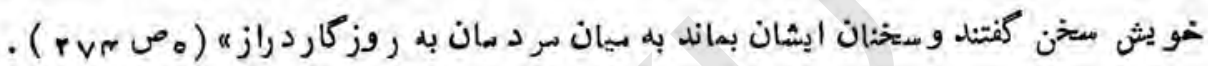

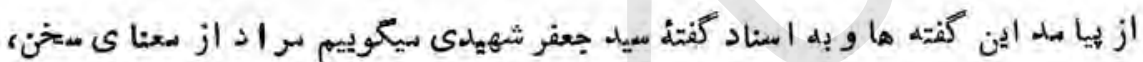

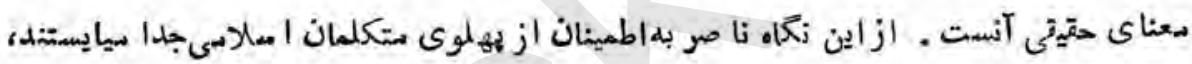
" هجه از ديد آنان صو رت بيداى سخن ارز شى ند ارد و با يد تأ و يل شو د ـ ما به تا ييد اين

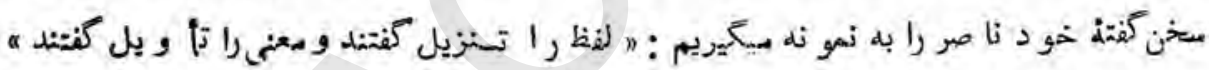

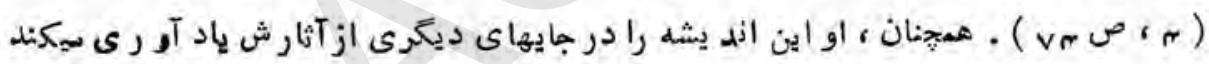

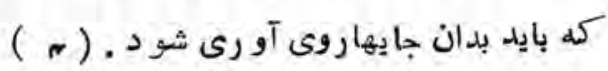

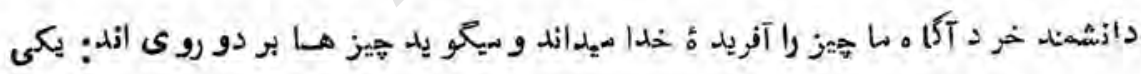

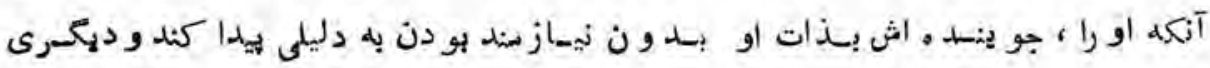

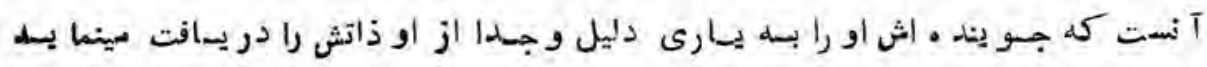

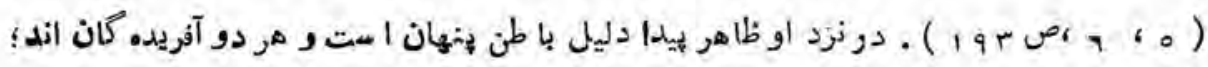

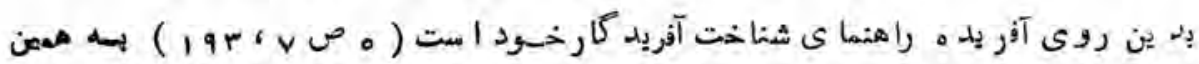
سبب بود كم كفتيم سعنى ار نكا ه نا صر خسرو حقيقت حيز است . 


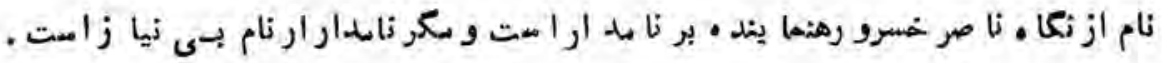
او نام را حرفهاى تركيب كرد ه سيداند كه در زيسرآن آواز است و ب-ازدر ز يسر آواز سعنى

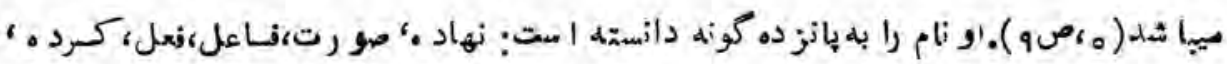

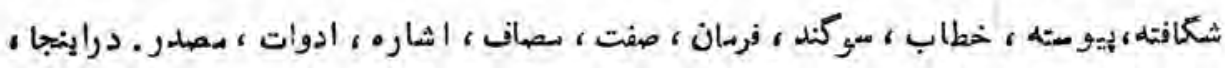

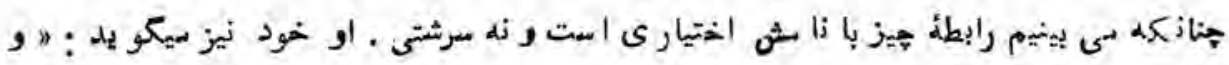

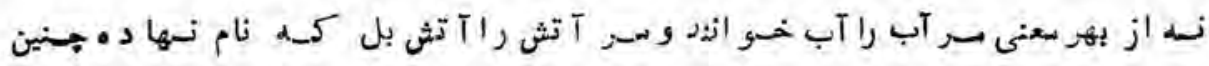

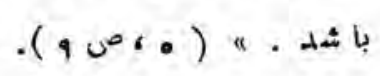

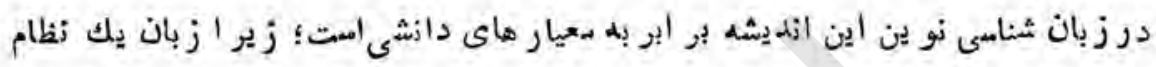

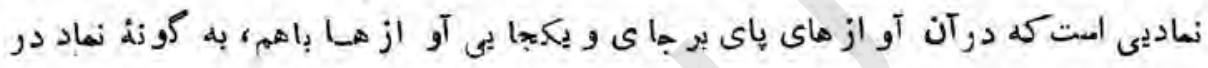

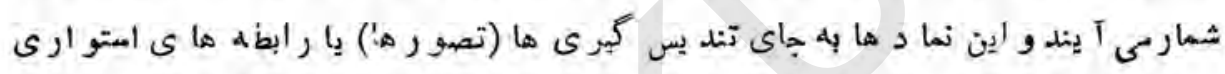

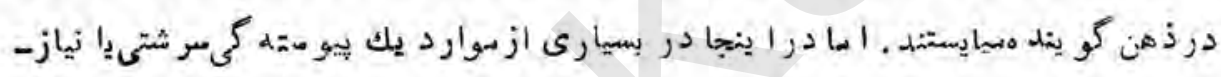

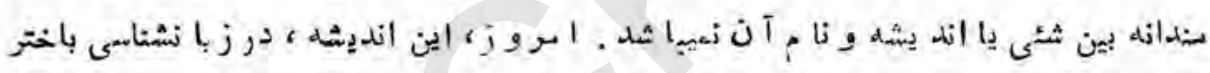

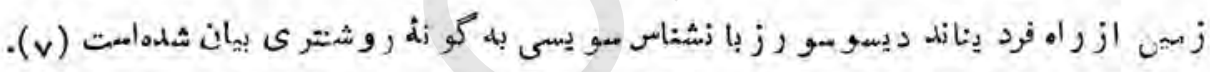

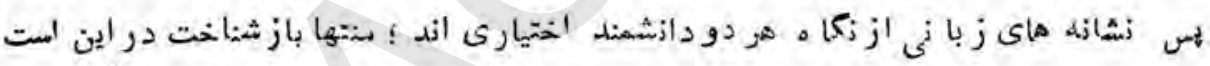

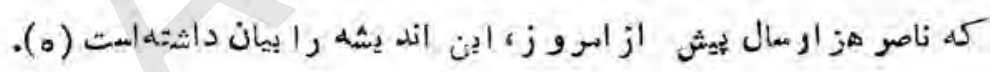

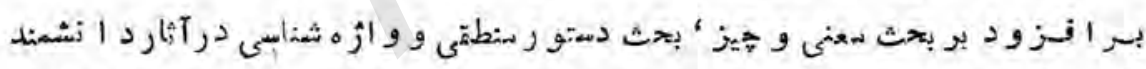

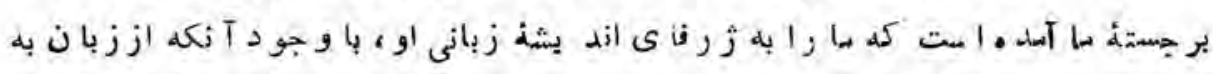

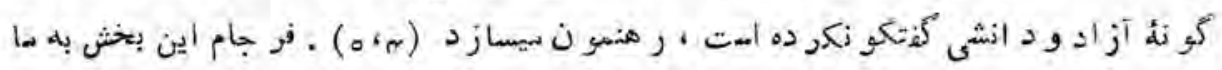

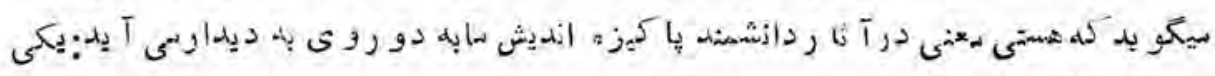

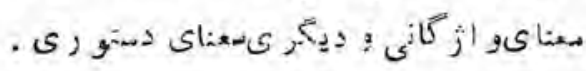

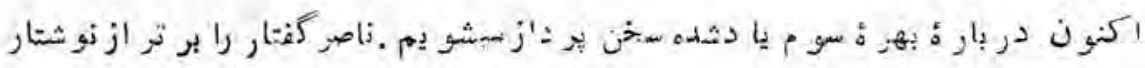

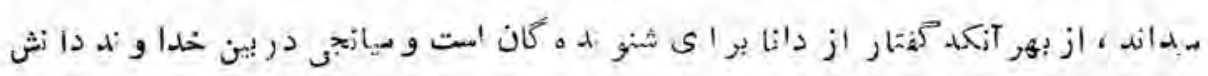




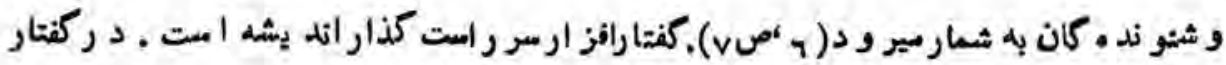

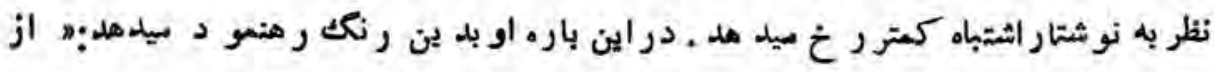

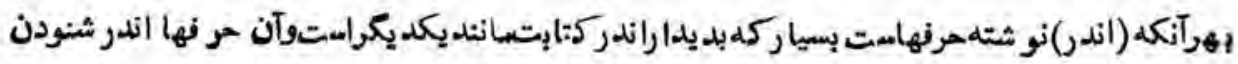

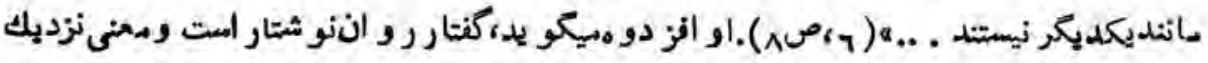

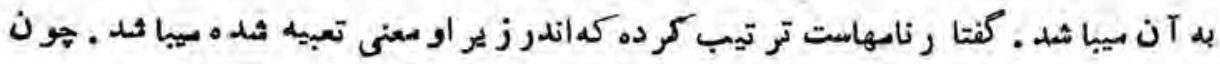

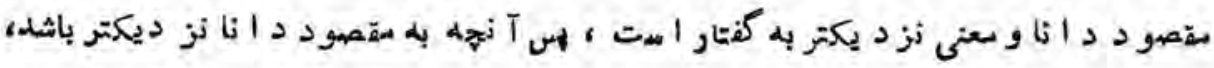

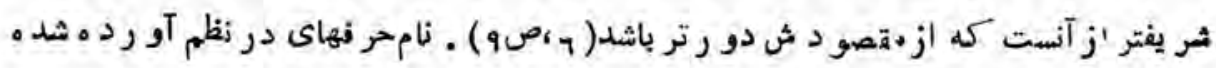

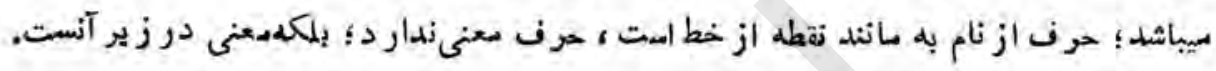

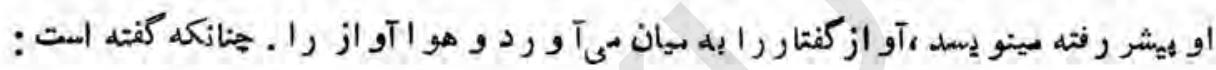

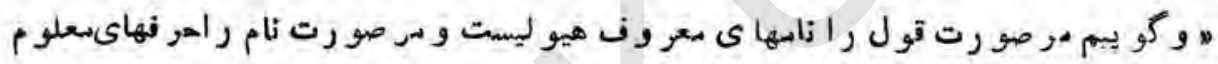

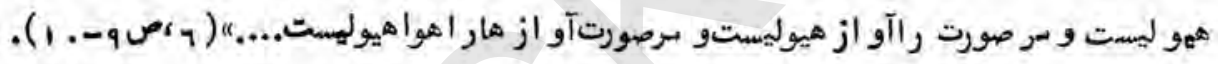

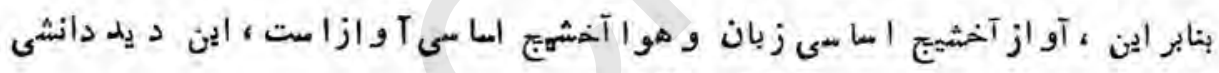

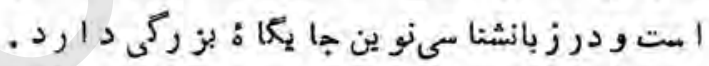

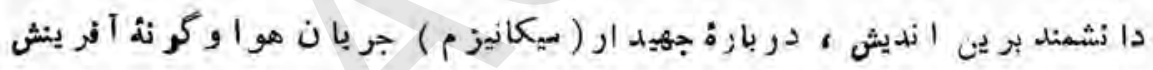

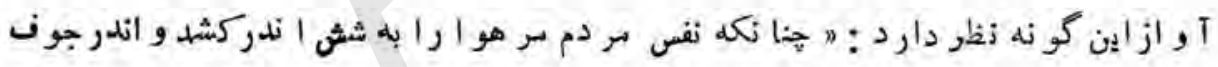

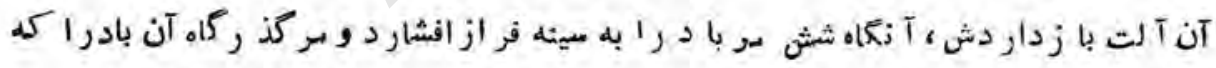

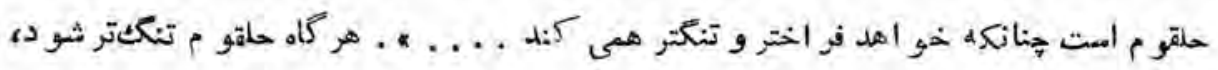

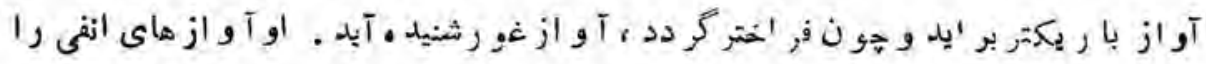

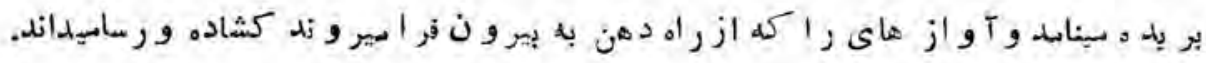

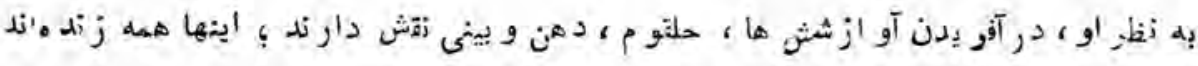

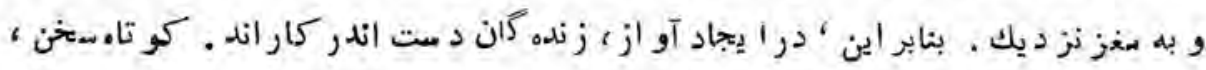




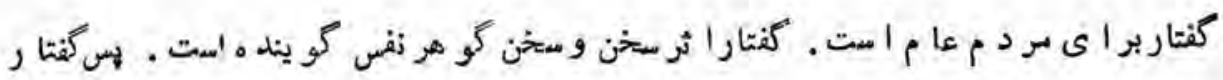

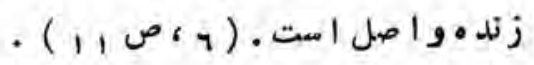

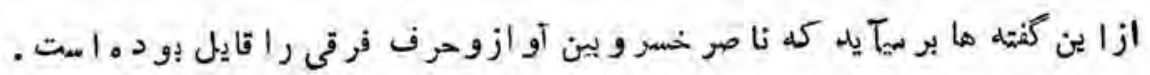

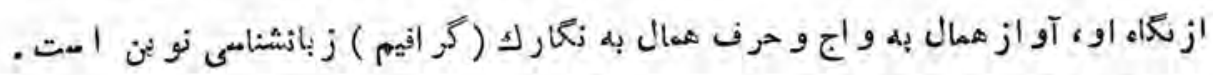

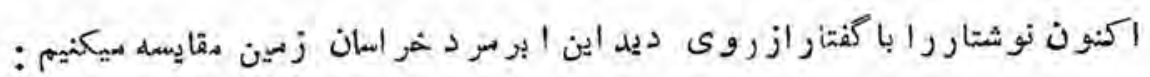

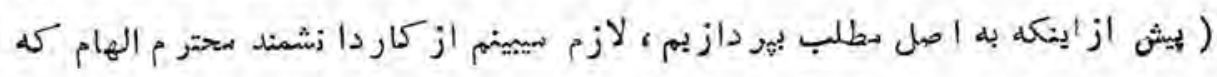

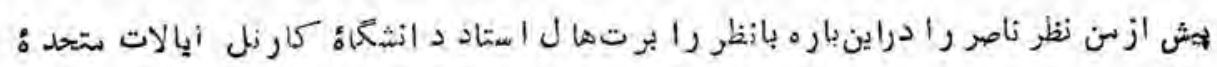

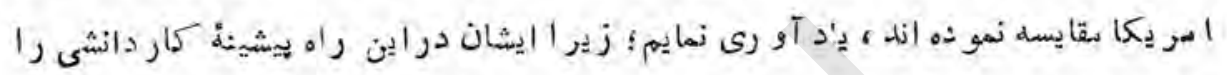

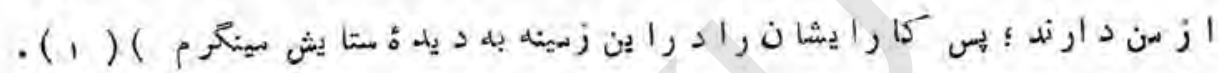

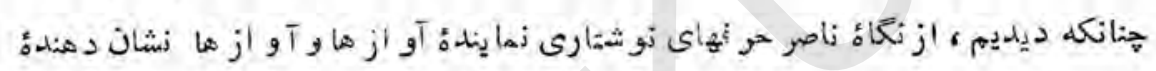

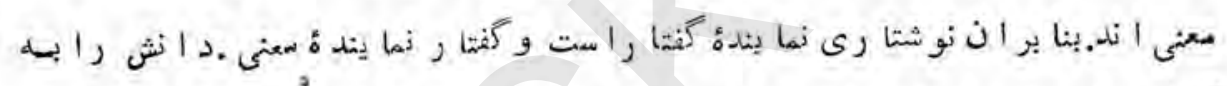

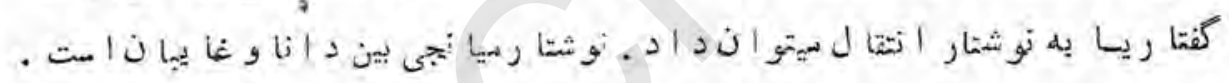

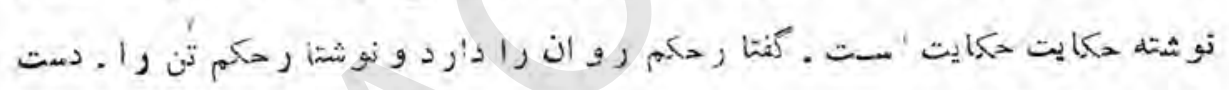

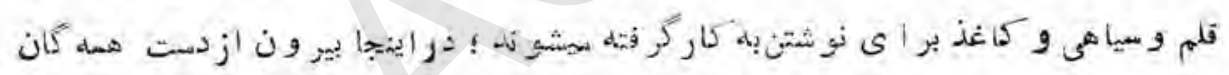

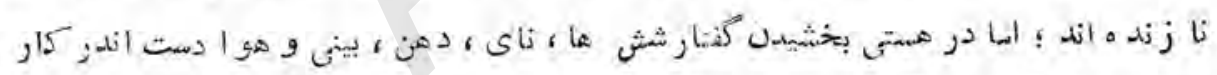

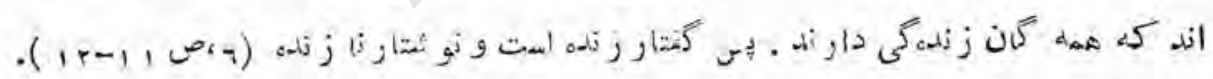

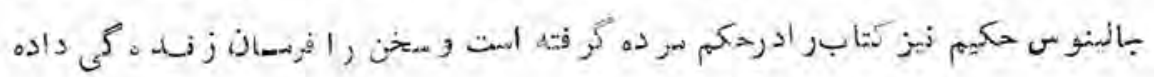

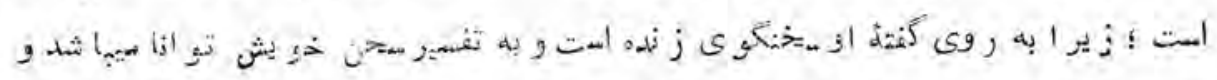

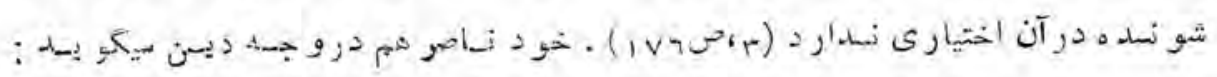

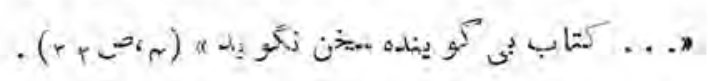

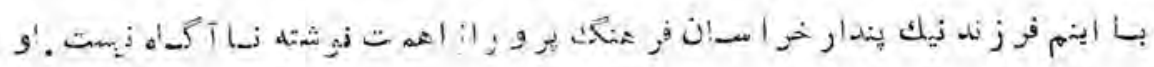




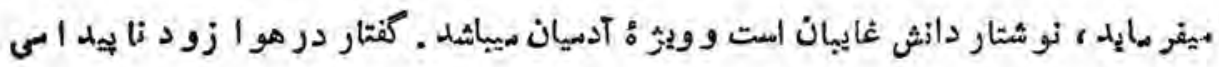

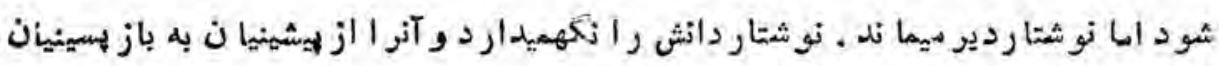

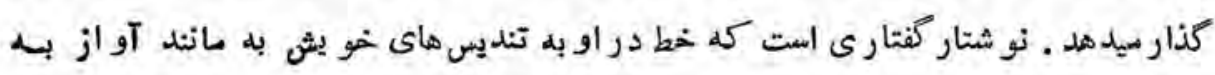

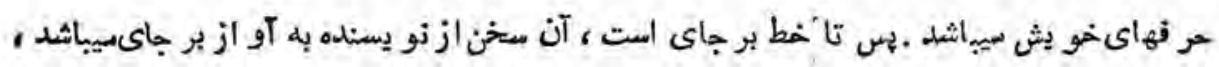

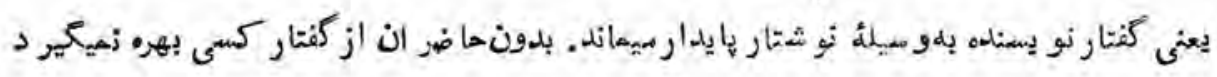

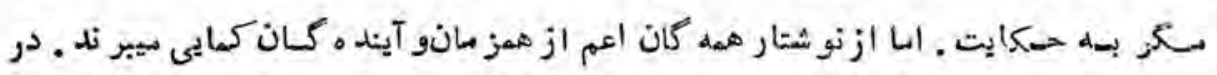

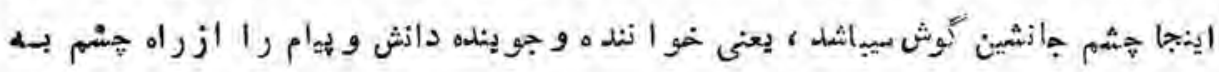

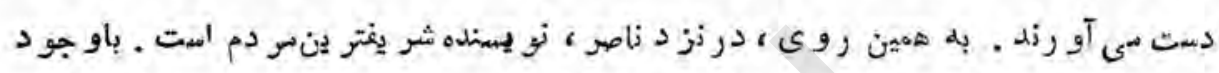

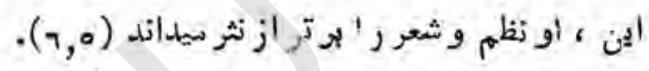

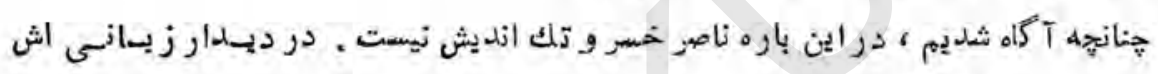

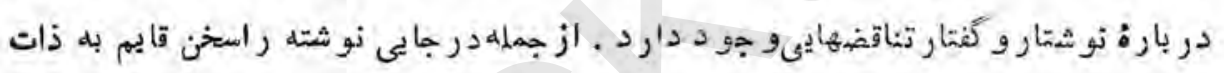

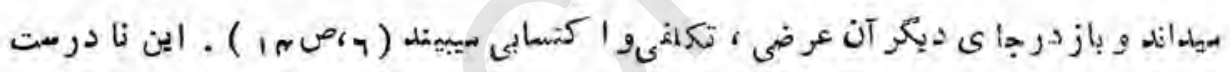

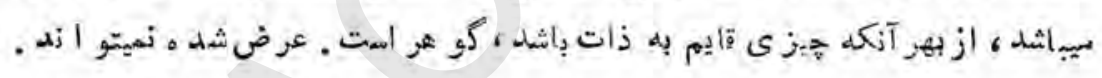

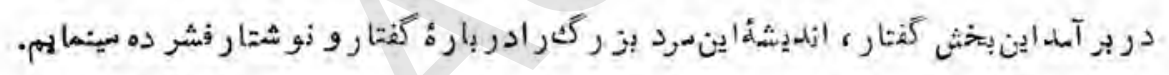

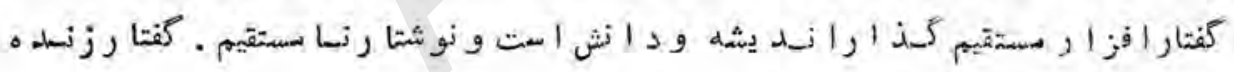

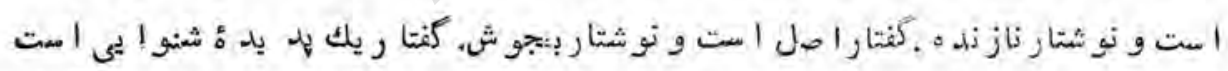

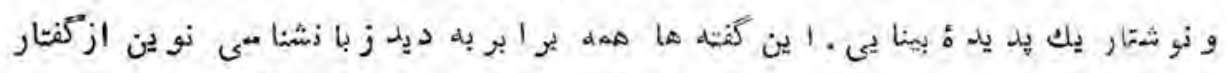

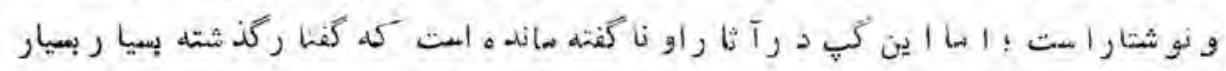

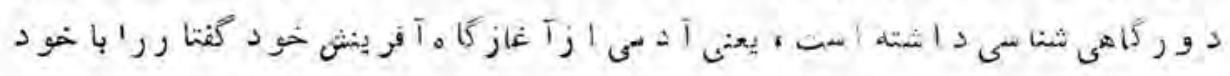

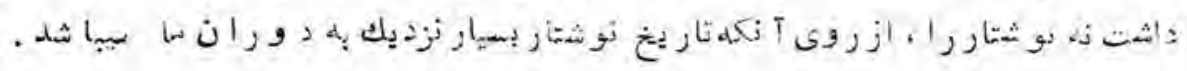

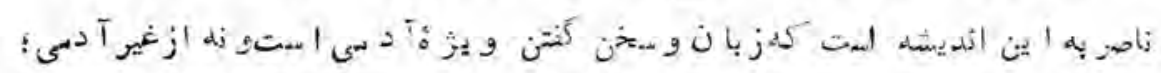

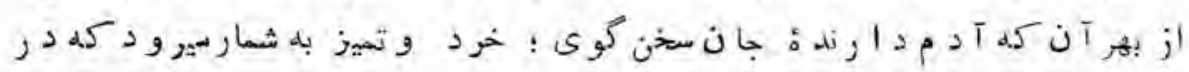




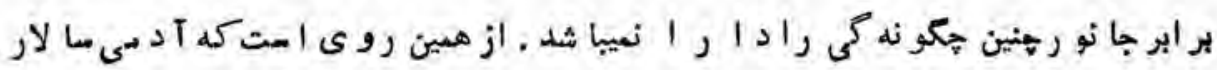

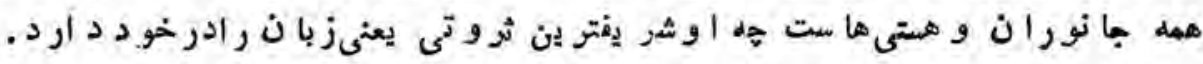

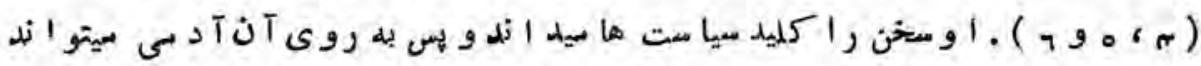

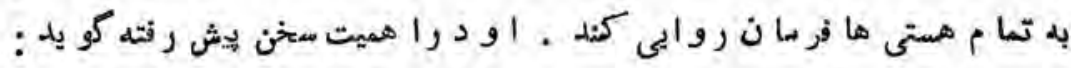

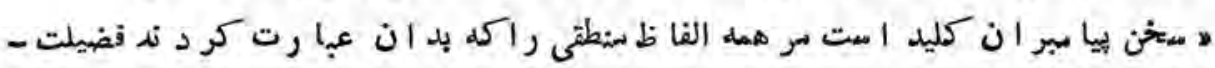

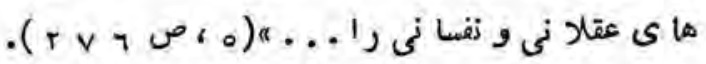

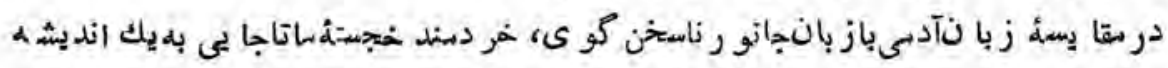

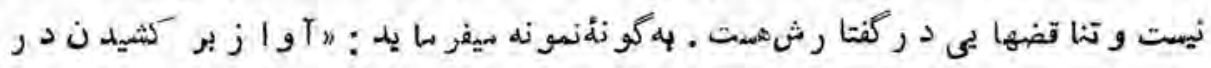

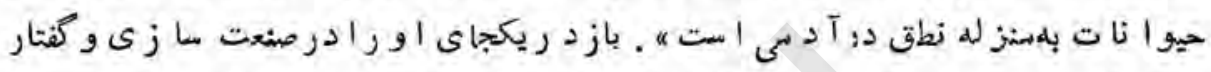

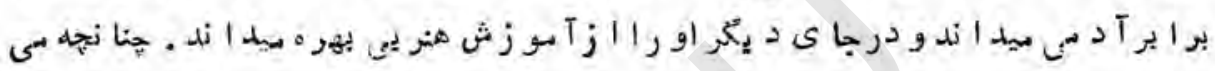

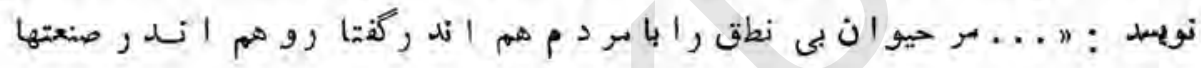

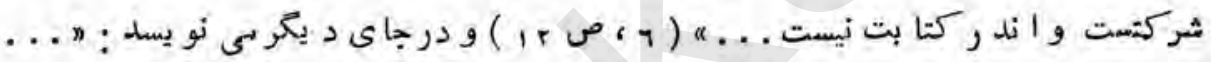

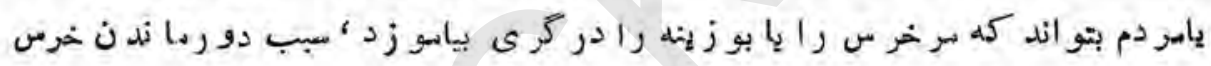

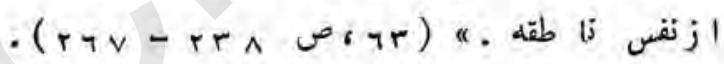

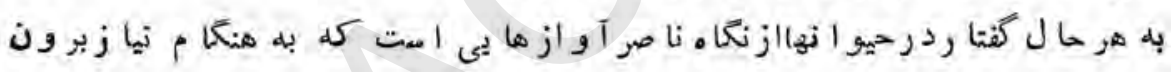

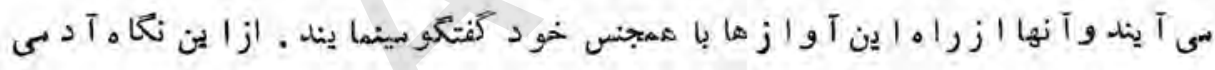

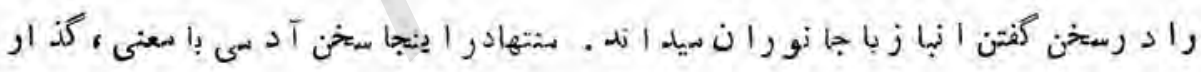

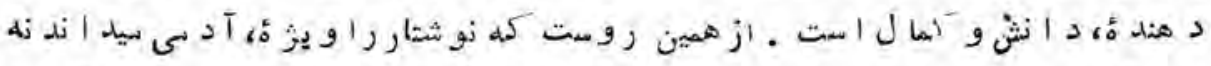

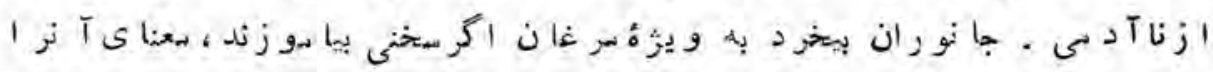

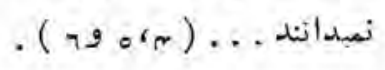

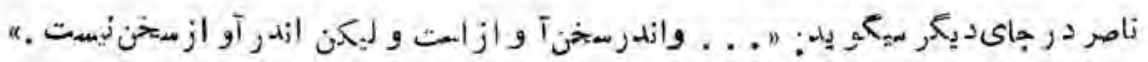

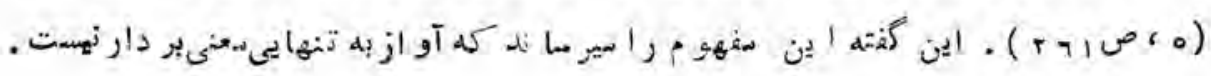

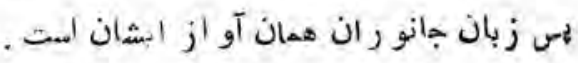


نظر زاصر راجع به زبان جانو ران ا شاره به نا بار ور ى ز بان انها است . اليشان از

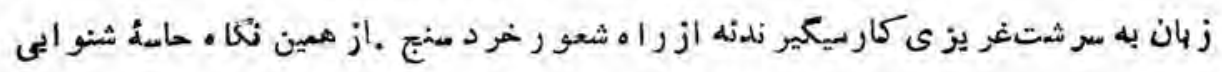

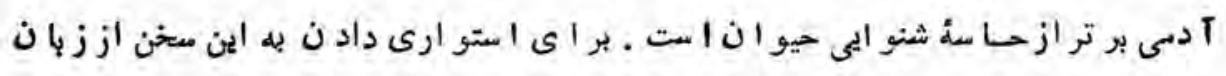

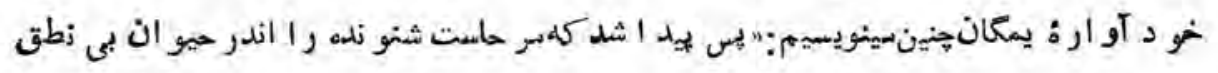

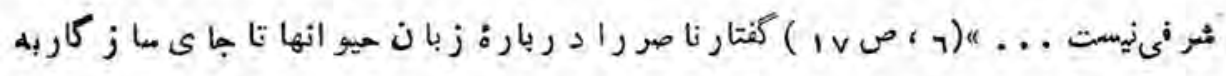

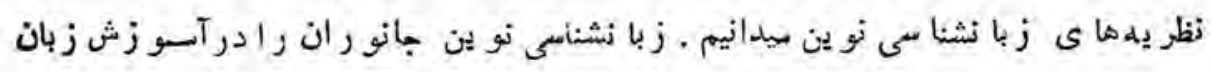

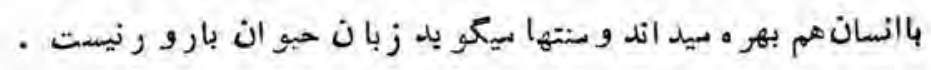

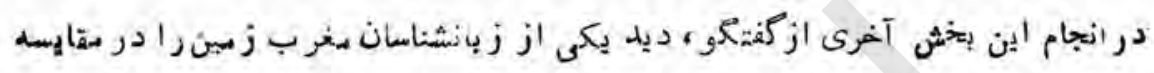

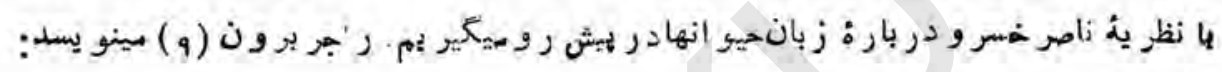

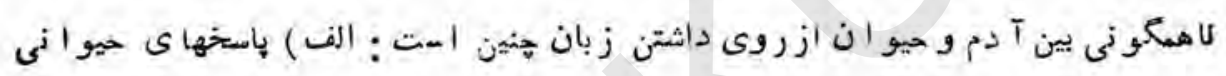

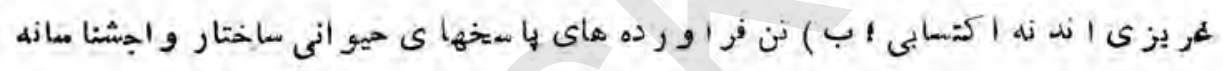

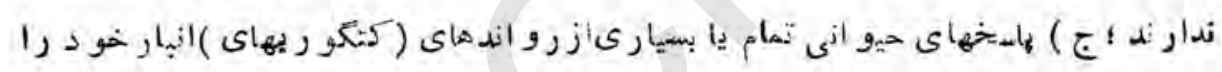

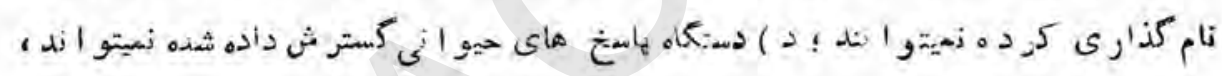

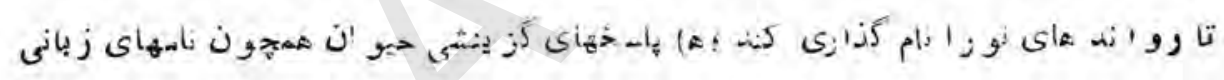

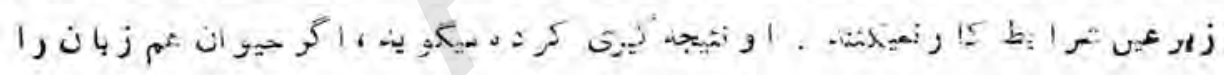

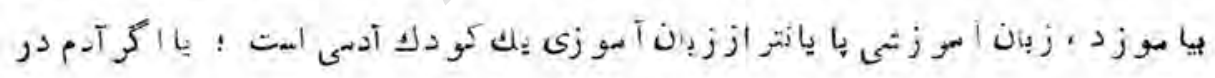

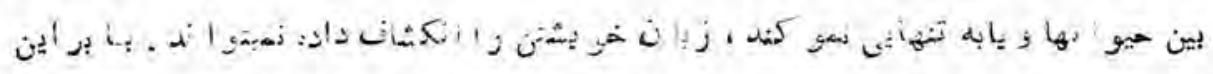

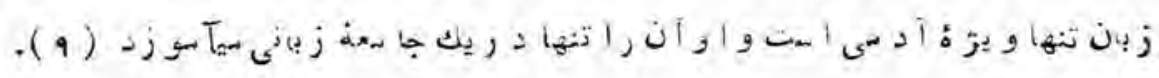

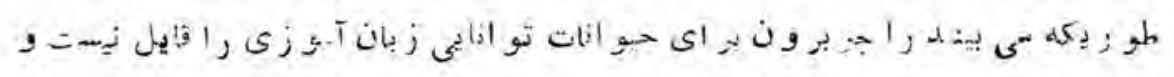

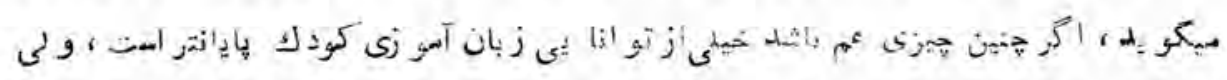

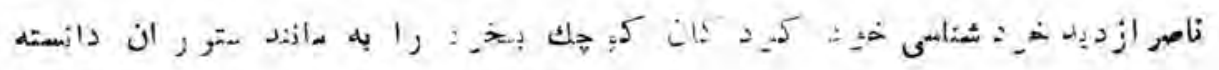


است ( r ، ص م. ) . از اينجاست كه هستى خرد ، نها يانكر مستى زبأن درنز د دانشور

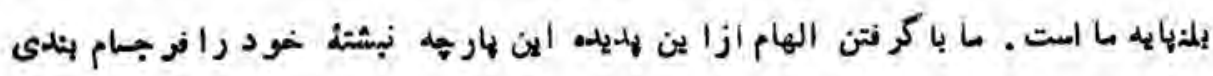
مينمايم • د رماليكه در ز بانشاسى نو ين علت بى ز يانى جا نو وان ، نبو د ن ماروارة (اركانيز م (و الك ماز امت .

ز بان سله روى بر داشت اين تعر يف همه كانى - يعنى هـر هيز ى كسه اند يشه لهى را

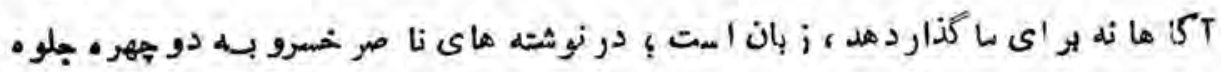

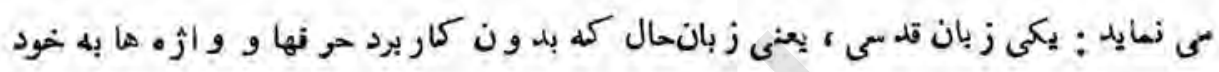

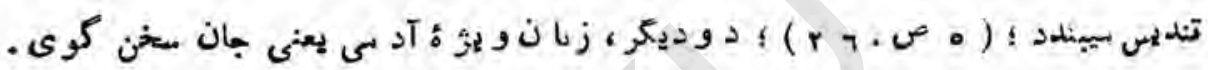

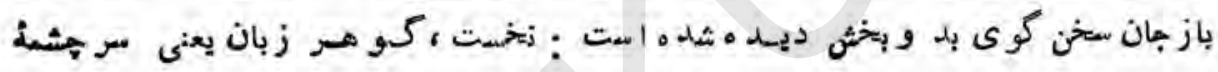

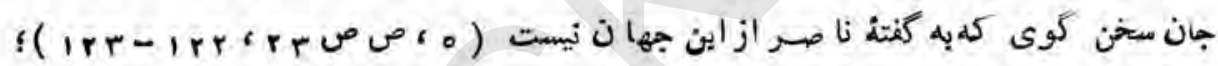

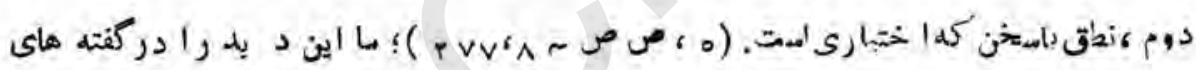

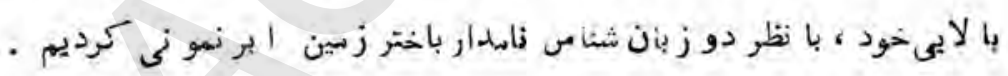

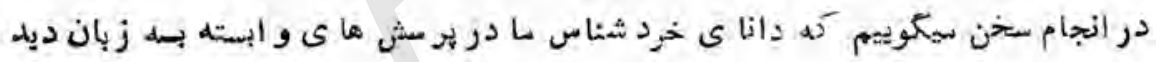

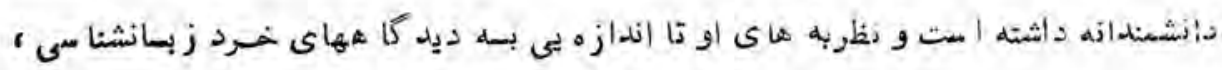

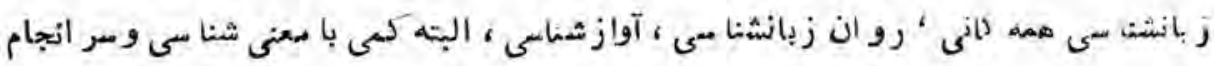

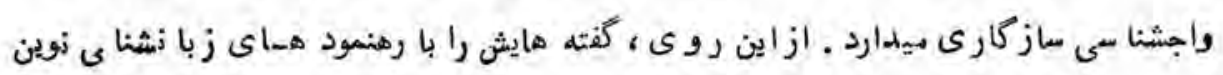

سيتوان درست سنجيد .

(1 re) 


\section{ماخلف}

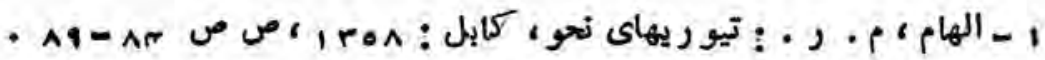

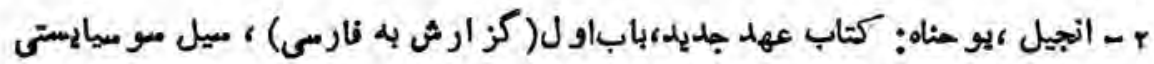

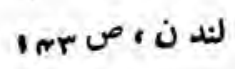

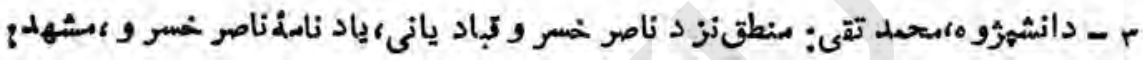

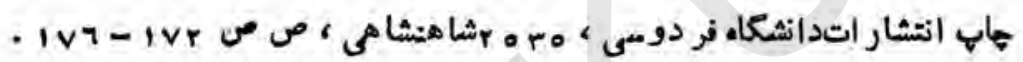

" - نا عو خسر و . و جله دين ، تهر ان : انتشار ات ا زجمن شاهنشاهى فلسفل اير انه

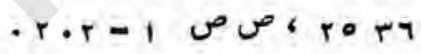

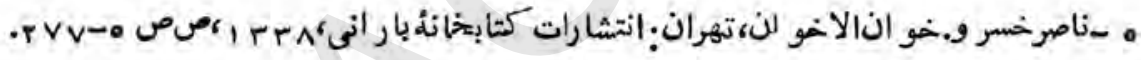

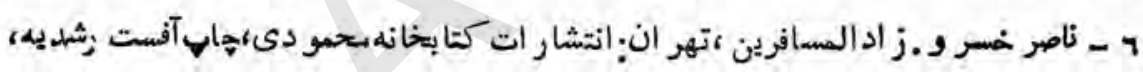

. r...v ص ص

7- Arlotto, A. : Introduction to Historical Linguistics, Boston: Houghton Hifflin Company, 1972. PP. 33-35

8- Bach. E. : Syntactic Theory. New York: Holt, Ririehart and Winston, INC., 1974, P. 110.

S- Brown, R.: Words and Things, Glencoe, Illinois: The Free Press, 1954, PF. 192-193. 


\title{
Abstracts of Papers Published in
}

Danish, Journal of

Kabul University

$0039 / v-04 / 01 / V 1-N 5$

\begin{abstract}
Epidemiological Studeis of
Leptopirosis in Different

Species of Animals in Kabul
\end{abstract}

i) I. J, Abher \& Dr. G. Mo Arzo

Dept. of Faraclinic, Faculty of

Veterinary Science, Kabul Univ.

Using the slide agelutination test, 105 animals were studied against Leptospirosig infection with four pool of antigen, out of 70 cattle both sexes $(30 \%)$ were showing positive results, while out of 30 sheep $(23,3 \%)$ were positive. Hesiles that the results obtained from 5 Goats were negatin

$0040 / \mathrm{V}-05 / 02 / \mathrm{V} 1-\mathrm{N} 5$

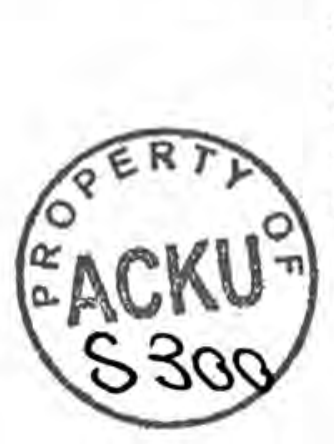

Zootechnical Characterestics
of Some Local Feeds or Foods

Chemical composition and

Nutritive Value of Some Energy

Concentrated Feeds

Fohandoy Dr. G. M. Tanin

Dept. of Animal froduction,

Faculty of Veterinary Science,

Kabul University.

The air aried samples of 7 enercy concentrated feeds 
from different parts of Afghanistan has been analysed.The main values for moisture, crude protein, crude fat, crude fiber, nitrogenfree ex ract and crude ash percentage are respectively given as follows: Corn $9.18,9.47 .4 .60,2.30$, 73.05 and $1.40 \%$; wheat $10.13,9.50,1.57,2.57 .75 .20$ and $1,68 \%$; 3ar1ey $-9.82,11.21,2.26,4.47,69.01$ and $3.23 \% ;$; 0at $9.18,9.62,2.21,2.79,74,38$ and $1.83^{6}$; Thin rice- 11.55 .5 .92 , $0.73,0,57,80,13$ and $0.83 \% ; 21110 \mathrm{t}-10.47,9.45,4.58,8 .=3$, 61. 04 and $5.40 \%$ and Italian millet-6.97,9.52,4.70,8.88, $6.2,44$ and 5.500.

(1) $141 / 4-06 / 103 / \mathrm{V} 1-\mathrm{v} 5$

Efect of ineryy on The l'erformance, inysicit and Chemical Coposition of the hody in liereford steers Johanmal N.A. Ahamad, Dept. of huimal Froduction, faculty of veteriascy science, iabul iniv.

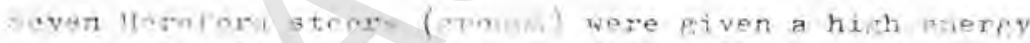

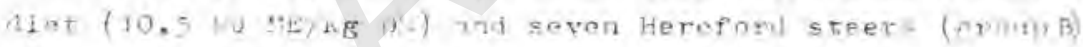

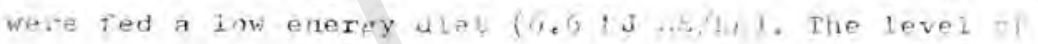

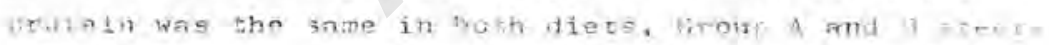

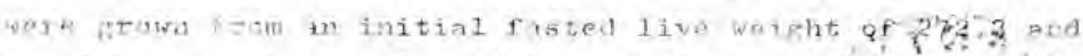

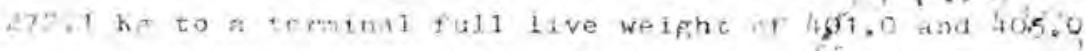
1.x. sespectiveiy. Group $A$ steuns had a lowef feed intake, a getter fred conversion tatio and a hisher dássing percentage then those of group 3.

the deposition of lat at the various fat depots and rib? joints were sienificantly greater for eroup A steers, thas those of group i steers. These differences between the two eroup still remalned sienificantly different after empty body weight was used as a covariate.

It is surzested that by keeping the protein content of the (2) 
diet costant, the deposition of fat at various fat depots, physical and chemical coposition of the rib joints may be altered by the manipolation of the energy concentation of the diet in Hereford teers at any given empty body weight.

$0042 / \mathrm{B}-01 / 04 / \mathrm{V} 1-\mathrm{N} 5$

Possibilities of Peanut (Arachis hypogaea L.) Cultivation and Development in Afghanistan .

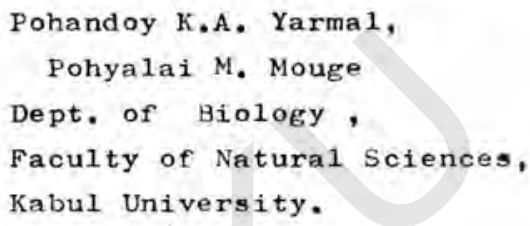

In this research project beside the quantitative determination of ohemical composition of shelled peanut, the vosibitities of growing peanut in the conditions existing (1) Afghanistan has also been discussed,

on the basis of quautitative determination, the obtaz of results of this research on plant auts' protein,fat,cse, motsture and dry matter is total have a small Aiflesence with tlie results of other futhors, who are antirfly sintlac to the values of two references but with the valces of two othei references show a high difference of 5 . 8 liq and a low difrerence of $0.4 \%$.

On the basis of consideration in climatic condations of Afthanistan and coliparison with the world's regious where pernut is frown, the frowthe possibilities for this plant in view of hish temporature and high amual rainfall especially are procurable in the south-eastern and eastern zones ix the eountry. 
$0043 / A-07 / 05 / V 1-N 5$

The Carbohydrates Metabolism

in Grape Berries

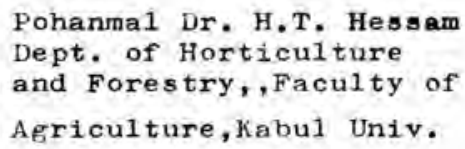

The most important materials produced in the metabolism of the grape berries are carbohydrates, acids, nitrogenous products, pigments and cations which produce salts with acids. Eight to 15 days after initiation of ripeninf process of the berries, sugars and nitrogenous materials accumulate in them and the amount of maleic acid is decreased prompetiy.

The accumulation of sugars is due to the carbohydrates of vegetalive parts of the plants.

The metabolic process depend upon the action of certain anzymes such as Invertase, Hexikinase, Phophatase sucrose etc. The glucose cuntent of the berries is high at the beginning of carbohydrate accumulation, but later an egvaliberioum establishes between the amount of glucose and fractose. During the ripening process of the berries, changes occur in the amount of important acids such as maleic,tartario and citric. It should be noted that Abscisis acid plays the role of a hormone in the ripening of grapes. pigments are not transformed to the berries instead they are produced inside them, except for the grapes that have coloured flesh and skins. 
$0044 / \mathrm{A}-08 / 06 / \mathrm{V} 1-\mathrm{N} 5$

\author{
Origin,Evolution and Economlc \\ Importance of Horses in Afghanistan
}

Pohanwal 0. Akbari

Dept. of Animal Siences, Faculty of Agriculture, habul University.

The horse as a farm mammal, probably was the last of the farm animals to be domisticated by man. It appears to have been first domisticated in central Asia more than 3,000 B.C.

The horse which in Afghanistan, is used for various purposes such as food,military, receration, sport, agriculture etc. has evolved from Eohippus (dawn horse). This horse which was only 11 inches ta11,1ived during the lower eocenp.

$004.5 / \mathrm{A} 09 / 07 / \mathrm{V} 1-\mathrm{N} 5$

$$
\begin{aligned}
& \text { Analysis of labor Productivity } \\
& \text { in Agriculture } \\
& \text { Pohandoy A. Ghani Taj } \\
& \text { Dept, of Agricultural Economy } \\
& \text { and Planing, Faculty of Agri- } \\
& \text { culture, Kabul University. }
\end{aligned}
$$

The main them of this article are:to distinguish the labor productivity in agriculture and to elaborate which factors are necessary for maximization of labor productivity Labor productivity depends on the amount of production produced per unit of time. The more the amount of output per unit of time, the higher the labor productivity.

Labor productivity indices vary according to the length of time and the between costs and revenue per unit of labar time. According to this, labor productivity could be illustrated by direct and indirect methods.

The factors affecting the labor productivity expansion 
in Agriculture are: Intensification of labor, Specialization in production, Application of science and technology. Fxiunston of production incentives, Training of qualified worker and Specialists.

$0046 / \mathrm{F}-02 / 08 / \mathrm{V} 1-\mathrm{N} 5$

Pharmacognostical Investigation of dcillea Santoline L. of Afghanistan

Pohand Dr. A. R. Roshan

Dept. of Yharnacognosy

Faculty of Jharmacy,

Kabul university

In this work there will be discussed some chemical properties of medicinal plants (Achillea Santolina L.) in tine country. The quantity of essential o11 will be evaluated by glvinf different samples collected from varlous parts of Afghanistan.

In conclusion, the samples selected from Kabul University area show the mani:uru quantity of essential oil (0.5\%). In aditition, the cindicnl compounds sucli as Lewco, anthocyan, anthocyn, rlavpuste s and tanin were detected in the plants.

$0047 / G-0 h / 00 / V 1-V=$

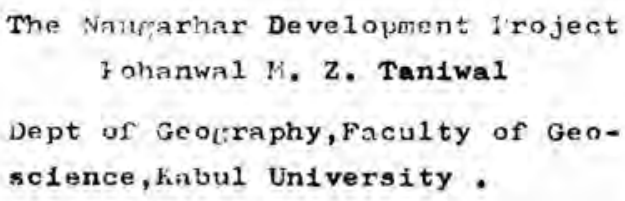

The Nangerhar valley development project is one of the most important projects in Afghanistan. The Nangarhar project started in 1339 was constructed with technical economical cooperation of the Soviet Union. 
The main purpose of this project is to mechanize the agriculture through founding the mechanized state farms,the development of apriculture and the stock raising including the production of citrus fruits and olives.

The main canal in the project has a lenfth of 70 kiloneters, ind the land under irrigation is around $(500) \mathrm{km}^{2}$, from which about $(5058,6)$ hectars of land are allocated to stete farms; From this lani $(10 \% /, h)$ hectars are under citrus fardens, $(3071,4)$ hectors for olive production and the remoininf $(2,8)$ hectare are for other pirposes. In ndaition to increasinf the agricultural and industrial production, the project had fob apportunities for more than (zono) persois.

$0048 / G-05 / 10 / v 1-v 5$

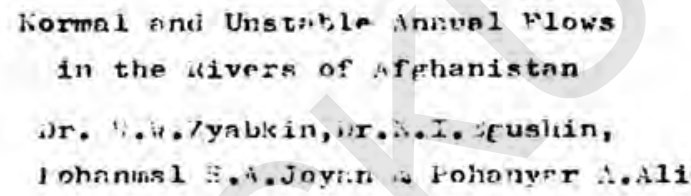

In this poper, there lins befn discassed ful evaluted the data for whter discharfo in 125 stations. (7)

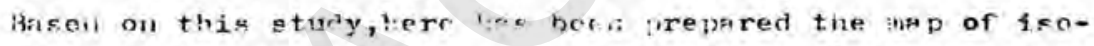
lines of snumal riows in folmuisten (fie. 2) for tie firs. time. The stutiy of the effects of ied;ht in the rirainse wfolis over tize flow woolel (rif. t) fud the calculation of metability factor (fif. F) rirde it oossible to Hivide the whole country into four primery ant two secondary hydrolofical znnes.For ench zone therc are found, refional ampirical ir oxperimental relations as inficated below. $\overline{\mathrm{H}} \boldsymbol{f}(\overline{\mathrm{H}})$ and $C_{v}=f(\bar{H})$. In addition to that in case of leck or insurficient hylrological data for determining the rlow regime in the rivers, there have been provided some necessary explanation. This study could be useful to students, candidates of higher studies, particulary in the area of protecting and makinf better use of water and 71 so those involved in the desicn of hydraulic structures. Noreover,it could also be used in zoning natural resources of the nation. 
$0049 / \mathrm{D}-\mathrm{n} / 4 / 11 / \mathrm{V} 1-\mathrm{N} 5$

\author{
Linfuistics and Naser Khosrau \\ Dohanmal A. Naser \\ sept, of bari, \\ raculty of languages and Literature \\ iabul University.
}

Acoording to a feueral Jefinjtion, anythinf which transpits to us an inea consctously is lanjuage. This phenomenon has tro foatures in the writing of Vaser. One is the holy language namily the esoteric language that takes its form without the use of letters and sounds. Another is the kuman lancunce maly the psychic spoalinr. In its turn, the psychic spenker is consicierea to hove two foscets. The first fascet is the escence of unfuate. That is to shy accordins to naser, the orting of the risychio speairr does uot heloner to this worli, whe secoul fiscet is the ordinary speech which is gutimat.

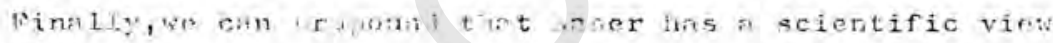

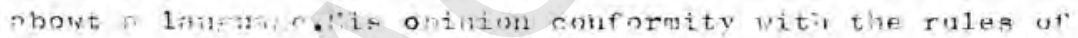

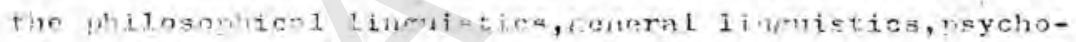

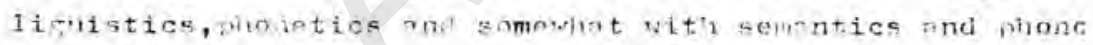

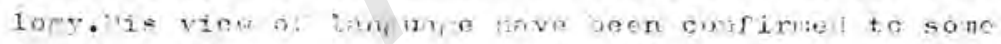
extents ly geq thidings an li inlistic romech. 


\section{EDITORIAL BOARD}

ohand Dr. M. L. Mehra Faculty of Natural Sciences

ohand Dr. A. Q. Qawim Faculty of Language \& Literature

'ohand Dr. S. A. Hasan yar Faculty of Agriculture

ohand Dr. F. M. Zmarai Faculty of Veterinary Sciences

ohand H. Amin Faculty of Geosciences

ohanwal Dr. Kh. Moqadar Faculty of. Pharmacy

ohanwal W. M. Rahimi Faculty of History \& Philosophy

ohandoy Dr. M. Y. Baazel Faculty of Law \&Political Sciences

ohandoy Dr. N. A. Shahidy Faculty of Economics

ohandoy Dr. M. S. Amiri Faculty of Natural Sciences

\section{Published by: Kabul Universcy}

\section{ミditor : Prof. Dr. Mohan Lal Mehra}

Address :

Danish- Journal

Kabul University

Kabul - Afyhanistan

Cel, : 47247

Subacription Rated

Afghanistan

$$
\text { Annual }
$$

Der Copy

Foreign Countries

Aff. 180

Afo. 50

Situdents

U15\$20

US \$ 6

Half Price 


\title{
DANDSET
}

\section{Bimonthly Scientific Journal}

\author{
of
}

Kabul University

$$
\text { Vol. } 1 \text { No. } 5
$$

December-January 1987-88 